NUREG/CR-6337

BMI-2186

\title{
Summary of Results from the IPIRG-2 Round-Robin Analyses
}

Manuscript Completed: January 1996

Date Published: February 1996

Prepared by

S. Rahman, R. Olson, A. Rosenfield, G. Wilkowski

Battelle

505 King Avenue

Columbus, OH 43201-2693

M. Mayfield, NRC Project Manager

Prepared for

Division of Engineering Technology

Office of Nuclear Regulatory Research

U.S. Nuclear Regulatory Commission

Washington, DC 20555-0001

NRC Job Code D2060 


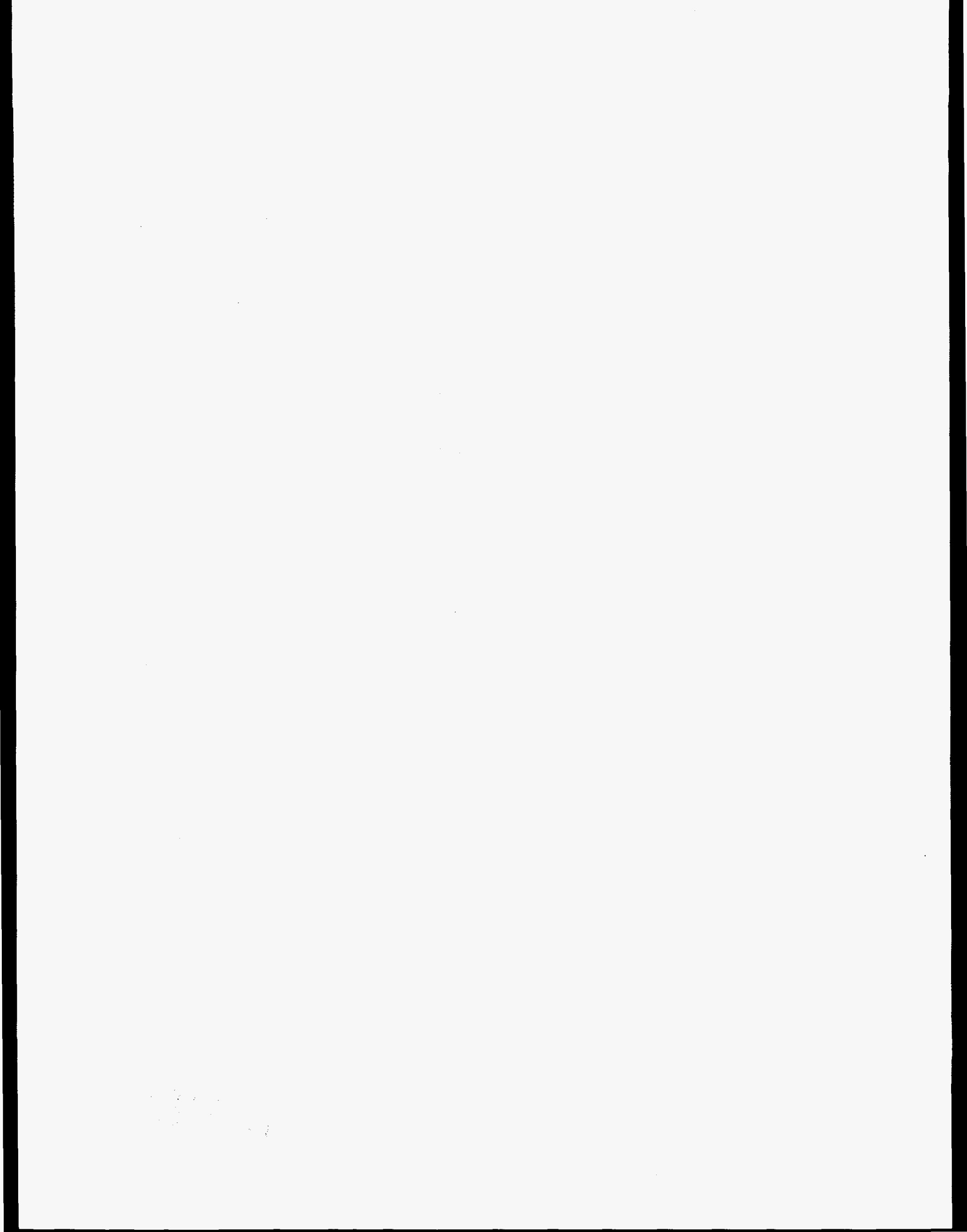




\section{ABSTRACT}

This report presents a summary of the results from three one-day international round-robin workshops which were organized by Battelle in conjunction with the Second International Piping Integrity Research Group (IPIRG-2) Program. The objective of these workshops was to develop a consensus in handling difficult analytical problems in leak-before-break and pipe flaw evaluations. The workshops, which were held August 5, 1993, March 4, 1994, and October 21, 1994 at Columbus, Ohio, involved various technical presentations on the related research efforts by the IPIRG-2 member organizations and solutions to several round-robin problems. Following review by the IPIRG-2 members, four sets of round-robin problems were developed. They involved: (1) evaluations of fracture properties and pipe loads, (2) crack-opening and leak-rate evaluations, (3) dynamic analysis of cracked pipes, and (4) fracture evaluations of elbows. A total of 18 organizations from the United States, Japan, Korea, and Europe solved these round-robin problems. The analysis techniques employed by the participants included both finite element and engineering methods. Based on the results from these analyses, several important observations were made concerning the predictive capability of the current fracturemechanics and thermal-hydraulics models for their applications in nuclear piping and piping welds. 



\section{DISCLAIMER}

This report was prepared as an account of work sponsored by an agency of the United States Government. Neither the United States Government nor any agency thereof, nor any of their employees, make any warranty, express or implied, or assumes any legal liability or responsibility for the accuracy, completeness, or usefulness of any information, appa. ratus, product, or process disclosed, or represents that its use would not infringe privately owned rights. Reference herein to any specific commercial product, process, or service by trade name, trademari, manufacturer, or otherwise does not necessarily constitute or imply its endorsement, recommendation, or favoring by the United States Government or any agency thereof. The views and opinions of authors expressed herein do not necessarily state or reflect those of the United States Government or any agency thereof. 


\section{DISCLAMMER}

Portions of this document may be illegible in electronic image products. Images are produced from the best available original document. 
EXECUTIVE SUMMARY $\ldots \ldots \ldots \ldots \ldots \ldots \ldots \ldots \ldots \ldots \ldots \ldots \ldots \ldots \ldots \ldots$

ACKNOWLEDGMENTS $\ldots \ldots \ldots \ldots \ldots \ldots \ldots \ldots \ldots \ldots \ldots \ldots \ldots$

NOMENCLATURE $\ldots \ldots \ldots \ldots \ldots \ldots \ldots \ldots \ldots \ldots \ldots \ldots \ldots \ldots \ldots$ xii

PREVIOUS REPORTS IN SERIES $\ldots \ldots \ldots \ldots \ldots \ldots \ldots \ldots \ldots \ldots \ldots \ldots \ldots$

1.0 INTRODUCTION $\ldots \ldots \ldots \ldots \ldots \ldots \ldots \ldots \ldots \ldots \ldots \ldots \ldots \ldots \ldots \ldots \ldots$

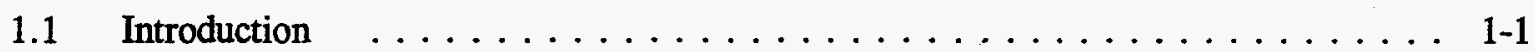

$1.2 \quad$ IPIRG-2 Round-Robin Analyses . . . . . . . . . . . . . . 1-1

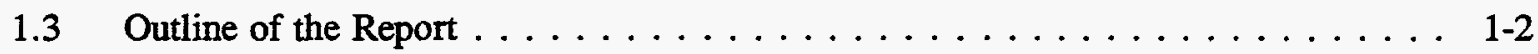

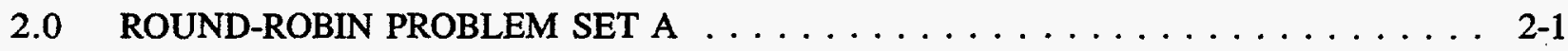

2.1 Round-Robin Problem A.1 - Predictions of J-R Curves and Tensile Properties Using Mill Data . . . . . . . . . . . . . 2-1

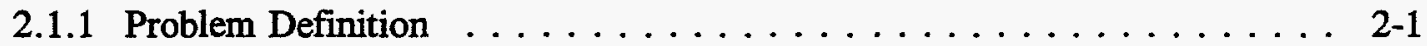

2.1.2 Summary and Conclusions . . . . . . . . . . . . . . 2-1

2.2 Round-Robin Problem A.2 - Evaluation of J-R Curves Using Various International Standards $\ldots \ldots \ldots \ldots$ 2-3

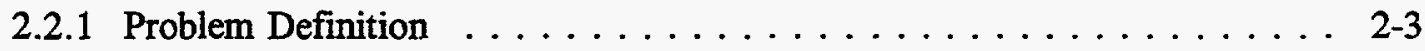

2.2.2 Summary and Conclusions . . . . . . . . . . . . . 2-3

2.3 Round-Robin Problem A.3 - Fracture Load Evaluations Using

J-R Curves from Various International Standards . . . . . . . . . . . 2-4

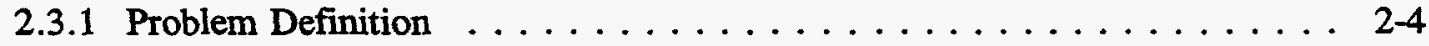

2.3.2 Summary and Conclusions . . . . . . . . . . . . . 2-4

2.4 Round-Robin Problem A.4 - Fracture Load Evaluations Using

J-R Curves from Different Load-Histories . . . . . . . . . . . 2-6

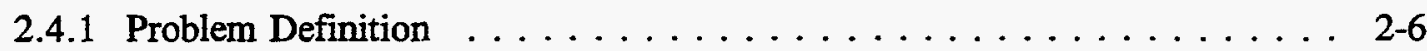

2.4 .2 Summary and Conclusions $\ldots \ldots \ldots \ldots \ldots \ldots \ldots \ldots . \ldots \ldots$ 


\section{CONTENTS}

$\underline{\text { Page }}$

2.5 Round-Robin Problem A.6 - Fracture Load Evaluations Using Stress-Strain Curves from Various Methods . . . . . . . . . . . . . 2-7

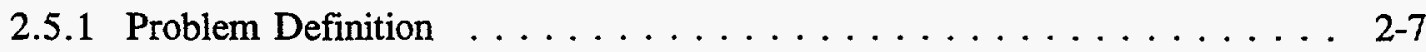

2.5 .2 Summary and Conclusions $\ldots \ldots \ldots \ldots \ldots \ldots \ldots \ldots \ldots \ldots \ldots \ldots$

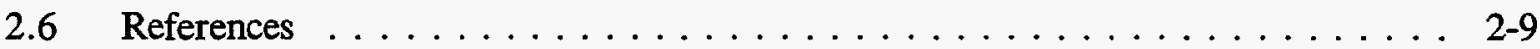

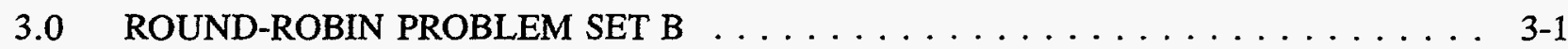

3.1 Round-Robin Problem B.1 - Calculation of Crack-Opening

Displacements for Pipes Under Various Loads . . . . . . . . . . . . . . . . . 3-1

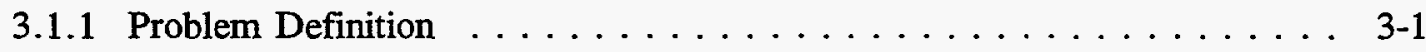

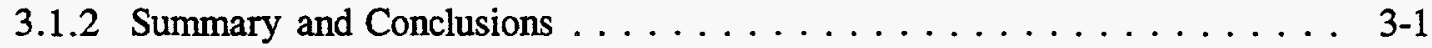

3.2 Round-Robin Problem B.2 - Leak-Rate Analysis of Cracked Pipes with Various Cracking Mechanisms $\ldots \ldots \ldots \ldots \ldots \ldots \ldots$ 3-2

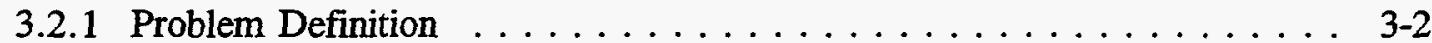

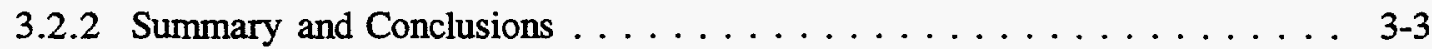

3.3 Round-Robin Problem B.3 - Crack-Opening-Area Analysis of Pipes with Off-Centered Cracks . . . . . . . . . . . . . . . 3-4

3.3.1 Problem Definition $\ldots \ldots \ldots \ldots \ldots \ldots \ldots \ldots \ldots \ldots \ldots$

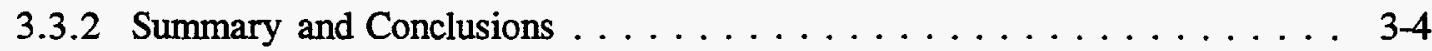

3.4 Round-Robin Problem B.4 - Effects of Weld Residual Stresses

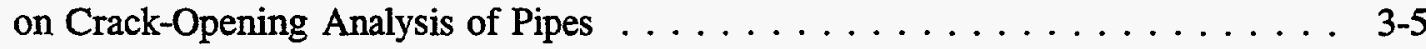

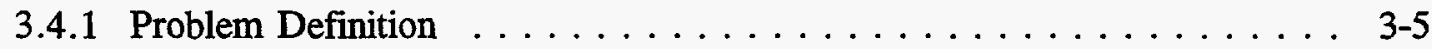

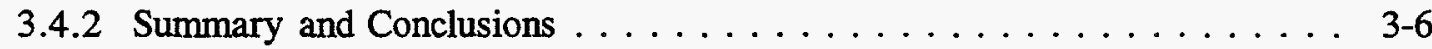

3.5 Round-Robin Problem B.5 - Crack-Opening Analysis of a Girth

Weld Nozzle Crack at a Thickness Transition . . . . . . . . . . . . . 3-7

3.5.1 Problem Definition $\ldots \ldots \ldots \ldots \ldots \ldots \ldots \ldots \ldots \ldots$. . . . . . . . . . . . . .

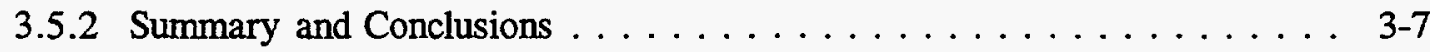

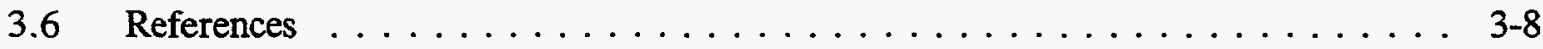


4.0 ROUND-ROBIN PROBLEM SET C

4.1 Round-Robin Problem C.1 - Spectrum-Compatible Time-Histories . . . . . . . . . . 4-1

4.1 .1 Problem Definition . . . . . . . . . . . . . . . . . . 4-1

4.1 .2 Summary and Conclusions $\ldots \ldots \ldots \ldots \ldots \ldots$ 4-1

4.2 Round-Robin Problem C.2-a - Analysis of IPIRG-2 Seismic

Surface-Cracked Pipe System Experiment . . . . . . . . . . . . . . . . 4-2

4.2.1 Problem Definition $\ldots \ldots \ldots \ldots \ldots \ldots \ldots \ldots \ldots \ldots \ldots$ 4-2

4.2 .2 Summary and Conclusions $\ldots \ldots \ldots \ldots \ldots \ldots \ldots$ 4-3

4.3 Round-Robin Problem C.2-b - Reconsideration of IPIRG-2 Seismic

Surface-Cracked Pipe System Experiment . . . . . . . . . . . . . 4-5

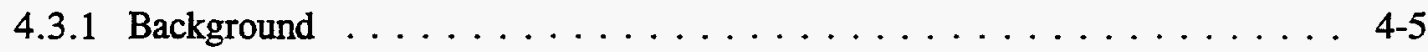

4.3 .2 Problem Definition . . . . . . . . . . . . . . . 4-5

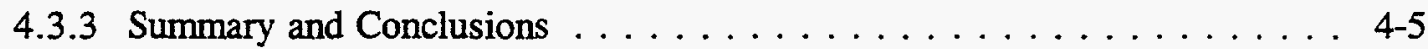

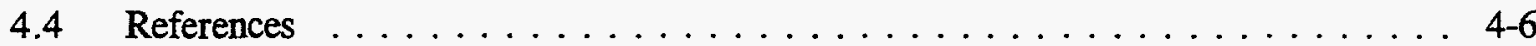

$5.0 \quad$ ROUND-ROBIN PROBLEM SET D $\ldots \ldots \ldots \ldots \ldots \ldots \ldots \ldots \ldots \ldots$

5.1 Round-Robin Problem D.1 - Displacement Calculations

for an Uncracked Elbow . . . . . . . . . . . . . . . . . . . . . . . 5-1

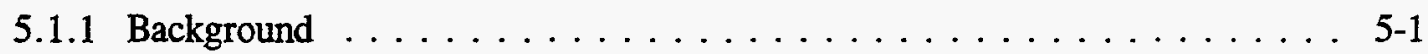

5.1 .2 Problem Definition . . . . . . . . . . . . . . . . . 5-1

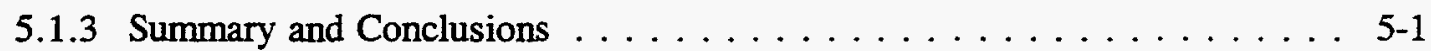

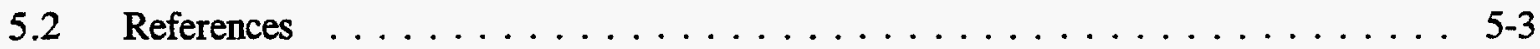

APPENDIX A DEFINITION OF PROBLEM SET A . . . . . . . . . . . A A-1

A.1 Problem A.1 - Predictions of J-R Curves and Tensile

Properties Using Mill Data . . . . . . . . . . . . . . . . . . . A-1

A.2 Problem A.2-a - Evaluation of J-R Curves Using Various

International Standards . . . . . . . . . . . . . . . . . . A-3

A.3 Problem A.2-b - Evaluation of J-R Curves Using Newly

Proposed ASTM Standard . . . . . . . . . . . . . . . . . A-8

A.4 Problem A.3 - Fracture Load Evaluations Using J-R Curves

from Various International Standards 


\section{CONTENTS}

$\underline{\text { Page }}$

A.5 Problem A.4 - Fracture Load Evaluations Using J-R Curves

from Different Load Histories $\ldots \ldots \ldots \ldots \ldots \ldots \ldots$. . . . . . . . . . .

A.6 Problem A.6 - Fracture Load Evaluations Using Stress-Strain

Curves from Various Methods . . . . . . . . . . . . . . . . . . . A-14

APPENDIX B DEFINITION OF PROBLEM SET B $\ldots \ldots \ldots \ldots \ldots \ldots \ldots$

B.1 Problems B.1-a and B.1-b - Calculation of Crack-Opening Displacements

for Pipes Under Various Loads Using F29 Material . . . . . . . . . . . . . . . B-1

B.2 Problem B.1-c - Calculation of Crack-Opening Displacements for

Pipes Under Various Loads Using F23 Material . . . . . . . . . . . . . . B-3

B.3 Problems B.2-a and B.2-b - Leak-Rate Analysis of Cracked Pipes with Various Cracking Mechanisms . . . . . . . . . . . . . . . B-4

B.4 Problems B.2-c and B.2-d - Leak-Rate Analysis of Cracked Pipes with Various Cracking Mechanisms . . . . . . . . . . . . . . B-5

B.5 Problem B.3 - Crack-Opening-Area Analysis of Pipes with Off-Centered Cracks

B.6 Problem B.4 - Effects of Weld Residual Stresses on Crack-Opening Analysis of Pipes $\ldots \ldots \ldots \ldots \ldots \ldots$ B-8

B.7 Problem B.5 - Crack-Opening Analysis of a

Girth Weld Nozzle Crack at a Thickness Transition . . . . . . . . . . . . . . B-10

APPENDIX $\mathrm{C}$ DEFINITION OF PROBLEM SET $\mathrm{C} \ldots \ldots \ldots \ldots \ldots \ldots \ldots$

C.1 Problem C.1 - Spectrum-Compatible Time-Histories $\ldots \ldots \ldots \ldots \ldots \ldots \ldots$. . .

C.2 Problem C.2 - Analysis of IPIRG-2 Seismic Surface-Cracked

Pipe System Experiment . . . . . . . . . . . . . . . . . C -4

C.3 IPIRG-2 Pipe Loop Finite Element Analysis Data for Problem C.2 _ . . . . . . C-15

APPENDIX D DEFINITION OF PROBLEM SET $\mathrm{D} \ldots \ldots \ldots \ldots \ldots \ldots \ldots$

D.1 Problem D.1 - Displacement Calculations for an Uncracked Elbow . . . . . . . . D-1 


\section{LIST OF FIGURES}

Figure

$\underline{\text { Page }}$

2.1 Stress-strain curves using Ramberg-Osgood model with the estimated parameters

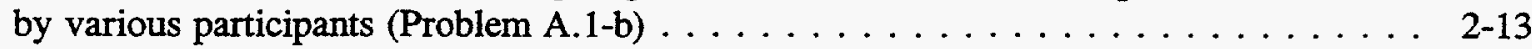

$2.2 \mathrm{~J}$-R curves for Material A using power-law model with the estimated parameters

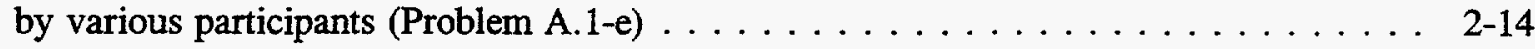

$2.3 \mathrm{~J}$-R curves for Material B using power-law model with the estimated parameters

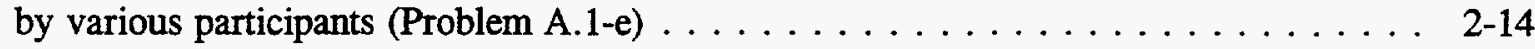

$2.4 \mathrm{~J}$-R curves for Material $\mathrm{C}$ using power-law model with the estimated parameters by various participants (Problem A.1-e) $\ldots \ldots \ldots \ldots \ldots \ldots \ldots \ldots \ldots$. . . . . . . . . . .

2.5 Calculated $\mathrm{J}-\mathrm{R}$ curves by the participants using various international standards

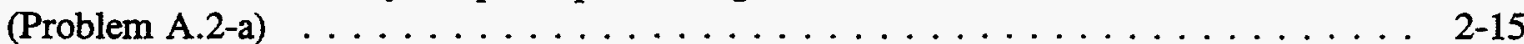

2.6 Calculated J-R curves by various participants using newly proposed ASTM standard

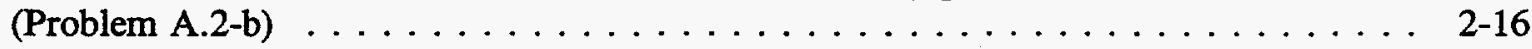

2.7 Comparisons of predicted initiation moments by various participants

for large-diameter through-wall-cracked pipes (Problems A.3-a and A.3-b) . . . . . . 2-17

2.8 Comparisons of predicted maximum moments by various participants

for large-diameter through-wall-cracked pipes (Problems A.3-a and A.3-b) . . . . . . 2 2-17

2.9 Comparisons of predicted initiation moments by various participants

for small-diameter through-wall-cracked pipes (Problems A.3-e and A.3-f) . . . . . . 2-18

2.10 Comparisons of predicted maximum moments by various participants

for small-diameter through-wall-cracked pipes (Problems A.3-e and A.3-f) . . . . . . 2-18

2.11. Comparisons of predicted initiation moments by various participants

for large-diameter surface-cracked pipes (Problems A.3-c and A.3-d)

2.12 Comparisons of predicted maximum moments by various participants

for large-diameter surface-cracked pipes (Problems A.3-c and A.3-d)

2.13 Comparisons of predicted initiation moments by various participants

for small-diameter surface-cracked pipes (Problems A.3-g and A.3-h) . . . . . . . 2-20

2.14 Comparisons of predicted maximum moments by various participants

for small-diameter surface-cracked pipes (Problems A.3-g and A.3-h) . . . . . . . . 2-20

2.15 Comparisons of predicted initiation moments by various participants

for large-diameter through-wall-cracked pipes (Problems A.4-a and A.4-b) . . . . . . 2-21

2.16 Comparisons of predicted maximum moments by various participants

for large-diameter through-wall-cracked pipes (Problems A.4-a and A.4-b) . . . . . . 2-21 


\section{LIST OF FIGURES}

Figure

2.17 Comparisons of predicted initiation moments by various participants

for small-diameter through-wall-cracked pipes (Problems A.4-e and A.4-f) . . . . . . 2-22

2.18 Comparisons of predicted maximum moments by various participants

for small-diameter through-wall-cracked pipes (Problems A.4-e and A.4-f) . . . . . . 2-22

2.19 Comparisons of predicted initiation moments by various participants

for large-diameter surface-cracked pipes (Problems A.4-c and A.4-d) . . . . . . . . . 2-23

2.20 Comparisons of predicted maximum moments by various participants

for large-diameter surface-cracked pipes (Problems A.4-c and A.4-d) $\ldots \ldots \ldots$. . . . 2-23

2.21 Comparisons of predicted initiation moments by various participants

for small-diameter surface-cracked pipes (Problems A.4-g and A.4-h) $\ldots \ldots \ldots$. . . . . 24

2.22 Comparisons of predicted maximum moments by various participants

for small-diameter surface-cracked pipes (Problems A.4-g and A.4-h) $\ldots \ldots$. . . . 2-24

2.23 Comparisons of predicted initiation moments by various participants

for large-diameter through-wall-cracked pipes (Problems A.6-a and A.6-b) . . . . . . 2-25

2.24 Comparisons of predicted maximum moments by various participants

for large-diameter through-wall-cracked pipes (Problems A.6-a and A.6-b) . . . . . . 2-25

2.25 Comparisons of predicted initiation moments by various participants

for small-diameter through-wall-cracked pipes (Problems A.6-e and A.6-f) $\ldots \ldots \ldots$ 2-26

2.26 Comparisons of predicted maximum moments by various participants

for small-diameter through-wall-cracked pipes (Problems A.6-e and A.6-f) . . . . . . 2-26

2.27 Comparisons of predicted initiation moments by various participants

for large-diameter surface-cracked pipes (Problems A.6-c and A.6-d)

2.28 Comparisons of predicted maximum moments by various participants

for large-diameter surface-cracked pipes (Problems A.6-c and A.6-d)

2.29 Comparisons of predicted initiation moments by various participants

for small-diameter surface-cracked pipes (Problems A.6-g and A.6-h) $\ldots \ldots \ldots \ldots$. . . . 28

2.30 Comparisons of predicted maximum moments by various participants

for small-diameter surface-cracked pipes (Problems A.6-g and A.6-h) $\ldots \ldots \ldots$. . . 2-28

3.1 Predicted center-crack-opening displacements by various participants

for a pipe under pure bending loads (Problem B.1-a) . . . . . . . . . . . . . . . . 3-14

3.2 Predicted center-crack-opening displacements by various participants

for a pipe under combined bending and tension (Problem B.1-b) $\ldots \ldots \ldots \ldots$. . . . . . 


\section{LIST OF FIGURES}

Figure

Page

3.3 Predicted center-crack-opening displacements by various participants for a pipe under combined bending and tension (Problem B.1-c) $\ldots \ldots \ldots \ldots$. . . . . .

3.4 Coefficients of variation of the predicted crack-opening displacements

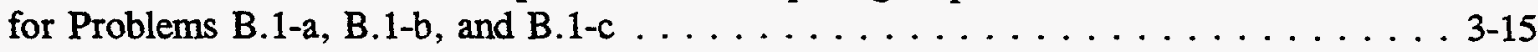

3.5 Calculated leak rates by various participants for a pipe with a corrosion-fatigue crack (Problem B.2-a) $\ldots \ldots \ldots \ldots \ldots \ldots \ldots \ldots \ldots$

3.6 Calculated leak rates by various participants for a pipe with an intergranular stress-corrosion crack (Problem B.2-b) $\ldots \ldots \ldots \ldots$. . . . . . . . . . .

3.7 Calculated leak rates by various participants for a pipe with a corrosion-fatigue crack (Problem B.2-c) $\ldots \ldots \ldots \ldots \ldots \ldots$. . . . . . . . . . . . .

3.8 Calculated leak rates by various participants for a pipe with an intergranular stress-corrosion crack (Problem B.2-d) $\ldots \ldots \ldots \ldots \ldots \ldots$. . . . . . . . .

3.9 Effects of cyclic rate on the crack-morphology variables $\ldots \ldots \ldots \ldots \ldots$

3.10 Comparisons of predicted center-crack-opening displacements by various participants for pipes with off-centered cracks (Problem B.3)

3.11 Comparisons of predicted crack-opening area by various participants for pipes with off-centered cracks (Problem B.3) . . . . . . . . . . . . . . . . 3-19

3.12 Comparisons of two finite element solutions from Participant $D$ for crack-opening displacements in pipes with off-centered cracks (inside surface) $\ldots \ldots$. . 3-20

3.13 Comparisons of two finite element solutions from Participant D for crack-opening displacements in pipes with off-centered cracks (outside surface) . . . . 3-20

3.14 Effects of residual stresses on the through-the-thickness variation of centercrack-opening displacement for a thick-walled large-diameter pipe (Problem B.4-a) . . . 3-21

3.15 Effects of residual stresses on the through-the-thickness variation of centercrack-opening displacement for a thin-walled small-diameter pipe (Problem B.4-b) . . . . 3-21

3.16 Center-crack-opening displacement in a girth weld nozzle versus location of the fixed plane for various applied moments (Problem B.5) $\ldots \ldots \ldots \ldots$. . . . . . 22

3.17 Predicted crack-opening shapes for a girth weld nozzle with thickness transition

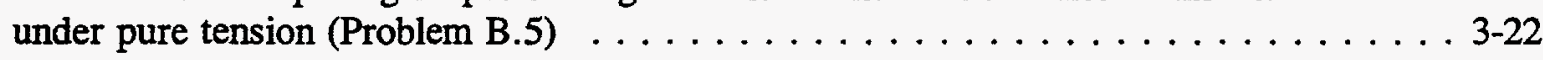

3.18 Predicted crack-opening shapes for a girth weld nozzle with thickness transition under combined bending and tension with $M=200 \mathrm{kN}-\mathrm{m}$ (Problem B.5) . . . . . 3-23 


\section{LIST OF FIGURES}

Figure

3.19 Predicted crack-opening shapes for a girth weld nozzle with thickness transition under combined bending and tension with $\mathbf{M}=1,000 \mathrm{kN}-\mathrm{m}$ (Problem B.5) $\ldots \ldots$. . 3-23

3.20 Comparisons of predicted center COD at inner surface of a girth weld nozzle by various participants as a function of the applied load (Problem B.5)

3.21 Comparisons of predicted center COD at outer surface of a girth weld nozzle by various participants as a function of the applied load (Problem B.5)

$4.1 \quad$ Peak-broadened actuator response spectrum for Problem C. $\ldots \ldots \ldots \ldots \ldots$. . . . . 4-11

4.2 Spectrum-compatible displacement time history predicted by Participant C . . . . . 4-12

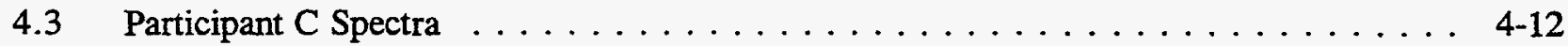

4.4 Spectrum-compatible displacement time history predicted by Participant D . . . . . 4-13

$4.5 \quad$ Participant D Spectra $\ldots \ldots \ldots \ldots \ldots \ldots \ldots \ldots \ldots \ldots \ldots$

4.6 Spectrum-compatible displacement time history predicted by Participant F-3a $\ldots . .44-14$

$4.7 \quad$ Participant F-3a Spectra $\ldots \ldots \ldots \ldots \ldots \ldots \ldots \ldots \ldots \ldots \ldots \ldots \ldots$. . . . . . . .

4.8 Spectrum-compatible displacement time history predicted by Participant F-3b . . . . 4-15

$4.9 \quad$ Participant F-3b Spectra $\ldots \ldots \ldots \ldots \ldots \ldots \ldots \ldots \ldots \ldots \ldots \ldots \ldots$

4.10 Predicted moment response at 0.5-percent damping using Participant C's spectrum-compatible displacement time history $\ldots \ldots \ldots \ldots \ldots \ldots$. . . . . . . . .

4.11 Predicted moment response at 0.5-percent damping using Participant D's spectrum-compatible displacement time history $\ldots \ldots \ldots \ldots \ldots \ldots$

4.12 Predicted moment response at 0.5-percent damping using Participant F-3's spectrum-compatible displacement time history (Solution F-3a)

4.13 Predicted moment response at 0.5-percent damping using Participant F-3's spectrum-compatible displacement time history (Solution F-3b) $\ldots \ldots \ldots \ldots$. . . . 4-17

4.14 IPIRG-2 SSE $\operatorname{spectra} \ldots \ldots \ldots \ldots \ldots \ldots \ldots \ldots \ldots \ldots \ldots \ldots \ldots \ldots$

4.15 IPIRG-2 SSE displacement time history $\ldots \ldots \ldots \ldots \ldots \ldots \ldots \ldots$

4.16 Moment response using IPIRG-2 SSE displacement time history . . . . . . . . . . . 4-19

4.17 Predicted moment response at 2-percent damping using Participant C's spectrum-compatible displacement time history . . . . . . . . . . . . . . . 4-20 


\section{LIST OF FIGURES}

Figure

4.18 Predicted moment response at 2-percent damping using Participant D's spectrum-compatible displacement time history . . . . . . . . . . . . . 4-20

4.19 Predicted moment response at 2-percent damping using Participant F-3's spectrum-compatible displacement time history (Solution F-3a) . . . . . . . . . 4-21

4.20 Predicted moment response at 2-percent damping using Participant F-3's spectrum-compatible displacement time history (Solution F-3b) . . . . . . . . . 4-21

4.21 IPIRG-2 Experiment $1-1$ initial flaw geometry $\ldots \ldots \ldots \ldots \ldots \ldots \ldots \ldots \ldots$

4.22 Quasi-static and dynamic stress-strain curves for Problems C.2-a and C.2-b . . . . . 4-23

4.23 Quasi-static and dynamic J-R curves for Problems C.2-a and C.2-b . . . . . . . 4-23

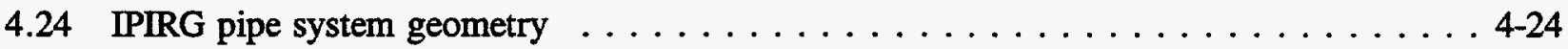

4.25 Forcing function in IPIRG-2 Experiment $1-1 \ldots \ldots \ldots \ldots \ldots \ldots \ldots$

4.26 Typical linear-elastic stress analysis results for Problems C.2-a and C.2-b . . . . . 4-25

5.1 Elbow geometry for Problem D.1 ... . . . . . . . . . . . $5-11$

A.1 Photograph of Specimen 108. Dashed line corresponds to crack front and load-displacement data in Table A.4, Footnote 1.

(Use the specimen thickness of $20.85 \mathrm{~mm}$ for scaling crack growth) . . . . . . . . A-5

A.2 Photograph of Specimen 107. Dashed line corresponds to crack front and load-displacement data in Table A.4, Footnote 2.

(Use the specimen thickness of $20.85 \mathrm{~mm}$ for scaling crack growth) . . . . . . . . . . A-6

A.3 Photograph of Specimen 109. Dashed line corresponds to crack front and load-displacement data in Table A.4, Footnote 3.

(Use the specimen thickness of $20.85 \mathrm{~mm}$ for scaling crack growth) $\ldots \ldots \ldots \ldots$. . . A-7

B.1 Weld residual stress field from ASME IWB-3640 draft technical basis document $\ldots \ldots$ B-9

B.2 Geometric details of a cracked carbon steel nozzle with thickness gradients . . . . . B-12

B.3 Idealized nozzle geometry with fixed boundary condition $\ldots \ldots \ldots \ldots \ldots \ldots \ldots$

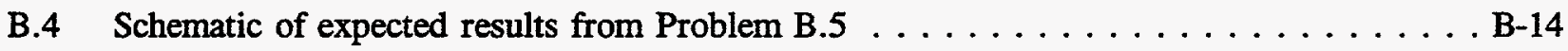

C.1 Actuator response spectrum at 2-percent damping $\ldots \ldots \ldots \ldots \ldots \ldots \ldots$

C.2 Flaw geometry for IPIRG-2 Experiment $1-1 \ldots \ldots \ldots \ldots \ldots \ldots \ldots \ldots \ldots$ C-14 


\section{LIST OF FIGURES}

$\underline{\text { Figure }}$

$\underline{\text { Page }}$

C.3 Artist's conception of the IPIRG Pipe Loop $\ldots \ldots \ldots \ldots \ldots \ldots \ldots \ldots \ldots \ldots$ C-21

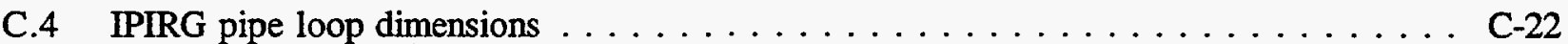

C.5 IPIRG-2 Experiment $1-1$ forcing function $\ldots \ldots \ldots \ldots \ldots \ldots \ldots \ldots \ldots \ldots$

D.1 Elbow geometry for IPIRG-2 Round-Robin Problem D.1 $\ldots \ldots \ldots \ldots \ldots \ldots \ldots$ 


\section{LIST OF TABLES}

$\underline{\text { Table }}$

$\underline{\text { Page }}$

1.1 List of IPIRG-2 Round-Robin problems $\ldots \ldots \ldots \ldots \ldots \ldots \ldots \ldots$

1.2 List of participating organizations for IPIRG-2 Round-Robin analyses $\ldots \ldots \ldots \ldots$. . . . .

2.1 Ratio of strengths at $288 \mathrm{C}(550 \mathrm{~F})$ and $20 \mathrm{C}(68 \mathrm{~F})$ in Problem A.1-a . . . . . . . 2-11

2.2 Comparisons of predicted upper shelf energy with actual data (Problem A.1-c) _ . . . 2-11

2.3 Comparisons of predicted $\mathrm{J}$ at crack initiation with actual data (Problem A.1-c) . . . . 2-12

2.4 Comparisons of predicted $\mathrm{d} J / \mathrm{da}$ with actual data (Problem A.1-d) $\ldots \ldots \ldots . . \ldots 2$

3.1 Summary of methods and codes used by various participants for solving Problem B.1 _ . 3-11

3.2 Summary of methods and codes used by various participants for solving Problem B.2 _ . 3-12

3.3 Summary of methods and codes used by various participants for solving Problem B.3 _ . 3-12

3.4 Center-crack-opening displacements calculated by Participant $\mathrm{G}$ with and without residual stresses from finite element analysis $\ldots \ldots \ldots \ldots \ldots \ldots$. . . . . . . .

4:1 IPIRG pipe system moment response summary using spectrum-compatible displacement time histories and linear stress analysis $\ldots \ldots \ldots \ldots \ldots \ldots$

4.2 Level-2 tensile properties at room temperature for Problems C.2-a and C.2-b . . . . . 4 4-8

4.3 Maximum moment predictions for IPIRG-2 Experiment 1-1 in Problem C.2-a . . . . . 4-9

4.4 Predicted time at attainment of maximum moment for IPIRG-2 Experiment 1-1

in Problem C.2-a . . . . . . . . . . . . . . . . . . . . . . . . . . . . . 4 4-9

4.5 Maximum moment predictions for IPIRG-2 Experiment 1-1 in Problem C.2-b . . . . . 4-10

4.6 Predicted time at attainment of maximum moment for IPIRG-2 Experiment 1-1 in Problem C.2-b ... . . . . . . . . . . . . . . . . . . . 4-10

5.1 Pipe geometry and material property information for Round-Robin Problem D.1 . . . . 5-4

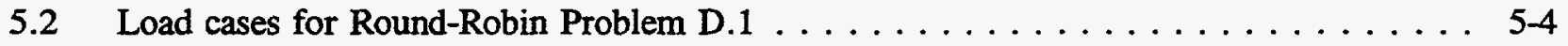

5.3 Results of load case A solution $\left[\mathrm{p}=15 \mathrm{MPa}(2,175 \mathrm{psi}), \mathrm{F}_{\mathrm{x}}=0, \mathrm{~F}_{\mathrm{y}}=0\right] \ldots \ldots$

5.4 Results of load case $B$ solution $\left[p=0, F_{x}=100 \mathrm{kN}(22,481 \mathrm{lb}), F_{y}=0\right] \ldots \ldots$

5.5 Results of load case $C$ solution $\left[p=0, F_{x}=0, F_{y}=100 \mathrm{kN}(22,481 \mathrm{lb})\right] \ldots \ldots .7$ 


\section{LIST OF TABLES}

$\underline{\text { Table }}$

5.6 Results of load case D solution [ $\mathrm{p}=15 \mathrm{MPa}(2,175 \mathrm{psi})$,

$\left.\mathrm{F}_{\mathrm{x}}=100 \mathrm{kN}(22,481 \mathrm{lb}), \mathrm{F}_{\mathrm{y}}=0\right]$

5.7 Results of load case E solution $\left[p=15 \mathrm{MPa}(2,175 \mathrm{psi}), \mathrm{F}_{\mathrm{x}}=0\right.$,

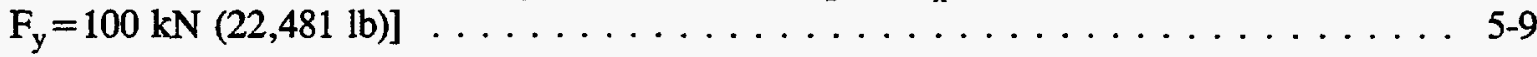

5.8 Results of load case F solution $[\mathrm{p}=15 \mathrm{MPa}(2,175 \mathrm{psi})$,

$\left.F_{x}=F_{y}=100 \mathrm{kN}(22,481 \mathrm{lb})\right]$

A.1 Low-temperature mill data for Material A . . . . . . . . . . . . A-1

A.2 Low-temperature mill data for Material B . . . . . . . . . . . . . A-1

A.3 Low-temperature mill data for Material $\mathrm{C} \ldots \ldots \ldots \ldots \ldots \ldots \ldots \ldots$

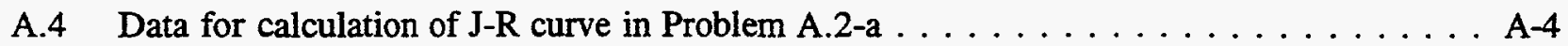

A.5 J-R curve parameters for Problem A.3 $\ldots \ldots \ldots \ldots \ldots \ldots \ldots \ldots \ldots$

A.6 J-R curve parameters for Problem A.4 $\ldots \ldots \ldots \ldots \ldots \ldots \ldots \ldots \ldots$

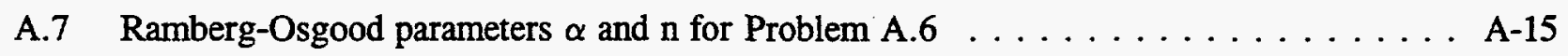

B.1 Crack-morphology variables for Problems B.2-c and B.2-d . . . . . . . . B-5

C.1 Floor response spectrum control points $\ldots \ldots \ldots \ldots \ldots \ldots \ldots \ldots \ldots$

C.2 Material properties at Level 2, room temperature longitudinal tensile-test data (Data for Specimen A8-35 from NUREG/CR-2175) $\ldots \ldots \ldots \ldots$. . . C-6

C.3 Material properties at Level 3, quasi-static longitudinal tensile-test data at $288 \mathrm{C}(550 \mathrm{~F})$ (Data from Specimen A8-40) . . . . . . . . . . C-6

C.4 Material properties at Level 3, quasi-static longitudinal stress-strain data at $288 \mathrm{C}(550 \mathrm{~F})$ (Data from Specimen A8-40) $\ldots \ldots \ldots \ldots$. . . . C-7

C.5 Material properties at Level 3, quasi-static L-C oriented C(T) specimen J-R curve at $288 \mathrm{C}(550 \mathrm{~F})$ (Specimen A8-12A, 20-percent side-grooved $1 \mathrm{~T} \mathrm{C}(\mathrm{T})$ specimen)

C.6 Material properties at Level 4, dynamic longitudinal tensile-test data at $288 \mathrm{C}(550 \mathrm{~F})\left(\right.$ Specimen A8-101, strain rate of $\left.1 \mathrm{sec}^{-1}\right) \ldots \ldots \ldots \ldots \ldots$

C.7 Material properties at Level 4, dynamic longitudinal stress-strain data at $288 \mathrm{C}(550 \mathrm{~F})$ (Specimen A8-101, strain rate of $\left.1 \mathrm{sec}^{-1}\right)$ 


\section{LIST OF TABLES}

Table

$\underline{\text { Page }}$

C.8 Material properties at Level 4, dynamic L-C oriented $C(T)$ specimen

J-R curve at $288 \mathrm{C}$ (550 F) (Data from Specimen A8-11A,

20-percent side-grooved $1 \mathrm{~T} \mathrm{C(T)} \mathrm{specimen)}$

C.9 Selected data records from elastic uncracked finite element stress analysis results

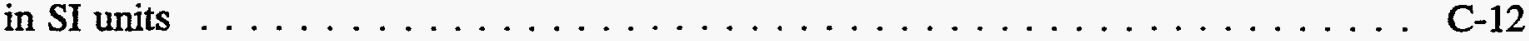

C.10 Static results from elastic uncracked finite element stress analysis $\ldots \ldots \ldots \ldots \ldots$

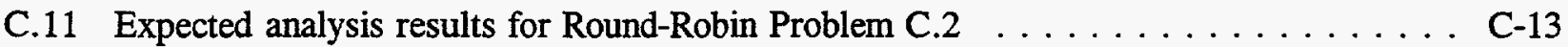

C.12 Elements used in Battelle ANSYS IPIRG-2 pipe system model $\ldots \ldots \ldots \ldots \ldots \ldots$. . . . . .

C.13 IPIRG-2 pipe loop material properties at $288 \mathrm{C}(550 \mathrm{~F}) \ldots \ldots \ldots \ldots \ldots \ldots \ldots$

C.14 Selected IPIRG-2 Experiment 1-1 simulated seismic loading forcing function data $\ldots \ldots$ C-20 


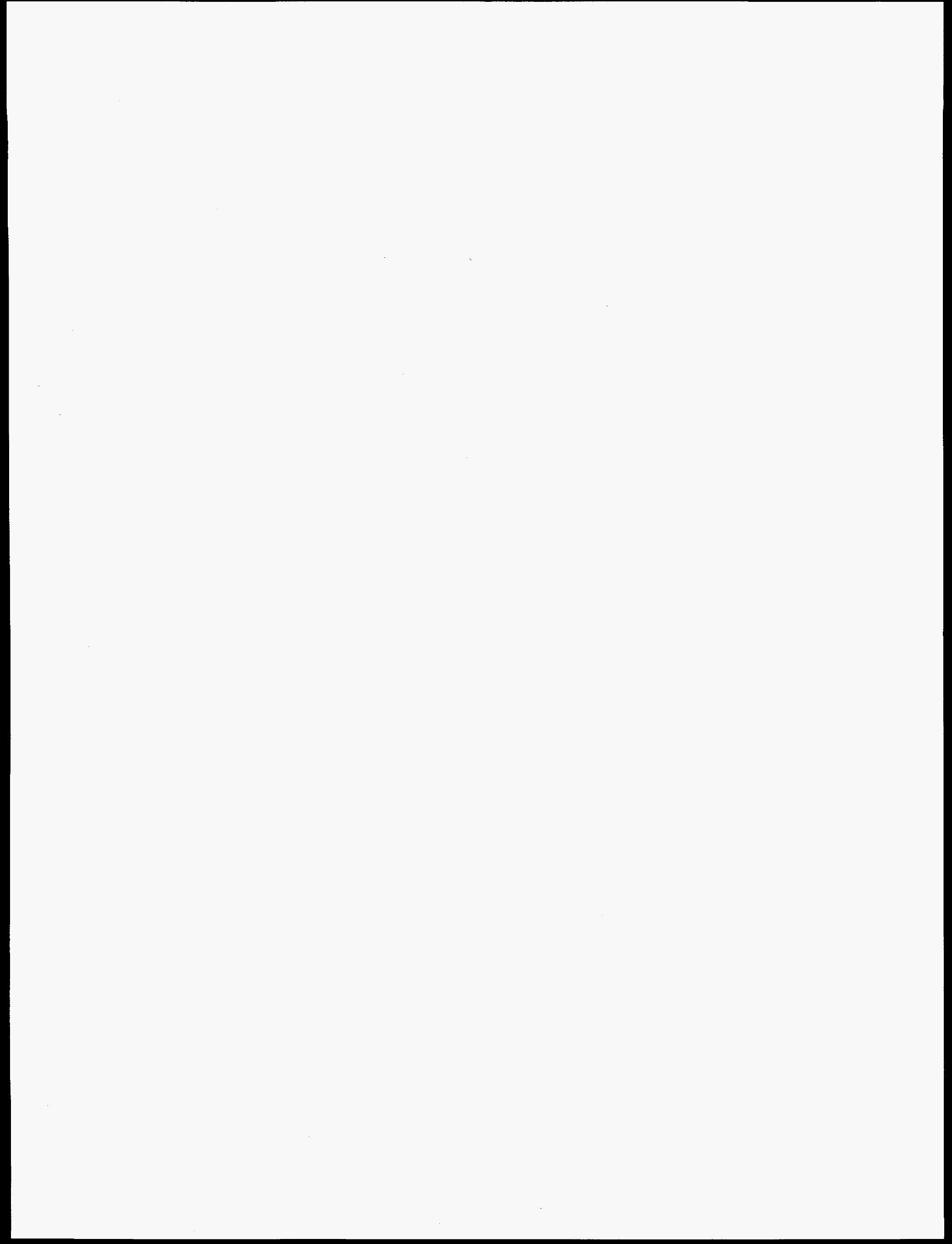




\section{EXECUTIVE SUMMARY}

This report summarizes the results of recently completed round-robin workshops that were organized by Battelle in conjunction with The Second International Piping Integrity Research Group (IPIRG-2) $^{(a)}$ Program. A series of three one-day workshops were held at Columbus, Ohio, on August 5, 1993, March 4, 1994, and October 21, 1994. The general objectives were to enhance the IPIRG-2 members' understanding of the various technical and regulatory bases in other countries and help develop a consensus on how to handle difficult analytical problems in leak-before-break (LBB) and pipe flaw evaluations for circumferentially cracked pipes and elbows.

Following review by the IPIRG-2 members, four sets of round-robin problems were developed by Battelle. They involved: (1) evaluations of fracture properties and pipe loads, (2) crack-opening and leak-rate evaluations, (3) dynamic analysis of cracked pipes, and (4) fracture evaluations of elbows. A total of 18 organizations presented their analyses of these problems. In this report, Battelle has compiled the contributions from each of the participants and made comparative assessments of the current state-of-the-art for fracture-mechanics and thermal-hydraulics models for application in nuclear piping and piping welds.

The following key observations were made from the results of the round-robin analyses.

\section{Problem Set A: Evaluations of Fracture Properties and Pipe Loads}

Problem Set A involved the following round-robin problems: (1) the evaluation of fracture properties of pipe at operating temperature from mill data, (2) an assessment of the differences in the international standards for determining $\mathrm{J}_{\mathrm{Ic}}$ and $\mathrm{J}-\mathrm{R}$ curves, and (3) the determination of the significance of the uncertainty in J-R curves and stress-strain curves for predicting the load-carrying capacity of pipes. The results showed that:

\section{From Prediction of High-Temperature Material Properties Using Low-Temperature Mill Data}

- The high temperature yield strengths were estimated to be 78 to 93 percent of room temperature values with the actual value being 86 percent for two different ferritic base metals (Materials A and B). The high temperature ultimate strengths were estimated to be 90 to 100 percent of room temperature values with the actual values being 118 and 124 percent for Materials A and B, respectively. The higher actual ultimate strengths are probably due to dynamic strain aging.

- The calculated Ramberg-Osgood hardening exponent (n) varied from accurate to underestimates, depending on the method and the ferritic pipe steel or weldment. The estimates of the Ramberg-Osgood coefficient ( $\alpha$ ) tended to be high, in general. From the Charpy V-notch data supplied in the transition region, the Charpy upper-shelf energy was overestimated. From the transitional Charpy data, the fracture toughness at crack initiation $\left(\mathrm{J}_{\mathrm{II}}\right)$ and $\mathrm{dJ}_{\mathrm{R}} / \mathrm{da}$ were both underestimated and overestimated. Hence, none of the methods used by the participants was consistently satisfactory. The

(a) The IPIRG-2 Program was an international group program consisting of 22 international organizations from 15 countries that was coordinated by the U.S. Nuclear Regulatory Commission and conducted at Battelle from October 1991 to December 1995. 
Executive Summary

coefficient of variation of the J estimates varied from 20 percent at $1 \mathrm{~mm}(0.04$ inch) of crack growth to 30 percent at $5 \mathrm{~mm}(0.2$ inch) of crack growth.

\section{From Evaluation of J-R Curve Standards}

- Given the same load-displacement-crack growth data and specimen dimensions, the J-R curves calculated by the participants were very similar when using different international standards. The comparisons of $\mathrm{J}$ at several crack growths indicated that the standard deviation in computed $J$ was on the order of ten percent of the mean. In addition, it was found that: (1) small differences might arise when comparing J-R curves with and without crack blunting, and (2) differences in the J-R curves using the newly proposed ASTM standard and ASTM E1152-87 were negligible for the materials evaluated.

\section{From Analyses of Cracked Pipes Using Various Quasi-Static J-R Curves}

- The predicted loads for through-wall-cracked (TWC) and surface-cracked (SC) pipes by the various participants were reasonably close to each other when the crack sizes were larger. For short through-wall cracks and short and shallow surface cracks, the load predictions indicated some scatter that was greater than those for long through-wall cracks and long and deep surface cracks.

- Three ferritic large diameter pipe fracture experiments (short TWC, long TWC, and short surface crack), which were conducted in the NRC's Degraded Piping Program (Phase $\mathrm{II}$ ) and Short Cracks in Piping and Piping Welds Program, were identified as having the same pipe geometry and material properties for some of the round-robin problems. The comparisons of solutions showed that the loads predicted by the participants were in good agreement with the test data from these experiments, except for the short TWC pipe experiment in which case all participants underpredicted the maximum load.

\section{From Analyses of Cracked Pipes Using J-R Curves from Various Load Histories}

- J-R curves from specimens with quasi-static-monotonic load, dynamic-monotonic load, and dynamic-cyclic load were supplied to make predictions of load-carrying capacity for TWC and SC pipes. The differences in J-R curves from various load histories can affect predictions of a pipe's load-carrying capacity. The predictions based on quasistatic-monotonic and dynamic-cyclic J-R curves provided the largest and smallest values of the loads, respectively.

- For the through-wall-cracked pipes, there was more scatter in the predicted loads when the crack size was smaller. There was far more scatter in predicted loads for the surface-cracked pipes than for the through-wall-cracked pipes.

\section{From Analyses of Cracked Pipes Using Various Quasi-Static Stress-Strain Curves}

- The predictions of initiation load were always lowest when the lower stress-strain curve was used. But, no consistent trend was observed in the maximum load predictions using the three supplied stress-strain curves that came from an earlier round-robin problem on predicting high temperature stress-strain curves from room temperature 
yield and ultimate data. Actually, maximum load predictions based on lower stressstrain curves provided the largest values of maximum loads in many cases. This was true for solutions from all participants.

- For a given stress-strain curve, the amount of the scatter in the predicted pipe maximum loads was comparable to the uncertainty in choosing the stress-strain curve itself. There was far more scatter in the results for predicted loads for surface-cracked pipes than for through-wall-cracked pipes. This showed a greater inconsistency in analysis methods for surface-cracked pipes than TWC pipes.

\section{Problem Set B: Crack-Opening and Leak-Rate Evaluations}

Problem Set B consisted of the following problems: (1) evaluation of current models for crackopening-area analysis of pipes, (2) evaluation of current models for predicting leak rates, (3) development of engineering models for predicting crack-opening for a pipe with an off-centered crack, (4) evaluation of the effects of weld residual stresses on the crack-opening predictions, and (5) crack-opening-area analysis of a girth weld crack in a nozzle with a thickness gradient on both sides. The key findings from this problem set were:

\section{From Analysis of Crack-Opening Area}

- The predicted crack-opening displacements (CODs) for a through-wall-cracked pipe by various participants agreed reasonably well. However, there was some scatter in the predictions, particularly in the solutions of problems that involved combined bending and tension. A quantitative measure of this scatter indicated that the largest coefficients of variation between the predictions were 6 and 10 percent for pipes under pure bending and combined bending and tension, respectively. This agreement among the different participants comes mainly from them all using the GE/EPRI method.

- The comparisons of predicted results with an IPIRG-2 pipe experiment (Experiment 1-8) that involved combined bending and tension showed that the experimental crackopening displacement would be overpredicted by the solutions of all participants, at least for the load range considered in this problem. Hence, for a given leak rate, the crack size would be underpredicted for LBB applications. This is consistent with analyses of additional experiments reported in NUREG/CR-6300, "Refinement and Evaluation of Crack-Opening-Area Analyses for Circumferential Through-Wall Cracks in Pipes."

\section{From Estimation of Leak Rates}

- The models of crack-morphology parameters and their values used for corrosion-fatigue cracks and IGSCC by the participants varied considerably. In consequence, the calculated leak rates for those cracks also varied widely. For a prescribed set of crackmorphology parameters, the calculated leak rates for corrosion-fatigue cracks and IGSCC predicted by various participants also showed some scatter. However, it was somewhat less than that observed in cases where the crack-morphology parameters were chosen by the participants. Nevertheless, there were some concerns on the scatter of the predictive models for general leak-rate calculations. Currently, there are few experimental data available to validate the analysis methods with the types of crack morphology that would be found in service. 
Executive Summary

From Analysis of Off-Centered Cracks

- The results of all participants showed that the maximum COD shifts from the center of the crack when the crack becomes off-centered with the bending plane. However, good predictions of crack-opening area could still be made by calculating center COD for a symmetrically centered crack subjected to the resolved component of the applied moment and assuming an elliptic crack-opening profile. The results suggest that for off-centered cracks when the crack opening is assumed to be elliptical with the length of the minor axis equal to the center COD, the actual COD from the finite element method would be underpredicted for one-half of the crack front and overpredicted for the other half of the crack front. However, calculations of crack-opening area by elliptical profile produced results in good agreement with those from explicit finite-element analysis. This is an important finding because the crack-opening area, which is more relevant for leak-rate prediction than COD itself, can be easily calculated just by knowing center COD (plus making elliptical assumption on the crack-opening profile) from simple GE/EPRI-type estimation formula.

\section{From Evaluation of Weld Residual Stresses}

- Finite element analyses were conducted to determine the effect of weld residual stress field on crack-opening displacements. The residual stress field from ASME IWB-3640 in addition to the remote moments were applied to a large-diameter thick-walled pipe and a small-diameter thin-walled pipe. The results showed that the prescribed residual stress did not significantly affect the crack-opening for the large-diameter pipe (outer diameter $=402.6 \mathrm{~mm}[15.85 \mathrm{inch}]$ ), but could seriously affect the crack-opening for a small-diameter pipe (outer diameter $=102.0 \mathrm{~mm}$ [4.02 inch]). More specifically, for the large-diameter pipe, when the residual stresses were considered, the center-crackopening displacement increased by 4.4 percent at the inside surface, decreased by 2.4 percent at the middle surface, and increased by 3.3 percent at the outer surface of the pipe. For the small-diameter pipe, when the residual stresses were included, the center COD at the inside, middle, and outside surfaces increased by 17.1 percent, decreased by 11.7 percent, and decreased by 31.7 percent, respectively. However, further studies involving other crack sizes and residual stress distributions are needed to verify these findings.

\section{From Analysis of a Girth Weld Nozzle Crack at a Thickness Transition}

- For the girth weld crack opening by a nozzle problem, the comparisons of results by the participants showed that the COD compared well when the applied bending moments were lower. However, for larger moments, the COD solutions by the participants varied significantly. It was surmised that the principal reason for such differences may be due to the application of bending moments in the finite element analyses. For example, in the analysis by one participant, the bending moment was applied as a linearly-distributed axial stress on the nozzle cross-section which varies from tensile to compressive stresses at the outermost fibers (lumped formulation). The axial stresses were calculated from the simple beam theory. On the other hand, in the analysis by another participant, the bending moment was applied using consistent nodal forces on all nodes on the cross-section of the nozzle (consistent formulation). The nodal loads were calculated using the formulation of the 20-noded isoparameteric solid elements. Another factor that may be responsible for the differences in the COD for 
higher loads is the fact that there were also differences in the finite-element modeling of the nozzle. For example, one participant used three elements through the thickness while another participant used only one element through the thickness. But the model of the latter participant had a finer mesh in the circumferential direction. Nevertheless, the degree of mesh refinement could also be a factor affecting crack-opening results. Hence, further studies are needed to resolve the differences in the results by these two participants.

\section{Problem Set C: Dynamic Analysis of Cracked Pipes}

In Problem Set C, the participants solved the following problems: (1) generation of seismic timehistories consistent with a given response spectrum and (2) determination of the accuracy of predictions for seismic pipe system tests with cracks. The results showed the following:

\section{From the Seismic Time Histories Problems}

- Four different but "equal" displacement time histories were created from a peakbroadened acceleration response spectrum. The maximum moments induced in a linear finite element model of the IPIRG piping system were similar (to within 20-percent), but the timing, number, and build-up of moment peaks were substantially different.

- It is not clear that merely being consistent with a given input spectrum is any guarantee that one will have an upper-bound, lower-bound, or average crack-driving potential due to differences in loading rate and load history effects. Other prescriptions on spectrum matching are probably required to give bounding crack-driving behavior. This work showed that although the IPIRG-2 program seismic displacement time-history forcing function met all of the current ASME, NRC, etc. design requirements, it is not known if it is lower-bound, upper-bound, or average in terms of crack driving force considerations.

\section{From Seismic Analysis of Cracked Pipe}

- There can be substantive differences between predicted moment-carrying capacities of flawed pipe, depending on which analysis methods are used and what material properties are known.

- "Better" knowledge of material properties at the crack location did not necessarily ensure a more accurate prediction of maximum moment.

- Nonlinearity caused by plasticity can dramatically alter the moment that can be applied at the crack. Whether the plasticity is from the crack or in remote piping, energy input to the system will be absorbed and stresses will not be as high as elastically calculated values using typical damping values. 


\section{Problem Set D: Fracture Evaluations of Elbows}

Problem Set $\mathrm{D}$ involved evaluation of the accuracy in predicting displacements for an uncracked pipe elbow. The results showed that:

- Many differences in solutions to elbow deflections under various loads can be traced to analysts not solving the same problem due to: (1) poorly documented finite element computer program features, (2) incorrect program inputs, (3) incomplete problem statements, and (4) finite element computer program errors.

- The issue of pressure-only loading of elbows in the finite element programs is somewhat problematic in that unless one has a very clear understanding of the theory for an element, one can get wrong answers that apparently look correct. Treatment of end cap loads and the surface that the internal pressure is applied to (mid-surface on shells, for instance) play a major role. 


\section{ACKNOWLEDGMENTS}

The IPIRG Program was an international group program coordinated by the U.S. Nuclear Regulatory Commission's Electrical, Materials, and Mechanical Engineering Branch of the Office of Nuclear Regulatory Research under Contract No. NRC-04-91-063 to Battelle. Mr. Michael Mayfield was the USNRC program manager. Dr. Allen Hopper was the Battelle program manager.

The members of the IPIRG-2 Program and their representatives to the IPIRG Technical Advisory Group (TAG) were:

Bulgaria

- CUAEPP

$\underline{\text { Canada }}$

$-\mathrm{AECB}^{(a)}$

- Ontario Hydro

Czech Republic

- NRI

France

$-\mathrm{EDF}^{(\mathrm{a})}$

- CEA

- Framatome

Hungary

- HAEC

Italy

- ANPA-DISP(a)

$\underline{\text { Japan }}$

- CRIEPI ${ }^{(a)}$

$\underline{\text { Lithuania }}$

- VATESI

Republic of China

- INER/AEC ${ }^{(a)}$

Republic of Korea

- KINS $^{(a)}$

- SKKU
Mr. Y. Yanev

Dr. B. Jarman ${ }^{(\mathrm{b})}$, Mr. J. K. Pereira

Mr. M. Kozluk

Dr. J. Zdárek, Dr. M. Brumovsky, Dr. P. Kadečka, Mr. J. Palyza

Mr. C. Faidy ${ }^{(b)}$, Mr. P. Le Delliou

Ms. F. Gantenbein, Mr. E. Debec-Mathet

Dr. Ph. Gilles

Mr. A. Fehérvári

Dr. C. Maricchiolo

Dr. K. Kashima ${ }^{(b)}$, Mr. N. Miura

Mr. P. Vaisnys

Dr. Li-Fu Lin

Dr. J. B. Lee ${ }^{(b)}$, Dr. Y. H. Choi

Dr. Y. J. Kim
(a) Contractual organization
(b) TAG representative 
Slovak Republic

$\begin{array}{ll}\text { - VUJE } & \text { Dr. L. Kupca } \\ \text { - NRA } & \text { Dr. J. Misak }\end{array}$

Sweden

- SKI ${ }^{(a)}$

Dr. G. Hedner

- SA

Dr. B. Brickstad

Switzerland

- KKL ${ }^{(a)}$

Mr. R. Wanner

- HSK

Dr. D. H. Njo

United Kingdom

- Nuclear Electric ${ }^{(a)}$

Dr. T. C. Chivers ${ }^{(b)}$, Dr. J. Darlastan

United States

- USNRC-RES ${ }^{(a)}$

Mr. M. Mayfield

- USNRC-NRR

Mr. K. Wichman

- EPRI ${ }^{(a)}$

Mr. S. Gosselin (b) , Dr. Y. K. Tang

We would like to express our appreciation for the support and interest of the IPIRG members in this program.

The scientists and engineers who contributed in the round-robin workshops were: K. Kashima and N. Miura (CRIEPI, Japan); H. Yokota (MAPI, Japan) and N. Kojima (MHI, Japan); H. Sugino (IHI, Japan); P. Chauhan (National Nuclear Corporation, UK); B. Neale, J. Bouchard, and T. Chivers (Nuclear Electric, UK); J. Wintle, K. May, and D. Sanderson (AEA, UK); Y. Choi, J. Chung, J. Lee, and Y. Kim (KINS, Republic of Korea); Y. Park, Y. Joh, C. Suk and Y. Kim (SKKU, Republic of Korea); S. Rahman, R. Olson, A. Rosenfield, N. Ghadiali, G. Wilkowski, R. Tenaglia, D.

Rudland, N. Bonora, A. Hopper, and P. Scott (Battelle, US); R. Gamble (Sartrex, US); D. Quinones (Robert L. Cloud \& Associates, US), P. Gilles and B. Houssin (Framatome, France); F. Gantenbein, N. Blay, B. Drubay, and D. Moulin (CEA, France); B. Brickstad and F. Moberg (AB Svensk Anläggningsprovning, Sweden); and P. Kadecka (Nuclear Research Institute, Czech Republic). We would like to thank them for their participation in the workshops.

Finally, we would like to thank Ms. Adele Armitage and Ms. Verna Kreachbaum for typing this report; Dr. A. Hopper for editorial comments; and Mr. P. Scott for management review.
(a) Contractual organization
(b) TAG representative 


\section{NOMENCLATURE}

\section{Symbols}

a

$a^{*}$

C

c

$\mathrm{D}_{\mathrm{m}}$

$\mathrm{D}_{\mathrm{o}}$

E

$F_{x}$

$F_{y}$

I

J

$\mathrm{J}_{\mathrm{D}}$

$\mathrm{J}_{\mathrm{D}}-\mathrm{R}$

$\mathbf{J}_{\text {Ic }}$

$\mathbf{J}_{\text {ins }}$

$\mathbf{J}_{\mathrm{M}}$

$\mathbf{J}_{\mathbf{M}}-\mathbf{R}$

J-R

$\mathrm{J}_{0.2}$

$\mathrm{J}_{0.2 / \mathrm{BL}}$

L

$\mathbf{L}_{\mathbf{F}}$

M

m

$\mathrm{N}$

n

$\mathbf{P}$

p

$\mathbf{R}$

Depth of internal surface crack in a pipe, or crack length

A dummy parameter with a value of unity

Power-law coefficient for modeling J-resistance curve

Half of through-wall crack length at mean pipe diameter

Mean diameter of pipe

Outside diameter of pipe

Modulus of elasticity

Force in the $\mathrm{x}$-direction

Force in the $y$-direction

Moment of inertia of uncracked pipe cross-section

J-integral (energy release rate)

Deformation J

Deformation J-R curve

Plane strain mode-I $\mathbf{J}$ at crack initiation by ASTM E813

$\mathrm{J}$ at instability

Modified J

Modified J-R curve

J-integral resistance (curve)

J-integral at $0.2 \mathrm{~mm}$ of crack growth

J-integral at $0.2 \mathrm{~mm}$ of crack growth with blunting line

Half of total pipe length

Distance between the fixed plane and the nozzle section with largest wall thickness

Bending moment

Power-law exponent for modeling J-resistance curve

Load

Strain-hardening exponent in Ramberg-Osgood model

Axial Load on a pipe

Internal pressure in the pipe

Stress or load ratio 


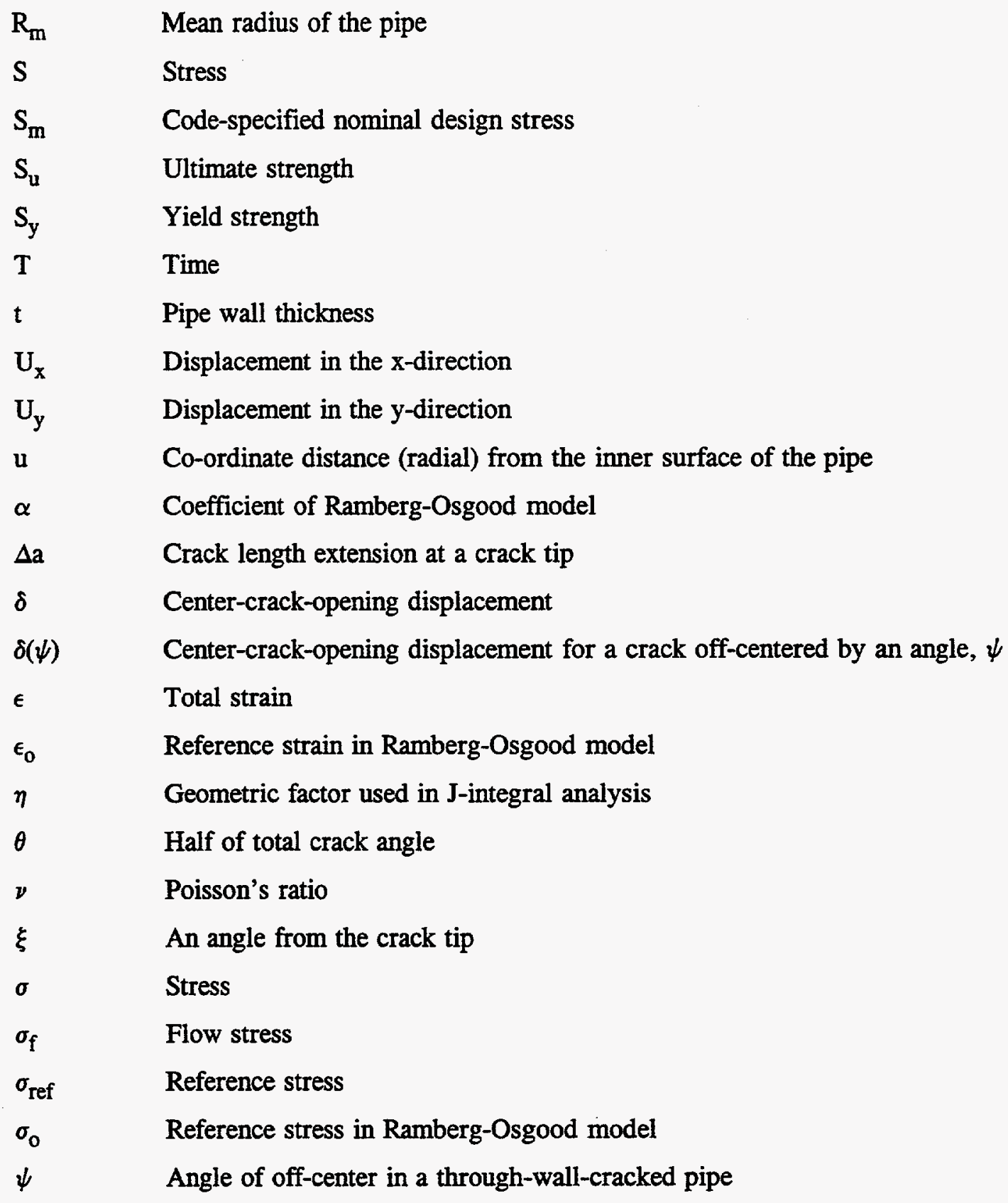

\section{Acronyms and Initialisms}

ASCII American Standard Code for Information Interchange

ASME American Society of Mechanical Engineers

ASTM American Society for Testing Materials

BWR Boiling water reactor

CEA Commissariat a L'Energie Atomique 
CEGB Central Electricity Generating Board (U.K.)

$\mathrm{COA} \quad$ Crack-opening area

COD Crack-opening displacement

$\mathrm{COV}$ Coefficient of variation (ratio of standard deviation to mean)

CRIEPI Central Research Institute of Electric Power Industry

$\mathrm{C}(\mathrm{T}) \quad$ Compact (tension) specimen

DPFAD Deformation plasticity failure analysis diagram

DYN Dynamic

EDF Electricité de France

EPFM Elastic-plastic fracture mechanics

EPRI Electric Power Research Institute

ESIS European Structural Integrity Society

FEA Finite element analysis

FEM Finite element method

GE General Electric

HDR Heissdampfreactor (an experimental reactor facility in Germany)

IBM International Business Machine

ID Inside diameter

IGSCC Intergranular stress corrosion cracking

IHI Ishikawajima - Harima Heavy Industries

IPIRG International Piping Integrity Research Group

IPSN Institut De Protection et Suréte Nucléaire

ISO International Standards Organization

JSME Japanese Society of Mechanical Engineers

J-R J-resistance

KINS Korea Institute of Nuclear Safety

LBB Leak-before-break

LEFM Linear-elastic fracture mechanics

MAPI Mitsubishi Atomic Power Industries

MHI Mitsubishi Heavy Industries

MPA Staatliche Materialprüfungsanstatt (University of Stuttgart)

NRC Nuclear Regulatory Commission

NUREG/CR Nuclear Regulatory Commission contractor report 
Nomenclature

OD Outside diameter

PC Personal computer

PICEP Pipe Crack Evaluation Program

PWR Pressurized water reactor

RCCM Regles de Conception et de Construction des Materiels Mechaniques des Reacteurs á Eau Pressurisée

RT Room temperature

QS Quasi-static

SAM Seismic anchor motion

SAW Submerged-arc weld

SC Surface crack or surface-cracked

SI System International

SKKU Sung Kyun Kwan University

SMAW Shielded-metal arc weld

SQUIRT Seepage Quantification of Upsets in Reactor Tubes

SSE Safe-shutdown earthquake

TAG Technical Advisory Group

TWC Through-wall-cracked

3D Three-dimensional 


\section{PREVIOUS REPORTS IN SERIES}

\section{Reports from the IPIRG-1 Program}

“Evaluation and Refinement of Leak-Rate Estimation Models," NUREG/CR-5128, Revision 1, June 1994.

"Loading Rate Effects on Strength and Fracture Toughness of Pipe Steels Used in Task 1 of the IPIRG Program," Topical Report, NUREG/CR-6098, October 1993.

“Stability of Cracked Pipe Under Inertial Stresses," NUREG/CR-6233, Volume 1, August 1994.

\section{Previous Related Documents from NRC's Short Cracks in Piping and Piping Welds Program}

"Short Cracks in Piping and Piping Welds," First Semiannual Report, NUREG/CR-4599, Vol. 1, No. 1, March 1991.

"Short Cracks in Piping and Piping Welds," Second Semiannual Report, NUREG/CR-4599, Vol. 1, No. 2, April 1992.

"Short Cracks in Piping and Piping Welds," Third Semiannual Report, NUREG/CR-4599, Vol. 2, No. 1, September 1992.

"Short Cracks in Piping and Piping Welds," Fourth Semiannual Report, NUREG/CR-4599, Vol. 2, No. 2, February 1993.

"Short Cracks in Piping and Piping Welds," Fifth Semiannual Report, NUREG/CR-4599, Vol. 3, No. 1, October 1993.

"Short Cracks in Piping and Piping Welds," Sixth Semiannual Report, NUREG/CR-4599, Vol. 3, No. 2, March 1994.

“Short Cracks in Piping and Piping Welds," Progress Report, NUREG/CR-4599, BMI-2173, Vol. 4, No. 1, April 1995.

"Fracture Behavior of Short Circumferential Short-Surface-Cracked Pipe," NUREG/CR-6298, November 1995.

"Fracture Evaluations of Fusion Line Cracks in Nuclear Pipe Bimetallic Welds," NUREG/CR-6297, April 1995.

"Effect of Dynamic Strain Aging on the Strength and Toughness of Nuclear Ferritic Piping at LWR Temperatures," NUREG/CR-6226, October 1994.

"Effects of Toughness Anisotropy and Combined Loading on Fracture Behavior of Ferritic Nuclear Pipe," NUREG/CR-6299, April 1995. 
Previous Reports in Series

"Refinement and Evaluation of Crack-Opening Analyses for Circumferential Through-Wall Cracks in Pipes," NUREG/CR-6300, April 1995.

"Probabilistic Pipe Fracture Evaluations for Leak-Rate Detection Applications," NUREG/CR-6004, April 1995.

“Stainless Steel Submerged Arc Weld Fusion Line Toughness," NUREG/CR-6251, April 1995.

"Validity Limits in J-Resistance Curve Determination: Volume 1: An Assessment of the $\mathrm{J}_{\mathbf{M}}$ Parameter," NUREG/CR-6264, Volume 1, February 1995.

"Validity Limits in J-Resistance Curve Determinations: Volume 2: A Computational Approach to Ductile Crack Growth Under Large-Scale Yielding Condition," NUREG/CR-6264, Volume 2, February 1995.

\section{Previous Related Documents from NRC's Degraded Piping Program - Phase I Reports}

"The Development of a Plan for the Assessment of Degraded Nuclear Piping by Experimentation and Tearing Instability Fracture Mechanics Analysis," NUREG/CR-3142, Vols. 1 and 2, June 1983.

\section{Previous Related Documents from NRC's Degraded Piping Program - Phase II Reports}

“Degraded Piping Program - Phase II," Semiannual Report, NUREG/CR-4082, Vol. 1, Oct. 1984.

“Degraded Piping Program - Phase II," Semiannual Report, NUREG/CR-4082, Vol. 2, June 1985.

“Degraded Piping Program - Phase II," Semiannual Report, NUREG/CR-4082, Vol. 3, March 1986.

“Degraded Piping Program - Phase II,” Semiannual Report, NUREG/CR-4082, Vol. 4, July 1986.

“Degraded Piping Program - Phase II,” Semiannual Report, NUREG/CR-4082, Vol. 5, Dec. 1986.

“Degraded Piping Program - Phase II,” Semiannual Report, NUREG/CR-4082, Vol. 6, April 1988.

“Degraded Piping Program - Phase II," Semiannual Report, NUREG/CR-4082, Vol. 7, March 1989.

“Degraded Piping Program - Phase II," Semiannual Report, NUREG/CR-4082, Vol. 8, March 1989.

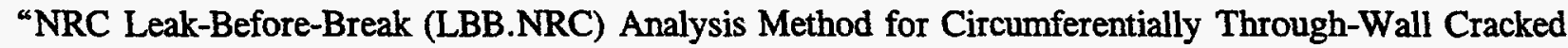
Pipes Under Axial Plus Bending Loads," Topical Report, NUREG/CR-4572, March 1986.

"Elastic-Plastic Finite Element Analysis of Crack Growth in Large Compact Tension and Circumferentially Through-Wall-Cracked Pipe Specimen--Results of the First Battelle/NRC Analysis Round Robin," Topical Report, NUREG/CR-4573, September 1986.

"An Experimental and Analytical Assessment of Circumferential Through-Wall Cracked Pipes Under Pure Bending," Topical Report, NUREG/CR-4574, June 1986. 
"Predictions of J-R Curves With Large Crack Growth From Small Specimen Data," Topical Report, NUREG/CR-4687, September 1986.

“An Assessment of Circumferentially Complex-Cracked Pipe Subjected to Bending," Topical Report, NUREG/CR-4687, September 1986.

“Analysis of Cracks in Stainless Steel TIG Welds," Topical Report, NUREG/CR-4806, November 1986.

"Approximate Methods for Fracture Analyses of Through-Wall Cracked Pipes," Topical Report, NUREG/CR-4853, January 1987.

“Assessment of Design Basis for Load-Carrying Capacity of Weld-Overlay Repair," Topical Report, NUREG/CR-4877, February 1987.

“Analysis of Experiments on Stainless Steel Flux Welds," Topical Report, NUREG/CR-4878, February 1987.

"Experimental and Analytical Assessment of Circumferentially Surface-Cracked Pipes Under Bending," Topical Report, NUREG/CR-4872, April 1987.

\section{Other Related Program Reports}

"Validation of Analysis Methods for Assessing Flawed Piping Subjected to Dynamic Loading," NUREG/CR-6234, August 1994. 



\subsection{INTRODUCTION}

\subsection{Introduction}

One of the key purposes for developing The Second International Piping Integrity Research Group Program (IPIRG-2) (a) was to promote a common technical basis for leak-before-break (LBB) analysis and pipe flaw evaluations. To enhance IPIRG-2 members' understanding of the various technical and regulatory bases in other countries and help develop a consensus on how to handle difficult analytical problems, a series of three one-day round-robin workshops was held at Battelle, Columbus, Ohio, on August 5, 1993 (first workshop), March 4, 1994 (second workshop), and October 21, 1994 (third workshop). The workshops were conducted in conjunction with the semiannual IPIRG-2 Technical Advisory Group (TAG) meetings. This report presents a summary of the results from these round-robin efforts.

\subsection{IPIRG-2 Round-Robin Analyses}

The workshops involved technical presentations on the related research efforts by the IPIRG-2 member organizations and solutions to several round-robin problems. Following review by the IPIRG-2 TAG members, four sets of round-robin problems were developed by Battelle during the course of this program. The problems sets are:

1. Problem Set A: Evaluations of Fracture Properties and Pipe Loads. The general objectives were to evaluate the material fracture properties and prediction of the initiation and maximum loads in pipes with cracks. The specific objectives were to:

- Evaluate fracture properties of pipe at operating temperature from mill data.

- $\quad$ Assess the differences in international standards for determining $\mathbf{J}_{\mathrm{Ic}}$ and $\mathrm{J}-\mathrm{R}$ curves.

- Determine the significance of the uncertainty in J-R curves (due to various standards and cyclic and dynamic load effects) and stress-strain curves (due to various standards) on the prediction of the load-carrying capacity of pipes.

2. Problem Set B: Crack-Opening and Leak-Rate Evaluations. The general objective was to assess the variability in the prediction of crack-opening and leak rate for leak-before-break analyses in pipes. The specific objectives were to:

- $\quad$ Assess current models for crack-opening-area analysis of pipes.

- $\quad$ Evaluate the adequacy of current models for predicting leak rates.

- Develop an engineering approach for predicting crack-opening for a pipe with an offcentered crack.

(a) The IPIRG-2 Program was an international group program consisting of 22 international organizations from 15 countries that was coordinated by the U.S. Nuclear Regulatory Commission and conducted at Battelle from October 1991 to December 1995. 
- Evaluate the effects of weld residual stresses on the crack-opening predictions.

- Conduct a crack-opening-area analysis of a girth weld crack in a nozzle with a thickness gradient on both sides.

3. Problem Set C: Dynamic Analysis of Cracked Pipes. The general objective was to evaluate quasi-static versus dynamic flaw analyses for cracked pipes. The specific objectives were to:

- Generate seismic time-histories consistent with a given response spectrum.

- Establish the accuracy of predictions for seismic pipe system tests with cracks.

4. Problem Set D: Fracture Evaluations of Elbows. The general objective was to evaluate various methods to predict the fracture behavior of cracks in pipe elbows. The specific objective was to determine the accuracy of displacement predictions for an uncracked pipe elbow.

These problem sets, many with several sub-problems, were structured to examine problems of increasing complexity starting with the simplest problem. Table 1.1 summarizes all of the problems considered in the round-robin workshops from the IPIRG-2 program.

A total of 41 engineers and scientists from 18 different organizations participated in the IPIRG-2 round-robin workshops. Table 1.2 lists the participating organizations and their countries. Each of these participants ma.je presentations of their own results for a given round-robin problem. Later, Battelle compiled the results from all participants to perform a comparative assessment of the current state-of-the art for fracture-mechanics and thermal-hydraulics models for application in nuclear piping and piping welds.

\subsection{Outline of the Report}

Sections 2, 3, 4, and 5 describe the solutions of Problem Sets A, B, C, and D, respectively. They provide the definition, comparison of the results by various participants, and general conclusions for each of the round-robin problems defined in Table 1.1. The corresponding problem statements are given in Appendices A, B, C, and D. The results of each participant, with a complete description of the solution methods, were compiled in the three-volume proceedings during the round-robin workshops. The proceedings were provided to each member of the IPIRG-2 TAG. 
Table 1.1 List of IPIRG-2 Round-Robin problems

\begin{tabular}{|c|c|}
\hline Problem & Title of the Problem ${ }^{(a)}$ \\
\hline \multicolumn{2}{|c|}{ 1. Problem Set A: Evaluations of Fracture Properties and Pipe Loads ${ }^{(b)}$} \\
\hline Problem A.1 & Predictions of J-R curves and tensile properties using mill data \\
\hline Problem A.2 & Evaluation of J-R curves using various international standards \\
\hline Problem A.3 & Fracture load evaluations using J-R curves from various international standards \\
\hline Problem A.4 & Fracture load evaluations using $\mathrm{J}-\mathrm{R}$ curves from different load-histories \\
\hline Problem A. 6 & Fracture load evaluations using stress-strain curves from various methods \\
\hline \multicolumn{2}{|r|}{ 2. Problem Set B: Crack-Opening and Leak-Rate Evaluations } \\
\hline Problem B.1 & Calculation of crack-opening displacements for pipes under various loads \\
\hline Problem B.2 & Leak-rate analysis of cracked pipes with various cracking mechanisms \\
\hline Problem B.3 & Crack-opening-area analysis of pipes with off-centered cracks \\
\hline Problem B.4 & Effects of weld residual stresses on crack-opening analysis of pipes \\
\hline Problem B.5 & Crack-opening analysis of a girth weld nozzle crack at a thickness transition \\
\hline \multicolumn{2}{|r|}{ 3. Problem Set C: Dynamic Analysis of Cracked Pipes } \\
\hline Problem C.1 & Spectrum-compatible time-histories \\
\hline Problem C. 2 & Analysis of IPIRG-2 seismic surface-cracked pipe system experiment \\
\hline \multicolumn{2}{|r|}{ 4. Problem Set D: Fracture Evaluations of Elbows } \\
\hline Problem D.1 & Displacement calculations for an uncracked elbow \\
\hline
\end{tabular}

(a) See Appendices A to D for complete definitions of the problems.

(b) Problem A.5 was eliminated from the Round-Robin workshop. 
Table 1.2 List of participating organizations for IPIRG-2 Round-Robin analyses

\begin{tabular}{ll}
\hline Organization & Country \\
\hline Central Research Institute of Electric Power Industry (CRIEPI) & Japan \\
Mitsubishi Atomic Power Industries (MAPI) & Japan \\
Toshiba & Japan \\
Ishikawajima-Harima Heavy Industries (IHI) & Japan \\
National Nuclear Corporation & U.K. \\
Nuclear Electric & U.K. \\
AEA Technology & U.K. \\
Korea Institute of Nuclear Safety (KINS) & Republic of Korea \\
Sung Kyun Kwan University (SKKU) & Republic of Korea \\
Battelle & U.S. \\
Sartrex & U.S. \\
Robert L. Cloud \& Associates, Inc. & U.S. \\
Framatome & France \\
Electricité de France (EDF) & France \\
Commissariat a L'Energie Atomique (CEA) & France \\
Institut De Protection et Sureté Nucléaire (IPSN) & France \\
AB Svensk Anläggningsprovning/Swedish Plant Inspection, Ltd. & Sweden \\
Nuclear Research Institute & Czech Republic \\
\hline
\end{tabular}




\subsection{ROUND-ROBIN PROBLEM SET A}

\subsection{Round-Robin Problem A.1 - Predictions of J-R Curves and Tensile Properties Using Mill Data}

\subsubsection{Problem Definition}

The objective of this problem was to estimate the high temperature ( $228 \mathrm{C}$ [550 F]) tensile and J-R curve properties of ferritic steel pipes using typical mill data. Frequently these are the only data available on the properties of a pipe material.

Three types of material were considered. Material A was an A106 Grade B carbon steel (DP2F29) ${ }^{(a)}$, Material B was an A516 Grade 70 ferritic steel (DP2-F26), and Material C was a ferritic steel flux-weld (DP2-F86W). The participants were given the room-temperature mill data developed during the past Degraded Piping Program (Ref. 2.1) at Battelle. Appendix A has details of these mill data.

There were five sub-problems. The participants were asked to calculate the yield and ultimate strengths (Problem A.1-a), Ramberg-Osgood coefficients (Problem A.1-b), J-integral value at crack initiation (Problem A.1-c), initial value of dJ/da (Problem A.1-d), and entire J-R curve in power-law form (Problem A.1-e), all at a temperature of $288 \mathrm{C}(550 \mathrm{~F})$. Four participants solved this problem. They are identified as Participants B-1, C-1, D, and F-1 in this report.

\subsubsection{Summary and Conclusions}

Problem A.1-a: Calculate vield and ultimate strengths at $288 \mathrm{C}$ (550 F). For this problem, all participants assumed fixed ratios of $288 \mathrm{C}(550 \mathrm{~F})$ strengths to room temperature strengths, with some participants also assuming different ratios for the base plate and weld. Table 2.1 shows the estimated ratio of yield strength at $288 \mathrm{C}(550 \mathrm{~F})$ and room temperature. A similar ratio is also shown for the ultimate strength in the same table. High temperature yield strengths were estimated to be 78 to 93 percent of the room temperature values with the actual value being 86 percent for both steels $\mathrm{A}$ and B. The high temperature ultimate strengths were estimated to be 90 to 100 percent of the room temperature values with the actual value being 118 and 124 percent for steels $A$ and $B$, respectively. The higher actual ratios are probably due to dynamic strain aging.

Problem A.1-b: Calculate Ramberg-Osgood parameters at $288 \mathrm{C}$ (550 F). For this problem, Participant B-1 assumed that the strain at ultimate tensile strength was about thirty percent of the reduced area. Combined with the yield criterion, this estimate gave two points to fix the two Ramberg-Osgood parameters. Participant C-1 employed equations developed in EPRI NP-2431 (Ref. 2.2), and Participant F-1 used a similar approach from ESIS Recommendation P2-90 (Ref. 2.3). Participant $D$ chose parameters from those found using three methods: an empirical correlation

(a) The designation DP2-Fxxx refers to materials which were used and characterized in the NRC's Degraded Piping Program, see Reference 2.1. 
between Ramberg-Osgood parameters and yield strength developed at Battelle (Ref. 2.4), an ASME Working Group on Flaw Evaluation method similar to that used by Participant C-1, and a master plot of $288 \mathrm{C}(550 \mathrm{~F})$ tensile data from EPRI Project 1757-65 (Ref. 2.5).

Figure 2.1 shows the plots of stress-strain curves estimated by various participants for Materials A, $B$, and $C$ and their comparisons with the actual measured data. It appears that the Ramberg-Osgood hardening exponent (n) calculated by Participant B-1 tended to be high compared with the actual values, while the other approaches gave exponents that varied from accurate to underestimates, depending on the method and material. The estimates of the Ramberg-Osgood coefficient $(\alpha)$ also tended to be high. For example, in Material B, the values of $\alpha$ predicted by Participants F-1 and B-1 were 2 and 2.5, respectively. The Ramberg-Osgood fit of the actual data from F26-5 and F26-6 tensile specimens showed that $\alpha$ should be about 1.2 .

Problem A.1-c: Calculate the J value at crack initiation at $288 \mathrm{C}$ (550 F). This problem also included estimation of the Charpy upper shelf energy. All participants postulated a linear dependence of energy on shear area and all overestimated the upper shelf energy. To calculate $J$ at initiation, Participants C-1 and F-1 used the correlations based solely on upper shelf energy. Participants B-1 and D used the Rolfe-Novak correlation (Ref. 2.6), based on yield strength and upper shelf energy, while Participant D also used a second correlation based solely on tensile properties (Ref. 2.7$)^{(b)}$. Tables 2.2 and 2.3 show the predicted upper shelf energy and $J$ at crack initiation, respectively, by various participants. The comparisons with the actual measured values, also shown in Tables 2.2 and 2.3, revealed that the upper-shelf energy was overestimated, while $J$ at crack initiation was both underestimated and overestimated. Hence, none of the methods was consistently satisfactory.

Problem A.1-d: Calculate the initial dJ/da at $288 \mathrm{C}(550 \mathrm{~F})$. For this problem, Participants B-1 and C-1 first solved Problem A.1-e to obtain a complete J-R equation, which they then differentiated and evaluated at $0.2 \mathrm{~mm}$ ( $0.008 \mathrm{inch})$ of crack growth to obtain the initial $\mathrm{dJ} / \mathrm{da}$. Participants $\mathrm{D}$ and F-1 developed estimates of $\mathrm{dJ} / \mathrm{da}$ based on reported behavior of similar steels and welds. They both suggested that there is a region where $\mathrm{dJ} / \mathrm{da}$ expressed in $\mathrm{MPa}$ is numerically equal to $\mathrm{J}_{\mathrm{Ic}}$ expressed in $\mathrm{kN} / \mathrm{m}$. Table 2.4 shows the comparisons of predicted $\mathrm{dJ} / \mathrm{da}$ by various participants with its actual measurement. Once again, none of the methods gave consistently satisfactory results since both overestimates and underestimates were obtained.

Problem A.1-e: Calculate the entire J-R curve in power law form at 288 C $(550$ F). Participants B-1 and D both based their estimate of the exponent (m) on assumptions of typical steel behavior. Participant B-1 calculated the coefficient $C$ using the condition that $J_{I c}$ (Problem A.1-c) is the value of $\mathrm{J}$ at $0.2 \mathrm{~mm}(0.008 \mathrm{inch})$ beyond the blunting line. Participant $\mathrm{D}$ suggested that $\mathrm{C}=0.001 \times \mathrm{dJ} / \mathrm{da}$ and used the results of Problem A.1-d. Participant C-1 developed two equations for the two unknowns by fixing two points on the J-R curve: $\mathrm{J}_{\mathrm{Ic}}$ from Problem A.1-c and $\mathrm{J}_{\text {ins }}$ ( $\mathrm{J}$ at instability, estimated using correlations from the literature). The approach of Participant F-1 was similar; it consisted of estimating the values of $J$ at crack growths of $1.5 \mathrm{~mm}(0.06 \mathrm{inch})$ and $10 \mathrm{~mm}(0.4 \mathrm{inch})$ by using a tri-linear curve, with slopes based on the result of Problem A.1-d and past experience.

(b) The solutions by Participant $\mathrm{D}$, which are based on Charpy and tensile correlations, are represented by $D_{c}$ and $D_{t}$, respectively. 
Figures 2.2 through 2.4 show the plots of the J-R curves estimated by the various participants for Materials A, B, and C, respectively, and their comparisons with the actual measured data. The results by the participants showed mixed trends. Some of these trends were already discussed in Problems A.1-c and A.1-d. The coefficient of variation of the $J$ estimates varied from 20 percent at 1 $\mathrm{mm}(0.04$ inch) of crack growth to 30 percent at $5 \mathrm{~mm}(0.2$ inch) of crack growth.

\subsection{Round-Robin Problem A.2 - Evaluation of J-R Curves Using Various International Standards}

\subsubsection{Problem Definition}

The objective of this problem was to assess the differences in calculated J-R curves using different international standards and the newly proposed ASTM standard. The output of this problem will also serve as the input to Problems A.3, A.4, and A.6.

The participants were given composite raw data from three compact-tension specimen crack-growth experiments at $288 \mathrm{C}(550 \mathrm{~F})$ : specimen dimensions, test temperature, and yield and tensile strengths. In addition, a table of loads and average crack growths was given for twenty separate values of loadline displacement. See Appendix A for further details of the input. There were two sub-problems both of which involved calculation of $J-R$ curves from the input defined above. In Problem A.2$a^{(a)}$, the participants were asked to calculate J-R curves from any international standard, whereas in Problem A.2-b, the participants were asked to calculate J-R curves using the newly proposed ASTM standard. There were six participants who solved this problem. They are identified as Participants A-1, B-1, B-2, C-1, C-2, and D in this report.

\subsubsection{Summary and Conclusions}

Problem A.2-a. For this problem, Participant A-1 used two JSME standards: S 001-1981 (Ref. 2.8) and S 001-1992 (Ref. 2.9) to compute the J-R curve. The equation used in the latter standard is identical to that in Paragraph A2.5 of ASTM E813-89 (Ref. 2.10). To provide crack length values, Participant A-1 used the fractographs to obtain three-point averages near the midplane. Because of tunneling, the crack lengths were somewhat higher than the tabulated values used by the other participants. In addition, the 1992 standard provided slightly higher values of $\mathrm{J}$ than did the 1981 standard. Participant B-1 used ASTM E813-89 and reported a $\mathrm{J}_{\mathrm{Ic}}$ value of $279 \mathrm{~kJ} / \mathrm{m}^{2}(1,593 \mathrm{in}$ $\mathrm{lb} / \mathrm{in}^{2}$ ) as well as a J-R equation. Participant B-2 also used ASTM E813-89, but only considered the plastic component of $\mathrm{J}$. The $\mathrm{J}_{\mathrm{Ic}}$ values were calculated using four methods: ASTM, CEGB $\left(\mathrm{J}_{0.2}\right)$, and ESIS $\left(\mathrm{J}_{0.2}\right.$ and $\left.\mathrm{J}_{0.2 / \mathrm{BL}}\right)$. These values ranged from $\left.160 \mathrm{~kJ} / \mathrm{m}^{2}\left(914 \mathrm{in}-\mathrm{lb}_{\mathrm{in}}\right)^{2}\right)$ to $196 \mathrm{~kJ} / \mathrm{m}^{2}(1,119 \mathrm{in}$ $\mathrm{lb} / \mathrm{in}^{2}$ ) and were significantly lower than the value predicted by Participant B-1. Participant C-1 calculated the J-R curve using ASTM E1152-87 (Ref. 2.11). J reached a maximum at a crack growth

(a) Problem A.2-a in this report was known as Problem A.2 in the First IPIRG-2 Round-Robin Workshop. This revision is needed due to the creation of Problem A.2-b discussed in the Second IPIRG-2 RoundRobin Workshop. 
of slightly over $2 \mathrm{~mm}(0.08$ inch), which was close to the point where the measurement capacity of the specimen was exceeded. The value of $J$ then decreased with increasing crack growth. Finally, Participant D also used ASTM E1152-87 (Ref. 2.11) and both $J$ and $J_{M}$ (paragraph 9.1.4 of the standard) were both calculated. The ratio of $\mathrm{J}_{\mathrm{M}}$ to $\mathrm{J}$ ranged from 1.0 at initiation to $1.2 \mathrm{at} 5 \mathrm{~mm}(0.2$ inch) of crack growth.

Figure 2.5 shows the plots of J-R curves estimated by various participants. Since the computation methods were very similar, it was not surprising that the calculated results were similar. The comparisons of $\mathbf{J}$ at several crack growths indicated that the standard deviation in computed $\mathbf{J}$ was on the order of ten percent of the mean.

Problem A.2-b. For this problem, only Participants C-1, C-2, and D provided the results. Figure 2.6 shows the J-R curves calculated by each of these participants. All solutions were virtually identical. In addition, further examination of detailed results by the participants, which are not explicitly shown in this report, indicated that (1) small differences might arise when comparing J-R curves with and without crack blunting (Participant D), and (2) differences in the J-R curves using the proposed ASTM standard and ASTM E1152 were negligible (Participant C-2).

\subsection{Round-Robin Problem A.3 - Fracture Load Evaluations Using J-R Curves from Various International Standards}

\subsubsection{Problem Definition}

The objectives of this problem were to predict the initiation and maximum loads for through-wallcracked (TWC) and surface-cracked (SC) pipes under pure bending and combined bending and tension, respectively, and determine if there were any significant differences in the load predictions using several J-R curves estimated from Problems A.1 and A.2.

The participants were given both the geometric and material properties of the pipes to solve eight subproblems involving four large-diameter pipes (Problems A.3-a to A.3-d) and four small-diameter pipes (Problems A.3-e to A.3-h). Two pipes from each size of the pipe diameters had through-wall and surface cracks. For each problem, one stress-strain curve and three J-R curves (upper limit, lower limit, and median) were prescribed. Appendix A has further details of the input. The solutions were presented by five TAG members and are identified as Participants A-1, B-3, C-1, D-1, and F-3 in this report.

\subsubsection{Summary and Conclusions}

A number of different methods were used by the participants to solve Problem A.3. Participant A-1 used the GE/EPRI (Ref. 2.12), R6 Option 1 and R6 Option 2 methods (Ref. 2.13) for the TWC pipes and the R6 Option 1 and R6 Option 2 methods (Ref. 2.13) for the SC pipes ${ }^{(2)}$. Participant B-3

(a) The selected methods for comparisons were GE/EPRI (Solution A-1a) and R6 Option 2 (Solution A-1b) for TWC pipes and R6 Option 1 (Solution A-1a) and R6 Option 2 (Solution A-1b) for SC pipes. 
used the R6 Option 2 and R6 Option 3 methods (Refs. 2.13 and 2.14) for the TWC pipes ${ }^{(b)}$. Participant C-1 used the GE/EPRI method (Ref. 2.5) for both the TWC and SC pipes. Participant D used the LBB.ENG2 (Ref. 2.15), LBB.NRC (Ref. 2.16), and GE/EPRI (Refs. 2.17 and 2.18) methods for the TWC pipes and the SC.TNP2 (Ref. 2.19), SC.TKP1 (Ref. 2.19), and SC.ENG2 methods (Ref. 2.19) for the SC pipes ${ }^{(a)}$. Finally, Participant F-3 used the DEFR (Refs. 2.20 and 2.21) and $\mathrm{J}_{\mathrm{s}}$ (Ref. 2.22) methods for the TWC pipes ${ }^{(\mathrm{b})}$.

Figures 2.7 through 2.10 and Figure 2.11 through 2.14 show plots of the predicted initiation and maximum moments by various participants for the through-wall-cracked and surface-cracked pipes, respectively, as a function of the J-R curve. The results by the participants were reasonably close when the crack sizes were larger. For short through-wall cracks and short and shallow surface cracks, the load predictions indicated scatter that was more than that for long through-wall cracks and long and deep surface cracks. This is consistent with our experience at Battelle which involved pipe fracture evaluations for a wide variety of piping systems with various pipe diameters, crack sizes, and material properties (Refs. 2.19 and 2.23). Nevertheless, the results predicted by all participants showed that:

- $\quad$ For both TWC and SC pipes, the initiation moments based on J-R curves using median and lower limits were close to each other. This can be explained from the fact that the values of fracture toughness at crack initiation $\left(J_{I C}\right)$ for these two $J-R$ curves were similar.

- In calculating the maximum moments, close results were obtained when using J-R curves from (1) median and upper limits for TWC pipes and (2) median and lower limits for SC pipes. This is because the values of median and upper J-R curves following ductile crack growth in TWC pipes were also close to each other. Since, the amount of crack growth in SC pipes was very small compared with that in TWC pipes, the effects of J-R curves on the initiation and maximum moments were very similar.

- The uncertainty in J-R curve characteristics (e.g., lower limit, upper limit, or median curves) had relatively small effects on the scatter of the moment-carrying capacity of pipes.

For Problem A.3, we also identified several pipe fracture experiments, such as Experiments 1.1.1.21, 4111-2, and 1.2.3.15 corresponding to the Problems A.3-a, A.3-b, and A.3-d, respectively. These pipe fracture data were developed in the NRC's Short Cracks in Piping and Piping Welds Program

(b) For comparisons, the selected method was R6 Option 2.

(a) The selected methods for comparisons were LBB.ENG2 (Solution Da), LBB.NRC (Solution Db), and GE/EPRI (Solution Dc) for TWC pipes and SC.TNP2 (Solution Da), SC.TKP1 (Solution Db), and SC.ENG2 (Solution Dc) for SC pipes.

(b) The selected methods for comparisons were DEFR (Solution F-3a) and Js (Solution F-3b) for TWC pipes. 
(Ref. 2.24) and the Degraded Piping Program (Ref. 2.1). The initiation and maximum moments for Experiment 1.1.1.21 were 2,778 kN-m (24,588 inch-kip) and 3,225 kN-m (28,545 inch-kip), respectively (Ref. 2.24), and for Experiment 4111-2 were $809 \mathrm{kN}-\mathrm{m}$ (7,161 inch-kip) and 1,196 $\mathrm{kN}$-m (10,586 inch-kip), respectively (Ref. 2.1). The maximum moment for Experiment 1.2.3.15 was $2,189 \mathrm{kN}-\mathrm{m}$ (19,375 inch-kip) (Ref. 2.24). These experimental loads, also shown in Figures 2.7, 2.8 , and 2.12 , suggest that good correlations exist between the predicted results by the participants and the above experimental data.

\subsection{Round-Robin Problem A.4 - Fracture Load Evaluations Using J-R Curves from Different Load Histories}

\subsubsection{Problem Definition}

The objectives of this problem were to predict the initiation and maximum loads for through-wallcracked and surface-cracked pipes under pure bending and combined bending and tension, respectively, and determine if there were any significant differences in the load predictions using the $\mathrm{J}-\mathrm{R}$ curves from different load-histories. This problem is similar to Problem A.3, except that in Problem A.4, the effects of load-history on the J-R curve and its influence on a pipe's load-carrying capacity were evaluated.

As before, the participants were given both the geometric and material properties of the pipes to solve eight sub-problems involving four large-diameter pipes (Problems A.4-a to A.4-d) and four smalldiameter pipes (Problems A.4-e to A.4-h). For each problem, one stress-strain curve and three J-R curves obtained from quasi-static and monotonic, dynamic and monotonic, and dynamic and cyclic tests were given. Appendix A has further details of the input. Six solutions of this problem were offered. They were submitted by Participants A-1, B-3, C-1, C-2, D, and F-3.

\subsubsection{Summary and Conclusions}

As in Problem A.3, several methods were used by the participants to solve Problem A.4. Participant A-1 used the GE/EPRI method (Ref. 2.12) for the TWC pipes. Participant B-3 used the R6 Option 1 and R6 Option 2 methods (Refs. 2.13 and 2.14) also for the TWC pipes ${ }^{(2)}$. Participant C-1 used the GE/EPRI method (Refs. 2.5, 2.17, and 2.18) from two different computer codes for the TWC pipes and SC.TNP1 (Ref. 2.19) and the GE/EPRI method (Ref. 2.5) for the SC pipes ${ }^{(b)}$. Participant C-2 used the GE/EPRI (Ref. 2.5) method for both the TWC and SC pipes. Participant D used the LBB.ENG2 (Ref. 2.15), LBB.NRC (Ref. 2.16), and GE/EPRI (Refs. 2.17 and 2.18) methods for the TWC pipes and the SC.TNP1, SC.TNP2, SC.TKP1, SC.TKP2, and SC.ENG2

(a) The methods for comparisons were R6 Option 1 (Solution B-3a) and R6 Option 2 (Solution B-3b) for TWC pipes.

(b) The computer codes/methods for comparisons were NRCPIPE, Version 2.0 developed at Battelle (Solution C-1a) and the participants's in-house code (Solution C-1b) for TWC pipes and SC.TNP1 (Solution C-1a) and GE/EPRI (Solution C-1b) for SC pipes. 
methods (Ref. 2.19) for the SC pipes ${ }^{(c)}$. Finally, Participant F-3 used the DEFR method (Refs. 2.20 and 2.21) for TWC pipes.

Figures 2.15 through 2.18 show the plots of predicted initiation and maximum moments by various participants for the through-wall-cracked pipes as a function of the J-R curve. Similar plots are also shown in Figures 2.19 through 2.22 for the surface-cracked pipes. The comparisons of results showed the following:

- The differences in J-R curves from various load histories can affect predictions of a pipe's load-carrying capacity.

- The predictions based on quasi-static-and-monotonic and dynamic-and-cyclic J-R curves provided the largest and smallest values of the loads.

- $\quad$ For the through-wall-cracked pipes, there was more scatter in the predictive moments when the crack size was smaller.

- There was far more scatter in predictive moments for the surface-cracked pipes than those for the through-wall-cracked pipes.

\subsection{Round-Robin Problem A.6 - Fracture Load Evaluations Using Stress- Strain Curves from Various Methods}

\subsubsection{Problem Definition}

The objectives of this problem were to predict the initiation and maximum loads for through-wallcracked and surface-cracked pipes under pure bending and combined bending and tension, respectively, and determine if there were any significant differences in the load predictions using several quasi-static stress-strain curves of the same material.

As before, the participants were given both the geometric and material properties of the pipes to solve eight problems involving four large-diameter pipes (Problems A.6-a to A.6-d) and four small-diameter pipes (Problems A.6-e to A.6-h). For each problem, one J-R curve and three quasi-static stress-strain curves representing its upper limit, lower limit, and actual estimates were prescribed. For further details of the input, see Appendix A. The solutions were presented by four members who are identified as Participants A-1, C-1, C-2, and D in this report.

(c) The methods for comparisons were LBB.ENG2 (Solution Da), LBB.NRC (Solution Db), and GE/EPRI (Solution Dc) for TWC pipes and SC.TNP1 (Solution Da), SC.TNP2 (Solution Db), SC.TKP1 (Solution Dc), SC.TKP2 (Solution Dd), and SC.ENG2 (Solution De) for SC pipes. 


\subsubsection{Summary and Conclusions}

To solve Problem A.6, a number of different methods were used by the participants. Participant A-1 used the GE/EPRI (Ref. 2.12) method for the TWC pipes. Participant C-1 used the GE/EPRI (Refs. 2.5, 2.17, and 2.18) method from two different computer codes for the TWC pipes and SC.TNP1 (Ref. 2.19) and GE/EPRI (Ref. 2.5) methods for the SC pipes ${ }^{(a)}$. Participant C-2 used the GE/EPRI (Ref. 2.5) method for both the TWC and SC pipes. Finally, Participant D used the LBB.ENG2 (Ref. 2.15), LBB.NRC (Ref. 2.16), and GE/EPRI (Refs. 2.17 and 2.18) methods for the TWC pipes and the SC.TNP1, SC.TNP2, SC.TKP1, SC.TKP2, and SC.ENG2 methods (Ref. 2.19) for the SC pipes ${ }^{(a)}$.

Figures 2.23 through 2.26 show the plots of predicted initiation and maximum moments by various participants for the through-wall-cracked pipes as a function of the J-R curve. Figures 2.27 through 2.30 show similar results for the surface-cracked pipes. The following conclusions can be drawn from the results presented in these figures:

- The predictions of initiation moment were always lowest (as expected) when the lower stress-strain curve was used. Yet, no consistent trend was observed in the maximum moment predictions using these three stress-strain curves. Actually, maximum moment predictions based on lower stress-strain curves provided the largest values of maximum moments in many cases. This was true for solutions from all participants.

- Once again, there was scatter in the predictive results for a given stress-strain curve. The amount of the scatter is comparable to the uncertainty in choosing the stress-strain curve itself. Similar to Problem A.4, there was far more scatter in the results for predictive moments for surface-cracked pipes than those for through-wall-cracked pipes. This suggests that more research is needed in the flaw evaluation of surfacecracked pipes.

Similar to Problem A.3, we also identified several pipe fracture experiments, such as Experiments 1.1.1.21, 4111-2, and 1.2.3.15, corresponding to the Problems A.6-a, A.6-b, and A.6-d, respectively. The comparisons of these experimental data with the predicted moments are shown in Figures 2.23, 2.24, and 2.27. In general, the moments predicted by the participants were in good agreement with the test data from these experiments, except for Experiment 1.1.1.21 (Figure 2.23) in which case all participants underpredicted the maximum moment.

(a) The computer codes/methods for comparisons were NRCPIPE, Version 2.0 developed at Battelle (Solution C-1a) and the participants's in-house code (Solution C-1b) for TWC pipes and SC.TNP1 (Solution C-1a) and GE/EPRI (Solution C-1b) for SC pipes.

(a) The methods for comparisons were LBB.ENG2 (Solution Da), LBB.NRC (Solution Db), and GE/EPRI (Solution Dc) for TWC pipes and SC.TNP1 (Solution Da), SC.TNP2 (Solution Db), SC.TKP1 (Solution Dc), SC.TKP2 (Solution Dd), and SC.ENG2 (Solution De) for SC pipes. 


\subsection{References}

2.1 Wilkowski, G. M., Ahmad, J., Barnes, C. R., Brust, F., Ghadiali, N., Guerrieri, D., Jones, D., Kramer, G., Landow, M., Marschall, C. W., Olson, R., Papaspyropoulos, V., Pasupathi, V., Rosenfeld, M., Scott. P., and Vieth, P., “Degraded Piping Program - Phase II: Summary of Technical Results and Their Significance to Leak-Before-Break and In-Service Flaw Acceptance Criteria, March 1984 - January 1989," NUREG/CR-4082, Vol. 8, U.S. Nuclear Regulatory Commission, Washington, D.C., March 1989.

2.2 "Procedure for the Assessment of the Integrity of Nuclear Pressure Vessels and Piping Containing Defects," EPRI Report NP-2431, prepared by Babcock \& Wilcox, Electric Power Research Institute, Palo Alto, 1982.

2.3 Schwalbe, K. H., Hayes, B., and Baustian, K., "Validation of the Fracture Mechanics Test Method EGF P1-87D (ESIS P1-90/ESIS P1-92)," Fatigue \& Fracture of Engineering Materials and Structures, Vol. 16, No. 11, pp. 1231-1284, 1993.

2.4 Rosenfield, A. R. and Hahn, G. T., "Numerical Descriptions of the Ambient LowTemperature, and High-Strain Rate Flow and Fracture Behavior of Plaine Carbon Steel," Trans. ASM, Vol. 59, pp. 962-980, 1966.

2.5 Zahoor, A., "Ductile Fracture Handbook," EPRI Report NP-6301-D, Volumes 1, 2, and 3, Electric Power Research Institute, Palo Alto, CA, 1989-1991.

2.6 Rolfe, S. T. and Novak, S. R., "Correlation Between $\mathrm{K}_{\mathrm{Ic}}$ and Charpy V-Notch Test Results in the Transition Temperature Range," ASTM STP 463, pp. 281-302, 1970.

2.7 Hahn, G. T. and Rosenfield, A. R., "Sources of Fracture Toughness: The Relation Between $\mathrm{K}_{\mathrm{Ic}}$ and Ordinary Tensile Properties,” ASTM STP 432, pp. 5-32, 1968.

2.8 "Standard Method of Test for Elastic-Plastic Fracture Toughness $\mathrm{J}_{\mathrm{Ic}}$ " JSME S 001-1981, 1981.

2.9 "Standard Method of Test for Elastic-Plastic Fracture Toughness $\mathrm{J}_{\mathrm{Ic}}$ " Supplement, 1st Edition, JSME S 001-1992, 1992.

2.10 "Standard Test Method for $\mathrm{J}_{\text {Ic }}$, A Measure of Fracture Toughness," ASTM E813-89, Volume 03.01, Metals - Mechanical Testing; Elevated and Low-Temperature Tests; Metallography, 1994.

2.11 “Standard Test Method for Determining J-R Curves," ASTM E1152-87, Volume 03.01, Metals - Mechanical Testing; Elevated and Low-Temperature Tests; Metallography, 1994.

2.12 Kumar, V., German, M. D., "Elastic-Plastic Analysis of Through-Wall and Surface Flaws in Cylinders," EPRI Report NP-5596, Electric Power Research Institute, Palo Alto, CA, January 1988. 
2.13 "R6 Assessment of the Integrity of Structures Containing Defects," Nuclear Electric maintained procedure R/H/R6, Revision 3, reprinted February 1988 with amendments up to and including May 1991.

2.14 R6-CODE, Users Guide, Version 1.00, Nuclear Electric plc, Gloucester, England, 1992.

2.15 Brust, F. W., "Approximate Methods for Fracture Analyses of Through-Wall Cracked Pipes," NUREG/CR-4853, U.S. Nuclear Regulatory Commission, Washington, D.C., February 1987.

2.16 Klecker, R., Brust, F., and Wilkowski, G., "NRC Leak-Before-Break (LBB.NRC) Analysis Method for Circumferentially Through-Wall-Cracked Pipes Under Axial Plus Bending Loads," NUREG/CR-4572, U.S. Nuclear Regulatory Commission, Washington, D.C., May 1986.

2.17 Kumar, V., German, M., and Shih, C., "An Engineering Approach for Elastic-Plastic Fracture Analysis,” EPRI Report NP-1931, Electric Power Research Institute, Palo Alto, CA, July 1981.

2.18 Kumar, V., German, M., Wilkening, W., Andrews, W., deLorenzi, H., and Mowbray, D., "Advances in Elastic-Plastic Fracture Analysis," EPRI Final Report NP-3607, Electric Power Research Institute, Palo Alto, CA, August 1984.

2.19 Krishnaswamy, P., Scott, P., Mohan, R., Rahman, S., Choi, Y., Brust, F., Kilinski, T., Francini, R., Ghadiali, N., Marschall, C., and Wilkowski, G., "Fracture Behavior of Short Circumferentially Surface-Cracked Pipe,” NUREG/CR-6298, U.S. Nuclear Regulatory Commission, Washington, D.C., November 1995.

2.20 Brochard, J., Petit, M., and Millard, A., "A Special Cracked Pipe Element for Leak Before Break Application," Proceedings of 10th SMiRT Meeting, Los Angeles, California, Volume G, pp. 357-362, 1989.

2.21 Brochard, J., Combescure, A., and Jamet, Ph., "A Cracked Pipe Element Coupling Plasticity and Crack Growth for Leak before Break Applications," Proceedings of 11th SMiRT Meeting, Tokyo, Japan, Volume G2, pp. 225-230, 1991.

2.22 Moulin, D., Nedelec, M., and Clement, G., "Simplified Method to Estimate J Development and Application," Proceedings of 12th SMiRT Meeting, Stuttgart, Germany, Volume A, pp. 151-156, 1993.

2.23 Brust, F. W., Scott, P., Rahman, S., Ghadiali, N., Kilinski, T., Francini, T., Marschall, C., Miura, N., Krishnaswamy, P., and Wilkowski, G., "Assessment of Short Through-Wall Circumferential Cracks in Pipes - Experiments and Analysis,” NUREG/CR-6235, U.S. Nuclear Regulatory Commission, Washington, D.C., April 1995.

2.24 Wilkowski, G. M., and others, "Short Cracks in Piping and Piping Program," Semiannual reports by Battelle, NUREG/CR-4599, Vols. 1 to 3, Nos. 1 and 2, U.S. Nuclear Regulatory Commission, Washington, D.C., 1991-1994. 
Table 2.1 Ratio of strengths at $288 \mathrm{C}(550 \mathrm{~F})$ and $20 \mathrm{C}$ (68 F) in Problem A.1-a

\begin{tabular}{ccccccc}
\hline & \multicolumn{4}{c}{ Ratio of Strengths (288 C/20 C) } \\
\cline { 2 - 7 } Participant & Yield & Ultimate & Yield & Ultimate & Yield & Ultimate \\
\cline { 2 - 7 } C-1 & 0.93 & 1.00 & 0.93 & 1.00 & 0.93 & 1.00 \\
D & 0.90 & 0.90 & 0.90 & 0.90 & 0.90 & 0.90 \\
F-1 & 0.78 & 1.00 & 0.78 & 1.00 & 0.86 & 0.96 \\
Actual & 0.86 & 1.18 & 0.86 & 1.24 & NA $^{(a)}$ & NA $^{(\text {a) }}$ \\
\hline
\end{tabular}

(a) Not available

Table 2.2 Comparisons of predicted upper shelf energy with actual data (Problem A.1-c)

\begin{tabular}{cccc}
\hline & \multicolumn{3}{c}{ Upper Shelf Energy, J } \\
\cline { 2 - 4 } Participant & Material A & Material B & Material C \\
\hline C-1 & 110 & 218 & 283 \\
D & 122 & 222 & 263 \\
Actual & NA $^{(a)}$ & 172 & 228 \\
\hline
\end{tabular}

(a) Not available 
Table 2.3 Comparisons of predicted $J$ at crack initiation with actual data (Problem A.1-c)

\begin{tabular}{cccc}
\hline & \multicolumn{3}{c}{ J-integral, $\mathbf{k J} / \mathbf{m}^{2}$} \\
\cline { 2 - 4 } Participant & Material A & Material B & Material C \\
\hline C-1 & 89 & 291 & 539 \\
$\mathrm{Dt}^{(\mathbf{a})}$ & 357 & 164 & 102 \\
$\mathrm{Dc}^{(\mathrm{b})}$ & 100 & 151 & 246 \\
Actual $^{(\mathrm{c})}$ & 111,149 & 216 & 105,165 \\
\hline
\end{tabular}

(a) Based on tensile correlation.

(b) Based on Charpy correlation.

(c) Where two values are given, they refer to non-side-grooved and side-grooved specimens, respectively.

Table 2.4 Comparisons of predicted dJ/da with actual data (Problem A.1-d)

\begin{tabular}{cccc}
\hline & \multicolumn{3}{c}{$\mathrm{dJ} / \mathrm{da}, \mathbf{M J} / \mathbf{m}^{3}$} \\
\cline { 2 - 4 } Participant & Material A & Material B & Material C \\
\hline C-1 & 85 & 195 & 336 \\
$\mathrm{Dt}^{(\mathrm{a})}$ & 67 & 25 & 26 \\
$\mathrm{Dc}^{(\mathrm{b})}$ & 14 & 23 & 68 \\
Actual $^{(\mathrm{c})}$ & 113,89 & 130 & 214,160 \\
\hline
\end{tabular}

(a) Based on tensile correlation.

(b) Based on Charpy correlation.

(c) Where two values are given, they refer to non-side-grooved and side-grooved specimens, respectively. 
- Measured Values

- Estimated by Participants

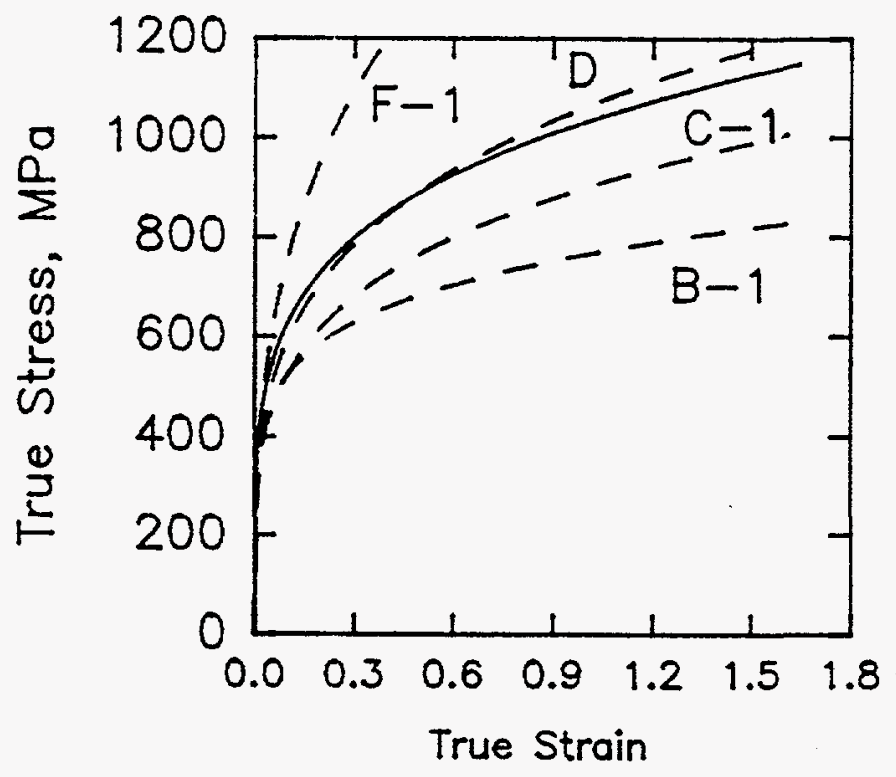

Steel A

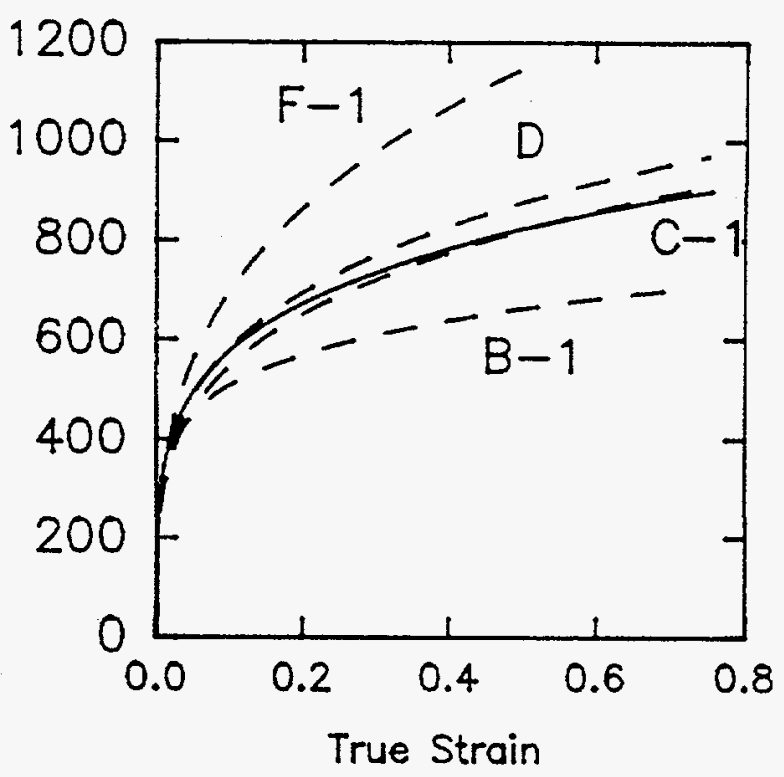

Steel B

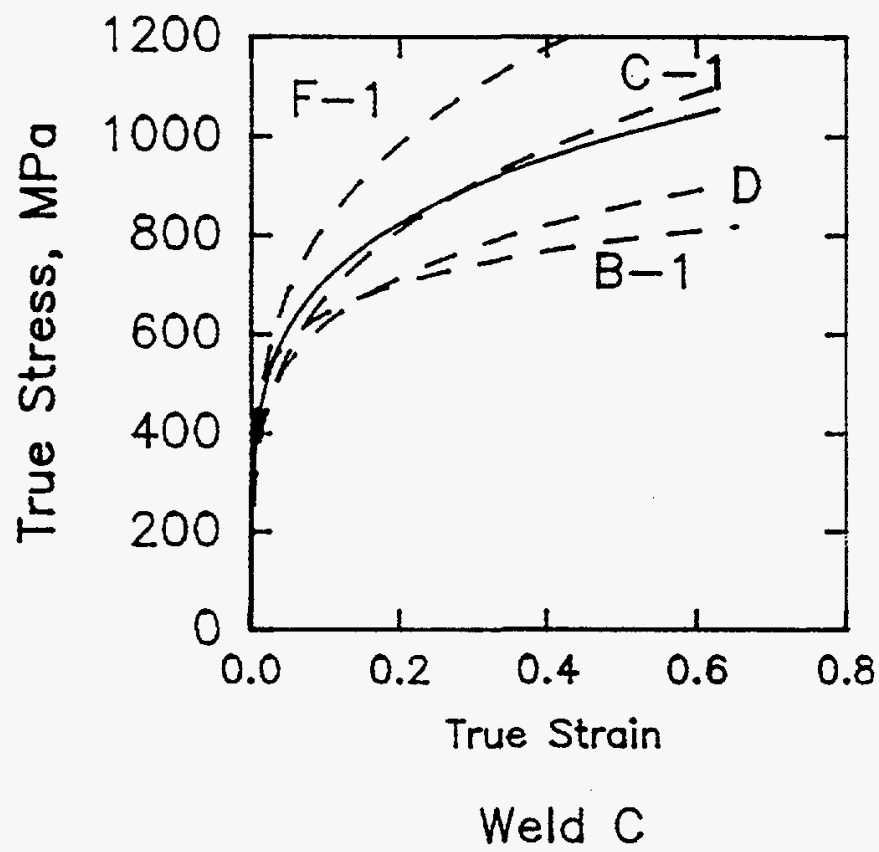

Figure 2.1 Stress-strain curves using Ramberg-Osgood model with the estimated parameters by various participants (Problem A.1-b) 


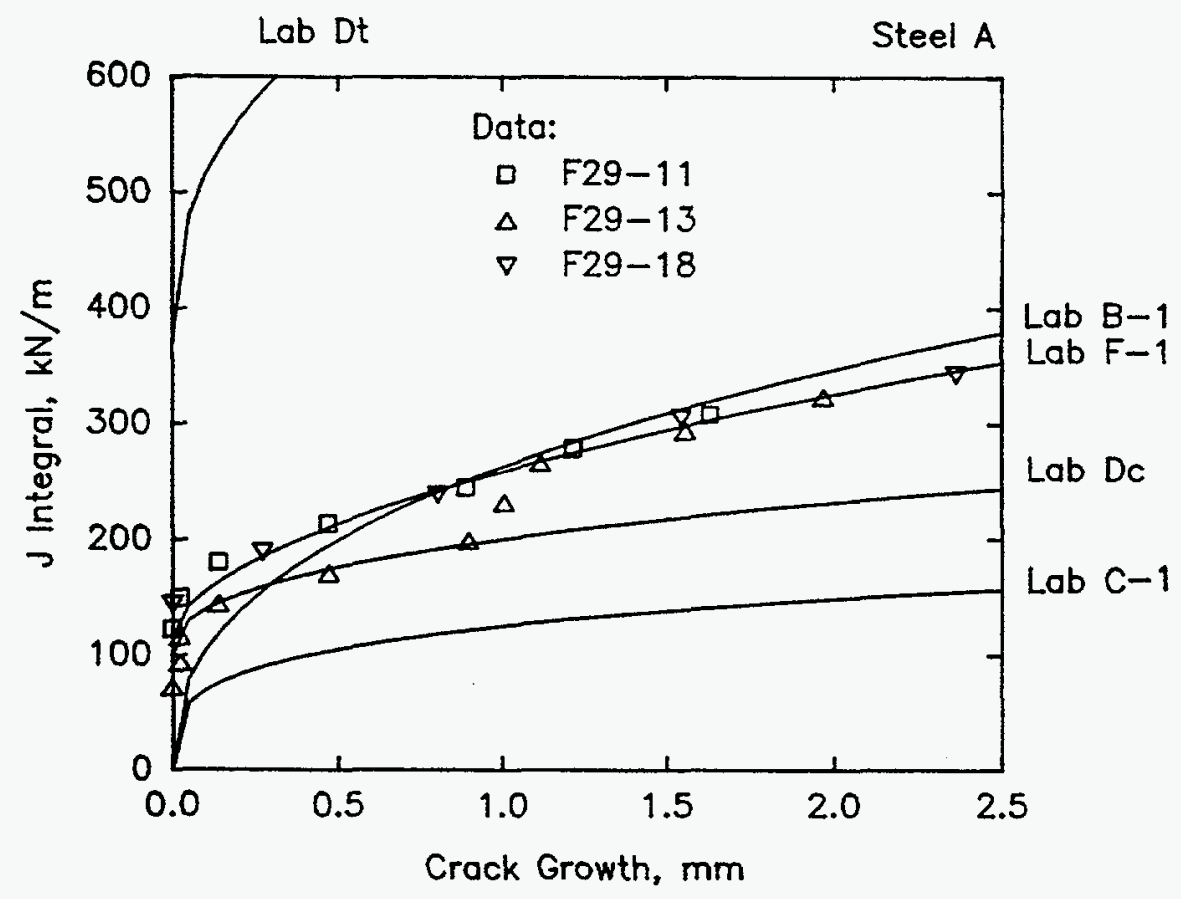

Figure 2.2 J-R curves for Material A using power-law model with the estimated parameters by various participants (Problem A.1-e)

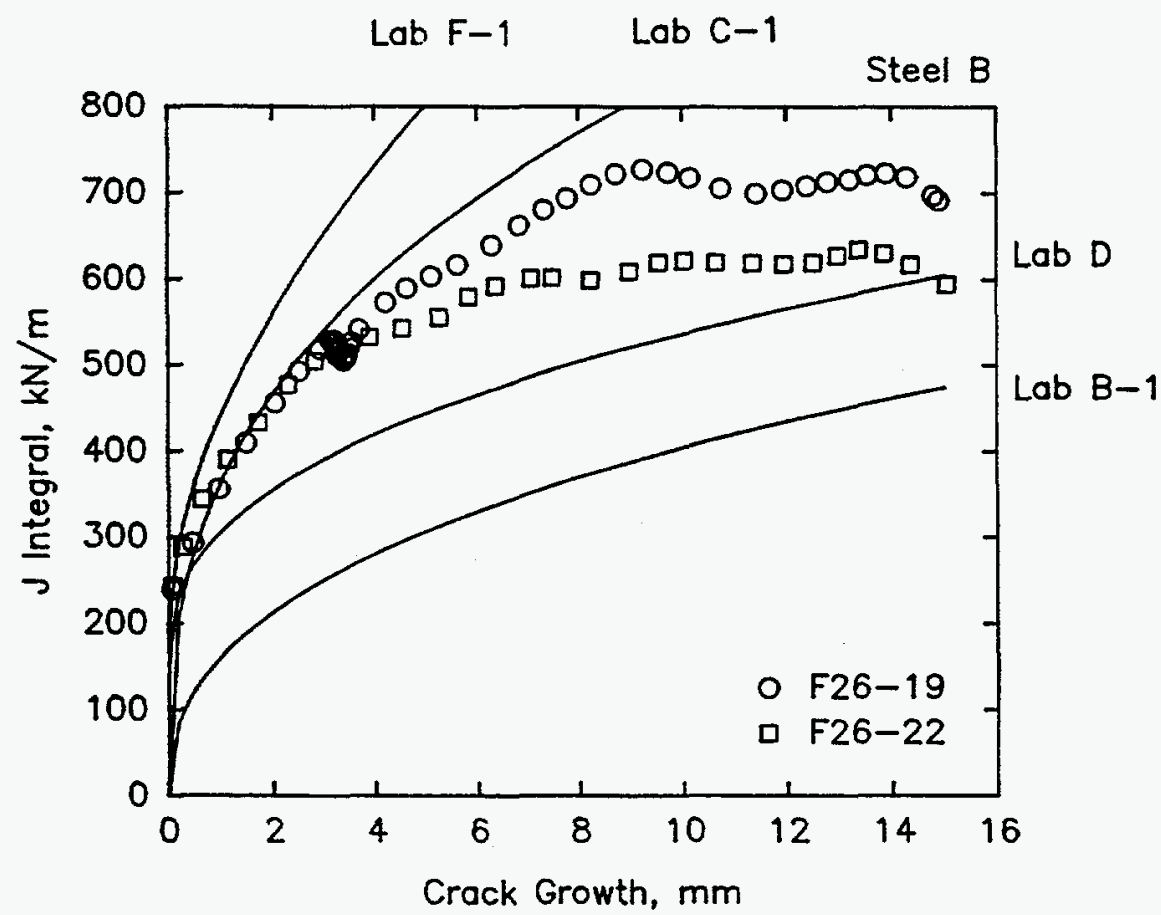

Figure $2.3 \mathrm{~J}$-R curves for Material B using power-law model with the estimated parameters by various participants (Problem A.1-e) 


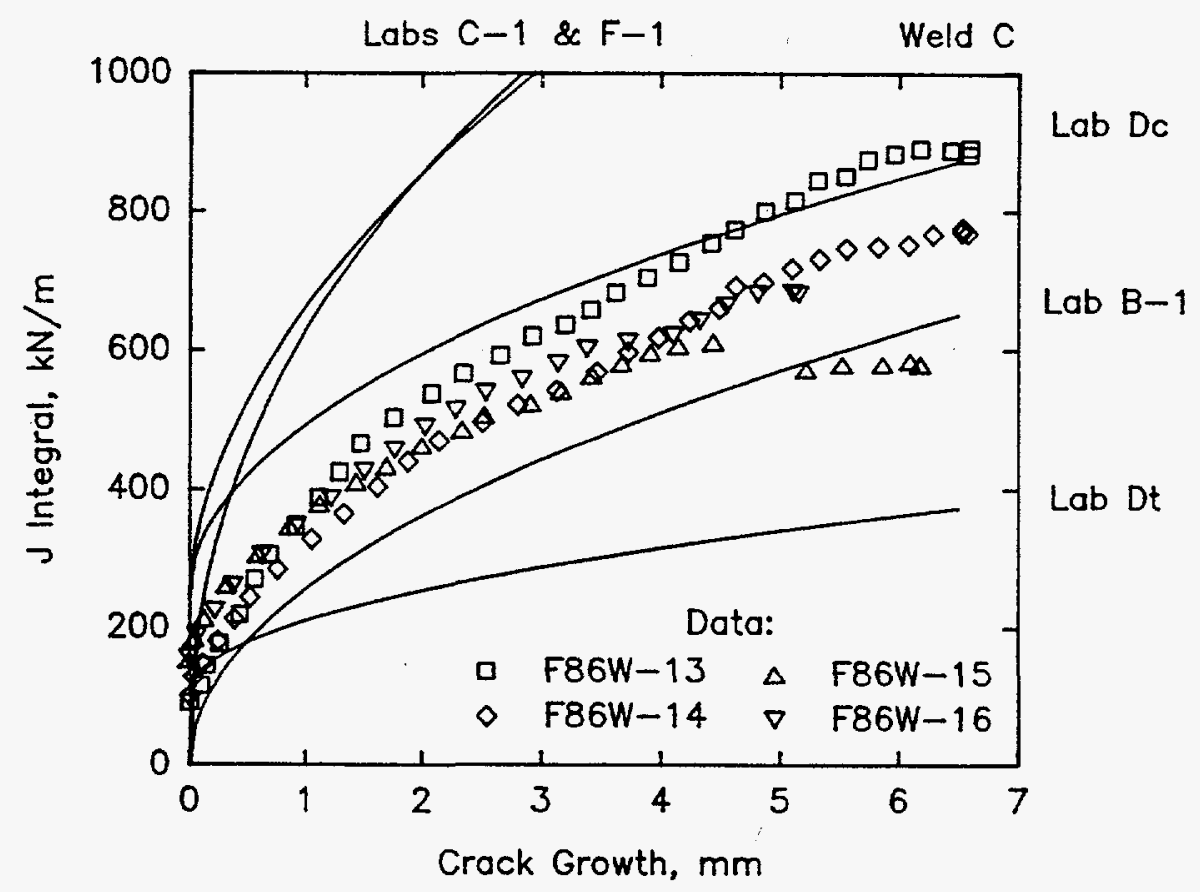

Figure 2.4 J-R curves for Material $C$ using power-law model with the estimated parameters by various participants (Proōlem A.1-e)

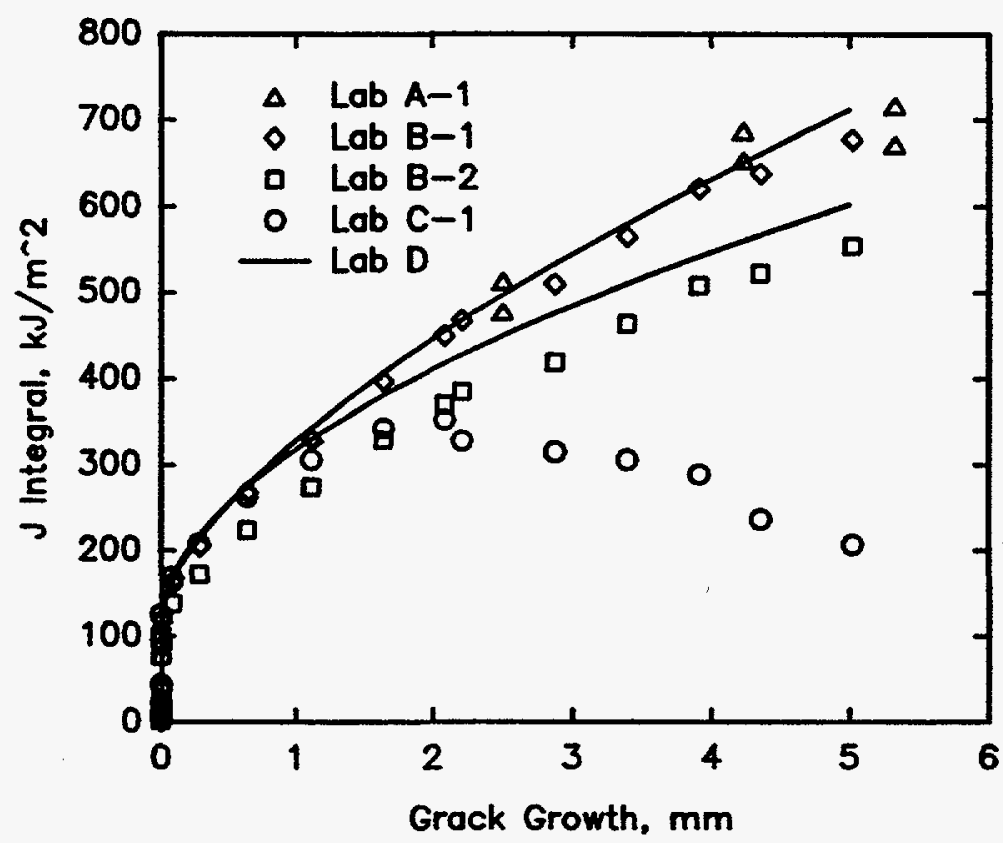

Figure 2.5 Calculated J-R curves by the participants using various international standards (Problem A.2-a) 


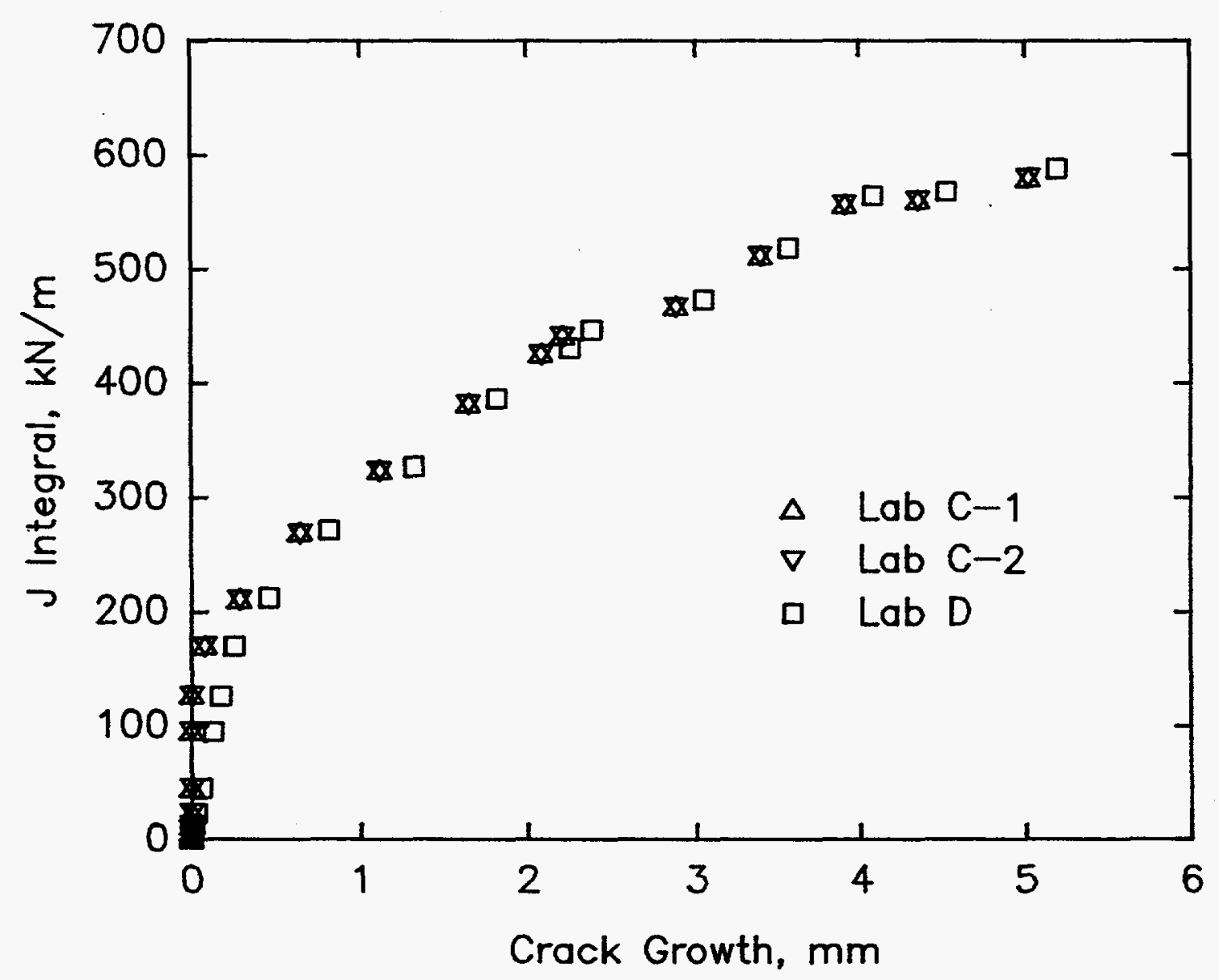

Figure 2.6 Calculated J-R curves by various participants using newly proposed ASTM standard (Problem A.2-b) 


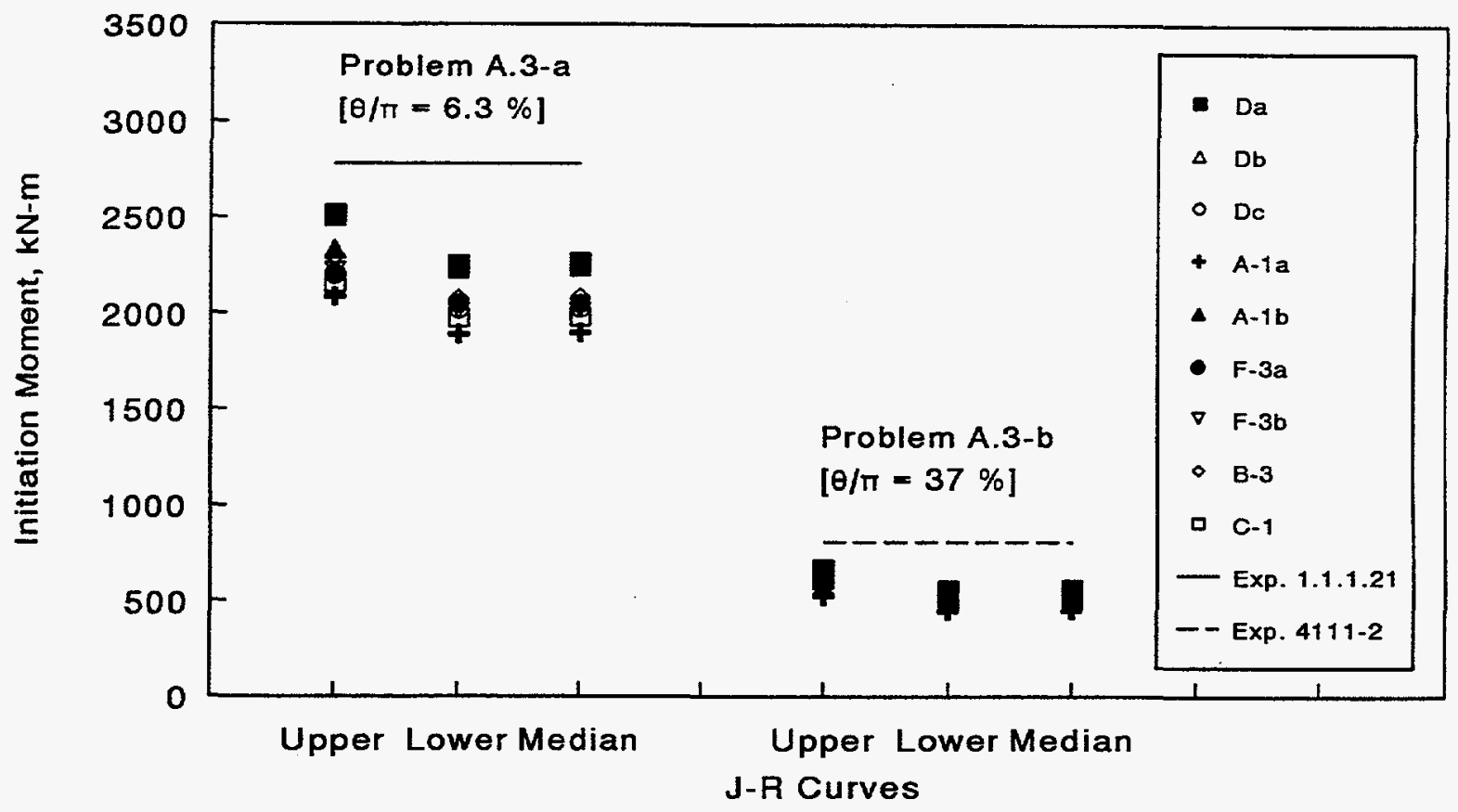

Figure 2.7 Comparisons of predicted initiation moments by various participants for largediameter through-wall-cracked pipes (Problems A.3-a and A.3-b)

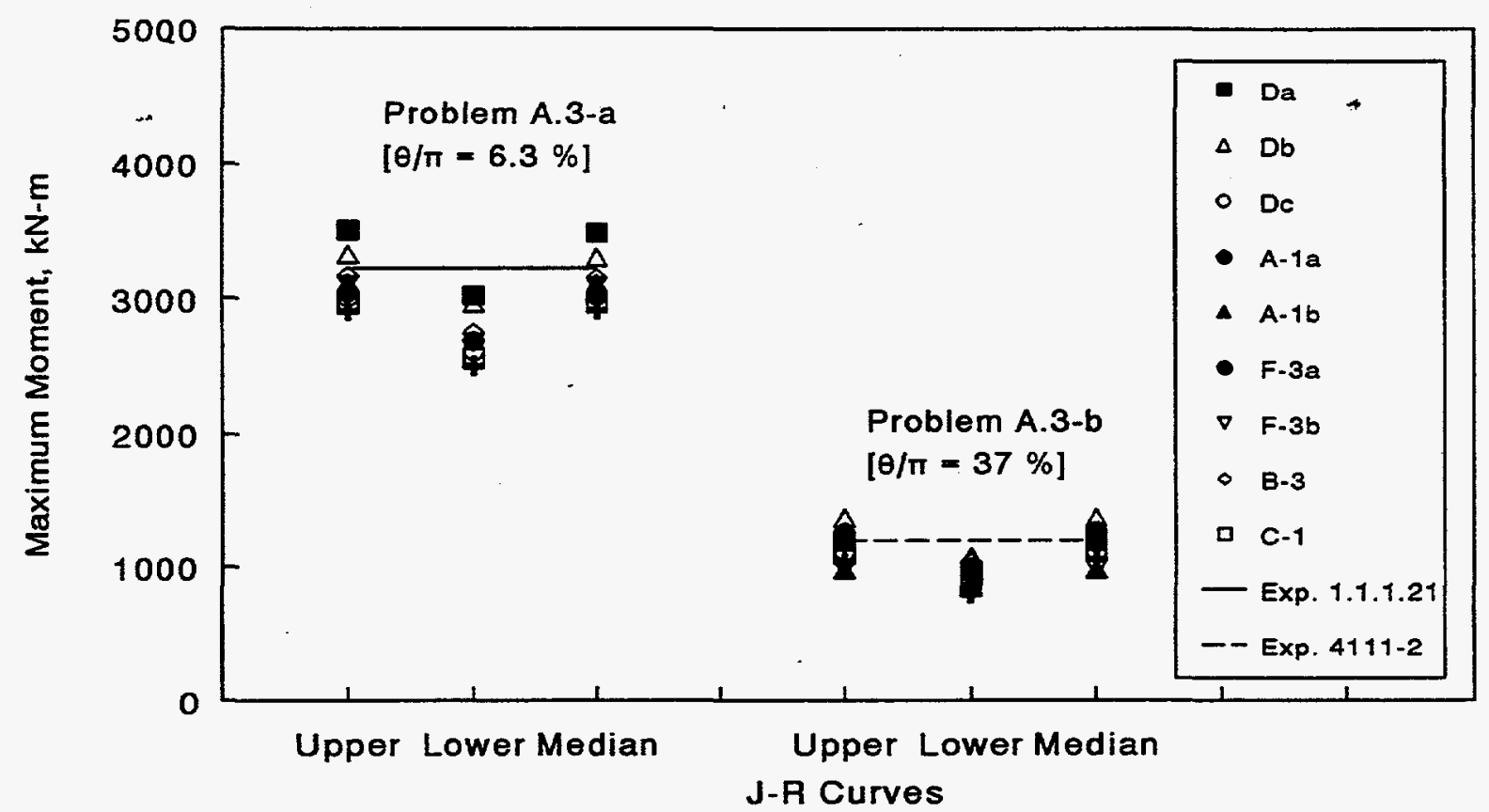

Figure 2.8 Comparisons of predicted maximum moments by various participants for largediameter through-wall-cracked pipes (Problems A.3-a and A.3-b) 


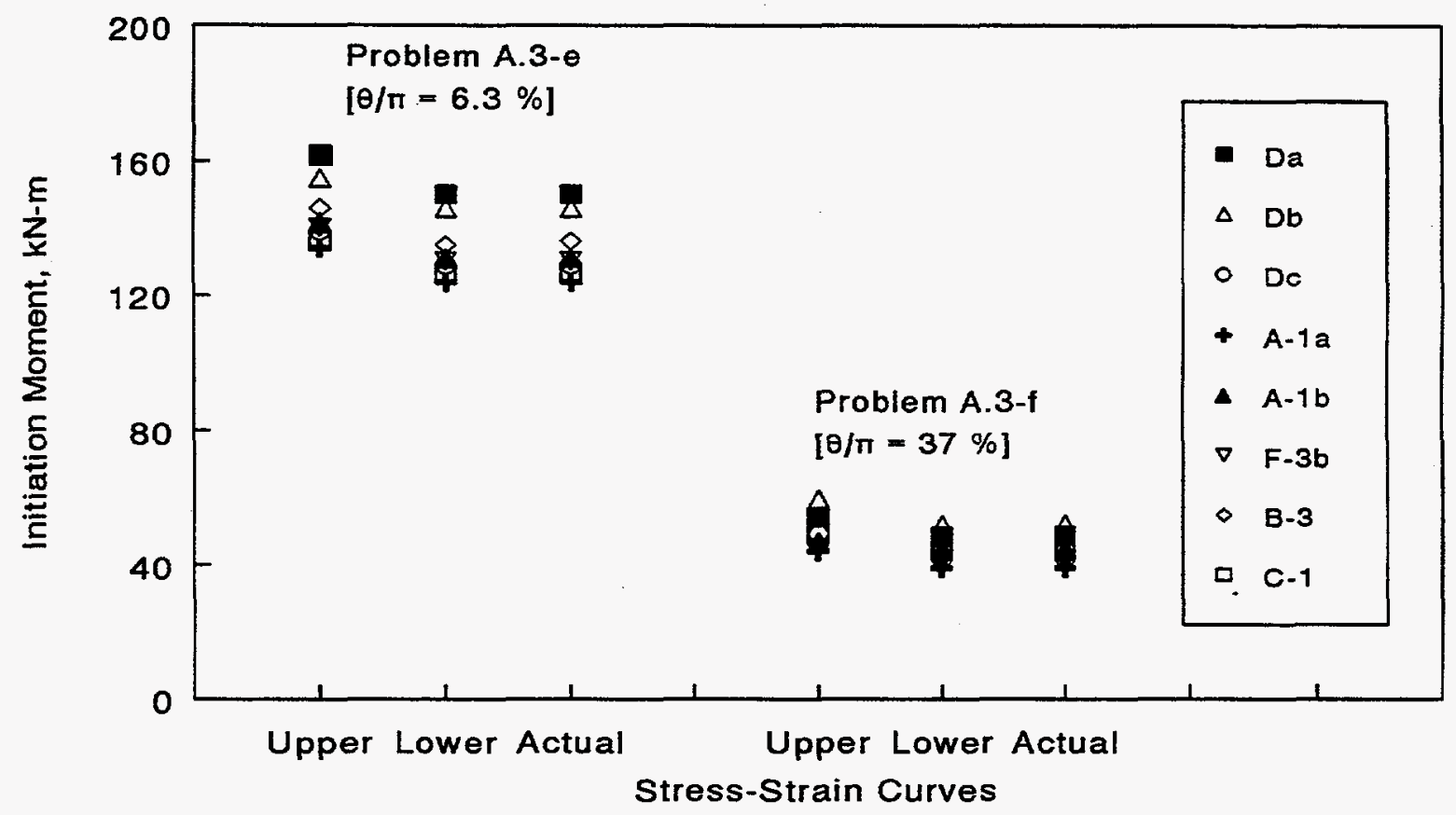

Figure 2.9 Comparisons of predicted initiation moments by various participants for smalldiameter through-wall-cracked pipes (Problems A.3-e and A.3-f)

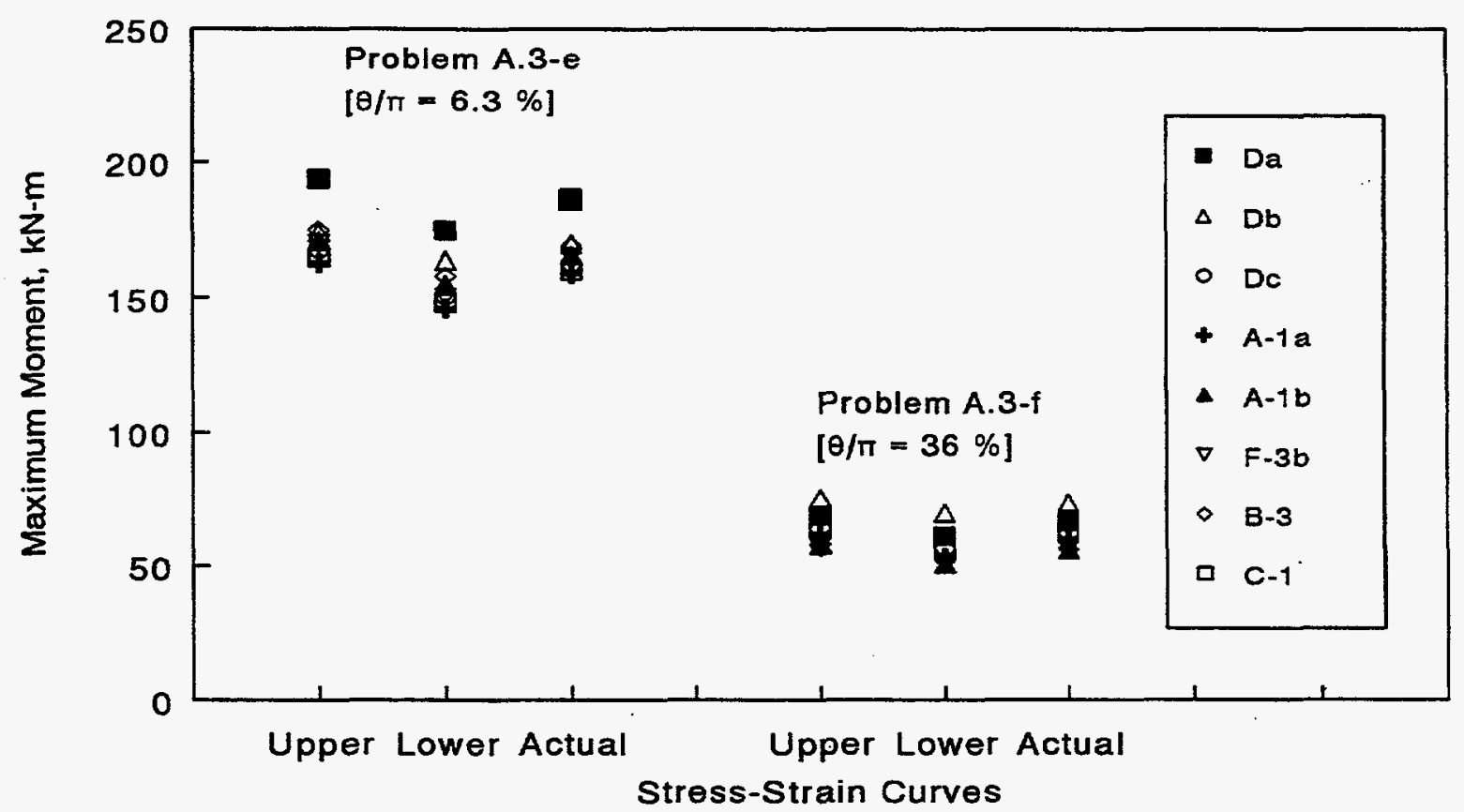

Figure 2.10 Comparisons of predicted maximum moments by various participants for smalldiameter through-wall-cracked pipes (Problems A.3-e and A.3-f) 


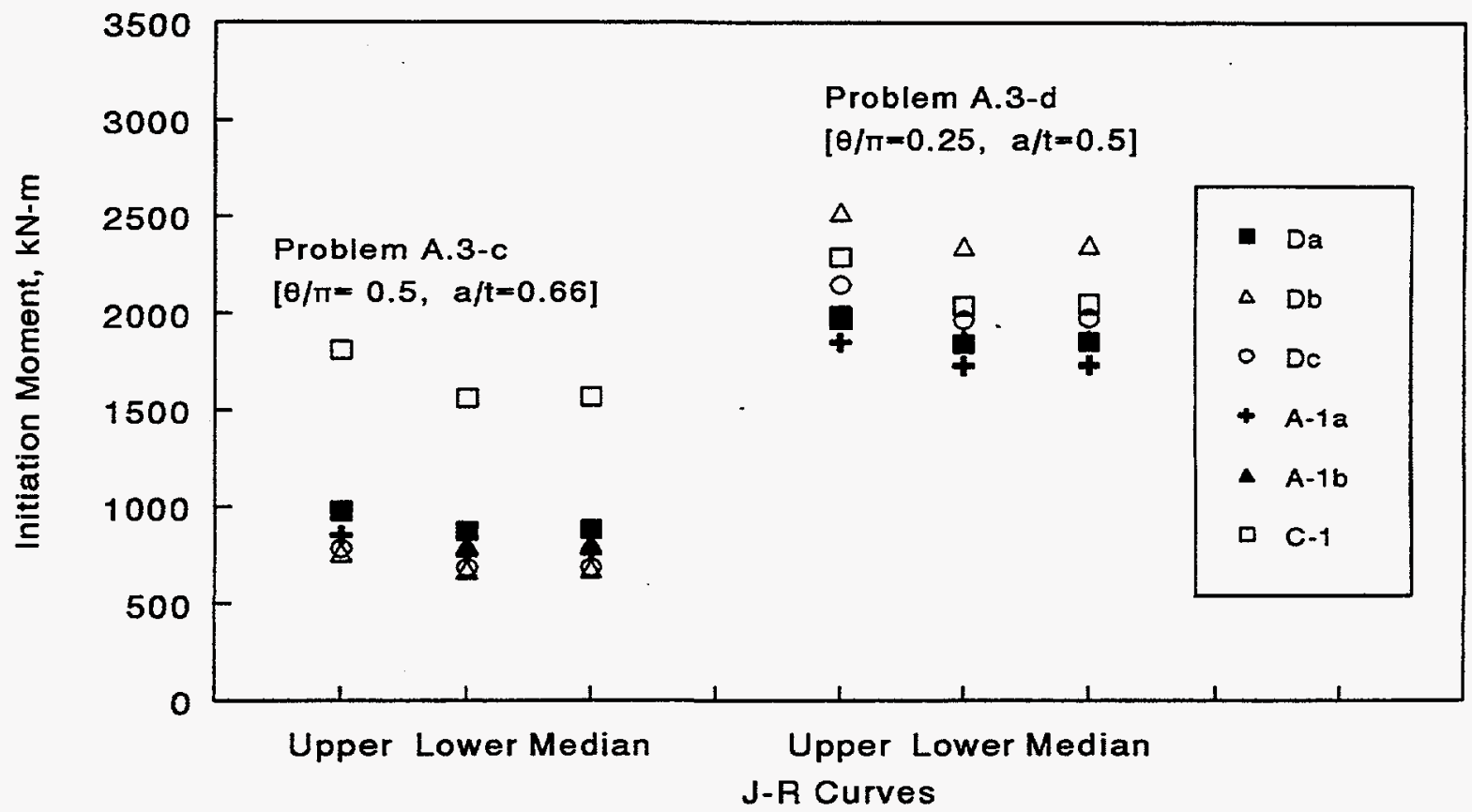

Figure 2.11 Comparisons of predicted initiation moments by various participants for largediameter surface-cracked pipes (Problems A.3-c and A.3-d)

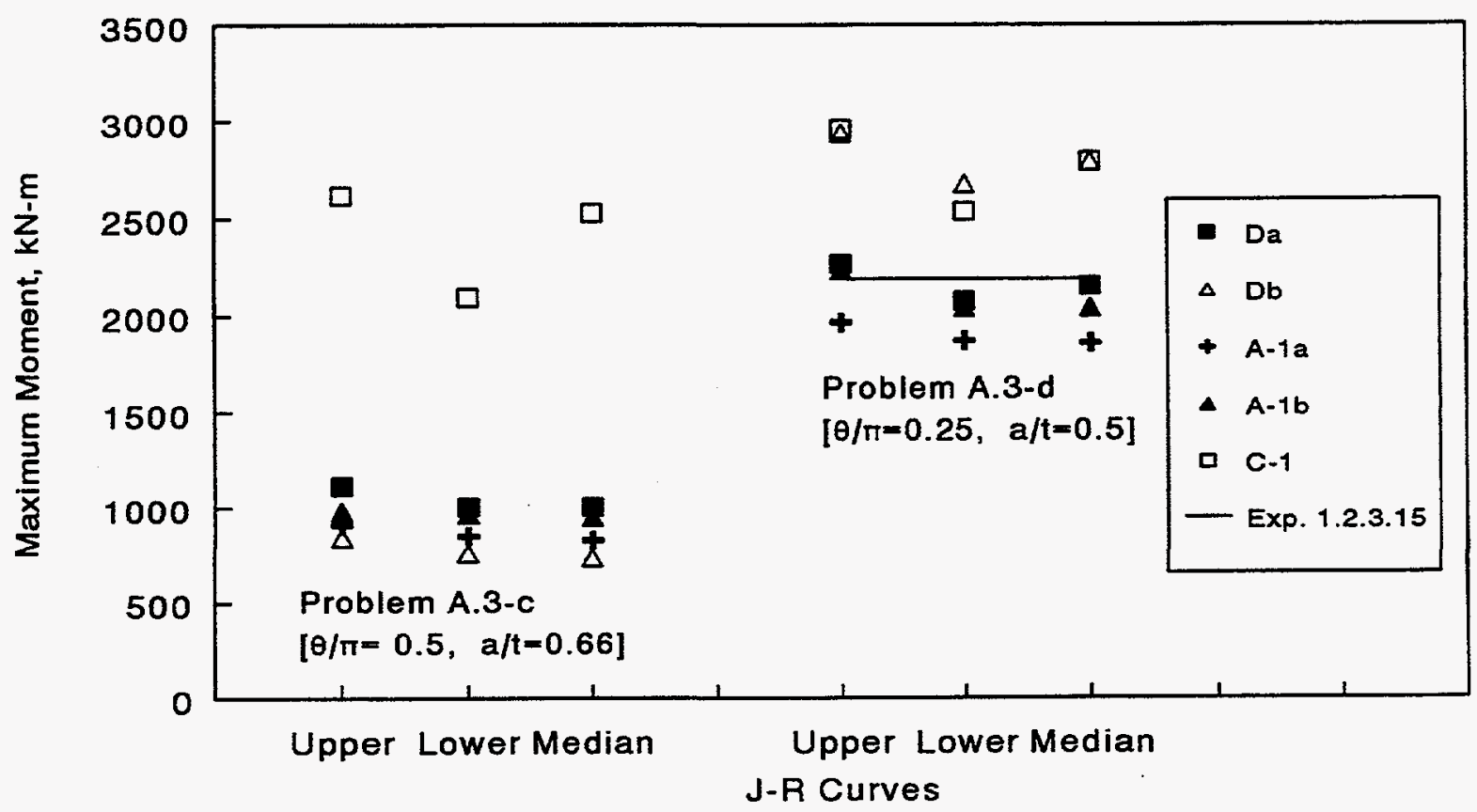

Figure 2.12 Comparisons of predicted maximum moments by various participants for largediameter surface-cracked pipes (Problems A.3-c and A.3-d) 


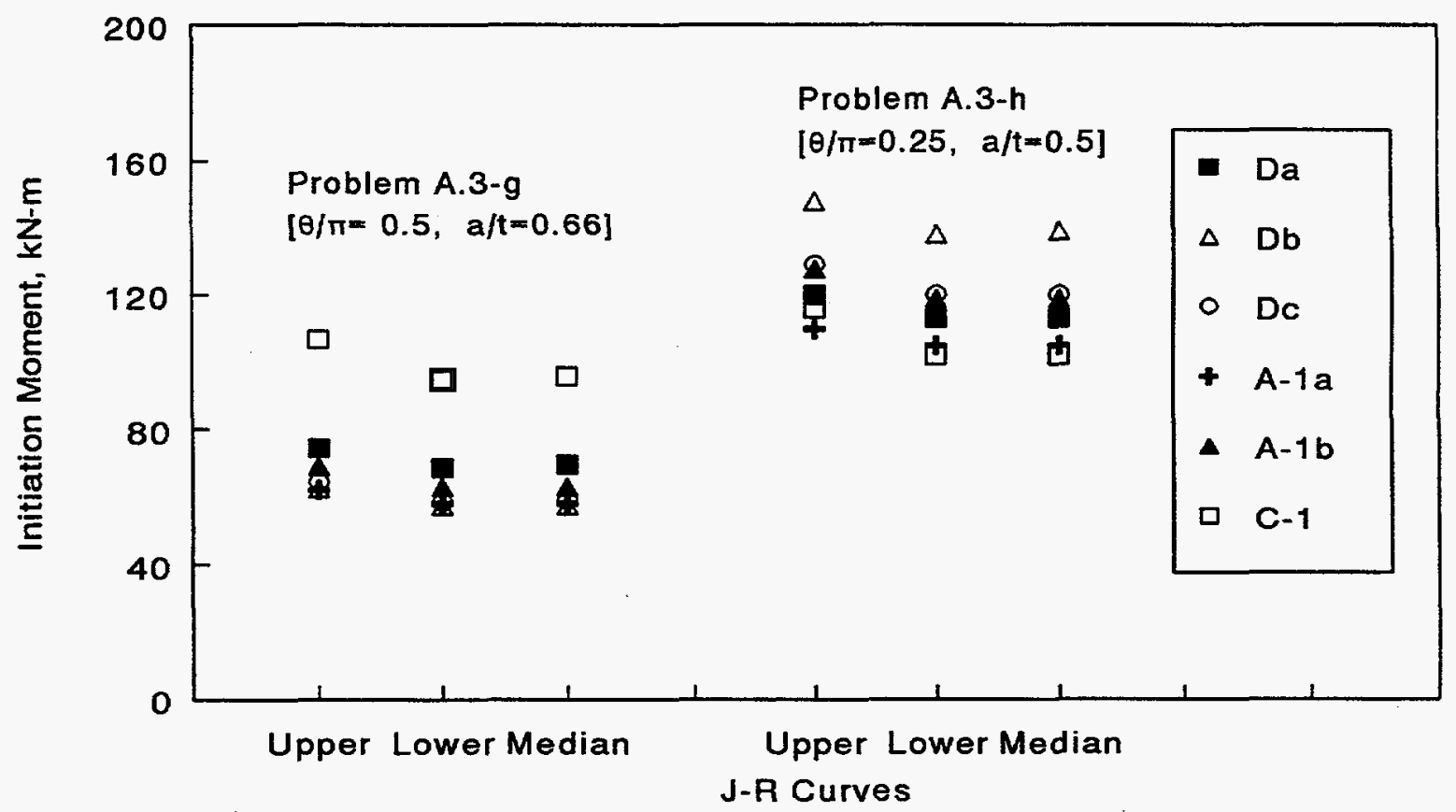

Figure 2.13 Comparisons of predicted initiation moments by various participants for smalldiameter surface-cracked pipes (Problems A.3-g and A.3-h)

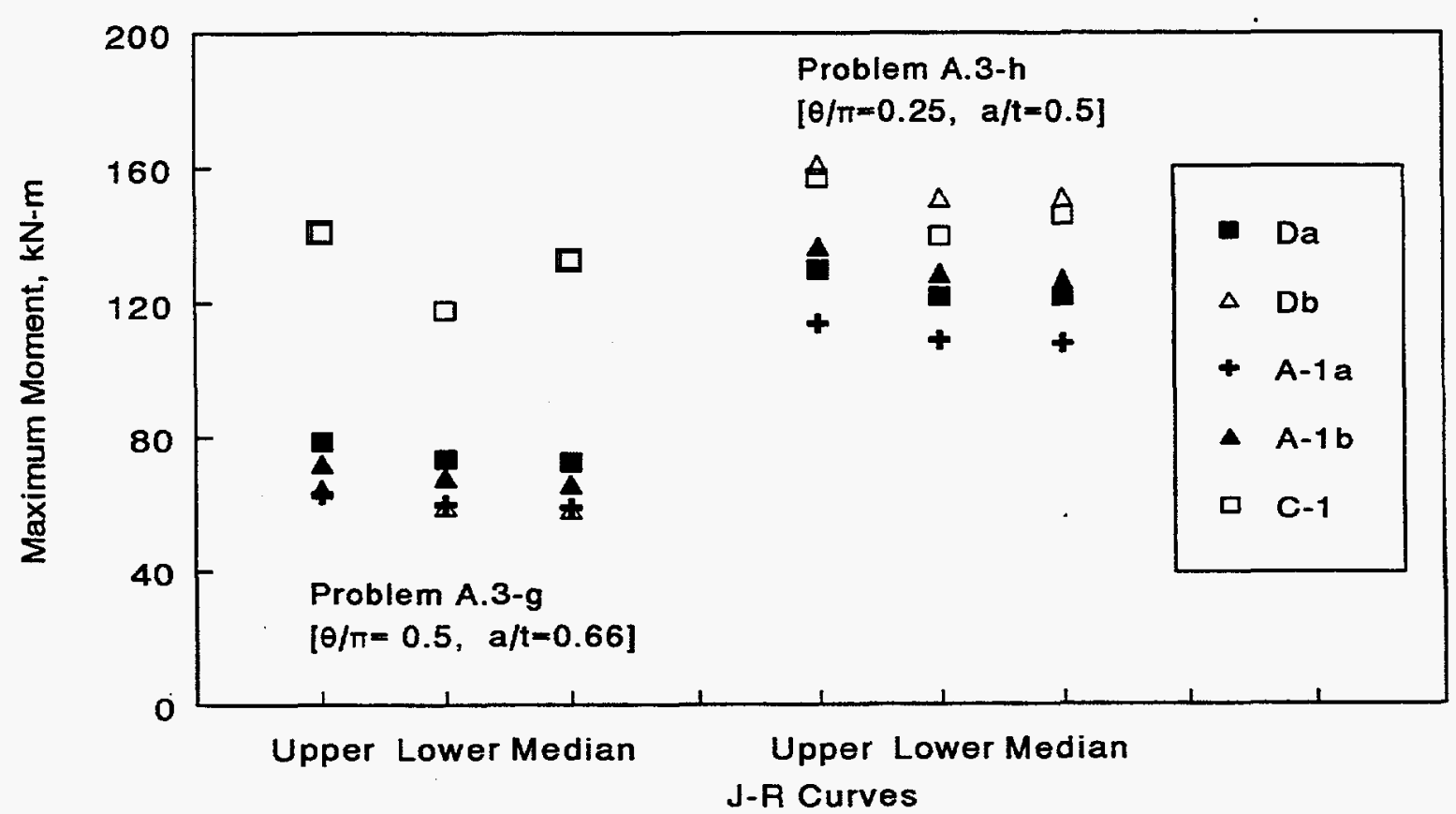

Figure 2.14 Comparisons of predicted maximum moments by various participants for smalldiameter surface-cracked pipes (Problems A.3-g and A.3-h) 


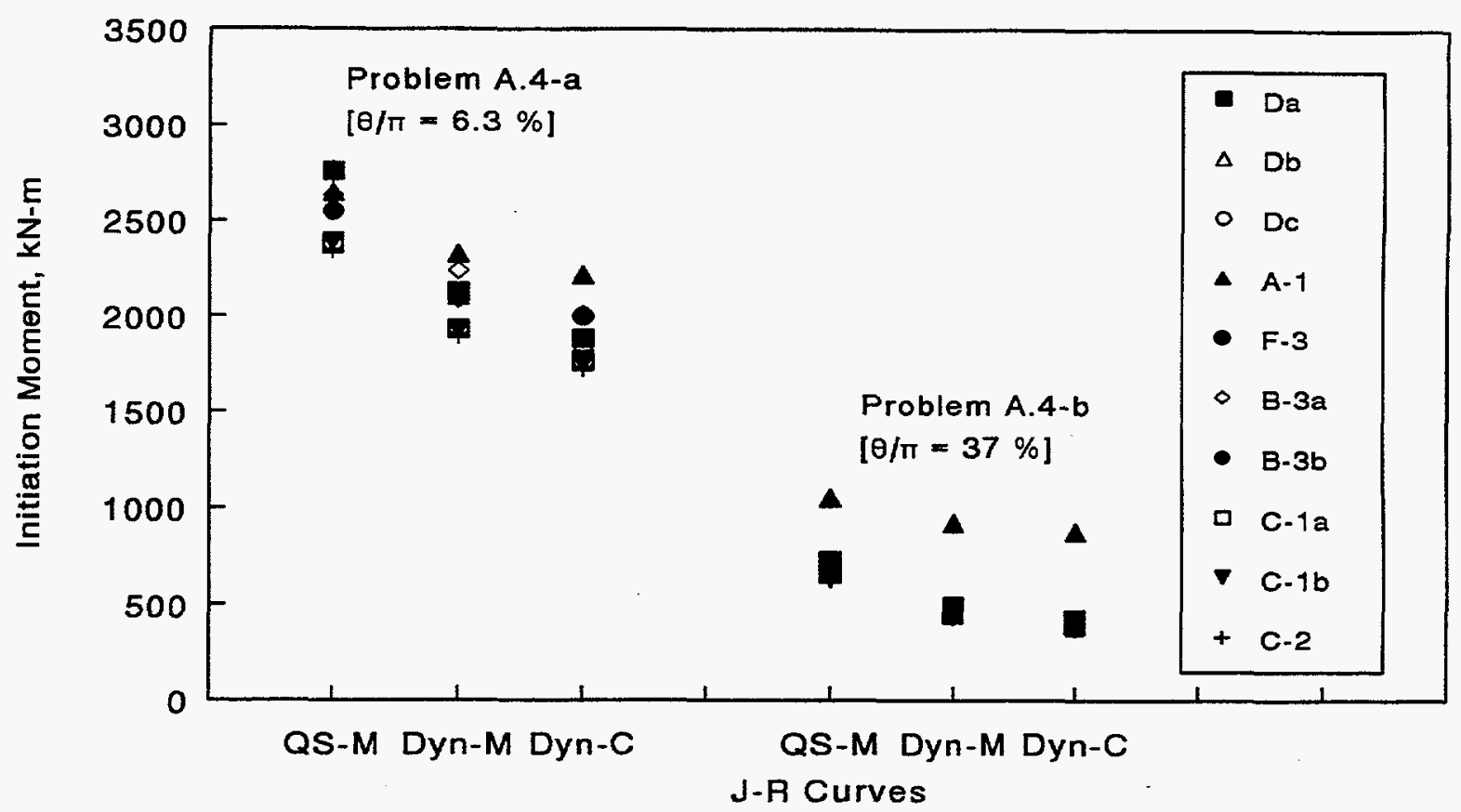

Figure 2.15 Comparisons of predicted initiation moments by various participants for largediameter through-wall-cracked pipes (Problems A.4-a and A.4-b)

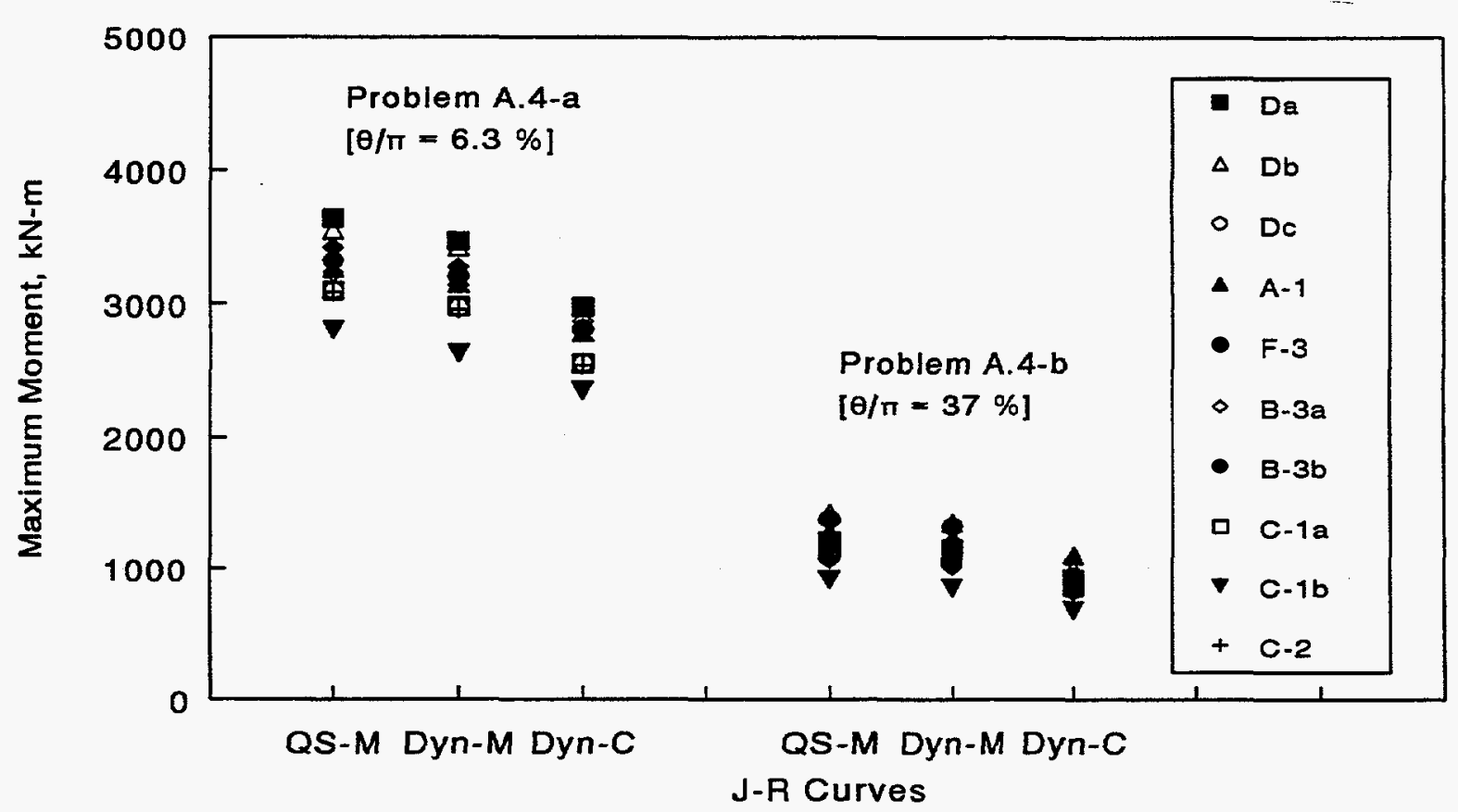

Figure 2.16 Comparisons of predicted maximum moments by various participants for largediameter through-wall-cracked pipes (Problems A.4-a and A.4-b) 


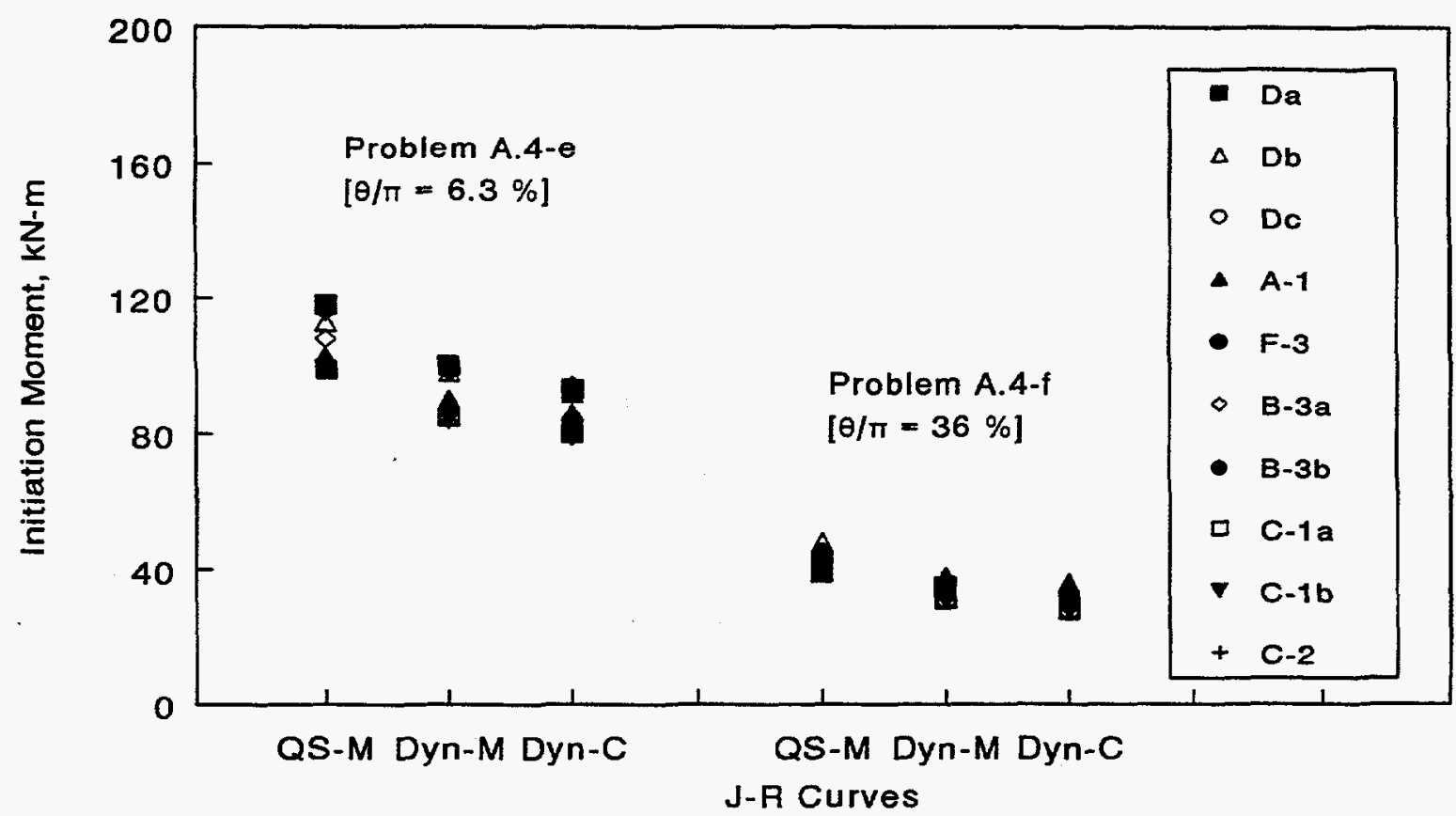

Figure 2.17 Comparisons of predicted initiation moments by various participants for smalldiameter through-wall-cracked pipes (Problems A.4-e and A.4-f)

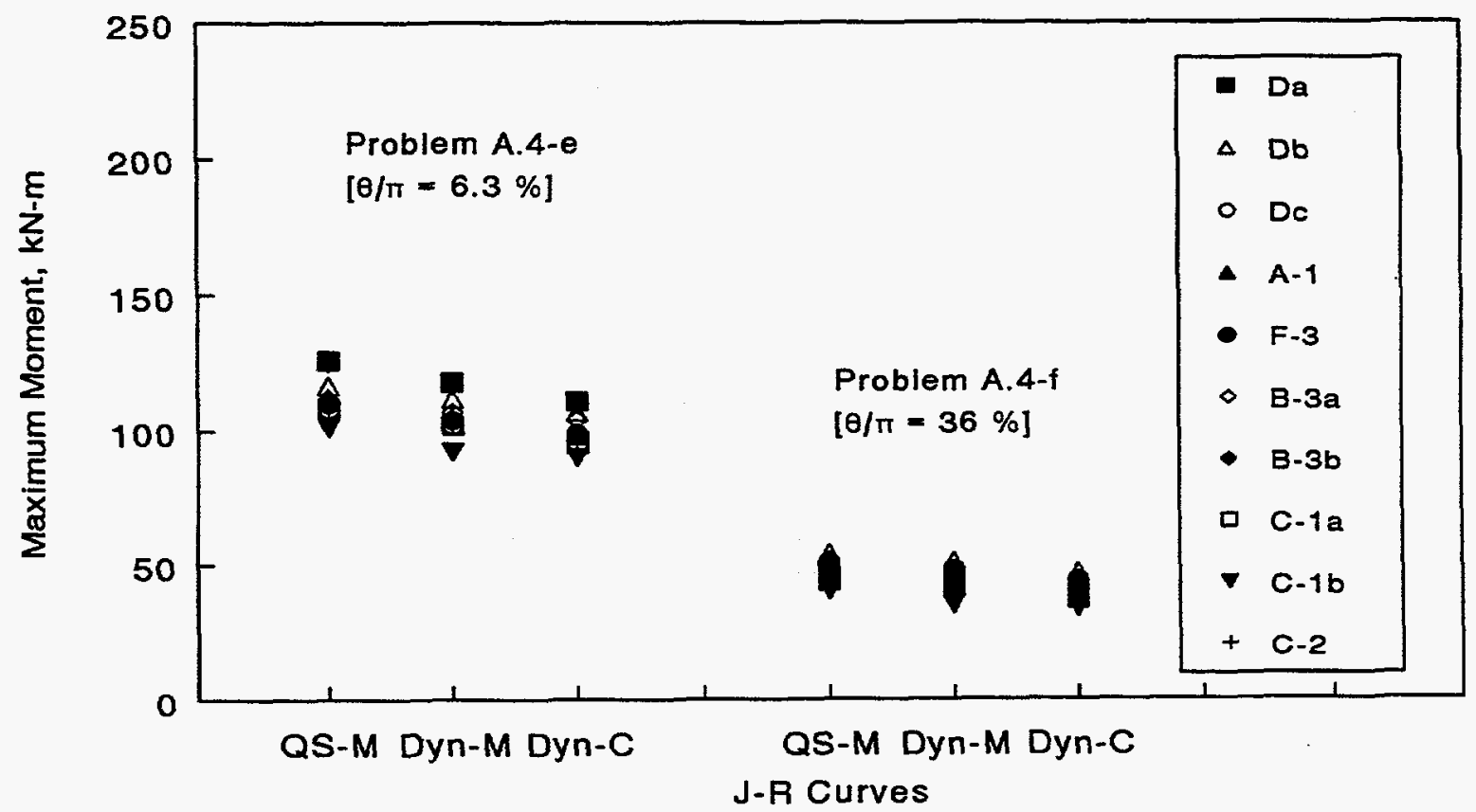

Figure 2.18 Comparisons of predicted maximum moments by various participants for smalldiameter through-wall-cracked pipes (Problems A.4-e and A.4-f) 


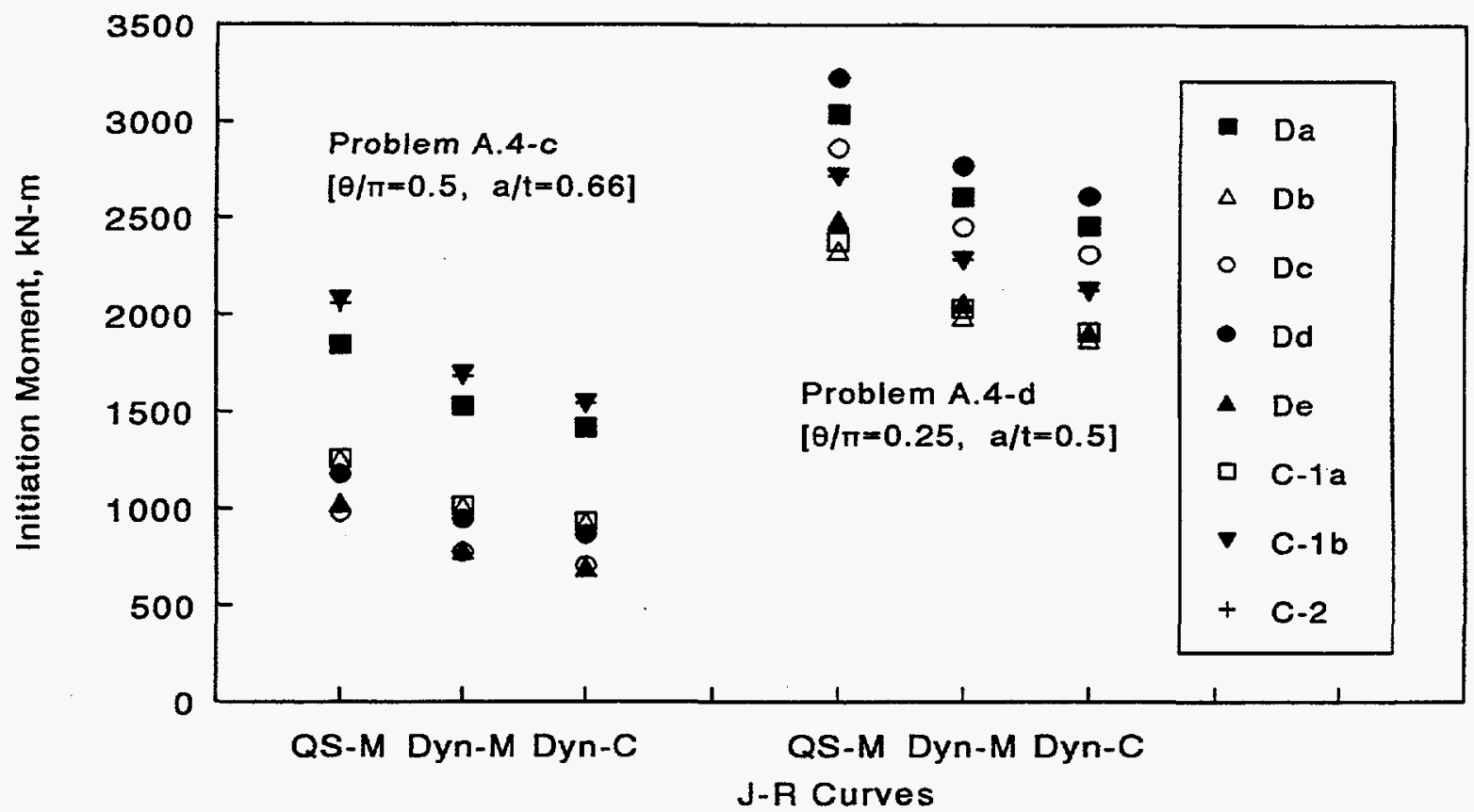

Figure 2.19 Comparisons of predicted initiation moments by various participants for largediameter surface-cracked pipes (Problems A.4-c and A.4-d)

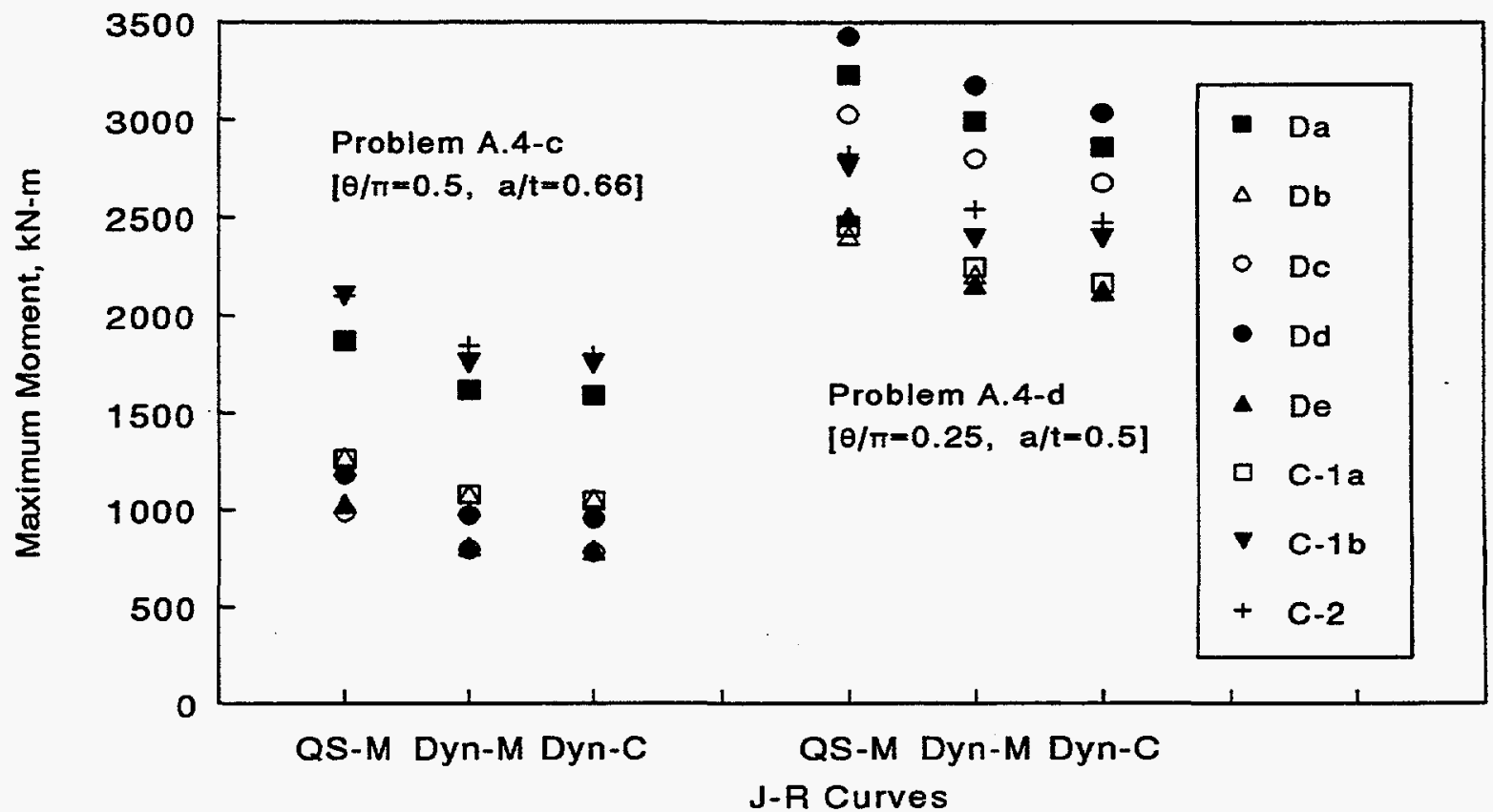

Figure 2.20 Comparisons of predicted maximum moments by various participants for largediameter surface-cracked pipes (Problems A.4-c and A.4-d) 


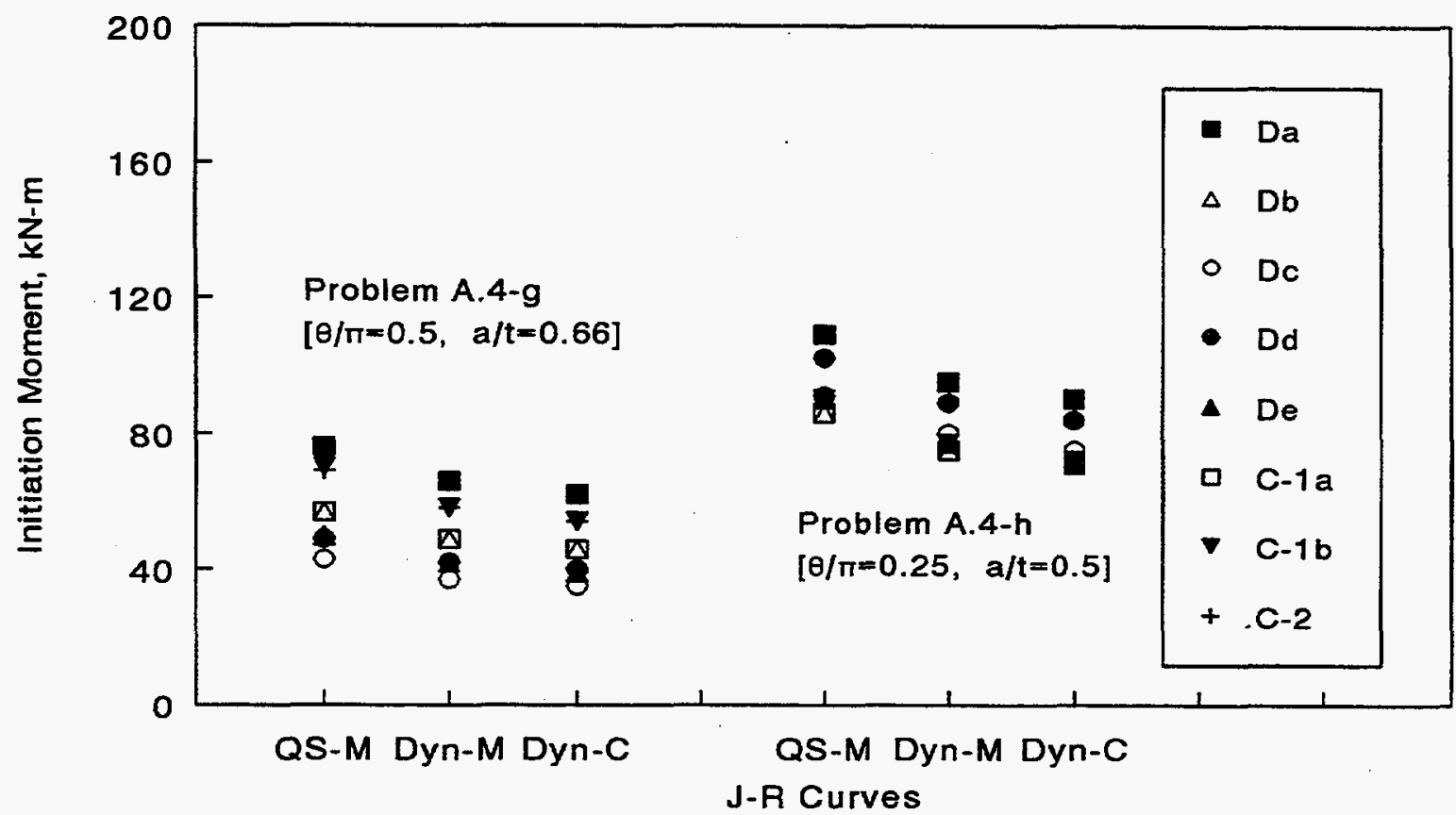

Figure 2.21 Comparisons of predicted initiation moments by various participants for smalldiameter surface-cracked pipes (Problems A.4-g and A.4-h)

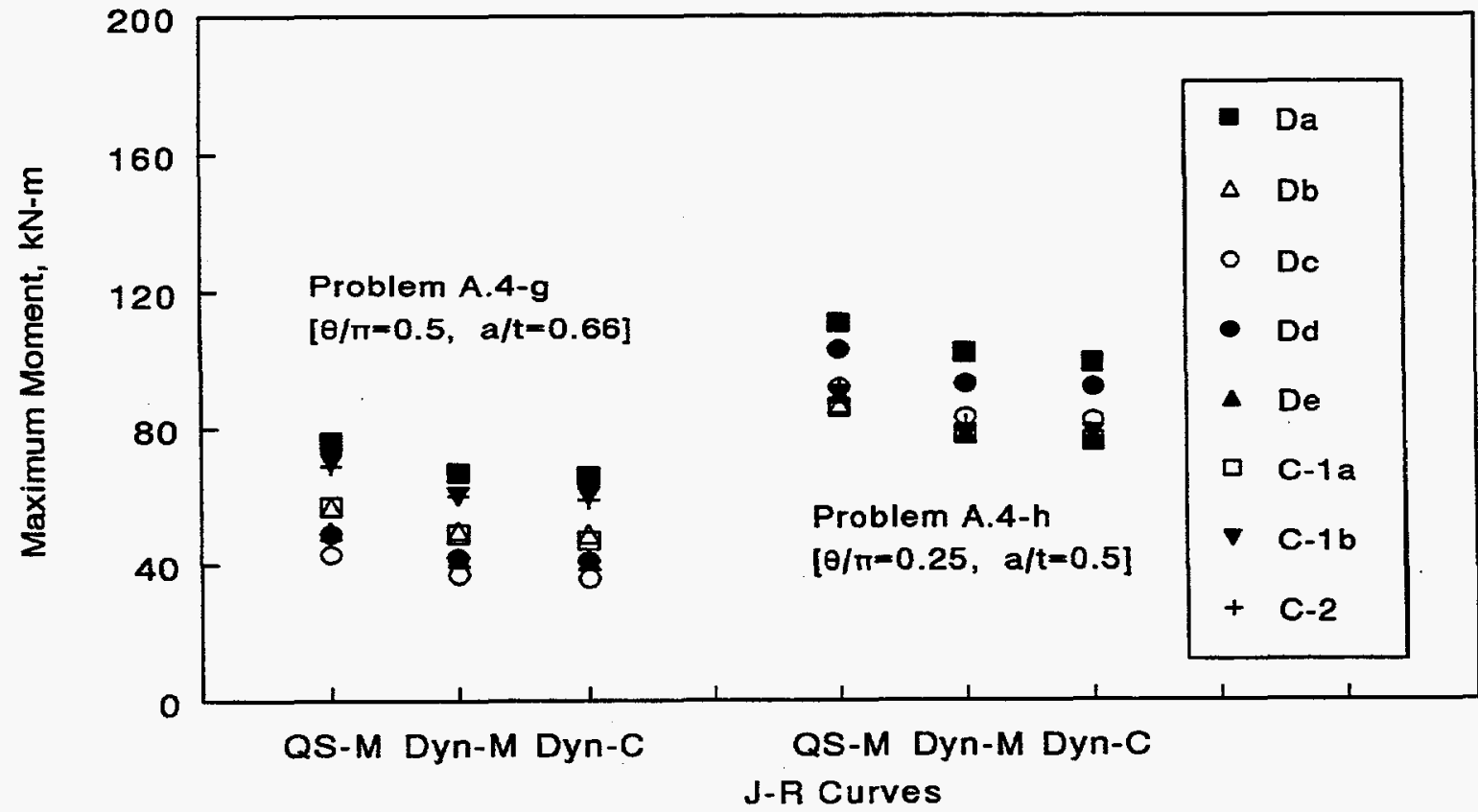

Figure 2.22 Comparisons of predicted maximum moments by various participants for smalldiameter surface-cracked pipes (Problems A.4-g and A.4-h) 


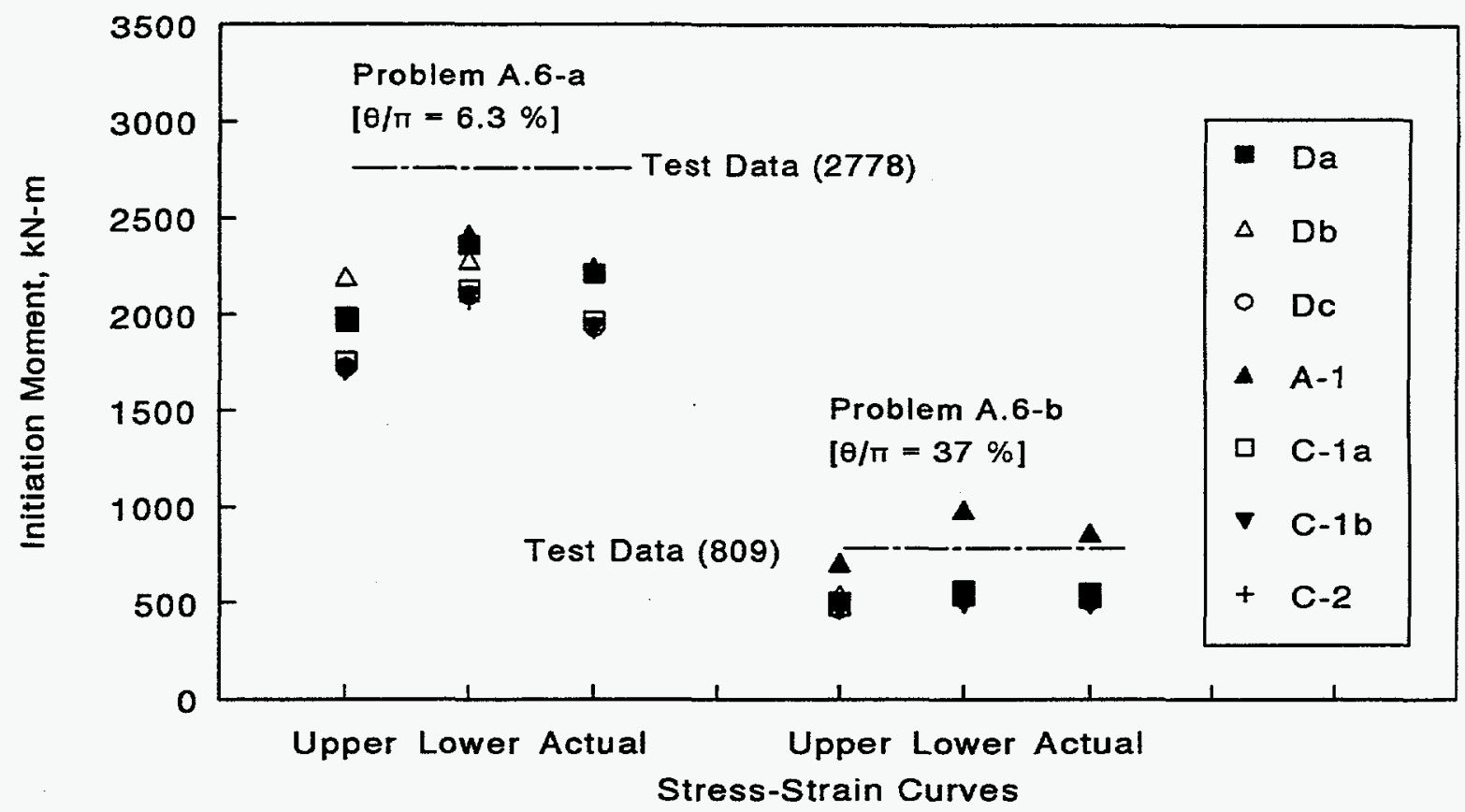

Figure 2.23 Comparisons of predicted initiation moments by various participants for largediameter through-wall-cracked pipes (Problems A.6-a and A.6-b)

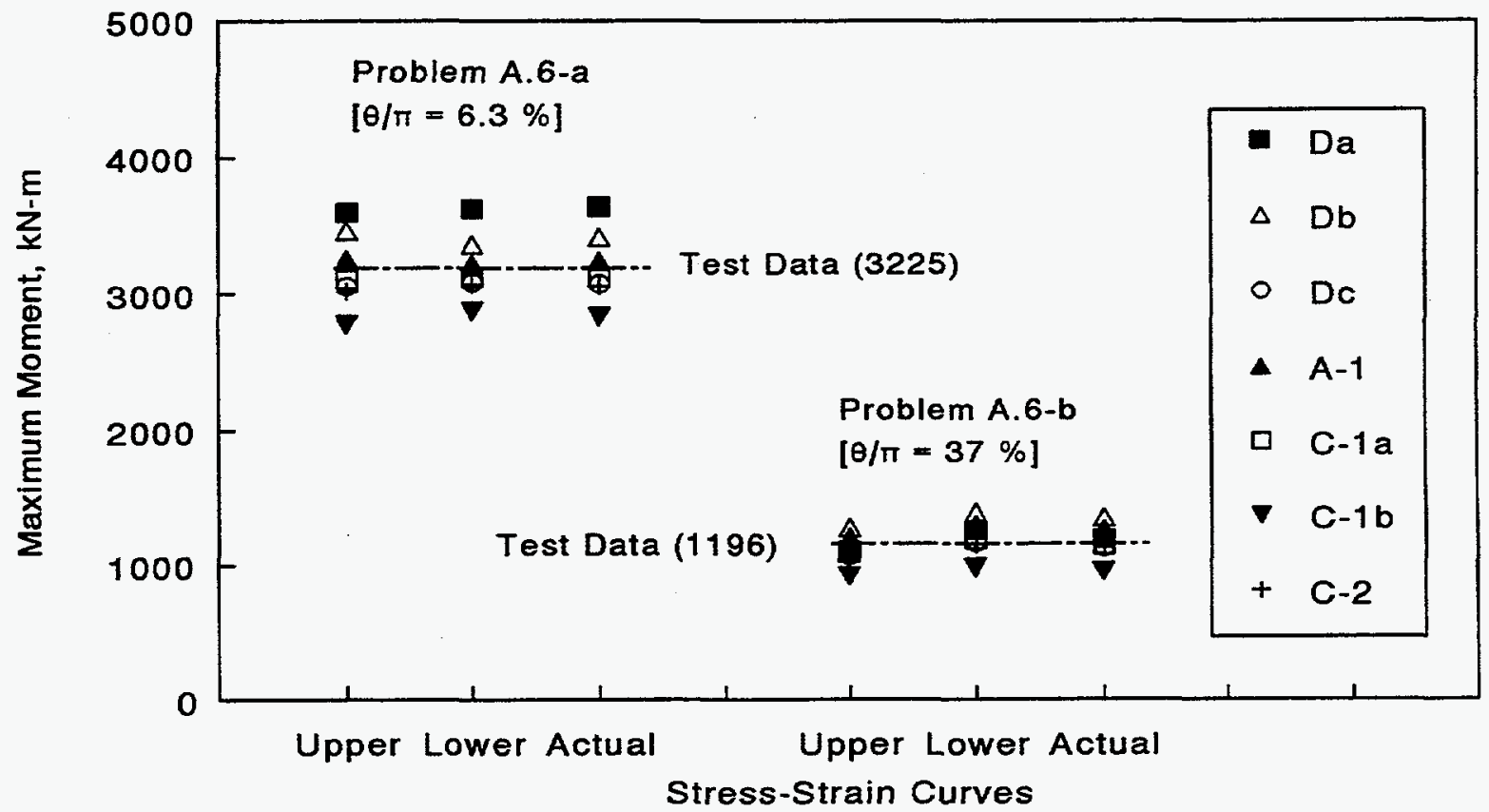

Figure 2.24 Comparisons of predicted maximum moments by various participants for largediameter through-wall-cracked pipes (Problems A.6-a and A.6-b) 


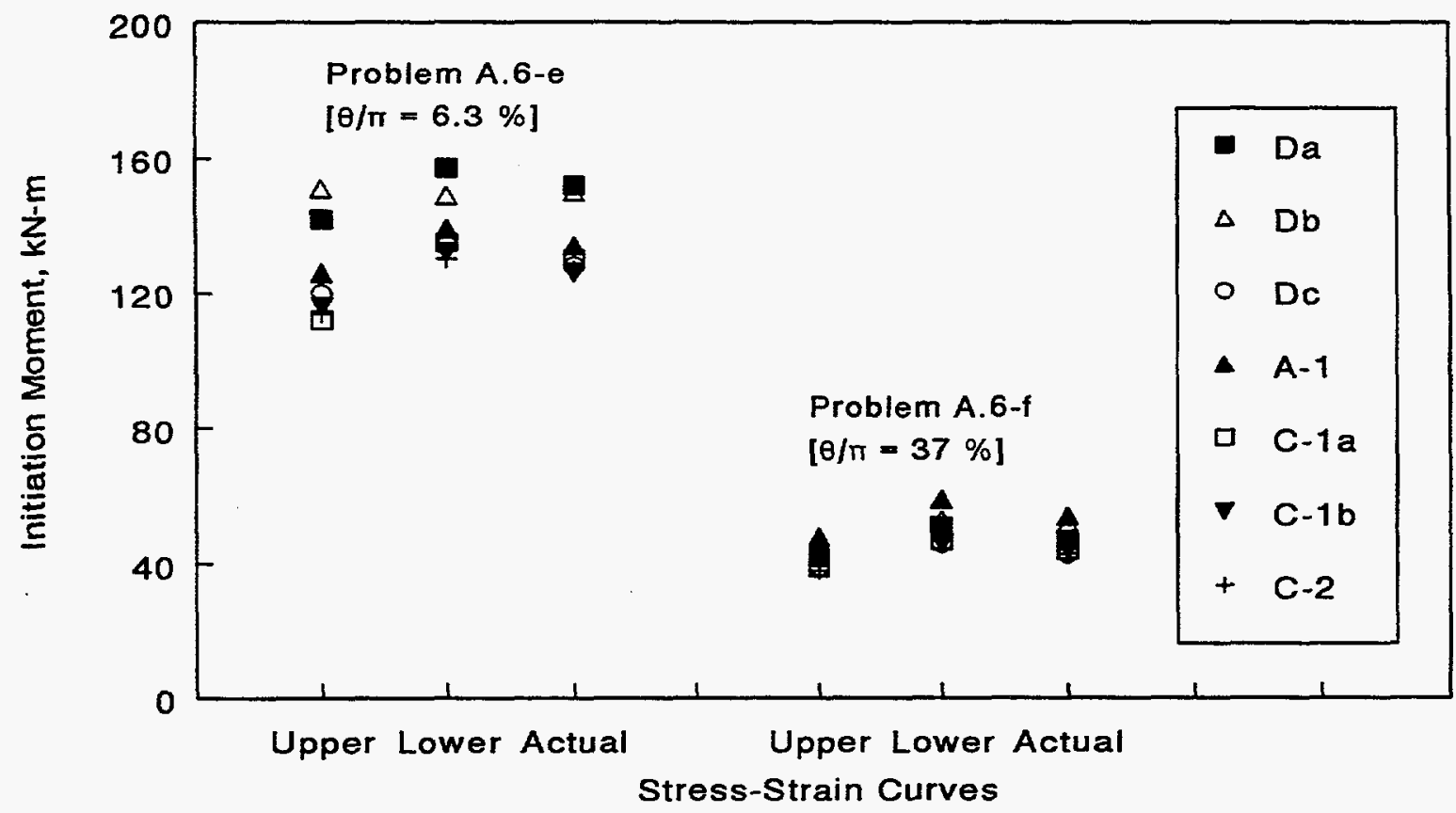

Figure 2.25 Comparisons of predicted initiation moments by various participants for smalldiameter through-wall-cracked pipes (Problems A.6-e and A.6-f)

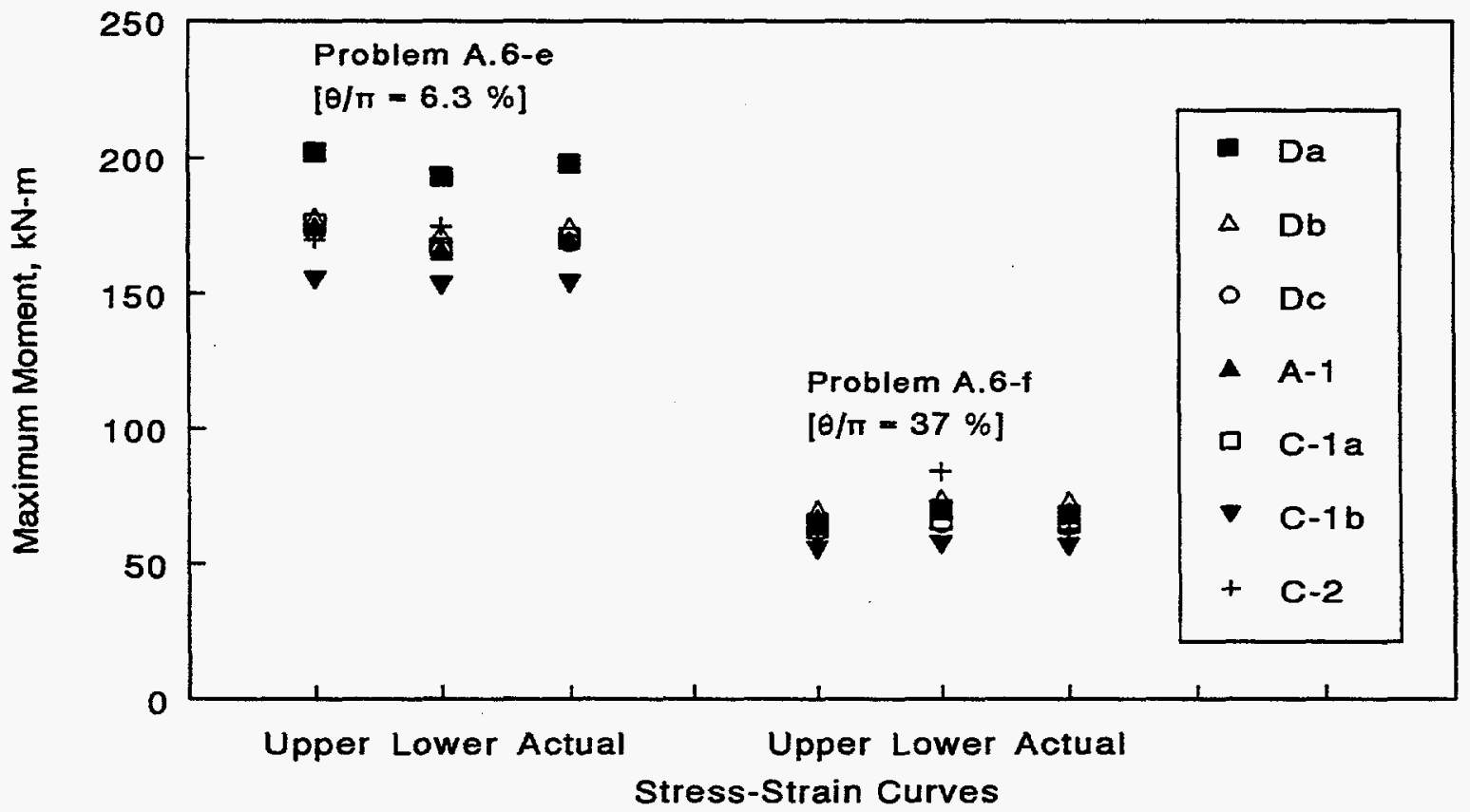

Figure 2.26 Comparisons of predicted maximum moments by various participants for smalldiameter through-wall-cracked pipes (Problems A.6-e and A.6-f) 


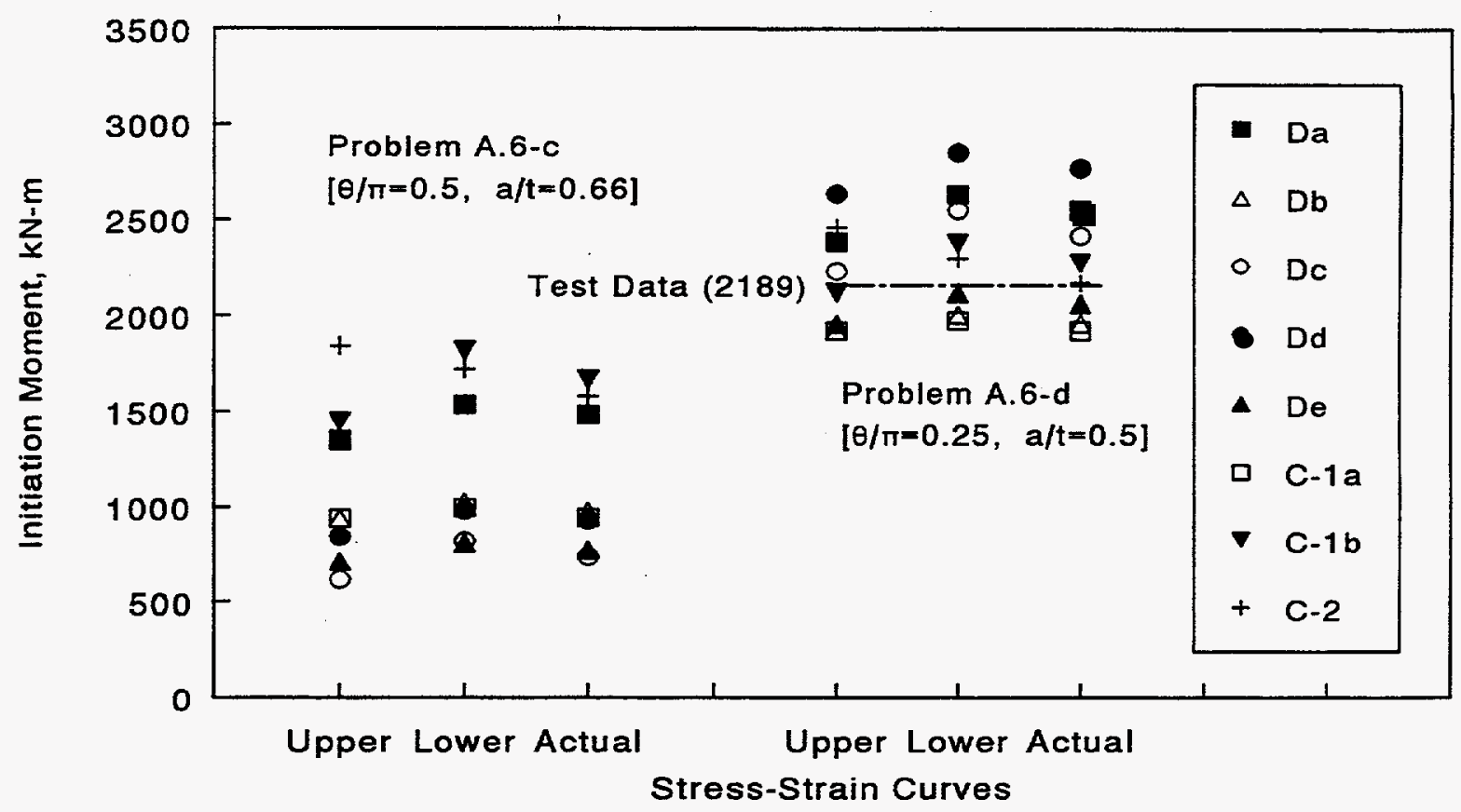

Figure 2.27 Comparisons of predicted initiation moments by various participants for largediameter surface-cracked pipes (Problems A.6-c and A.6-d)

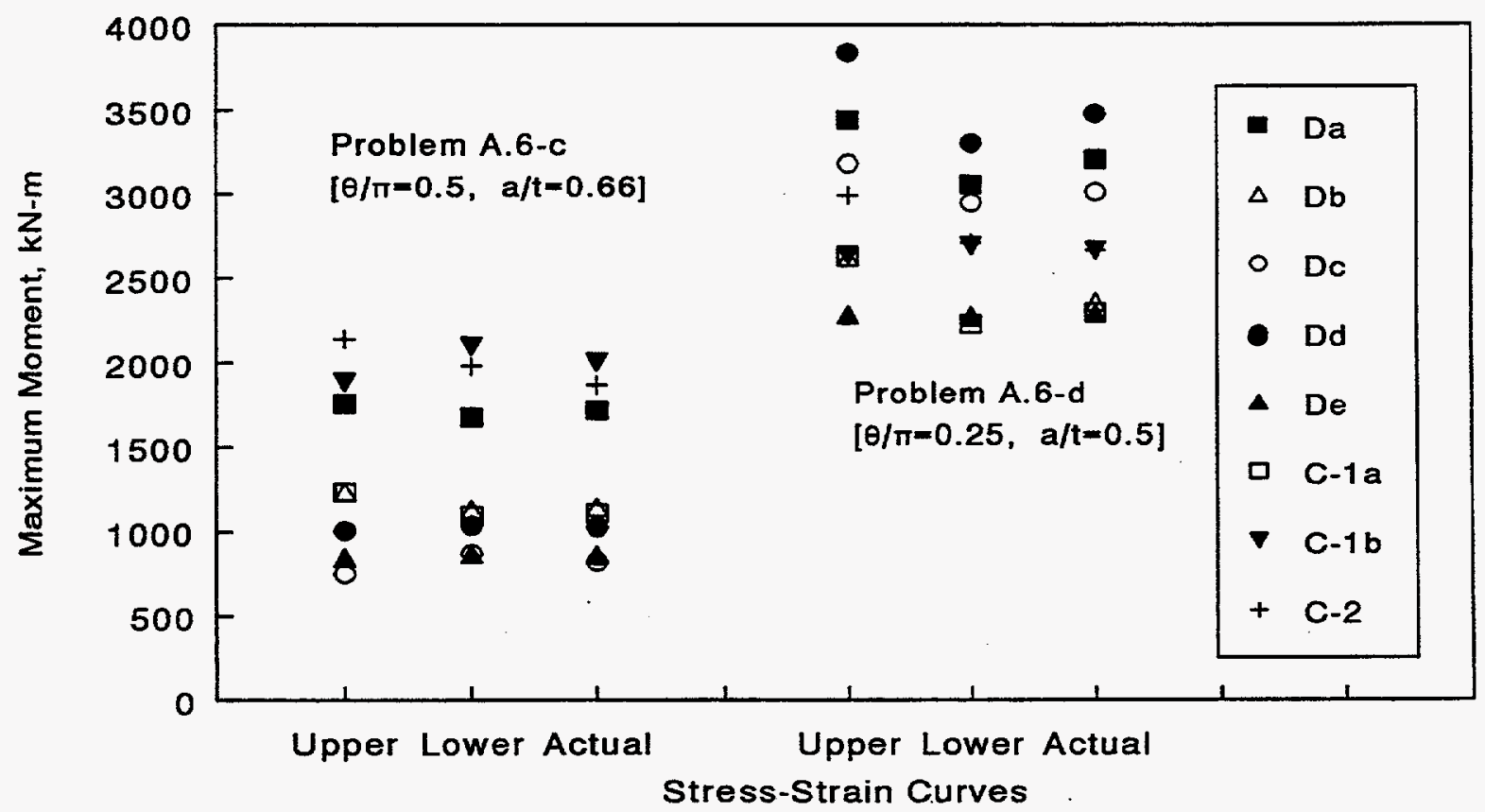

Figure 2.28 Comparisons of predicted maximum moments by various participants for largediameter surface-cracked pipes (Problems A.6-c and A.6-d) 


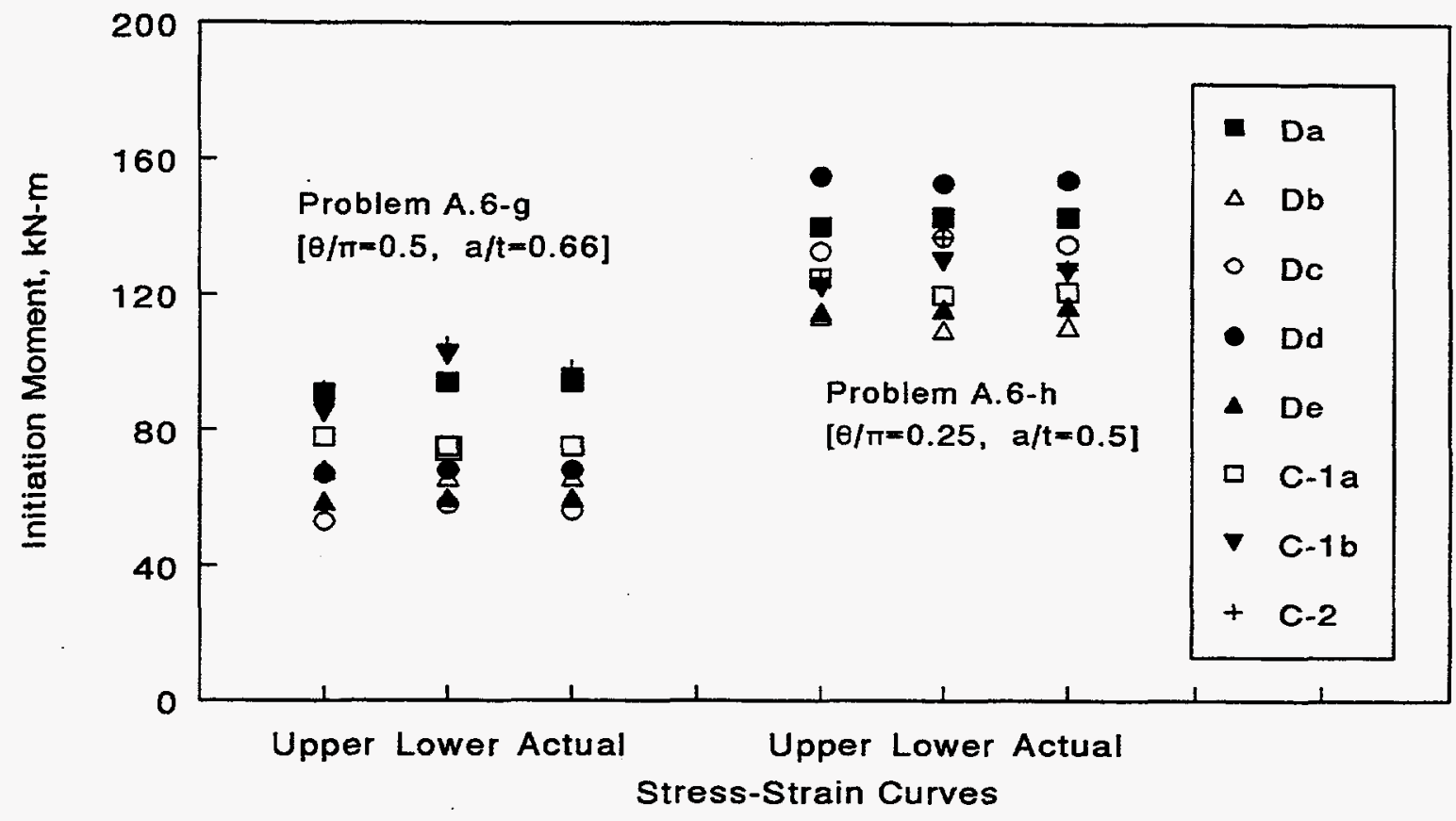

Figure 2.29 Comparisons of predicted initiation moments by various participants for smalldiameter surface-cracked pipes (Problems A.6-g and A.6-h)

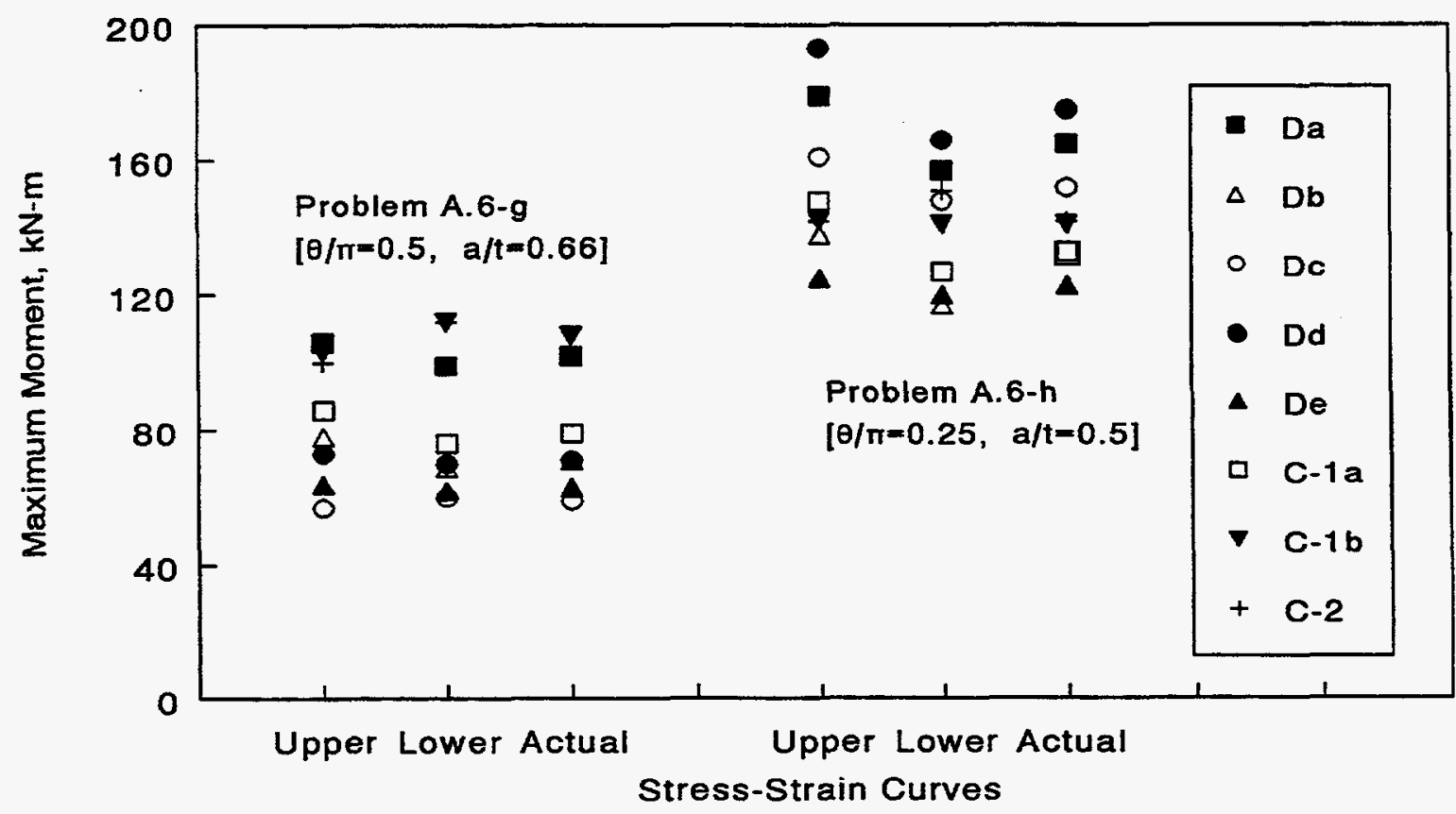

Figure 2.30 Comparisons of predicted maximum moments by various participants for smalldiameter surface-cracked pipes (Problems A.6-g and A.6-h) 


\subsection{ROUND-ROBIN PROBLEM SET B}

\subsection{Round-Robin Problem B.1 - Calculation of Crack-Opening Displacements for Pipes Under Various Loads}

\subsubsection{Problem Definition}

The objective of this problem was to assess current methods to predict crack-opening-area in a through-wall-cracked (TWC) pipe for leak-before-break (LBB) analysis.

Problem B.1 involved calculating center-crack-opening displacements (CODs) for a circumferential through-wall-cracked pipe under pure bending and combined bending and tension (pressure induced) for several values of applied load. The participants were given the pipe geometry, crack size, and material properties to perform the analyses. There were three sub-problems: Problems B.1-a, B.1-b, and B.1-c. Problem B.1-a involved pure bending, whereas Problems B.1-b and B.1-c involved combined bending and tension. The material properties of the pipes in Problems B.1-a and B.1-b are for Pipe DP2-F29 and the material properties for Problem B.1-c are for Pipe DP2-F23. See Appendix $B$ for further details of input. Ten participants solved this problem. They are identified as Participants A-1, B-3, B-4, C-1, C-2, D, E-1, E-2, F-1, and G in this report.

\subsubsection{Summary and Conclusions}

In solving Problem B.1, most participants used the well-known GE/EPRI method (Refs. 3.1 to 3.5) to compute COD with various assumptions. For example, Participant A-1 used the GE/EPRI formula from the EPRI/NP-5596 report (Ref. 3.5) without considering a plasticity correction for the crack length. Participant B-3 used six different methods from which the Langston method with the plane stress option (Ref. 3.6) was suggested as the first choice. Participant B-4 conducted elastic-plastic finite element analysis using the ABAQUS code (Ref. 3.7 ) and provided results at both the inner (Solution B-4a) and outer (Solution B-4b) surfaces of the pipe. Participants C-1 and C-2 used the GE/EPRI formula documented in the report EPRI/NP-6301 (Ref. 3.8). The solution by Participant D was also based on the GE/EPRI method documented in the EPRI/NP-3607 report (Ref. 3.2).

However, for Problems B.1-b and B.1-c, that involved combined bending and tension, a Battelle modification of the GE/EPRI method was used. In this modified form, the plastic influence functions for combined bending and tension were approximated from the knowledge of individual influence functions for pure bending and pure tension and the internal pipe pressure. Two sets of results using (Solution $\mathrm{Da}$ ) and not using (Solution $\mathrm{Db}$ ) the plastic-zone correction were presented. These results were calculated by the computer code NRCPIPE, Version 1.4G. Participant E-1 used the GE/EPRI method to present his results following Sections 6.5 and 6.6 of the EPRI Ductile Fracture Handbook, Volume 1 (Ref. 3.8). Participant E-2 used the GE/EPRI method including the plastic-zone correction with the help of program PICEP, Rev. 4 (Ref. 3.9). Participant F-1 also used the GE/EPRI method with the plastic-zone size correction (Ref. 3.8). Finally, Participant G performed elastic-plastic finite element analysis with shell elements using the ABAQUS code (Ref. 3.7). Table 3.1 provides a summary of the methods and/or computer codes used by the participants to solve Problem B.1. 
Figures 3.1 through 3.3 show the plots of center-crack-opening displacement versus applied load predicted by various participants for Problems B.1-a, B.1-b, and B.1-c, respectively. The comparisons of the results show that the COD solutions by various participants agreed reasonably well. However, there was some scatter in the predictions, particularly in the solutions of Problems B.1-b and B.1-c that involved combined bending and tension. A quantitative measure of this scatter was determined in terms of the coefficient of variation which is defined as the ratio of standard deviation to the mean of the predicted results by various participants. Figure 3.4 shows how this coefficient of variation varies with the applied load. From the results of Figures 3.4, the largest coefficient of variation was about 6 percent for Problem B.1-a (pure bending) and 10 percent for Problems B.1-b and B.1-c (combined bending and tension) ${ }^{(a)}$.

In the IPIRG-2 program, a quasi-static pipe experiment (Experiment 1-8) was conducted with the same pipe geometry, crack size, and material properties defined for Problem B.1-c. For comparison, the test data from this pipe experiment are also shown in Figure 3.3. However, in this experiment, the measured COD values due to the initial pipe pressure were initialized before the application of additional bending loads. Hence, to be consistent with the predicted CODs which involved combined bending and tension, the component of COD due to pipe pressure estimated from the GE/EPRI method was added to the test data in Figure 3.3. The comparison of results showed that the experimental COD would be slightly overpredicted by the solutions of all participants at least for the load range considered in this problem. Hence, for a given leak rate or crack-opening area, the crack size would be underpredicted for LBB applications.

It is worth noting that Experiment 1-8 was recently analyzed by Battelle using a number of estimation models other than the GE/EPRI method. The results from that study, reported in Reference 3.10, showed that the LBB.ENG2 and LBB.NRC methods (Ref. 3.10) would provide good predictions of COD for the load range similar to that considered in Problem B.1-c, but could significantly underpredict $C O D$ for loads close to the initiation or maximum loads of the pipe. The Paris/Tada and LBB.NRC methods (Ref. 3.10) showed similar behavior in predicting COD. For larger loads when there was significant plasticity, the GE/EPRI method, however, provided the best results (Ref. 3.10).

\subsection{Round-Robin Problem B.2 - Leak-Rate Analysis of Cracked Pipes with Various Cracking Mechanisms}

\subsubsection{Problem Definition}

The objectives of this problem were to characterize the crack-morphology variables for a given cracking mechanism and determine the effects of these input variables for the prediction of leak rate through a crack in a pipe.

Problem B.2 involved several leak rate analyses. For each analysis, the participants were given the pipe geometry, crack length and shape, and water temperature and pressure inside the pipe to

0 Since the statistics involved COD at mid-thickness of the pipe, an average value of inner and outer CODs predicted by Participant B-4 was used. 
calculate the leak rates for several values of center-crack-opening displacement. There were four subproblems: Problems B.2-a, B.2-b, B.2-c, and B.2-d. Problems B.2-a and B.2-b involved pipes with a corrosion-fatigue crack and an intergranular stress-corrosion crack (IGSCC), respectively. The participants were asked to define the crack-morphology variables, assign appropriate values for these input variables, and estimate the resulting leak rates. Problems B.2-c and B.2-d involved the same two pipes as in Problems B.2-a and B.2-b, except that the crack-morphology variables were defined explicitly to eliminate any differences in input for leak-rate calculations. The values of these crackmorphology variables came from studies at Battelle, see References 3.10 and 3.11. Details of input are given in Appendix B. The participants were then asked to predict the leak rates. Five participants solved this problem. They are identified as Participants C-2, D, F-1, G, and H in this report.

\subsubsection{Summary and Conclusions}

Several computer codes and methods were used to calculate the leak rates for this problem. All of these codes can handle two-phase flow conditions for estimating leak rates. Participant C-2 used the PICEP code developed by EPRI (Ref. 3.9). In his analysis, the corrosion-fatigue crack in Problem B.2-a was assumed to be straight, and the IGSCC crack in Problem B.2-b was assumed to contain 24 45-degree turns per $25.4 \mathrm{~mm}$ ( 1 inch) of wall thickness. Participants D and G both used the SQUIRT code developed at Battelle (Refs. 3.12 and 3.12). In the analyses by Participant $D$, the values of crack-morphology parameters were chosen from the improved models of NUREG/CR-6300 (Solution $\mathrm{Da}$ ) and the original models of NUREG/CR-5128, Revision 1 (Solution Db). Participant G used the crack-morphology parameters from the NUREG/CR-5128, Revision 1. Participant F-1 used his own in-house code assuming two-phase flow regardless of the crack-opening. Finally, Participant $\mathrm{H}$, who used his own LEAKH code, provided results when the surface roughness was $20 \mu \mathrm{m}$ (787 $\mu$-inch) [Solution Ga] and $40 \mu \mathrm{m}$ (1575 $\mu$-inch) [Solution Gb]. Table 3.2 gives a summary of the methods and/or computer codes used by the participants to solve Problem B.2.

Problems B.2-a and B.2-b. For Problems B.2-a and B.2-b, the results were provided by Participants $\mathrm{C}-2, \mathrm{D}$, and $\mathrm{H}$. Figures 3.5 and 3.6 show the plots of calculated leak rates by these three participants as a function of center-crack-opening displacement in a pipe for Problems B.2-a and B.2-b, respectively. Due to the freedom given in choosing crack-morphology variables and their numerical values for these two problems, the solutions by various participants varied considerably. For example, Participant $G$ used two different surface roughness values, but did not account for any number of turns that are responsible for velocity head loss. Participant $D$ used both a simple and an improved (COD dependent) crack-morphology variable to predict the leak rates. The improved crack-morphology involved dependence of surface roughness, number of turns, path-deviation factors on COD and new statistics of local and global crack morphology parameters for IGSCC and corrosion fatigue cracks. Analyses by Participant $D$ based on both simple and improved crack-morphology produced widely-varying leak-rate estimates and are shown in Figure 3.5.

Problems B.2-c and B.2-d. For Problems B.2-c and B.2-d, the results were provided by Participants D, F-2, G, and H. Figures 3.7 and 3.8 show the plots of estimated leak rate versus center-crackopening displacement in a pipe by these four participants for Problems B.2-c and B.2-d, respectively. There was still some scatter in the predicted leak rates for both corrosion-fatigue and IGSCC cracks. However, it was somewhat less than that observed in Problems B.2-a and B.2-b. The results by 
Participant F-1 were significantly different from those by others (Problem B.2-c). Participant F-1 suggested that this may be due to the two-phase flow assumption in all of his calculations.

From the results of this round-robin problem, there were some concerns on the scatter of the predictive models for leak rate calculations. Currently, there are few experimental data available to validate the analysis methods. Another concern shared by the participants was the usefulness of further experiments conducted in a laboratory, because even if one designs a new leak-rate experiment, it would not be very representative of actual crack morphology found in power plants.

From this round-robin problem, it was also suggested that a database be developed for the crackmorphology variables relevant for various types of cracking mechanisms, e.g., corrosion-fatigue, IGSCC, thermal fatigue, etc., from examination of service cracks. Since most of the past leak-rate experiments involved fatigue cracks made in air or water at high frequency, this produces a relatively smooth crack. However, the results of an HDR experiment conducted at Staatliche Materialprüfungsanstalt (MPA), which are shown in Figure 3.9, suggest that a slow cycling can greatly increase the surface roughness and number of turns compared with a faster cycling loading.

\subsection{Round-Robin Problem B.3 - Crack-Opening-Area Analysis of Pipes with Off-Centered Cracks}

\subsubsection{Problem Definition}

The objectives of this problem were to perform crack-opening-area analyses for an off-centered crack in a pipe and to evaluate engineering models by comparing results from the finite element method (FEM).

In Problem B.3, the crack-opening was calculated for a pipe containing a crack which is off-centered with respect to the plane of bending. The participants were given the information regarding pipe geometry, crack size, angle of off-center, material properties, and applied load. See Appendix B for explicit details of the input. There were six sub-problems. They were Problems B.3-a to B.3-f and were designed to calculate the center-crack-opening displacement and crack-opening area when the angle of off-center was $0,15,30,45,60$, and 90 degrees, respectively, from the center of the bending plane. Six members solved this problem. They are identified as Participants A-2, B-4, C-2, $D, F-1$, and $G$ in this report.

\subsubsection{Summary and Conclusions}

Both finite element and estimation analyses were conducted by the participants to solve Problem B.3. Most participants used commercial finite element codes, except Participant F-1, who used the GE/EPRI estimation method to predict the crack-opening. For the participants conducting finite element analysis, Participant A-2 used the ANSYS code (Ref. 3.14), while the rest of the participants used the ABAQUS code (Ref. 3.7). In addition, Participant D provided three sets of solutions. The first solution (Solution $\mathrm{Da}$ ) was obtained by performing FEM for each value of the off-centered angle. The second and third solutions were derived by conducting one analysis for a symmetrically centered 
crack (i.e., when the angle of the off-centered crack is zero) and then resolving the solution into its cosine components depending on the angle of off-center. These solutions were named Solution $\mathrm{Db}$ and Solution Dc based on the finite element and estimation (GE/EPRI method) analyses for the symmetrically centered crack, respectively. Table 3.3 provides a summary of the methods and/or computer codes used by each of these participants to solve Problem B.3.

Figures 3.10 and 3.11 show the plots of center-crack-opening displacement and crack-opening area, respectively, predicted by various participants as a function of the off-centered angle $(\psi)$. The results are in reasonably good agreement although there was some scatter in the predictions. Participants D (Solution Da) and C-2 provided the largest and smallest values of crack-opening, regardless of $\psi$. The standard deviations for the center-crack-opening displacement and crack-opening area were 13 and 18 percent of the mean, respectively. One of the main reasons for such scatter is due to the fact that the results predicted by some participants were obtained at mid-thickness of the pipe (e.g., when using shell finite elements or estimation models) although the problem statement asked that the calculations be made at the outer surface of the pipe, see Appendix B.

The results of all participants also showed that the maximum COD shifts from the center when the crack becomes off-centered. However, good predictions of crack-opening area could still be made using center COD and assuming an elliptic crack-opening profile. This was explicitly verified by Participant D for off-centered cracks in which comparisons were made for crack-opening displacement and crack-opening area from full-scale 3D finite-element analyses and elliptical crack-opening profiles. Figures 3.12 and 3.13 show the comparisons of two finite element solutions from Participant $\mathrm{D}$ for predicting the crack-opening displacements for off-centered cracks as a function of $\xi / 2 \theta$, where $\xi$ is an angle from the crack tip and $2 \theta$ is the total crack angle. The results suggest that for off-centered cracks, when the crack opening is assumed to be elliptical with the length of the minor axis equal to the center COD, the actual COD from the FEM would be underpredicted for onehalf of the crack front and overpredicted by the other half of the crack front. However, calculations of crack-opening area by elliptical profile produced results in good agreement with those from the explicit finite-element analysis, see the results of F-1 and D in Figure 3.11. This is an important finding because the crack-opening area, which is more relevant for leak-rate prediction than COD itself, can be easily calculated just by knowing the center COD (plus making elliptical assumption on the crack-opening profile) from simple GE/EPRI type estimation formulas.

\subsection{Round-Robin Problem B.4 - Effects of Weld Residual Stresses on Crack-Opening Analysis of Pipes}

\subsubsection{Problem Definition}

The objective of this problem was to determine the effects of a typical residual stress distribution on the center-crack-opening displacement of a cracked pipe.

Problem B.4 involved calculating crack-opening characteristics for a pipe with and without residual stresses typically found in a stainless steel weld. The participants were provided the pipe geometry, crack size, material properties, remote bending load, and typical residual stresses for a thick-walled 
large diameter pipe (Problem B.4-a) and thin-walled small diameter pipe (Problem B.4-b). The details of the input are provided in Appendix B. The residual stresses were derived from the IWB-3640 analysis procedure of ASME Section XI (Ref. 3.15). Only one participant, identified as G in this report, solved this problem.

\subsubsection{Summary and Conclusions}

Participant $G$ applied the prescribed residual stresses as crack-face pressure since the superposition principle is applicable for linear-elastic stress analysis (Ref. 3.16). The stresses were applied as force-controlled, as for a very long pipe far from restraints. The superposition principle implies that the state of stress due to two or more loads acting together is equal to the sum of the stresses due to each load acting separately. The redistribution of stresses that occurs due to the presence of the crack, growing or non-growing, does not imply that the superposition principle is invalid. This fact has been pointed out by Parker (Ref. 3.17) for fatigue crack growth and demonstrated by Quinones and Reaugh (Ref. 3.18) for stress corrosion crack growth. The residual stresses applied by Participant $\mathrm{G}$ were only for the axial direction. No circumferential residual stresses were applied since they claimed that they would have negligible effects for a circumferential crack.

Linear-elastic finite element analyses were conducted by ABAQUS (Ref. 3.7) to determine the crackopening for each pipe with the two load cases. In the first case, the remote bending load was applied without any residual stresses. In the second case, the bending load was applied with the residual stresses. In both cases, the loadings were assumed to be elastic, so there was no plasticity and/or crack growth. This was justified since normal operating stresses associated with a leaking crack are typically elastic.

Table 3.4 shows the predicted values of center COD at the inside, middle, and outside surfaces calculated with and without residual stresses. It appears that the prescribed residual stress field did not significantly affect the crack-opening for the large-diameter pipe $\left(D_{0}=402.6 \mathrm{~mm}[15.85 \mathrm{inch}]\right)$, but seriously affected the crack-opening for small-diameter pipe $\left(\mathrm{D}_{\mathrm{o}}=102.0 \mathrm{~mm}[4.02 \mathrm{inch}]\right)$. More specifically, for the large-diameter pipe, when the residual stresses were considered, the center-crackopening displacement increased by 4.4 percent at the inside surface, decreased by 2.4 percent at the middle surface, and increased by 3.3 percent at the outer surface of the pipe. For the small-diameter pipe, when the residual stresses were included, the center COD at the inside, middle, and outside surfaces increased by 17.1 percent, decreased by 11.7 percent, and decreased by 31.7 percent, respectively.

More detailed results related to the effects of the above residual stresses are provided in Figures 3.14 and 3.15, which show plots of center-crack-opening displacement as a function of a normalized distance, $u / t$, where $u$ is the coordinate distance (radial) from the inside surface of the pipe and $t$ is the pipe wall thickness. The functional variations of center COD with respect to $\mathrm{u} / \mathrm{t}$ were calculated with and without residual stresses for both thicker-wall large-diameter pipe and thinner-wall smalldiameter pipe and are shown in Figures 3.14 and 3.15, respectively. The analyses showed that the effects of residual stresses for the thinner-wall pipe were significantly greater than those for the thicker-wall pipe. It would be interesting to see if the same conclusions would hold for pipes containing other crack sizes and residual stress distributions. 


\subsection{Round-Robin Problem B.5 - Crack-Opening Analysis of a Girth Weld Nozzle Crack at a Thickness Transition}

\subsubsection{Problem Definition}

The objective of this problem was to assess the effects of thickness transition on the crack-openingarea analysis of pipes with a circumferential crack.

Problem B.5 involved calculating the center-crack-opening displacement for a crack in a girth weld at a nozzle with a thickness taper on both sides with differential gradients. The participants were provided the geometry of the carbon steel nozzle, crack size, material properties, and applied loads. Appendix $B$ has the details of these input parameters. Four load cases including one pure tension (pressure induced) and three combined bending and tension (pressure induced) with increasing bending moments and three cases of fixed boundary conditions were considered. See Appendix B for further details of the boundary and load cases. There were two participants who solved this problem. They are identified as Participants A-1 and D in this report.

\subsubsection{Summary and Conclusions}

To solve this problem, both Participants A-1 and D used three-dimensional finite element analysis using the commercial codes MARC (Ref. 3.19) and ABAQUS (Ref. 3.7), respectively. Since the applied loads were large for some of the load cases, the stress analysis was elastic-plastic.

Figure 3.16 shows the sensitivity of the finite element results from Participant $D$ to the fixed locations defined by the Sections A-A, B-B, and C-C, see Appendix B. From this figure, the center-crackopening displacements calculated at the inner and the outer surfaces of the pipe subjected to two extreme loadings (one was pure pressure and other was combined pressure and bending of 1.00 $\mathrm{MN}-\mathrm{m}\left[8,851\right.$ inch-kip]) do not appear to be dependent on length, $\mathrm{L}_{\mathrm{F}}$, which defines the location of the fixed plane. Clearly, the crack-opening results were not affected by the choice of the boundary conditions defined earlier. This also implies that the analysis of an idealized nozzle geometry instead of modeling the combined nozzle and cold-leg pipe is a useful simplification for crack-opening-area analyses.

From the results of Participant D, Figures 3.17 through 3.19 provide the detailed plots of crackopening displacement versus normalized distance from the crack-tip for four different load cases showing the crack-opening profiles of the nozzle crack. For a better understanding of the problem, the components of the COD in the direction of both thinner and thicker sides of the cracked section are shown. The "zero" horizontal lines in Figures 3.17 to 3.19 simply denote a straight line joining two crack tips at the deformed configuration of the pipe. A positive value of the COD denotes the component of COD in the thinner side of the crack, whereas a negative value of the COD denotes the component of COD in the thicker side of the crack. Both components of the COD were calculated at the inner and outer surfaces of the pipe from the finite element analyses and are presented in Figures 3.17 to 3.19. The results indicate that due to thickness gradient on both sides of the crack, the component of COD in the thinner side is much larger than that in the thicker side, thereby breaking the symmetry of the crack-opening profile about the crack length. The differences in these COD 
components can be significant when the applied moment is large, e.g., when $\mathrm{M}=1.00 \mathrm{MN}-\mathrm{m}$ (8,851 inch-kip) in this study (see Figure 3.19).

Figures 3.20 and 3.21 show the variation of the center-crack-opening displacement as a function of the applied moment calculated at the inner and outer surfaces of the pipe, respectively. The results by both Participants A-1 and D are shown. The comparisons of results showed that the COD compared well when the applied bending moments were lower. However, for larger moments, the COD solutions by both participants varied significantly. To comprehend this better, the analysis procedures used by each participant were studied. It is surmised that the principal reason for such differences may be due to the applications of bending moment for the finite element analyses. For example, in the analysis by Participant $\mathrm{A}-1$, the bending moment was applied as a linearly-distributed axial stress on the nozzle cross-section which varies from tensile to compressive stresses at the outermost fibers (lumped formulation). The axial stresses were calculated from simple beam theory. On the other hand, in the analysis by Participant $\mathrm{D}$, the bending moment was applied using consistent nodal forces on all nodes on the cross-section of the nozzle (consistent formulation). The nodal loads were calculated using the formulation of the 20-noded isoparametric solid elements. In this way, the application of bending moment accounts for the tensile axial stress to compressive axial stress variation on the pipe surface, but since it uses the isoparametric formulation, the bending moment representation is exact at each corner or midside node on the surface.

Another factor that may be responsible for the differences in the COD for higher loads is the fact that there were also differences in the finite-element modeling of the nozzle. For example, Participant $D$ used three elements through the thickness while Participant A-1 used only one element through the thickness. But the model of Participant A-1 had a finer mesh in the circumferential direction. Nevertheless, the degree of mesh refinement could also be a factor affecting crack-opening results. Hence, further studies are needed to resolve the differences in the results by these two participants.

\subsection{References}

3.1 Kumar, V., German, M., and Shih, C., "An Engineering Approach for Elastic-Plastic Fracture Analysis," EPRI Report NP-1931, Electric Power Research Institute, Palo Alto, CA, July 1981.

3.2 Kumar, V., German, M., Wilkening, W., Andrews, W., deLorenzi, H., and Mowbray, D., "Advances in Elastic-Plastic Fracture Analysis," EPRI Final Report NP-3607, Electric Power Research Institute, Palo Alto, CA, August 1984.

3.3 Kishida, K. and Zahoor, A., "Crack-Opening Area Calculations for Circumferential ThroughWall Pipe Cracks," EPRI Special Report NP-5959-SR, Electric Power Research Institute, Palo Alto, CA, August 1988.

3.4 Brust, F., Rahman, S., and Ghadiali, N., "Elastic-Plastic Analysis of Small Cracks in Tubes," Journal of Offshore Mechanics and Arctic Engineering, Vol. 117, No. 1, pp. 57-62, February 1995. 
3.5 Kumar, V., German, M. D., "Elastic-Plastic Analysis of Through-Wall and Surface Flaws in Cylinders,” EPRI Report NP-5596, Electric Power Research Institute, Palo Alto, CA, January 1988.

3.6 Langston, D. B., “A Reference Stress Approximation for Determining Crack-Opening Displacements in Leak-before-Break Calculations," Nuclear Electric Report, TD/SID/REP/0112, 1990.

3.7 ABAQUS, User's Guide and Theoretical Manual, Versions 4.8 to 5.3, Hibbitt, Karlsson, \& Sorensen, Inc., Pawtucket, RI, 1993.

3.8 Zahoor, A., "Ductile Fracture Handbook," EPRI Report NP-6301-D, Volumes 1, 2, and 3, Electric Power Research Institute, Palo Alto, CA, 1989-1991.

3.9 Norris, D. and others, "PICEP: Pipe Crack Evaluation Program," EPRI Report NP-3596-SR, Electric Power Research Institute, Palo Alto, CA, 1984.

3.10 Rahman, S., Brust, F., Ghadiali, N., Choi, Y., Krishnaswamy, P., Moberg, F., Brickstad, B., and Wilkowski, G., "Refinement and Evaluation of Crack-Opening-Area Analyses for Circumferential Through-Wall Cracks in Pipes," NUREG/CR-6300, U.S. Nuclear Regulatory Commission, Washington, D.C., April 1995.

3.11 Rahman, S., Ghadiali, N., Paul, D., and Wilkowski, G., "Probabilistic Pipe Fracture Evaluations for Leak-Rate-Detection Applications," NUREG/CR-6004, U.S. Nuclear Regulatory Commission, Washington, D.C., April 1995.

3.12 Paul, D., Ahmad, J., Scott, P., Flanigan, L., and Wilkowski, G., "Evaluation and Refinement of Leak-Rate Estimation Models,” NUREG/CR-5128, Rev. 1, U.S. Nuclear Regulatory Commission, Washington, D.C., June 1994.

3.13 Rahman, S., Ghadiali, N., Wilkowski, G., and Paul, D., "A Computer Model for Probabilistic Leak-Rate Analysis of Nuclear Piping and Piping Welds," Fatigue and Fracture Mechanics in Pressure Vessels and Piping, ASME/JSME PVP Conference, PVP-Vol. 304, pp 355-374, July 1995.

3.14 ANSYS, User's Guide, Theoretical Manual, and Seminar Notes, Version 5.1, Swanson Analysis Systems, Inc., Houston, PA, 1994.

3.15 "Evaluation of Flaws in Austenitic Steel Piping," (Technical basis document for ASME IWB3640 analysis procedure), prepared by Section XI Task Group for Piping Flaw Evaluation, EPRI Report NP-4690-SR, Electric Power Research Institute, Palo Alto, CA, July 1986.

3.16 Bergman, M. and Brickstad, B., "A New Computerized Procedure to Analyze LBB in Pipes with Complex Crack Shapes," Proceedings of the 20th MPA-Seminar, Stuttgart, Germany, October 1994. 
3.17 Parker, A. P., “LEFM and Fatigue Crack Growth - Residual Stress Effects,” Residual Stress and Stress Relaxation, edited by E. Kula, Plenum Publication Corporation, pp. 249-271, 1982.

3.18 Quinones, D. F. and Reaugh, J. E., "Weld Residual Stress Distribution Near Growing Cracks," EPRI Report NP-2694, Electric Power Research Institute, Palo Alto, CA, 1983.

3.19 MARC, User's Information Manual, MARC Analysis Research Corporation, Rev. K.3, Palo Alto, CA, 1988. 
Table 3.1 Summary of methods and codes used by various participants for solving Problem B.1

\begin{tabular}{|c|c|c|c|}
\hline Participant & Method and/or Computer Code Used & $\begin{array}{c}\text { Legend } \\
\text { Code }\end{array}$ & Reference $^{(a)}$ \\
\hline A-1 & GE/EPRI without plastic-zone correction & A-1 & 3.5 \\
\hline B-3 & Langston with plane stress option & B-3 & 3.6 \\
\hline B-4 & FEM; ABAQUS code & B-4a & 3.7 \\
\hline$C-1$ & GE/EPRI & C-1 & 3.8 \\
\hline $\mathrm{C}-2$ & GE/EPRI with plastic-zone correction & $\mathrm{C}-2$ & 3.1 to 3.4 \\
\hline $\mathrm{D}$ & $\begin{array}{l}\text { Modified GE/EPRI; NRCPIPE code, } \\
\text { Version } 1.4 \mathrm{G} \\
\text { - With plastic-zone correction } \\
\text { - Without plastic-zone correction }\end{array}$ & $\begin{array}{l}\mathrm{Da} \\
\mathrm{Db}\end{array}$ & 3.1 to 3.4 \\
\hline E-1 & GE/EPRI & E-1 & 3.8 \\
\hline $\mathrm{E}-2$ & $\begin{array}{l}\text { GE/EPRI with plastic-zone correction; } \\
\text { PICEP code }\end{array}$ & $\mathrm{E}-2$ & 3.9 \\
\hline F-1 & GE/EPRI with plastic-zone correction & F-1 & 3.8 \\
\hline $\mathbf{G}$ & $\begin{array}{l}\text { FEM with 8-noded shell elements; } \\
\text { ABAQUS code, Version } 5.3\end{array}$ & G & 3.7 \\
\hline
\end{tabular}

(a) The reference provides further information on the method used only. 
Table 3.2 Summary of methods and codes used by various participants for solving Problem B.2

\begin{tabular}{|c|c|c|c|}
\hline Participant & Method and/or Computer Code Used & $\begin{array}{c}\text { Legend } \\
\text { Code }\end{array}$ & Reference $^{(\mathrm{a})}$ \\
\hline $\mathrm{C}-2$ & Single and two-phase flow; PICEP code & $\mathrm{C}-2$ & 3.9 \\
\hline $\mathrm{D}$ & $\begin{array}{l}\text { Single and two-phase flow; SQUIRT code } \\
\text { - Using improved crack-morphology } \\
\text { - Using original crack-morphology }\end{array}$ & $\begin{array}{l}\mathrm{Da} \\
\mathrm{Db}\end{array}$ & 3.12 \\
\hline F-1 & Two-phase flow only & F-1 & $\mathrm{NA}^{(\mathrm{b})}$ \\
\hline $\mathbf{G}$ & Single and two-phase flow; SQUIRT code & G & 3.12 \\
\hline $\mathbf{H}$ & $\begin{array}{l}\text { Single and two-phase flow; LEAKH code } \\
\text { - Using surface roughness }=20 \mu \mathrm{m} \\
\text { - Using surface roughness }=40 \mu \mathrm{m}\end{array}$ & $\begin{array}{l}\mathrm{Ha} \\
\mathrm{Hb}\end{array}$ & $\mathrm{NA}^{(\mathrm{b})}$ \\
\hline
\end{tabular}

(a) The reference provides further information on the method used only.

(b) Not available

Table 3.3 Summary of methods and codes used by various participants for solving Problem B.3

\begin{tabular}{clcc}
\hline Participant & Method and/or Computer Code Used & $\begin{array}{c}\text { Legend } \\
\text { Code }\end{array}$ & Reference $^{(\text {a) }}$ \\
\hline A-2 & $\begin{array}{l}\text { FEM with 4-noded plate elements } \\
\text { ANSYS code }\end{array}$ & A-2 & 3.14 \\
B-4 & FEM; ABAQUS code & B-4 & 3.7 \\
C-2 & FEM with 20-noded solid elements & C-2 & 3.7 \\
& ABAQUS code, Version 5.2 & & \\
D & FEM with 20-noded solid elements & & \\
& ABAQUS code, Version 5.3 and & & \\
& J-estimation method (GE/EPRI) & Da & \\
& - Explicit FEM & Db & \\
& - Resolution of FEM results & Dc & 3.8 \\
& F-1 Resolution of GE/EPRI results & J-estimation method (GE/EPRI) & F-1 \\
G & FEM with 8-noded shell elements & G & 3.7 \\
\hline
\end{tabular}

(a) The reference provides further information on the method used only. 
Table 3.4 Center-crack-opening displacements calculated by Participant G with and without residual stresses from finite element analysis

\begin{tabular}{|c|c|c|c|c|c|}
\hline \multirow[b]{2}{*}{ Pipe } & \multirow{2}{*}{$\begin{array}{c}\text { Outer } \\
\text { Diameter, } \\
\text { mm }\end{array}$} & \multirow[b]{2}{*}{$\begin{array}{l}\text { Load } \\
\text { Case }\end{array}$} & \multicolumn{3}{|c|}{$\begin{array}{l}\text { Center-Crack-Opening } \\
\text { Displacement, mm }\end{array}$} \\
\hline & & & $\begin{array}{l}\text { Inside } \\
\text { Surface }\end{array}$ & $\begin{array}{l}\text { Middle } \\
\text { Surface }\end{array}$ & $\begin{array}{l}\text { Outside } \\
\text { Surface }\end{array}$ \\
\hline \multirow{3}{*}{$\begin{array}{c}\text { Thicker-Wall } \\
\text { Large-Diameter } \\
\text { Pipe }\end{array}$} & \multirow{3}{*}{402.6} & 1. Problem B.4-a & & & \\
\hline & & $\begin{array}{c}\text { Bending Moment }{ }^{(2)} \\
\text { Only }\end{array}$ & 0.274 & 0.334 & 0.395 \\
\hline & & $\begin{array}{c}\text { Bending Moment }{ }^{(a)} \text { and } \\
\text { Residual Stress }\end{array}$ & $\begin{array}{c}0.286 \\
(+4.4)^{(b)}\end{array}$ & $\begin{array}{c}0.326 \\
(-2.4)^{(\mathrm{b})}\end{array}$ & $\begin{array}{c}0.408 \\
(+3.3)^{(b}\end{array}$ \\
\hline \multirow{3}{*}{$\begin{array}{c}\text { Thinner-Wall } \\
\text { Small-Diameter } \\
\text { Pipe }\end{array}$} & \multirow{3}{*}{102.0} & 2. Problem B.4-b & & & \\
\hline & & $\begin{array}{l}\text { Bending Moment } \\
\text { Only }\end{array}$ & 0.111 & 0.137 & 0.164 \\
\hline & & $\begin{array}{l}\text { Bending Moment }{ }^{(c)} \text { and } \\
\text { Residual Stress }\end{array}$ & $\begin{array}{c}0.130 \\
(+17.1)^{(b)}\end{array}$ & $\begin{array}{c}0.121 \\
(-11.7)^{(b)}\end{array}$ & $\begin{array}{c}0.112 \\
(- \\
31.7)^{(b)}\end{array}$ \\
\hline
\end{tabular}

(a) Moment $=522.07 \mathrm{kN}$-m with corresponding elastic stress $=189.4 \mathrm{MPa}(1.08 \times$ ASME Service Level A limit)

(b) Percent change relative to center COD calculated without residual stress $(+=$ increase; - $=$ decrease)

(c) Moment $=8.83 \mathrm{kN}-\mathrm{m}$ with corresponding elastic stress $=158.23 \mathrm{MPa}(0.9 \times \mathrm{ASME}$ Service Level A limit) 


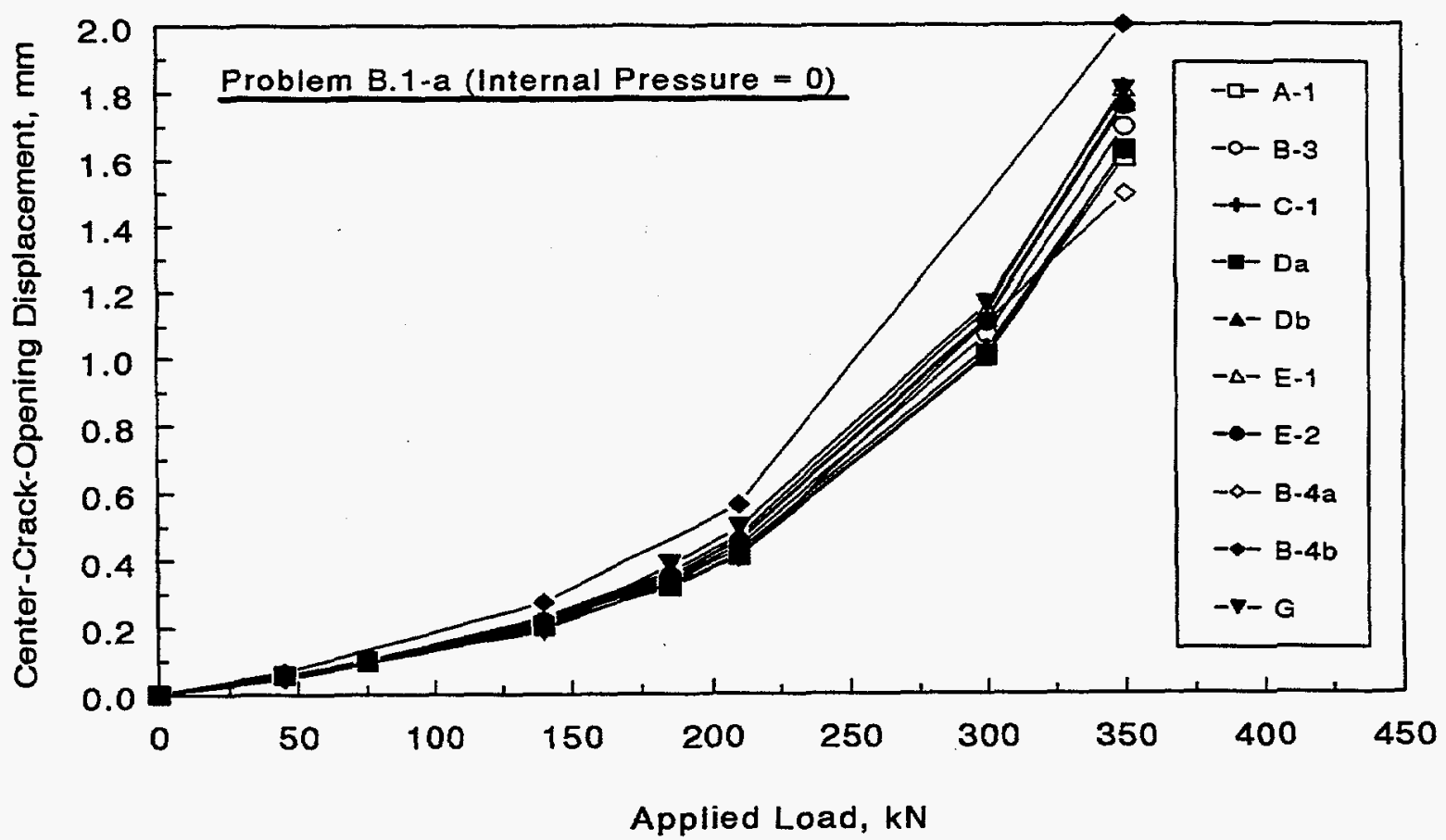

Figure 3.1 Predicted center-crack-opening displacements by various participants for a pipe under pure bending loads (Problem B.1-a)

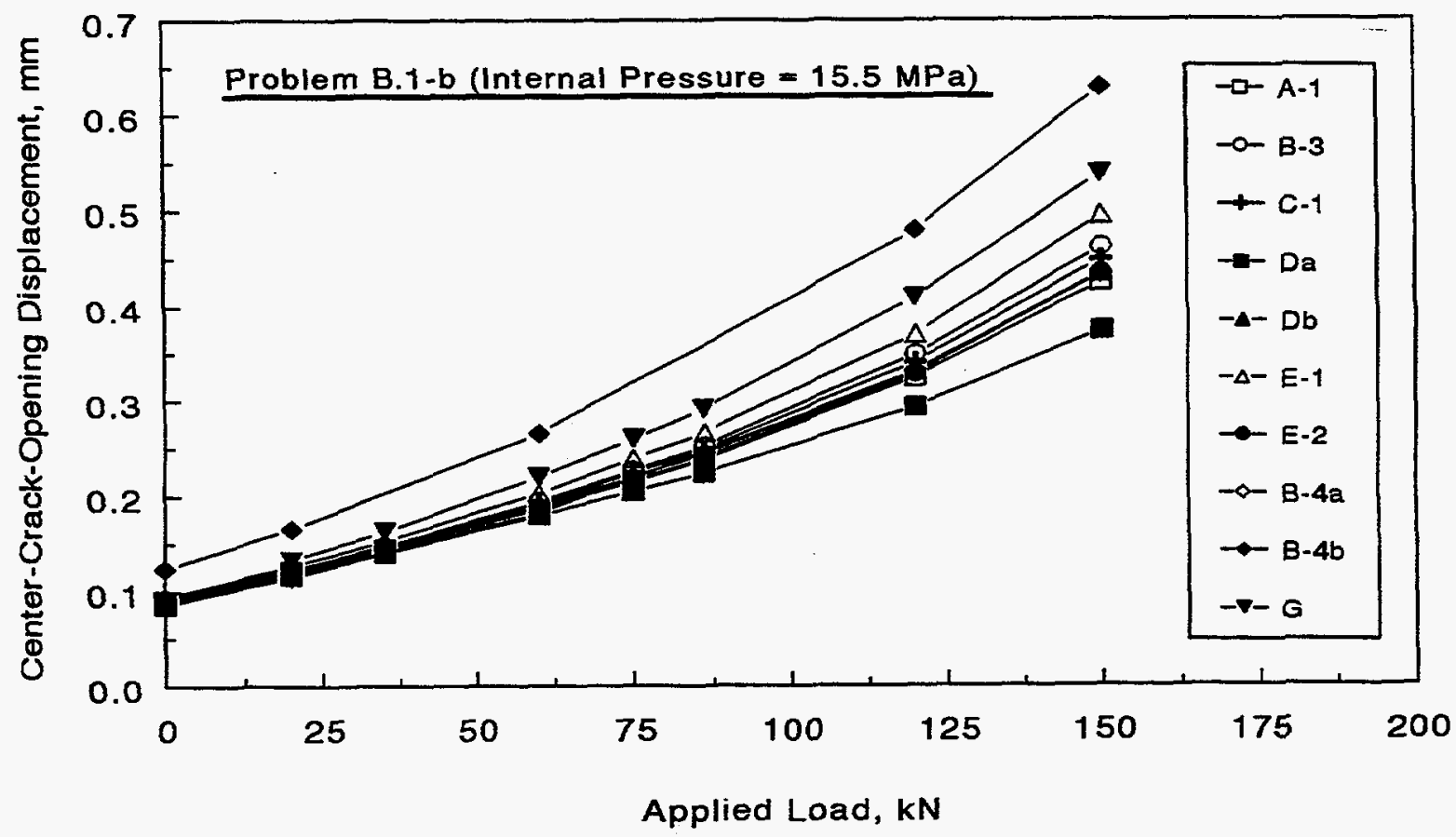

Figure 3.2 Predicted center-crack-opening displacements by various participants for a pipe under combined bending and tension (Problem B.1-b) 


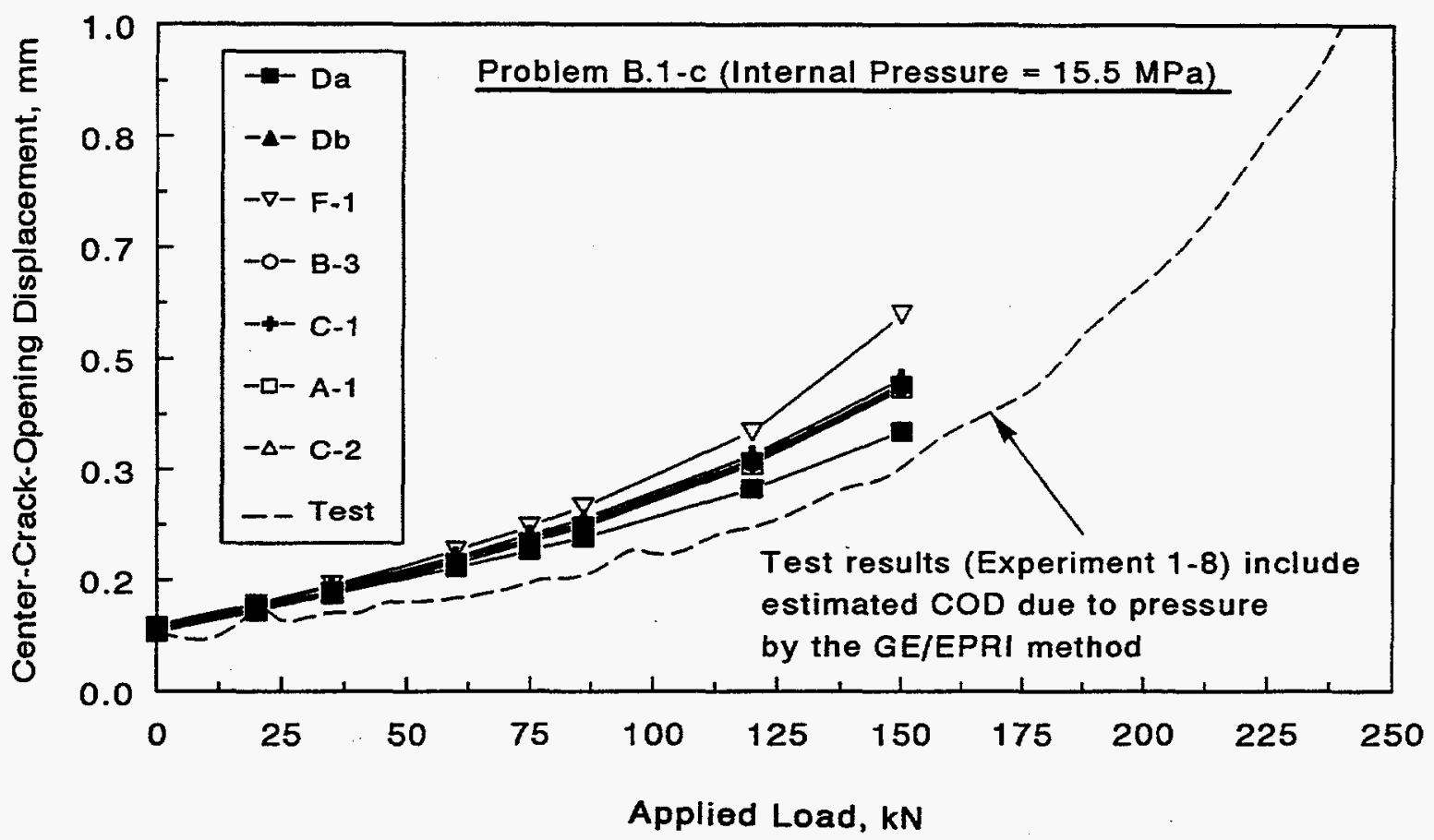

Figure 3.3 Predicted center-crack-opening displacements by various participants for a pipe under combined bending and tension (Problem B.1-c)

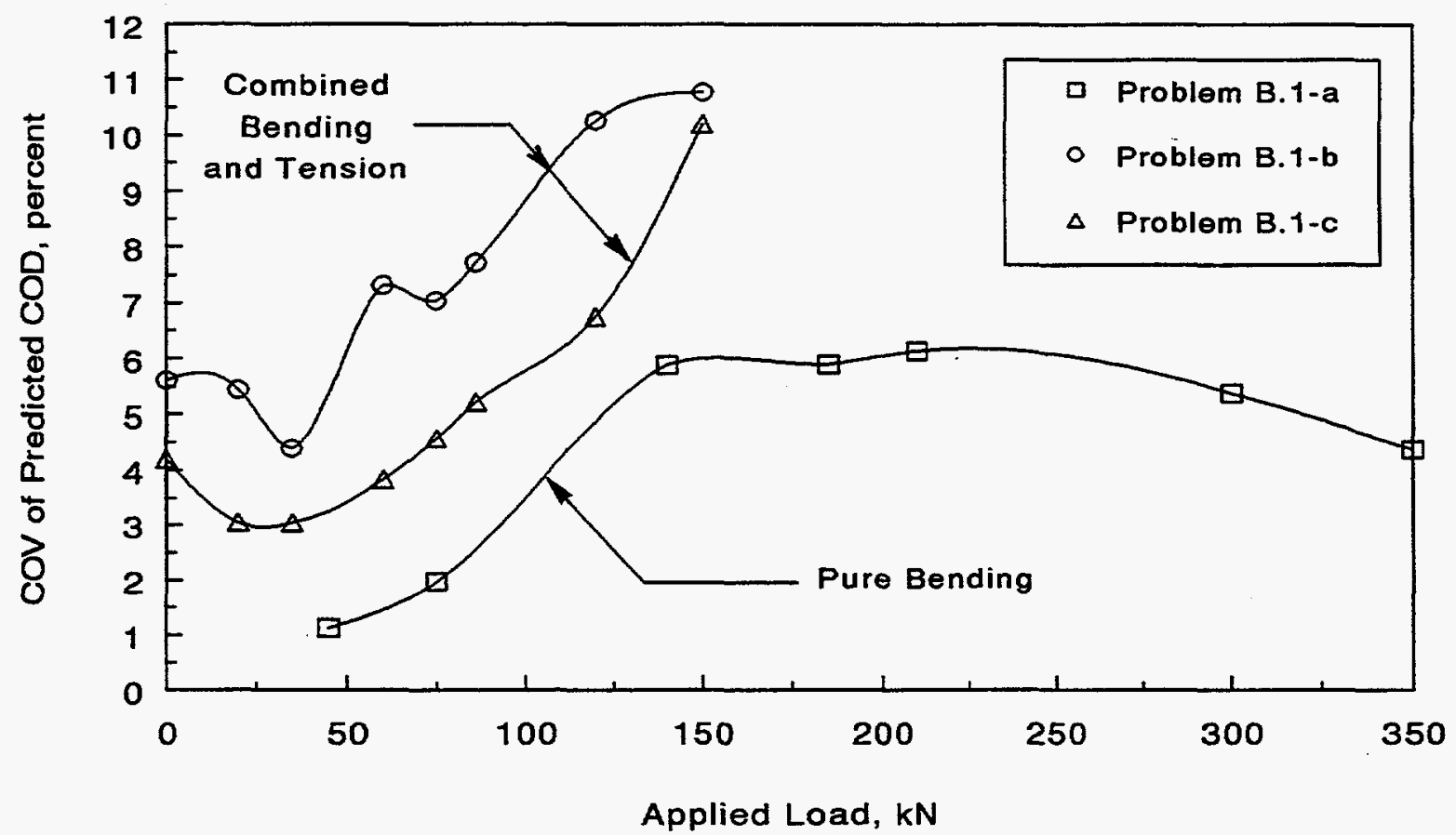

Figure 3.4 Coefficients of variation of the predicted crack-opening displacements for Problems B.1-a, B.1-b, and B.1-c 


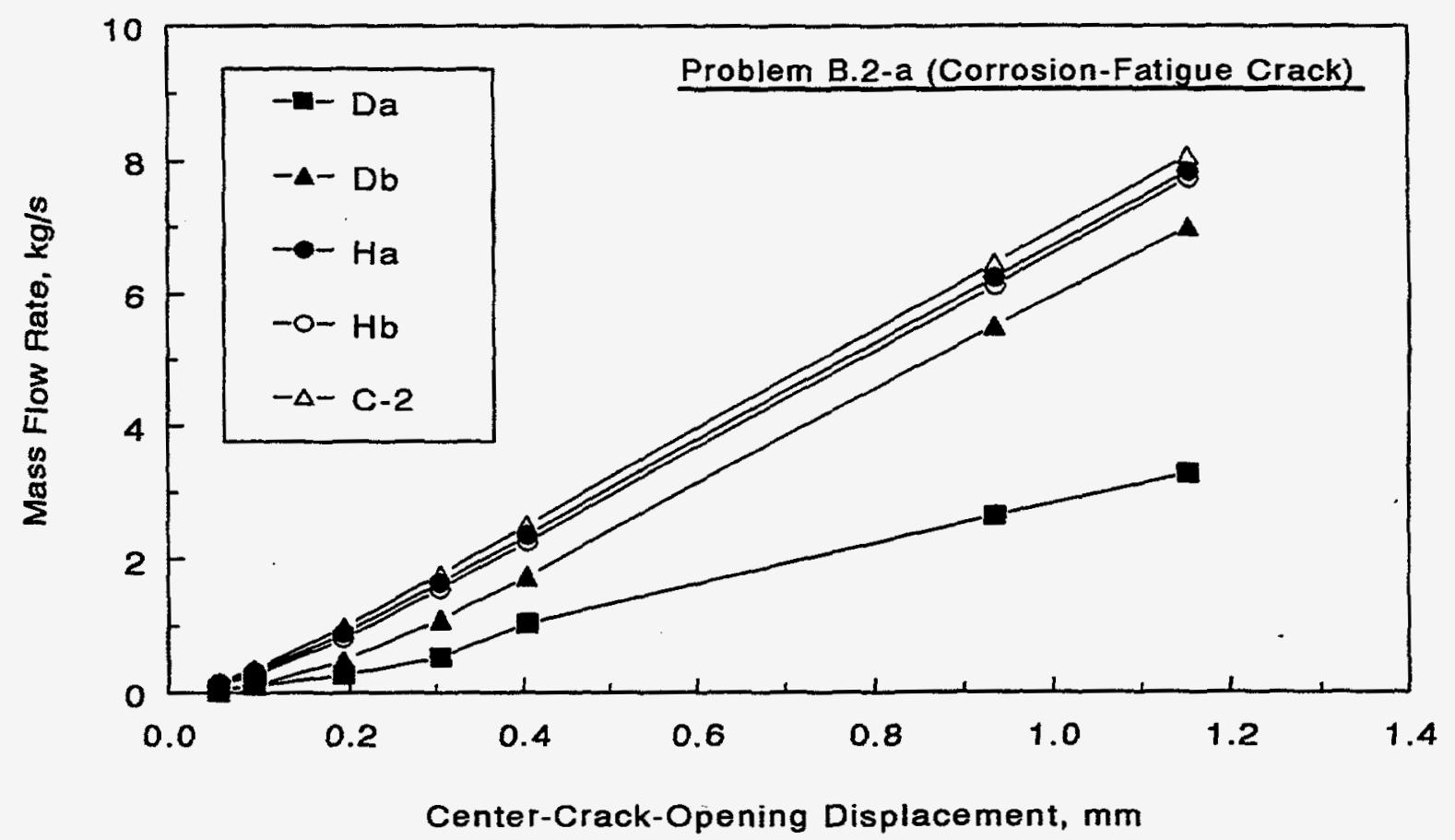

Figure 3.5 Calculated leak rates by various participants for a pipe with a corrosion-fatigue crack (Problem B.2-a)

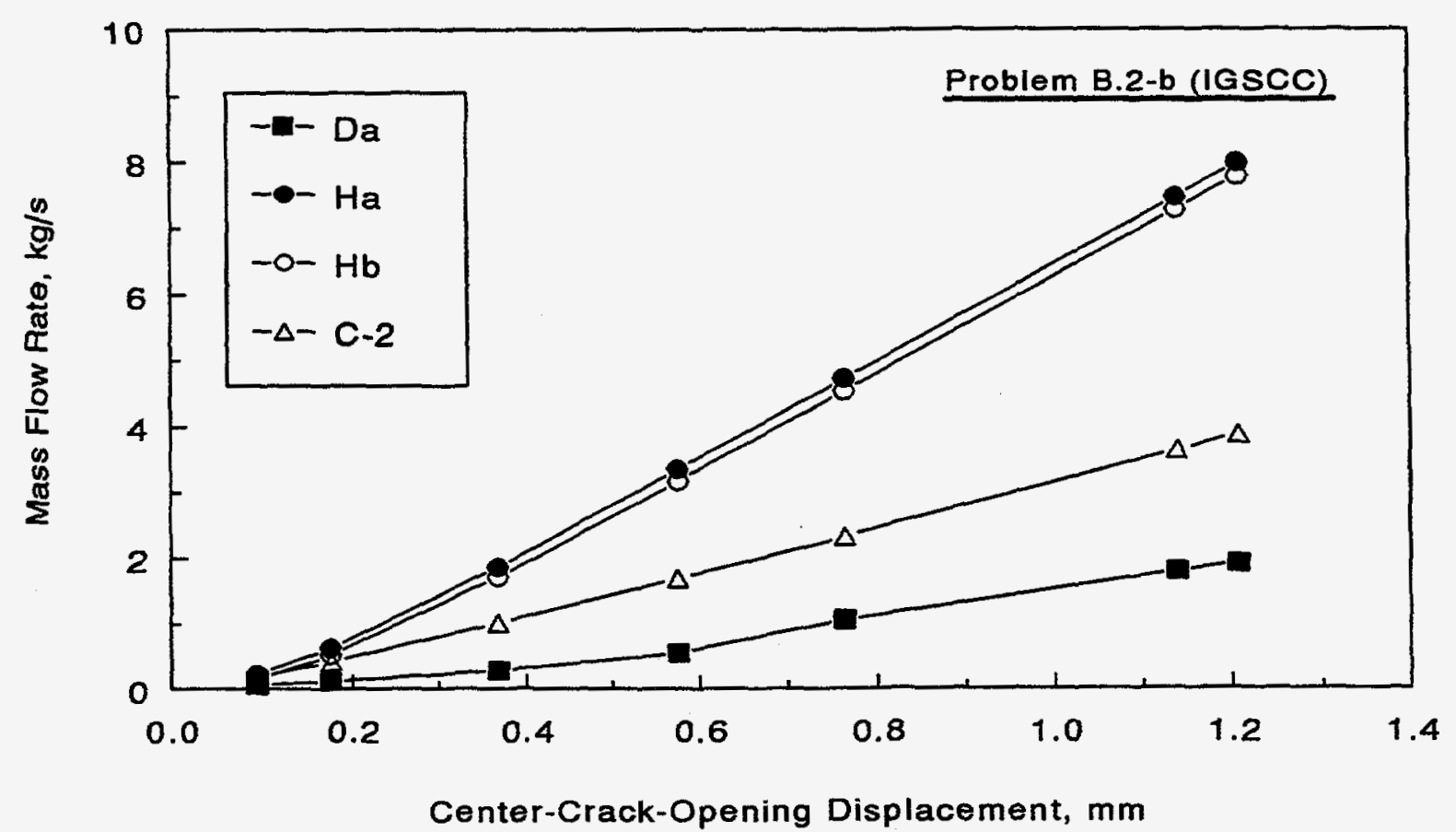

Figure 3.6 Calculated leak rates by various participants for a pipe with an intergranular stress-corrosion crack (Problem B.2-b) 


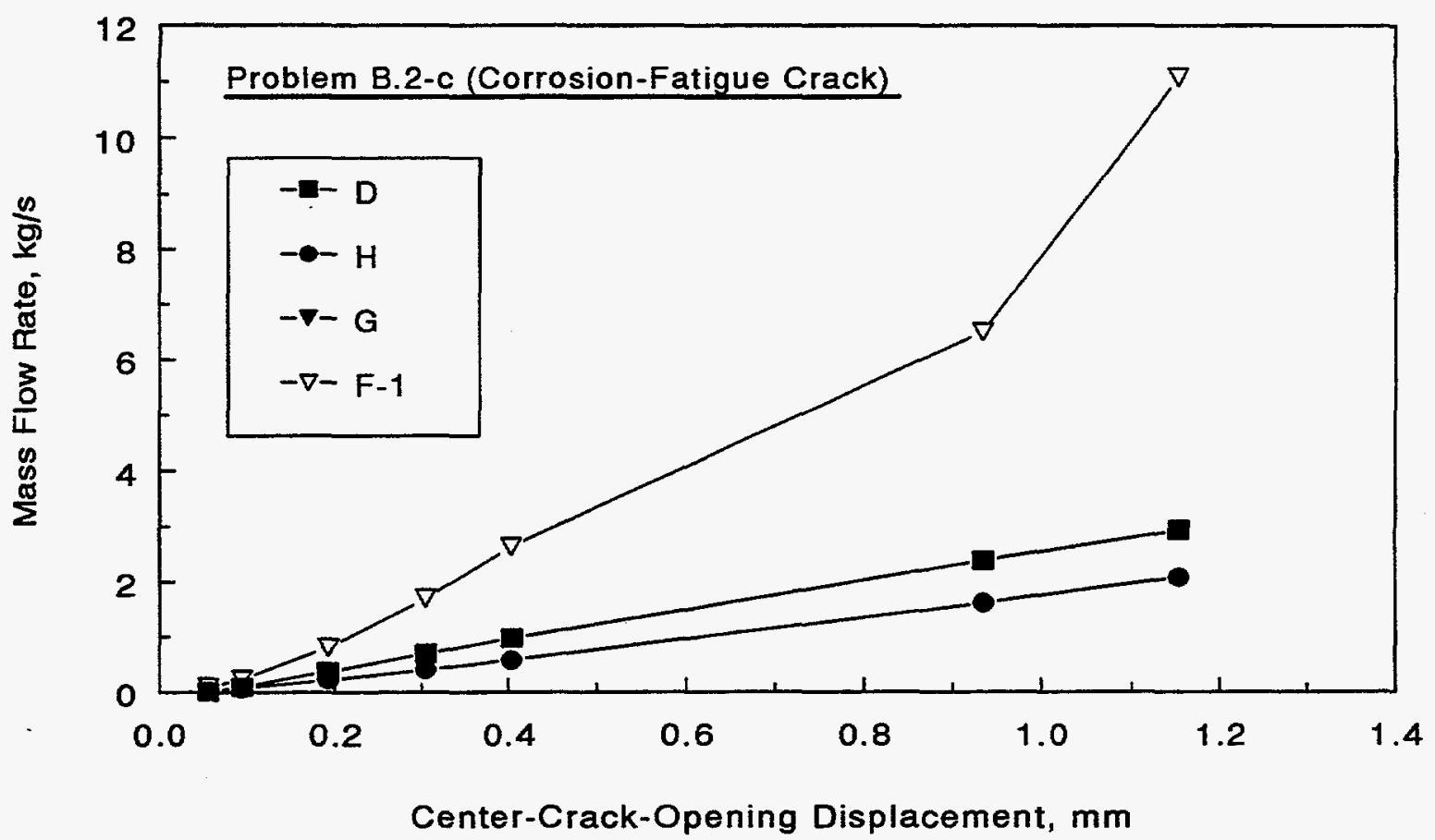

Figure 3.7 Calculated leak rates by various participants for a pipe with a corrosion-fatigue crack (Problem B.2-c)

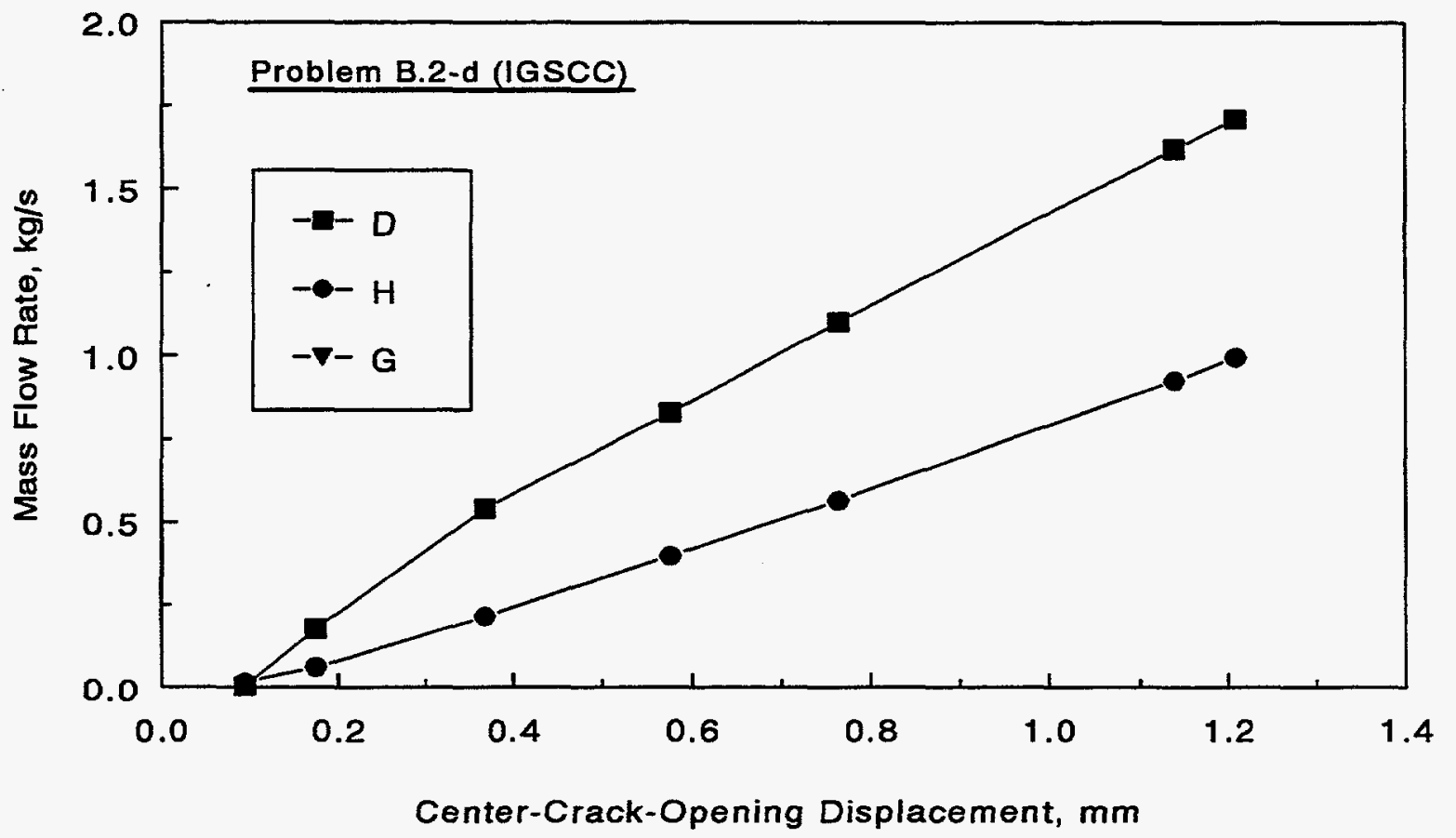

Figure 3.8 Calculated leak rates by various participants for a pipe with an intergranular stress-corrosion crack (Problem B.2-d) 


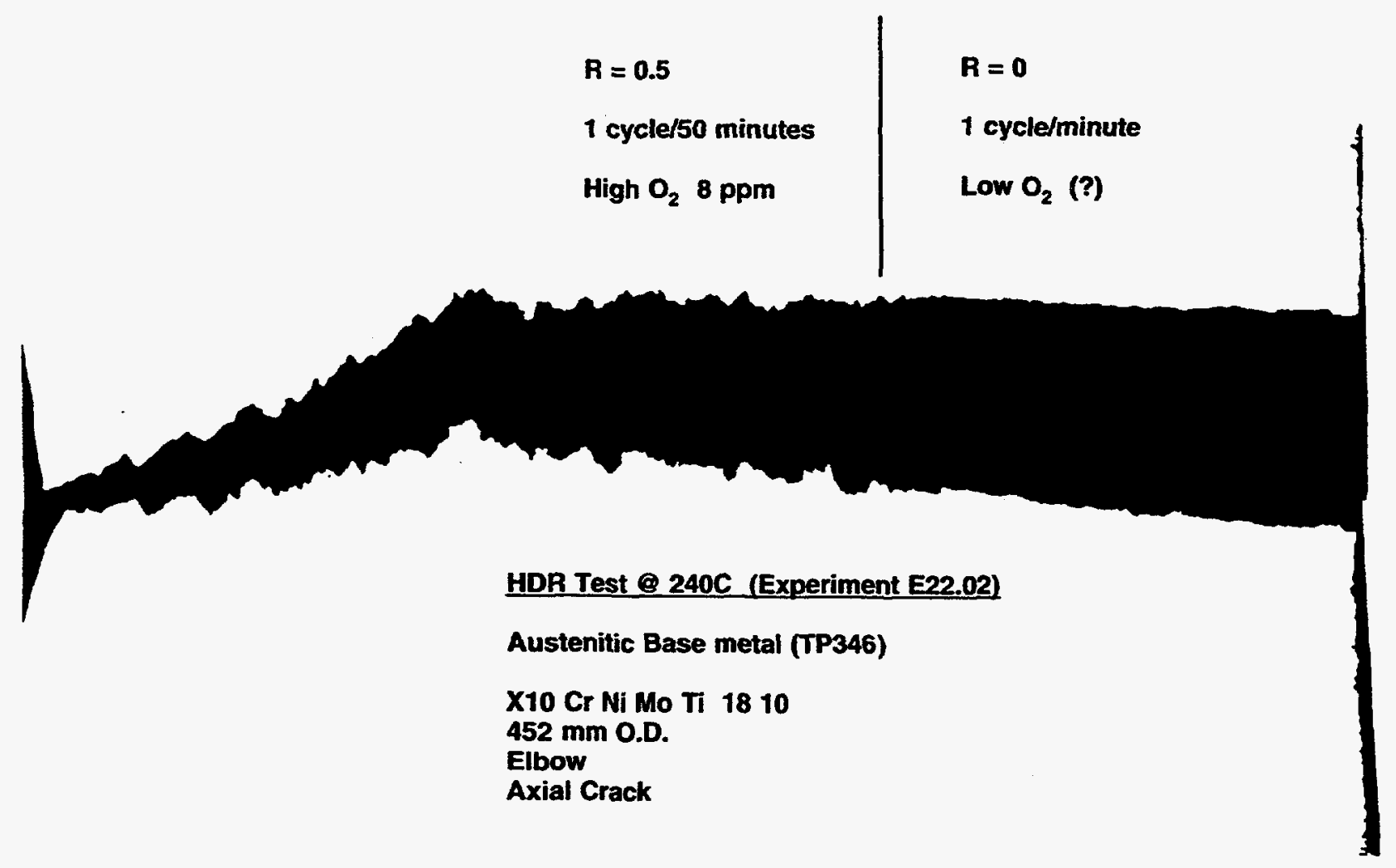

Figure 3.9 Effects of cyclic rate on the crack-morphology variables 


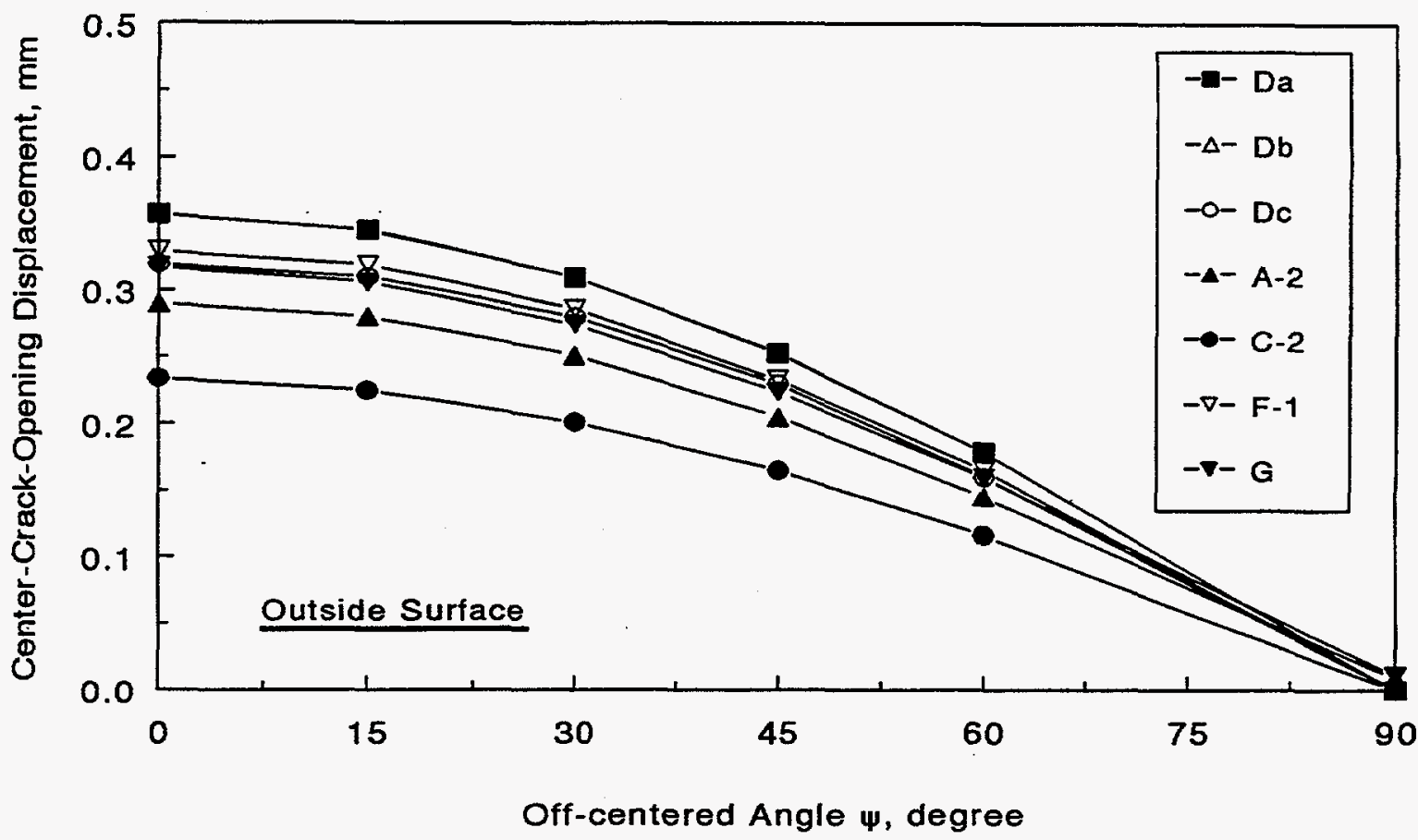

Figure 3.10 Comparisons of predicted center-crack-opening displacements by various participants for pipes with off-centered cracks (Problem B.3)

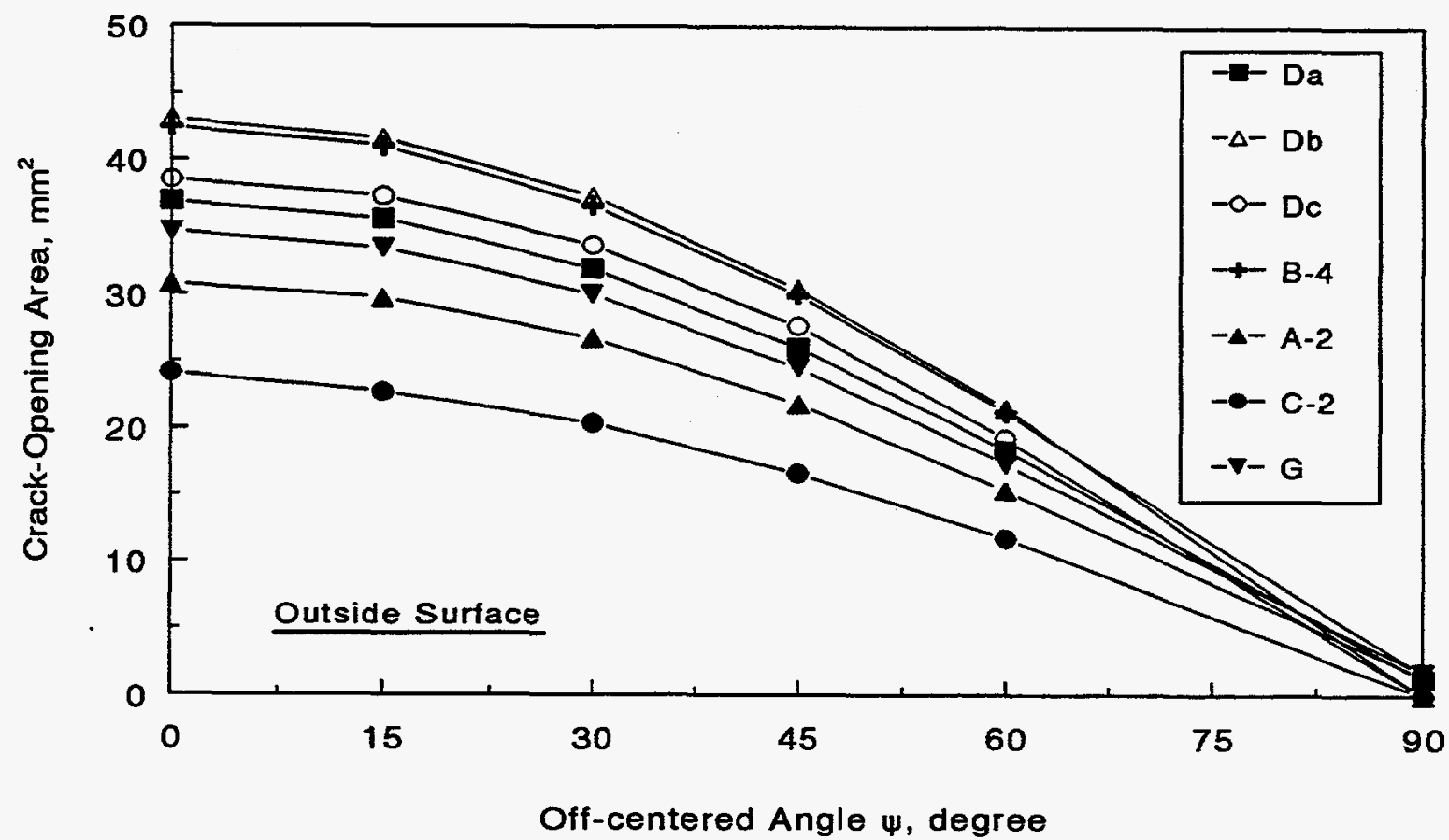

Figure 3.11 Comparisons of predicted crack-opening area by various participants for pipes with off-centered cracks (Problem B.3) 


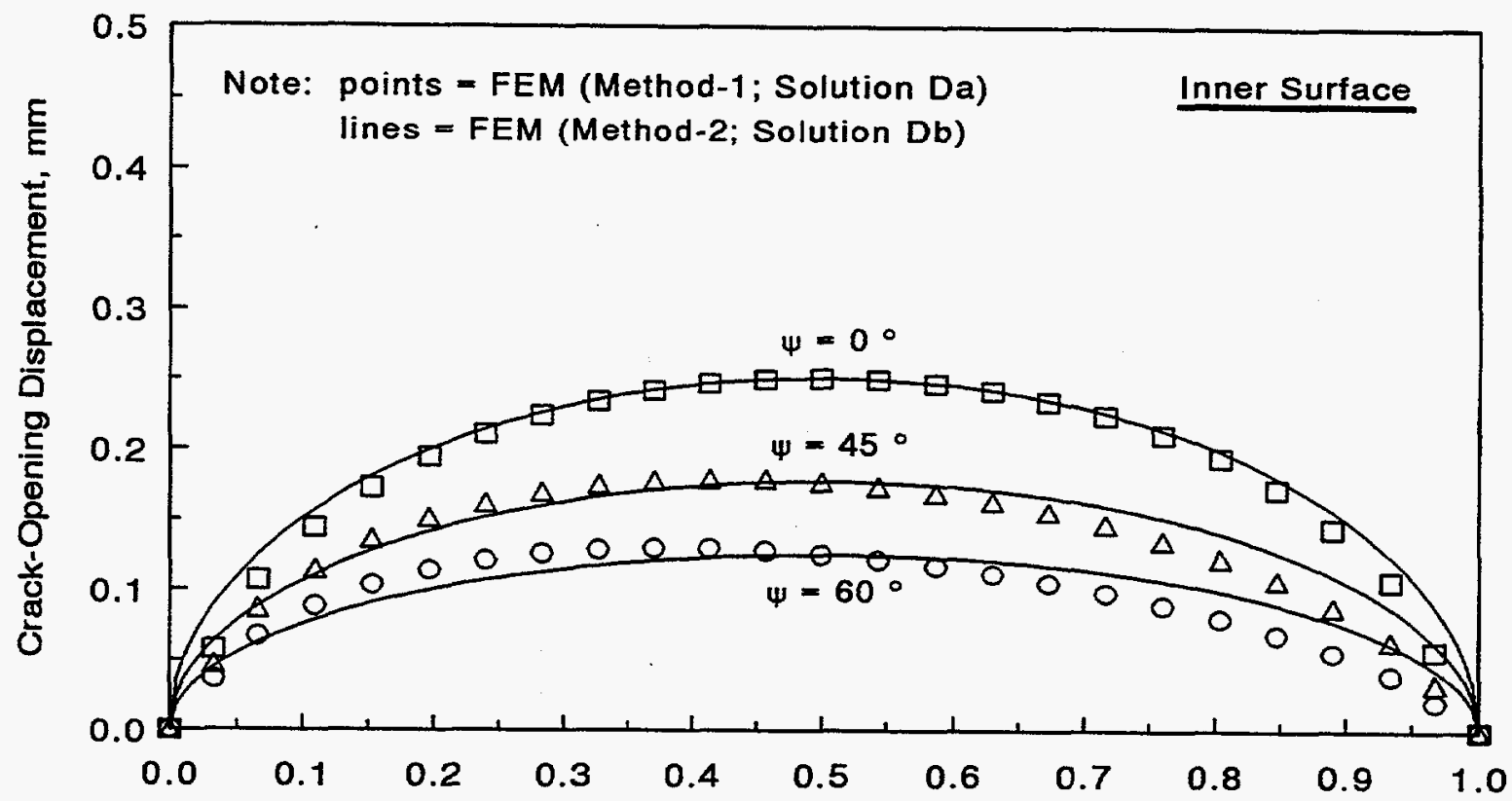

Normalized Crack-Tip Angle, $\xi / 2 \Theta$

Figure 3.12 Comparisons of two finite element solutions from Participant $D$ for crack-opening displacements in pipes with off-centered cracks (inside surface)

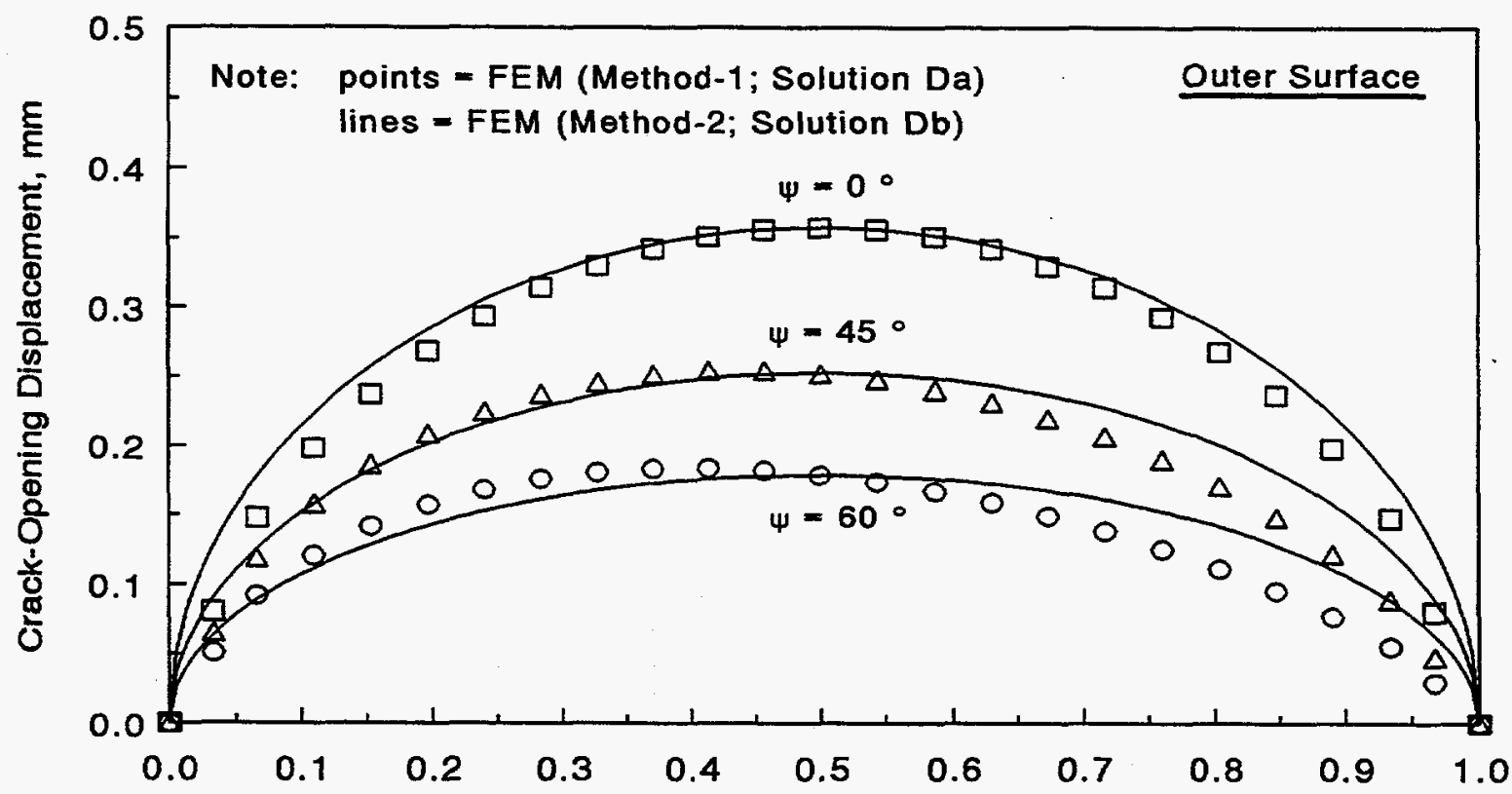

Normalized Crack-Tip Angle, $\xi / 2 \Theta$

Figure 3.13 Comparisons of two finite element solutions from Participant $D$ for crack-opening displacements in pipes with off-centered cracks (outside surface) 
ID

$O D$

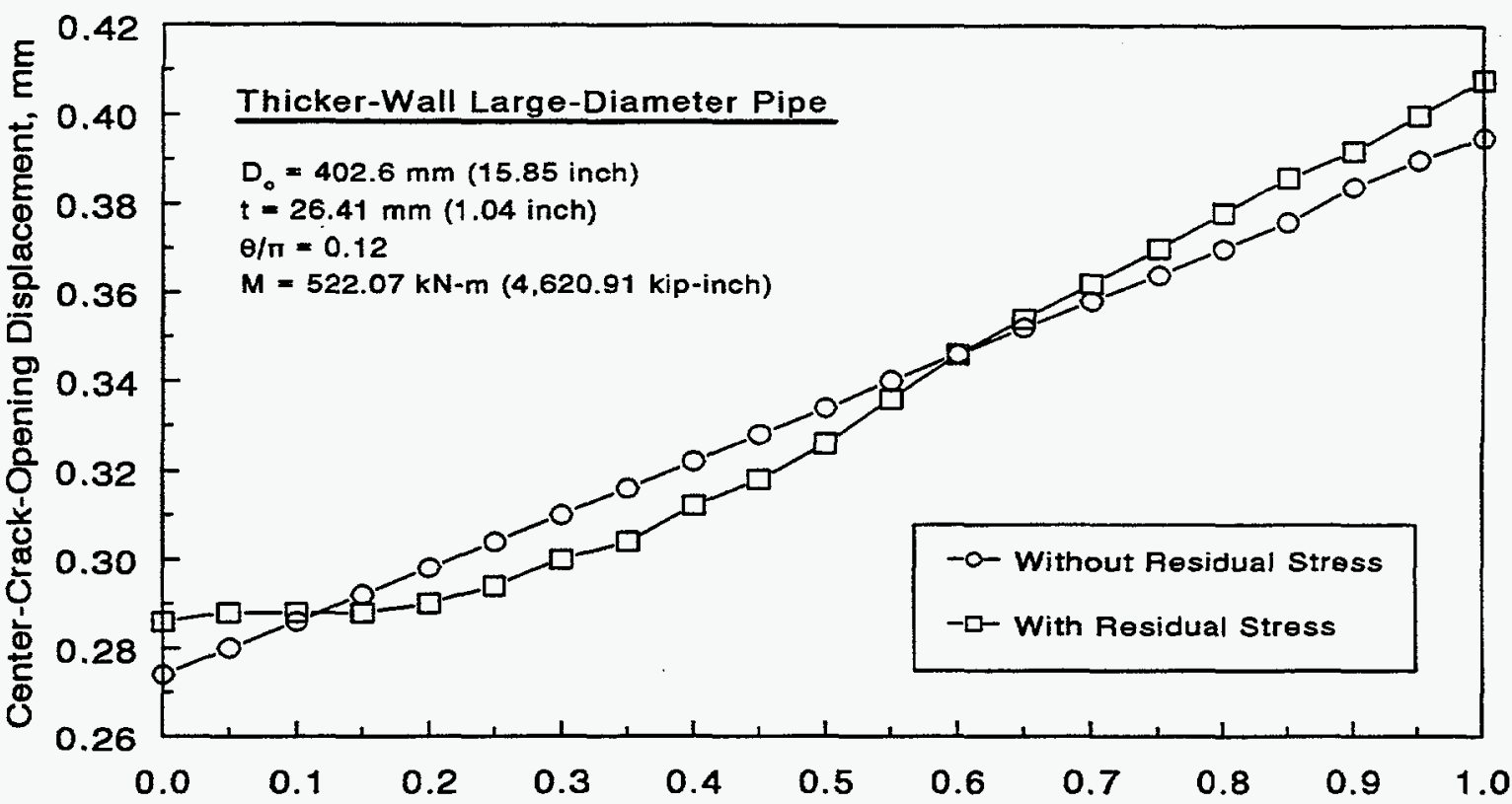

Normalized Distance, $u / t$

Figure 3.14 Effects of residual stresses on the through-the-thickness variation of center-crackopening displacement for a thick-walled large-diameter pipe (Problem B.4-a) 10

$O D$

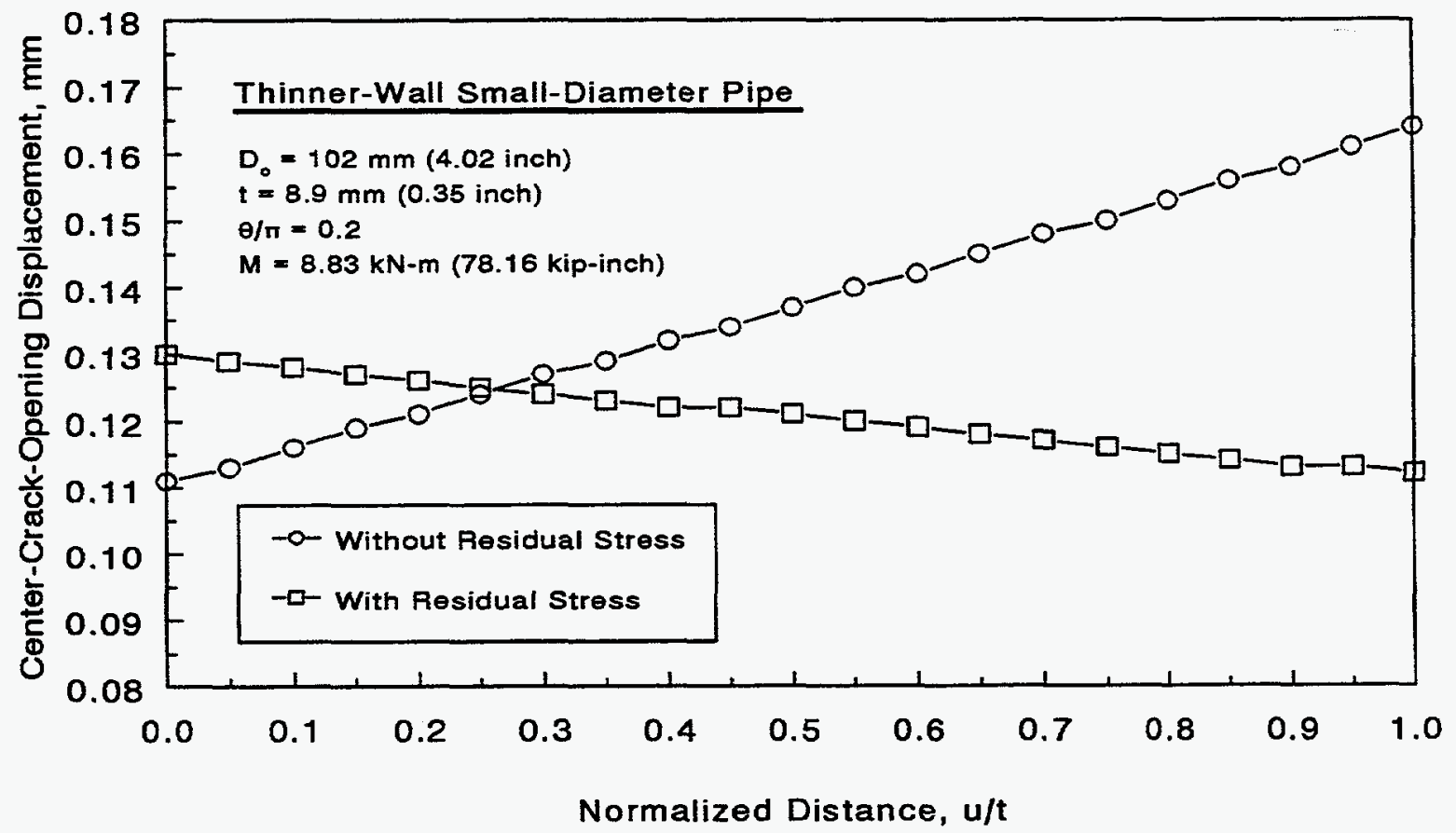

Figure 3.15 Effects of residual stresses on the through-the-thickness variation of center-crackopening displacement for a thin-walled small-diameter pipe (Problem B.4-b) 


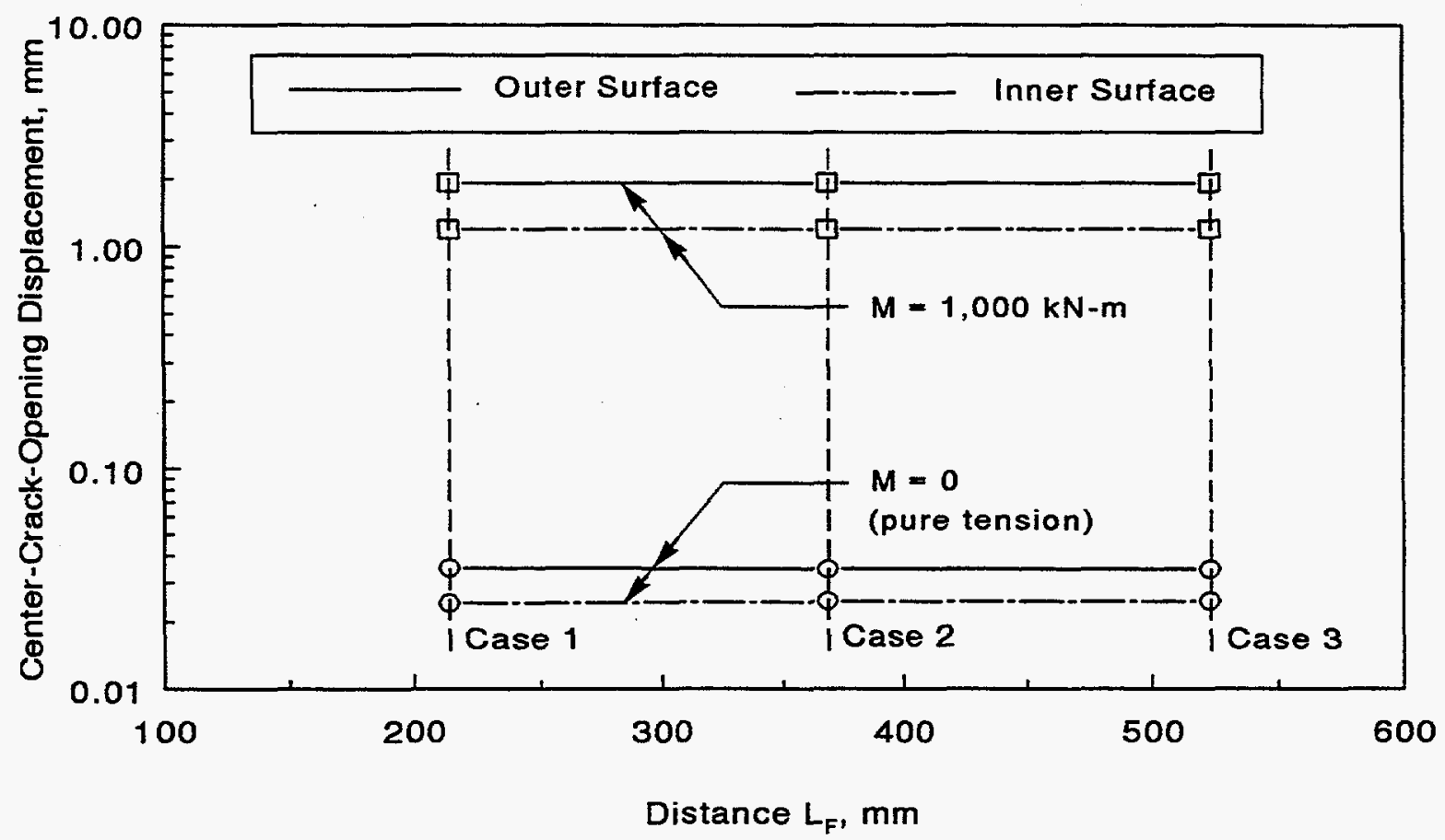

Figure 3.16 Center-crack-opening displacement in a girth weld nozzle versus location of the fixed plane for various applied moments (Problem B.5)

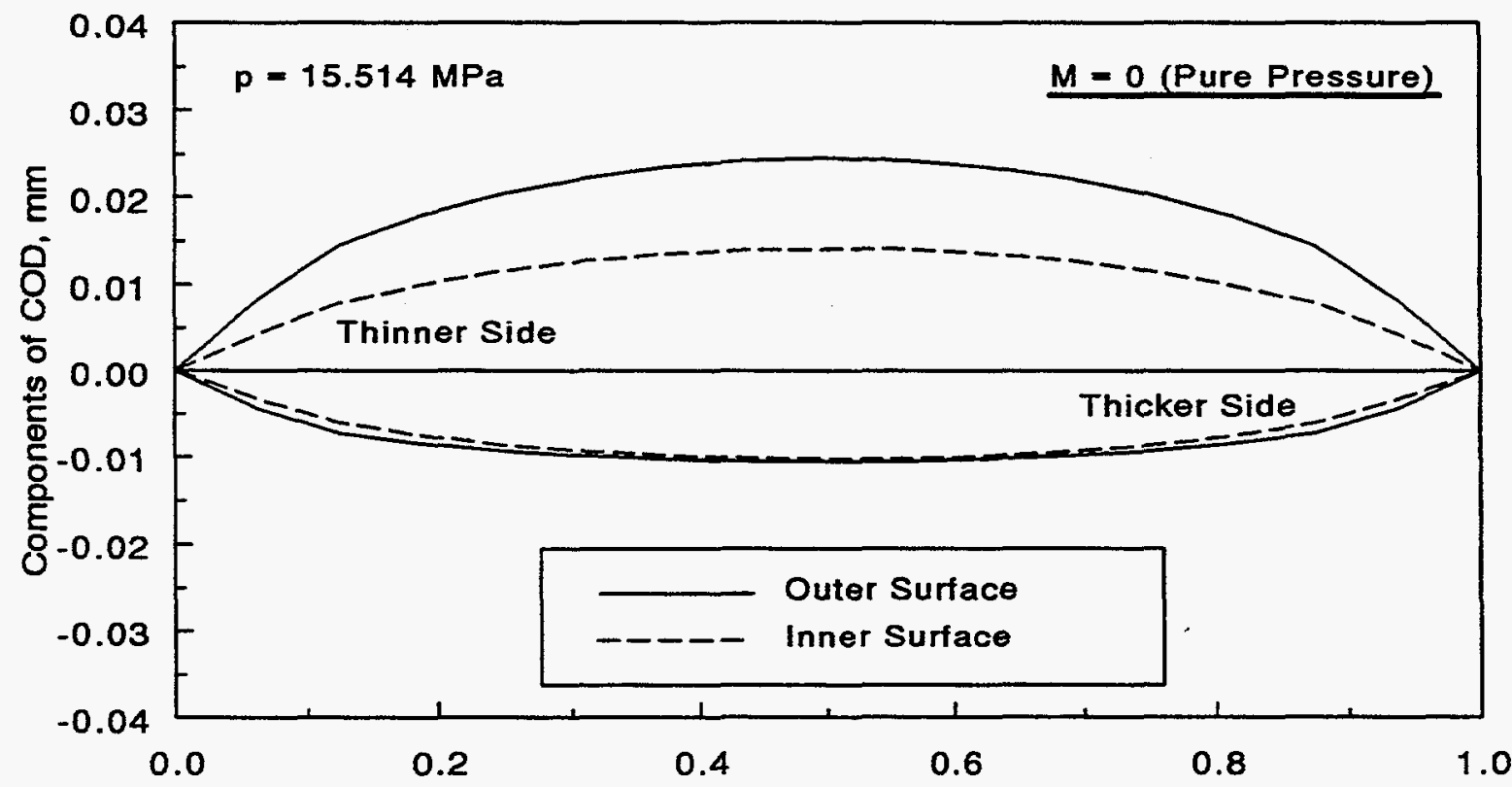

Crack-Tip Distance/Crack Length, $\mathrm{mm}$

Figure 3.17 Predicted crack-opening shapes for a girth weld nozzle with thickness transition under pure tension (Problem B.5) 


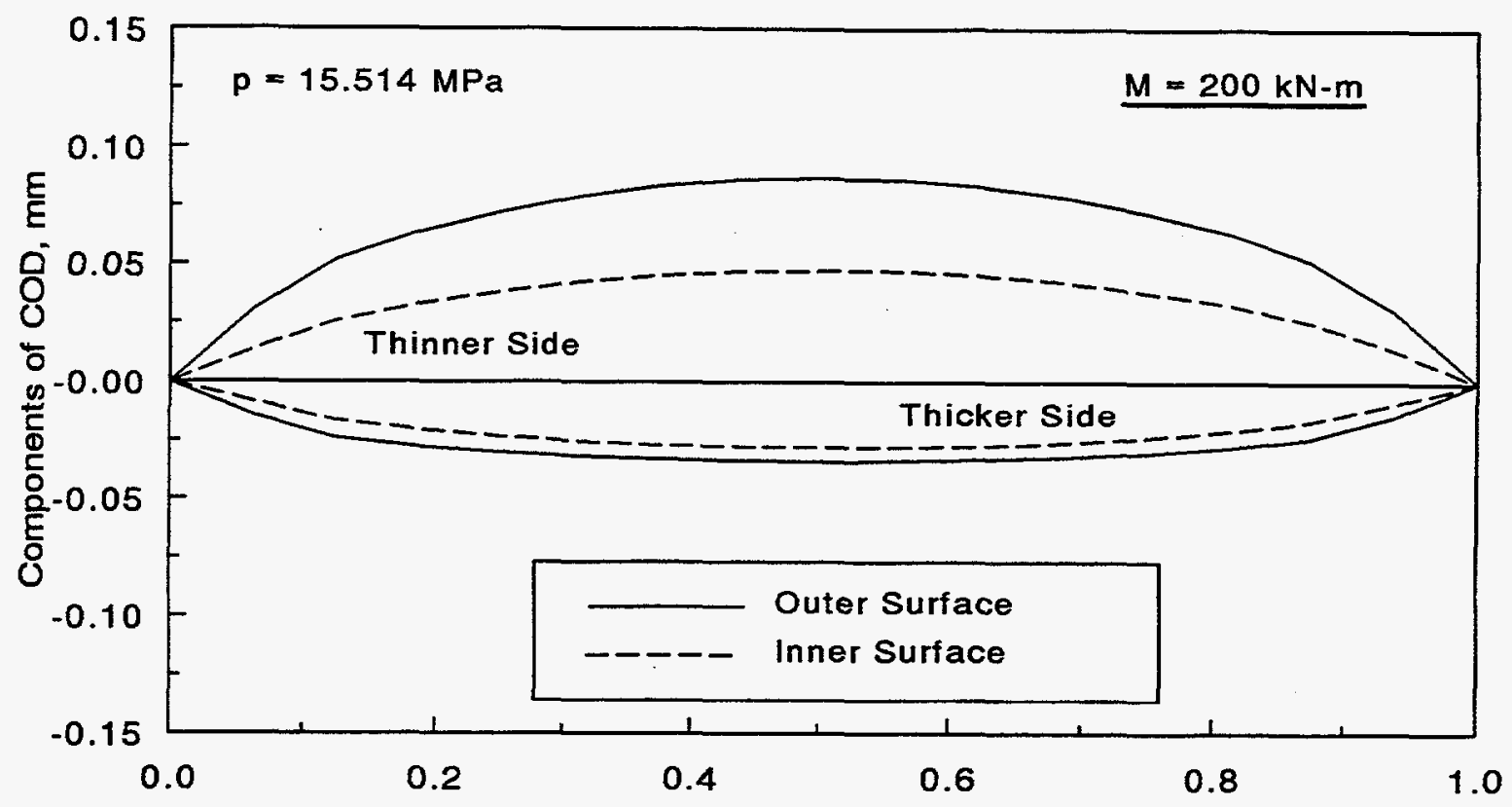

Crack-Tip Distance/Crack Length, mm

Figure 3.18 Predicted crack-opening shapes for a girth weld nozzle with thickness transition under combined bending and tension with $M=200 \mathrm{kN}-\mathrm{m}$ (Problem B.5)

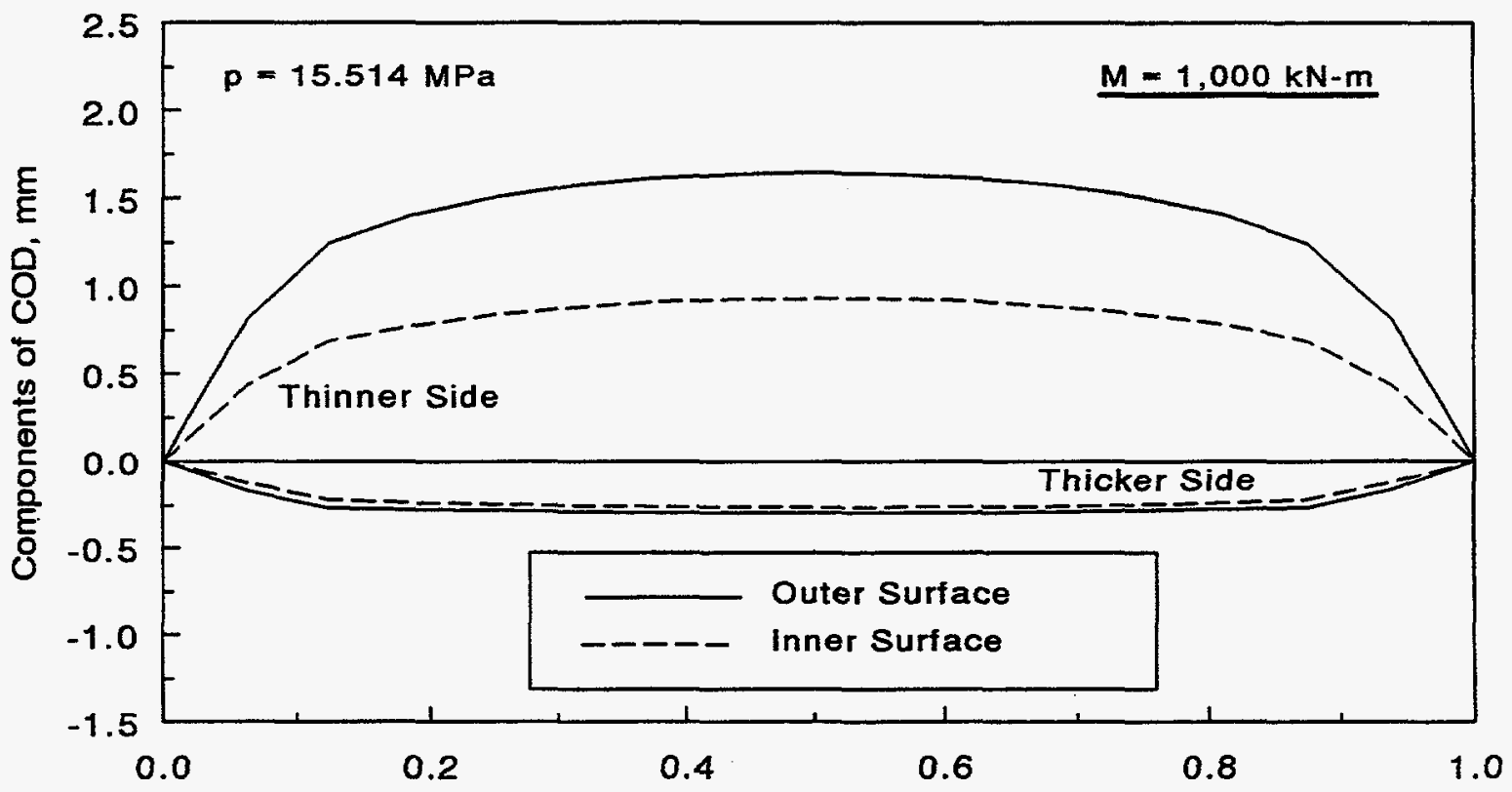

Crack-Tip Distance/Crack Length, $\mathrm{mm}$

Figure 3.19 Predicted crack-opening shapes for a girth weld nozzle with thickness transition under combined bending and tension with $M=1,000 \mathrm{kN}-\mathrm{m}$ (Problem B.5) 


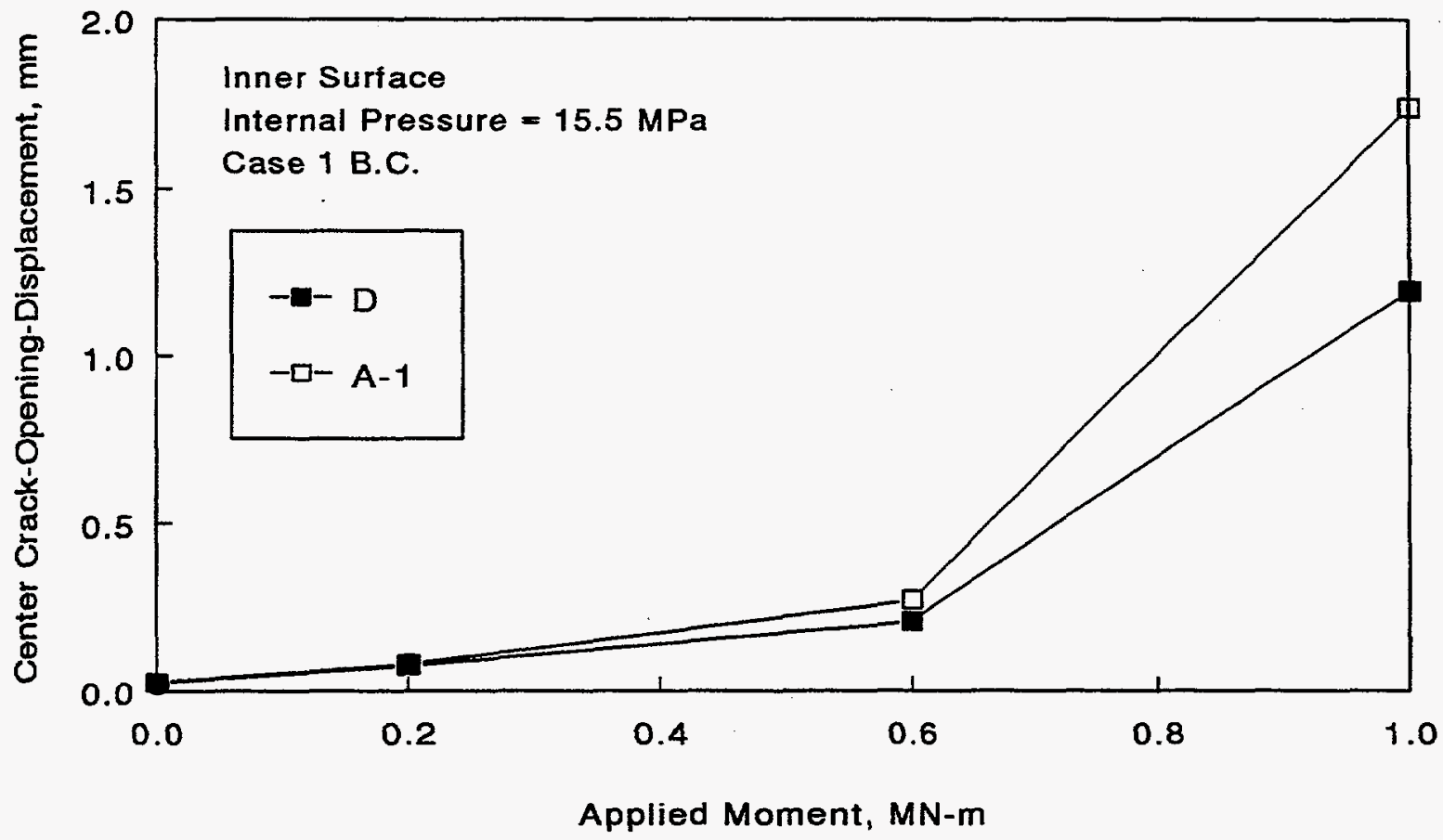

Figure 3.20 Comparisons of predicted center COD at inner surface of a girth weld nozzle by various participants as a function of the applied load (Problem B.5)

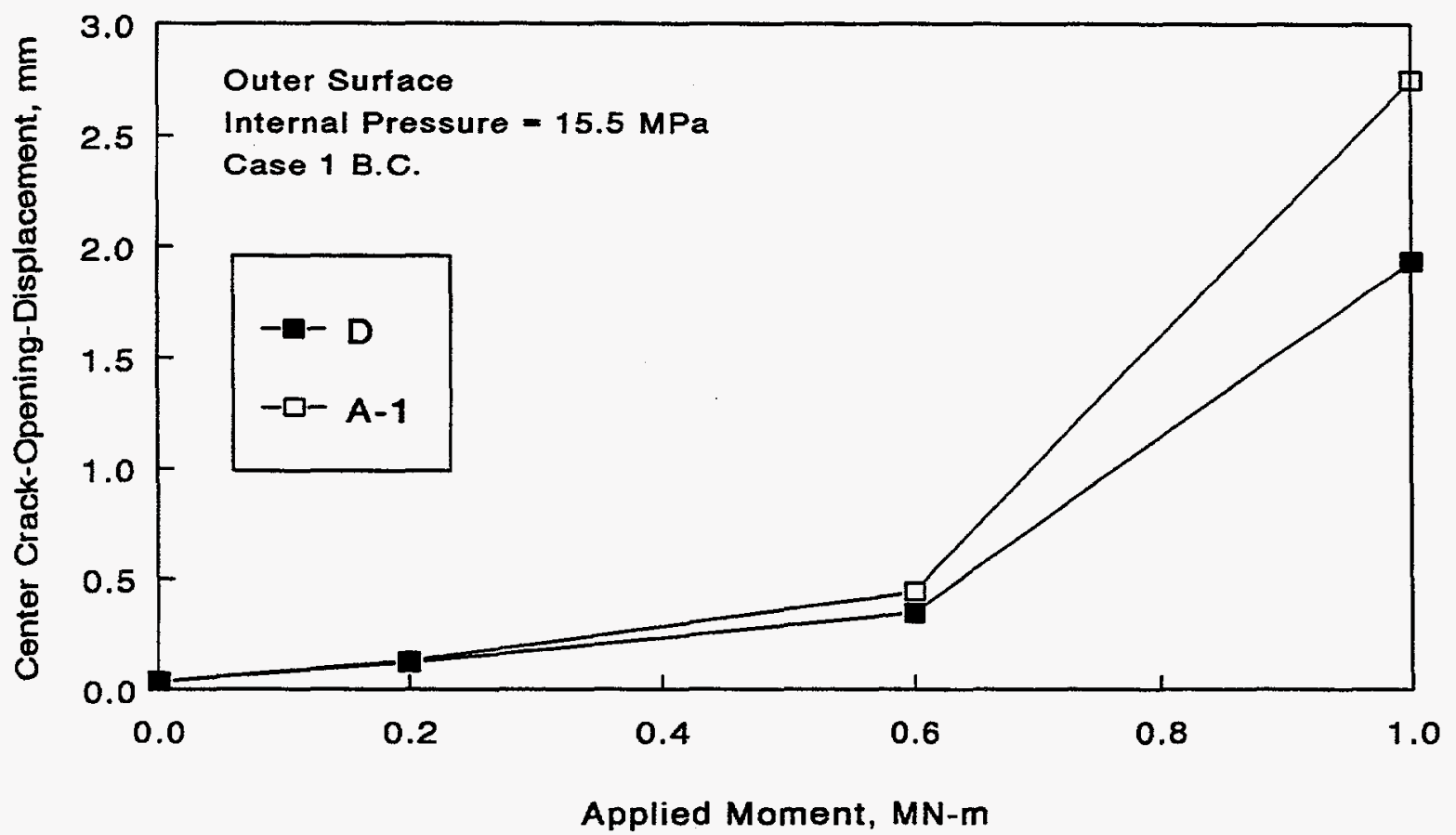

Figure 3.21 Comparisons of predicted center COD at outer surface of a girth weld nozzle by various participants as a function of the applied load (Problem B.5) 


\subsection{ROUND-ROBIN PROBLEM SET C}

\subsection{Round-Robin Problem C.1 - Spectrum-Compatible Time-Histories}

\subsubsection{Problem Definition}

The objective of Problem C.1 was to generate response-spectrum-consistent time histories for the IPIRG pipe system so that possible differences in "equivalent" time histories could be observed. The analysts were given the peak-broadened IPIRG-2 safe-shutdown earthquake (SSE) actuator acceleration response spectrum at 2-percent damping (see Figure 4.1), and were asked to provide a compatible displacement time history limited to $\pm 15 \mathrm{~mm}$. See Appendix $C$ for further details of input. Given the time histories, Battelle then performed linear uncracked pipe stress analyses with the IPIRG pipe system model to determine the moment at the test section so that differences in crack driving potential would be apparent.

\subsubsection{Summary and Conclusions}

The solutions were presented by three participants. All three of the solutions presented were generated using very similar approaches. Acceleration was assumed to be the sum of a number of sine functions with variable amplitudes and with random phase angles. The amplitudes of the sine functions were fixed using an iterative process. The "raw" acceleration signals were then modified by filtering so that when integrated, the prescribed displacement limitations were met. Participants C and D generated one time history each, while Participant F-3 generated two (Solutions F-3a and F-3b) by varying the random phase angles.

All of the time histories met the required displacement limitations and matched the input response spectrum reasonably well, see Figures 4.2 through 4.9. All solutions looked qualitatively similar. Moment-time responses for the four displacement time histories at the measured damping of the IPIRG pipe system (0.5-percent), shown in Figures 4.10 through 4.13, were quite different, however. At 0.5-percent damping, Solution F-3a generated a maximum moment of $467.3 \mathrm{kN}-\mathrm{m}(4,136$ inch-kip) and Solution C generated a maximum moment of only $302.4 \mathrm{kN}-\mathrm{m}$ (2,677 inch-kip). For reference, the actual IPIRG-2 "SSE" loading spectrum, displacement time history, and moments from linear analysis are shown in Figures 4.14, 4.15, and 4.16, respectively. Table 4.1 summarizes the predicted moments by various participants and actual data from the IPIRG pipe system experiment.

There was no controversy regarding solution techniques, and the approaches followed made good sense for this particular problem. Surprisingly, there was a factor of 1.55 difference between the largest and smallest (excluding the IPIRG-2 result) crack opening moments. Upon inspection of the linear analysis solutions, it was discovered that the spectra were calculated at 2-percent damping, while the linear stress analysis was done at 0.5-percent damping. Because this would have an impact on the maximum and minimum moments, the linear analyses were repeated using 2-percent damping.

Moment results at 2-percent damping for the four artificial time histories are shown in Figures 4.17 through 4.20. Not surprisingly, the maximum moments have dropped substantially [more than 150 $\mathrm{kN}-\mathrm{m}(1,327$ inch-kips)] and the difference between the largest and smallest maximum moments is 
only a factor of 1.21, when the 0.5-percent and 2-percent damping cases are compared. Participant C's solution still tends to be rather "smaller" than the others, and the two Participant F-3 solutions remain somewhat different from one another. Overall, the buildup to the largest-amplitude moment cycles is quite different among the four solutions, and this could in turn influence potential crack behavior.

To summarize, four different but "equal" displacement time histories were created from a peakbroadened acceleration response spectrum. The resulting time histories were fairly equal in terms of maximum moment induced in a linear finite element model of the IPIRG piping system (within 20 percent). There are, however, noticeable differences in the number of cycles to reach maximum moment and the manner in which the moment builds up, which suggests that a flaw may survive one of the time histories, but may leak when subjected to a different, but "equal" time history.

On the basis of what was learned in Round-Robin Problem C.1, it is probably reasonable to conclude that as long as care is exercised is the analyses, spectrum-compatible time histories are reasonably "equal" in terms of maximum moment. It is not clear, however, that merely being consistent with a given input spectrum is any guarantee that one will have upper bound, lower bound, or average crack driving potential, due to dynamic and history effects. This comment certainly applies to the IPIRG simulated seismic forcing function, and probably applies to other analyses that use spectrumcompatible time history excitations as well. Other prescriptions on spectrum matching are probably required to give bounding behavior.

\subsection{Round-Robin Problem C.2-a - Analysis of IPIRG-2 Seismic Surface- Cracked Pipe System Experiment}

\subsubsection{Problem Definition}

The objective of Problem C.2-a $\mathrm{a}^{(\mathrm{a})}$ was to make blind predictions of the fracture behavior for the IPIRG-2 simulated seismic stainless steel surface-cracked pipe test, Experiment 1-1. Appendix C has input details for this problem. Predictions of maximum moment and an estimate of when the maximum moment would be achieved in a prescribed seismic time history were requested.

Participants were free to use code approaches or more detailed fracture mechanics approaches to make the maximum moment prediction. The time at attainment of the maximum moment was to be estimated from a Battelle-supplied time-history stress analysis or an analysis done by the participant. Results of the predictions were compared with the observed experimental behavior.

The primary known factors were the test section dimensions and initial flaw geometry, material properties, test conditions, and results of a finite element stress analysis of the IPIRG-2 pipe system with seismic loading. The initial flaw geometry for Experiment 1-1 is shown in Figure 4.21. Flaw location material properties were provided at four different levels of detail:

(a) Problem C.2-a was known as Problem C.2 in the Second IPIRG-2 Round-Robin workshop. This revision is needed due to the creation of Problem C.2-b presented in the Third IPIRG-2 Round-Robin workshop. 
- Level 1: Knowing only that the material was ASTM A358 TP304 stainless steel.

- Level 2: The information from Level 1 plus typical mill test property data at room temperature, see Table 4.2.

- Level 3: The information from Levels 1 and 2 plus quasi-static tensile and J-R curve data at $288 \mathrm{C}(550 \mathrm{~F})$, see Figures 4.22 and 4.23.

Level 4: The information from Levels 1 through 3 plus dynamic tensile and dynamic J-R curve data at $288 \mathrm{C}(550 \mathrm{~F})$, see Figures 4.22 and 4.23.

The Battelle-supplied stress analysis results consisted of an elastic uncracked pipe finite element analysis of the IPIRG pipe system using the Experiment 1-1 loading. The pipe system geometry is shown in Figure 4.24, the simulated seismic forcing function is shown in Figure 4.25, and the elastic analysis moment-time history at the crack location is shown in Figure 4.26. Finite element results were supplied from $T=0$ seconds to $T=23.5$ seconds at 0.005 second increments. The elastically calculated loads at the crack location were separated into various components to facilitate use of analysis approaches where different stress components have different "safety factors". Static analysis data for thermal-only and pressure-only loading were also given. For participants that wanted to perform their own finite element pipe stress analysis, detailed dimensions, material property data, and loading for Experiment 1-1 were supplied.

The problem statement requested solutions for maximum moment and estimated time to attainment of maximum moment at each of the four levels of material property specification. Three members, identified as Participants C, D, and F-3, solved this problem.

\subsubsection{Summary and Conclusions}

The prediction of the maximum moment using four different material property specifications provides some indication of the possible range of predicted flaw behavior. At the first two levels of material property specification, engineering judgement must be used to estimate the properties needed to make the moment predictions. Because of the limited amount of information at the first two material property specification levels, the choices for methods to predict the moment are quite limited. With more detailed information available for the third and fourth levels of material property specification, the opportunity presents itself to use different, and potentially more sophisticated, fracture analyses.

For the solutions to Round-Robin Problem C.2-a, all three participants used a limit-load solution (Ref. 4.1) for Levels 1 and 2, but used different approaches to define the flow stress. For Levels 3 and 4, the participants used a variety of prediction techniques: limit load, GE/EPRI solutions (Refs. 4.2 and 4.3), the JSIN method, and the SC.TNP1 J-estimation scheme (Ref. 4.4). Multiple solutions were offered by some of the participants.

For the second part of the problem, determination of when maximum moment would be attained during a given seismic time history, the Battelle-supplied linear-elastic analysis results considering the total moment (pressure + thermal + seismic anchor motion + inertial) was used by all participants. No nonlinear analyses were performed by any of the participants. Battelle did offer the result of their 
pretest nonlinear cracked pipe experiment design prediction, $502 \mathrm{kN}$-m $(4,443$ inch-kip) with no surface crack penetration using an ideal 66-percent deep 180-degree flaw as a reference point.

Tables 4.3 and 4.4 summarize the predictions of maximum moment and time for attainment of the maximum moment made for Problem C.2-a. The lowest prediction was a Level 1 prediction of 347 $\mathrm{kN}-\mathrm{m}$ (3,071 inch-kip), while the highest was a solution at Level 4 at $959 \mathrm{kN}-\mathrm{m}(8,488 \mathrm{inch}$-kip). For reference, the IPIRG Experiment 1-1 results for maximum moment, moment at surface crack penetration, and time of attainment are also given in Tables 4.3 and 4.4.

The results presented by Participant F-3 were the most consistent, within the various levels of material property specification. The Participant $C$ results tended to be quite high, when compared with the other solutions. The solutions offered by Participant $D$ showed fairly wide scatter. Nearly all of the solutions showed a predicted increase in moment carrying capacity using measured dynamic properties when compared with the solutions using quasi-static properties. Comparing the predictions with the experimental result, some of them overestimated the flaw moment capacity.

All of the maximum moments were predicted to be attained during the IPIRG-2 simulated seismic loading, based on a linear stress analysis. The reason that this is so is because the linear stress analysis, in this case, tends to overestimate the stresses at the crack location.

All but one of Participant F-3's nine predicted maximum moments was below the maximum moment applied to the Experiment 1-1 specimen. Participants C and D had one of four and one of five predictions below the maximum applied moment, respectively. The predicted moment carrying capacities that were greater than the maximum applied moment in the experiment cannot strictly be interpreted as unconservative; because the loading was not increased continuously, there is no way to tell if the crack could have sustained a higher load. Because none of the analyses includes cyclic compressive damage or fatigue crack growth, none of the analyses can predict surface crack penetration at a moment below the maximum applied moment.

Concerning the nonlinear analysis of IPIRG-2 Experiment 1-1, Battelle's pretest predictions used an idealized 66-percent deep, 180-degree initial flaw. The predicted maximum moment capacity, with this flaw size, was $502 \mathrm{kN}-\mathrm{m}(4,443$ inch-kip) and it was not predicted to be attained during the given loading. Because the maximum moments predicted by many of the participants were substantially higher than $502 \mathrm{kN}-\mathrm{m}$ (4,443 inch-kip), surface crack penetration, presumably, would not be predicted using a nonlinear analysis. This is a somewhat disappointing result in light of the previously good predictions using nonlinear analysis made in IPIRG-1. The limitation is in the fracture (J-estimation scheme) analysis because all the nonlinear analysis does is ensure that the applied loads are correct.

In summary, the results suggest that there can be substantive differences between predicted momentcarrying capacities of flawed pipe, depending on which analysis methods are used and what material properties are known. "Better" knowledge of the stress-strain and J-resistance properties of the material, however, did not necessarily ensure a more accurate prediction of moment-carrying capacity. The fact that some of the predictions overestimated the moment-carrying capacity is a concern. There is no way to be certain that all of the equations have been correctly applied, but it has to be assumed that the calculations have been done correctly. Linear elastic stress analyses with 
realistic damping (i.e., damping that is not made artificially high to simulate the potential effects of crack location plasticity), tends to overpredict crack location stresses. When such a linear stress analysis is coupled with a contemporary fracture analysis method, the results will be biased towards predicting crack growth under the given load.

\subsection{Round-Robin Problem C.2-b - Reconsideration of IPIRG-2 Seismic Surface-Cracked Pipe System Experiment}

\subsubsection{Background}

Blind prediction of the IPIRG-2 stainless steel base metal seismic loading surface-cracked pipe system experiment, IPIRG-2 Experiment 1-1, was done as Round-Robin Problem C.2-a. As a part of that exercise, participants were offered the opportunity to perform their own IPIRG pipe system stress analysis. The problem statement for Round-Robin Problem C.2-a defined the IPIRG pipe system in great detail in terms of an ANSYS finite element model (Ref. 4.5), in case any of the participants wanted to perform their own linear or nonlinear analysis. Several inconsistencies in the ANSYS pipe system model geometry and seismic loading function were noted by the round-robin participants. Because some of the members wanted to conduct finite element analyses of the IPIRG pipe system, it was suggested that Round-Robin Problem C.2-a be reconsidered as Round-Robin Problem C.2-b.

\subsubsection{Problem Definition}

The objective of Problem C.2-b was to make predictions of the crack behavior for the IPIRG-2 simulated seismic stainless steel surface-cracked pipe test, Experiment 1-1, using the exact pipe loop geometry and Experiment 1-1 forcing function. The problem definition is as described for RoundRobin Problem C.2-a (see Section 4.2.1): four increasingly more detailed material property specifications and a requirement to predict the maximum moment capacity and time to reach that maximum capacity under a prescribed seismic time history.

\subsubsection{Summary and Conclusions}

Three participants offered solutions to Round-Robin Problem C.2-b. Two participants, F-3 and C, revised the solutions that they offered for Problem C.2-a. Participant A-3 offered a new solution. Tables 4.5 and 4.6 summarize the predictions for Problem C.2-b by the various participants. The revised maximum moment solutions of Participant F-3 were the product of modest refinements of their estimates of the flow stress. Participant $\mathrm{C}$ revised their Level 2 solution by using a different scheme for scaling the room temperature data to $288 \mathrm{C}(550 \mathrm{~F})$, and they revised their Levels 3 and 4 results by using different Ramberg-Osgood stress-strain coefficients. In addition, Participant $\mathrm{C}$ repeated the calculations for an equivalent crack length $(\theta / \pi=0.383)$. The moment solutions offered by Participant $A-3$, are based on similar techniques to those used by the others.

Prediction of when maximum moment would be reached was done by a variety of different methods; Participant F-3 performed their own linear finite element stress analysis, Participant $\mathbf{C}$ used the original Battelle-supplied linear stress analysis, and Participant A-3 performed a nonlinear stress 
analysis. Of particular interest was Participant A-3's approach, in that they performed 3D solid analysis of a cracked pipe using the stress-strain information from the various property specification levels to find moment-rotation response of the crack. They then used the moment-rotation response to define a nonlinear spring in a standard pipe element time-history stress analysis.

The predicted time to maximum moment for Participant F-3 did not change substantially from their original estimates given for Round-Robin Problem C.2-a. Differences were noted, however, between the Battelle-supplied time-history and Participant F-3's time history, probably related to the refinements of the geometry in Participant F-3's model.

Participant C's predicted time to reach maximum moment changed substantially from Round-Robin Problem C.2-a by virtue of the significant increase in predicted maximum moment. Participant A-3's results show significant differences between the linear and nonlinear results (see Level 4 results, for instance). Plasticity at the crack location absorbs energy making it harder to propagate the crack. This result is consistent with Battelle's original pretest design analyses which suggested that an ideal 66-percent deep 180-degree long flaw would not reach a maximum moment of $502 \mathrm{kN}$-m $(4,443$ inch-kip).

The following summarizes the findings from Round-Robin Problem C.2-b:

- At Level 1, less scatter in the results was expected, in light of the fact that all solutions were based on the same basic procedure.

- "Better" knowledge of properties did not necessarily ensure a more accurate prediction

- $\quad$ Flaw size assumptions dramatically affect the predicted moment

- Cyclic damage and low cycle fatigue are not considered which affect the moment carrying capacity

- The specific load history applied in the experiment influences the maximum moment observed - the moment observed is not necessarily the capacity

- Nonlinearity caused by plasticity rather dramatically alters the moment that can be applied at the crack. Whether the plasticity is from the crack or in remote piping, energy input to the system will be absorbed and be unavailable to help propagate the crack.

\subsection{References}

4.1 Kanninen, M. F. and others, "Mechanical Fracture Predictions for Sensitized Stainless Steel Piping with Circumferential Cracks," EPRI Report NP-192, Electric Power Research Institute, Palo Alto, CA, September 1976. 
4.2 Kumar, V., German, M., and Shih, C., "An Engineering Approach for Elastic-Plastic Fracture Analysis,” EPRI Report NP-1931, Electric Power Research Institute, Palo Alto, CA, July 1981.

4.3 Kumar, V., German, M., Wilkening, W., Andrews, W., deLorenzi, H., and Mowbray, D., “Advances in Elastic-Plastic Fracture Analysis," EPRI Final Report NP-3607, Electric Power Research Institute, Palo Alto, CA, August 1984.

4.4 Krishnaswamy, P., Scott, P., Mohan, R., Rahman, S., Choi, Y., Brust, F., Kilinski, T., Francini, R., Ghadiali, N., Marschall, C., and Wilkowski, G., "Fracture Behavior of Short Circumferentially Surface-Cracked Pipe," NUREG/CR-6298, U.S. Nuclear Regulatory Commission, Washington, D.C., November 1995.

4.5 ANSYS, User's Guide, Theoretical Manual, and Seminar Notes, Version 5.1, Swanson Analysis Systems, Inc., Houston, PA, 1994. 
Table 4.1 IPIRG pipe system moment response summary using spectrum-compatible displacement time histories and linear stress analysis

\begin{tabular}{ccc}
\hline Solution & $\begin{array}{c}\text { Maximum Moment, } \\
\mathbf{k N}-\mathbf{m}\end{array}$ & $\begin{array}{c}\text { Minimum Moment, } \\
\mathbf{k N}-\mathbf{m}\end{array}$ \\
\hline C & 302.4 & -50.2 \\
D & 370.3 & -174.2 \\
F-3a & 467.3 & -249.2 \\
F-3b & 360.5 & -174.2 \\
IPIRG & 273.0 & -65.1 \\
\hline
\end{tabular}

Table 4.2 Level-2 tensile properties at room temperature for Problems C.2-a and C.2-b(a)

\begin{tabular}{cc}
\hline Property & Value \\
\hline Yield Strength, MPa (ksi) & $295(42.8)$ \\
Ultimate Strength, MPa (ksi) & $743(107.8)$ \\
Elongation, percent & 75.9 \\
\hline
\end{tabular}

(a) Data obtained from Specimen A8-35 from NUREG/CR-2175 
Table 4.3 Maximum moment predictions for IPIRG-2 Experiment 1-1 in Problem C.2-a

\begin{tabular}{|c|c|c|c|c|c|c|c|c|}
\hline \multirow{3}{*}{$\begin{array}{c}\text { Material } \\
\text { Property } \\
\text { Specification }\end{array}$} & \multicolumn{6}{|c|}{ Participant } & \multirow{3}{*}{$\begin{array}{c}\text { Linear FEA } \\
\text { Moment, } \\
\text { kN-m }\end{array}$} & \multirow{3}{*}{$\begin{array}{c}\text { IPIRG-2 } \\
\text { Expt. 1-1 } \\
\text { Moment, } \\
\text { kN-m } \\
\end{array}$} \\
\hline & \multicolumn{2}{|l|}{ F-3 } & \multicolumn{2}{|l|}{$\mathrm{C}$} & \multicolumn{2}{|l|}{$\mathbf{D}$} & & \\
\hline & Method & $\begin{array}{c}\text { Moment, } \\
\text { kN-m }\end{array}$ & Method & $\begin{array}{c}\text { Moment, } \\
\text { kN-m }\end{array}$ & Method & $\begin{array}{c}\text { Moment, } \\
\mathrm{kN}-\mathrm{m}\end{array}$ & & \\
\hline Level 1 & $\begin{array}{l}\text { Limit Load } \\
\text { Limit Load } \\
\text { Li,3 }\end{array}$ & $\begin{array}{l}347 \\
550\end{array}$ & Limit Load 7,8 & 420 & $\begin{array}{l}\text { Limit Load } \\
\text { Limit Load } \\
\text { Lin }\end{array}$ & $\begin{array}{l}580 \\
474\end{array}$ & & 598 \\
\hline Level 2 & Limit Load ${ }^{2,4}$ & 778 & Limit Load ${ }^{7,9}$ & 904 & Limit Load ${ }^{2,12}$ & 828 & & maximum \\
\hline Level 3 & $\begin{array}{c}\text { Limit } \text { Load }^{2,4} \\
\text { JSIN }^{2,5} \\
\text { JSIN }^{2,6}\end{array}$ & $\begin{array}{l}589 \\
519 \\
546\end{array}$ & GE/EPRI ${ }^{8}$ & 933 & SC.TNP1 ${ }^{2}$ & 681 & 1143 & $\begin{array}{c}509 \mathrm{SC} \\
\text { penetration }\end{array}$ \\
\hline Level 4 & $\begin{array}{c}\text { Limit Load } \\
\text { JSIN }^{4} \\
\text { JSIN }^{5}\end{array}$ & $\begin{array}{l}576 \\
539 \\
570\end{array}$ & GE/EPRI ${ }^{8}$ & 959 & SC.TNP1 ${ }^{2}$ & 702 & & \\
\hline
\end{tabular}

1 using $\sigma_{\text {ref }}$ from level D ASME

$2 \theta / \pi=0.383$

3 using $\sigma_{\text {ref }}$ from RCCM

4 using $\sigma_{\text {ref }}$ from $\sigma_{\mathrm{f}}$

5 engineering stress-strain

6 true stress-strain
$7 \sigma_{\mathrm{f}}$ from ASME Section III

$8 \theta / \pi=0.527$

$9 \sigma_{\mathrm{f}}$ scaled using $\mathrm{E}$ from RT data to $288 \mathrm{C}$

10 avg $\sigma_{\mathrm{y}}, \sigma_{\mathrm{u}}, \mathrm{J}_{\mathrm{i}}$ from NUREG/CR-6098 \& NUREG/CR-4082, Vol.8

11 ASME IWB-3640, $\sigma_{\mathrm{f}}=3 S_{\mathrm{m}}$

$12 \sigma_{\mathrm{f}}$ scaled using ratio of ASME $S_{y}$ and $S_{u}$ at $288 \mathrm{C}$ to $R T$

Table 4.4 Predicted time at attainment of maximum moment for IPIRG-2 Experiment 1-1 in Problem C.2-a

\begin{tabular}{|c|c|c|c|c|c|c|c|c|c|c|}
\hline \multirow{3}{*}{$\begin{array}{c}\text { Material } \\
\text { Property } \\
\text { Specification }\end{array}$} & \multicolumn{6}{|c|}{ Participant } & \multirow{2}{*}{\multicolumn{2}{|c|}{ Linear FEA }} & \multirow{2}{*}{\multicolumn{2}{|c|}{$\begin{array}{c}\text { IPIRG-2 } \\
\text { Expt. 1-1 } \\
\end{array}$}} \\
\hline & \multicolumn{2}{|c|}{ F-3 } & \multicolumn{2}{|c|}{ C } & \multicolumn{2}{|c|}{ D } & & & & \\
\hline & $\begin{array}{l}\text { Moment, } \\
\text { kN-m }\end{array}$ & $\begin{array}{l}\text { Time, } \\
\text { sec }\end{array}$ & $\begin{array}{l}\text { Moment, } \\
\text { kN-m }\end{array}$ & $\begin{array}{l}\text { Time, } \\
\text { sec }\end{array}$ & $\begin{array}{c}\text { Moment, } \\
\text { kN-m }\end{array}$ & $\begin{array}{l}\text { Time, } \\
\text { sec }\end{array}$ & $\begin{array}{c}\text { Moment, } \\
\text { kN-m }\end{array}$ & $\begin{array}{l}\text { Time, } \\
\text { sec }\end{array}$ & $\begin{array}{l}\text { Moment, } \\
\text { kN-m }\end{array}$ & $\begin{array}{c}\text { Time, } \\
\text { sec }\end{array}$ \\
\hline Level 1 & $\begin{array}{l}347 \\
550\end{array}$ & $\begin{array}{l}2.365 \\
2.380\end{array}$ & 420 & 2.370 & $\begin{array}{l}580 \\
474\end{array}$ & $\begin{array}{l}2.380 \\
2.375\end{array}$ & & & & \\
\hline Level 2 & 778 & 6.650 & 904 & 12.735 & 828 & 11.645 & & & $\begin{array}{c}598 \\
\text { maximum }\end{array}$ & 5.03 \\
\hline Level 3 & $\begin{array}{l}589 \\
519 \\
546\end{array}$ & $\begin{array}{l}2.385 \\
2.380 \\
2.380\end{array}$ & 933 & 12.745 & 681 & 4.160 & 1143 & 13.395 & $\begin{array}{c}509 \\
\text { SC } \\
\text { penetration }\end{array}$ & 14.035 \\
\hline Level 4 & $\begin{array}{l}576 \\
539 \\
570\end{array}$ & $\begin{array}{l}2.385 \\
2.380 \\
2.385\end{array}$ & 959 & 13.375 & 702 & 4.165 & & & & \\
\hline
\end{tabular}


Table 4.5 Maximum moment predictions for IPIRG-2 Experiment 1-1 in Problem C.2-b

\begin{tabular}{|c|c|c|c|c|c|c|c|}
\hline \multirow{3}{*}{$\begin{array}{c}\text { Material } \\
\text { Property } \\
\text { Specification }\end{array}$} & \multicolumn{6}{|c|}{ Participant } & \multirow{3}{*}{$\begin{array}{c}\text { IPIRG-2 1-1 } \\
\begin{array}{c}\text { Moment, } \\
\text { kN-m }\end{array}\end{array}$} \\
\hline & \multicolumn{2}{|l|}{ F-3 } & \multicolumn{2}{|l|}{ C } & \multicolumn{2}{|l|}{ A-3 } & \\
\hline & Method & $\begin{array}{c}\text { Moment, } \\
\text { kN-m }\end{array}$ & Method & $\begin{array}{c}\text { Moment, } \\
\text { kN-m }\end{array}$ & Method & $\begin{array}{l}\text { Moment, } \\
\text { kN-m }\end{array}$ & \\
\hline 1 & $\begin{array}{l}\text { Limit Load }{ }^{1,2} \\
\text { Limit Load }\end{array}$ & $\begin{array}{l}374 \\
580\end{array}$ & $\begin{array}{l}\text { Limit Load } 2,7 \\
\text { Limit Load }\end{array}$ & $\begin{array}{l}418 \\
1100\end{array}$ & $\begin{array}{l}\text { Limit Load } 2,10 \\
\text { NL } F^{2}{ }^{2,10,11}\end{array}$ & $\begin{array}{l}519 \\
496\end{array}$ & \\
\hline 2 & Limit Load 2,4 & 816 & $\begin{array}{l}\text { Limit } \text { Load }^{2,9} \\
\text { Limit Load } \\
8,9\end{array}$ & $\begin{array}{l}2662 \\
3673\end{array}$ & $\begin{array}{c}\text { Limit Load }{ }^{2,10} \\
\text { NL FE }\end{array}$ & $\begin{array}{l}841 \\
605\end{array}$ & 598 maximum \\
\hline 3 & $\begin{array}{c}\text { Limit Load } 2,4 \\
\text { JSIN } 2,5 \\
\text { JSIN }^{2,6}\end{array}$ & $\begin{array}{l}625 \\
529 \\
556\end{array}$ & $\begin{array}{l}\text { GE/EPRI } \\
\text { GE}^{2} / \mathrm{EPRI}^{8}\end{array}$ & $\begin{array}{l}2773 \\
2960\end{array}$ & $\begin{array}{l}\text { DPFAD } \\
\text { NL FE }\end{array}$ & $\begin{array}{l}500 \\
607\end{array}$ & $\begin{array}{c}509 \\
\text { SC penetration }\end{array}$ \\
\hline 4 & $\begin{array}{c}\text { Limit } \text { Load }^{2,4} \\
\text { JSIN }^{2,5} \\
\text { JSIN }^{2,6}\end{array}$ & $\begin{array}{l}612 \\
553 \\
582\end{array}$ & 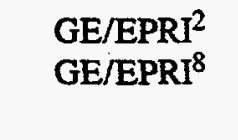 & $\begin{array}{l}3161 \\
3376\end{array}$ & $\begin{array}{l}\text { DPFAD } \\
\text { NL FE }^{2,11}\end{array}$ & $\begin{array}{l}669 \\
618\end{array}$ & \\
\hline
\end{tabular}

1 using $\sigma_{\text {ref }}$ from level D ASME

$\theta / \pi=0.383$

using $\sigma_{\text {ref }}$ from RCCM

using $\sigma_{\text {ref }}$ from $\sigma_{\mathbf{f}}$

engineering stress-strain

true stress-strain
$7 \sigma_{f}$ from ASME Section III

$8 \theta / \pi=0.527$

$9 \sigma_{\mathrm{f}}$ scaled using E from RT data to $288 \mathrm{C}$

10 rationale for $\sigma_{\mathrm{f}}$ unknown

11 3-D nonlinear finite element anslysis for crack behavior

Table 4.6 Predicted time at attainment of maximum moment for IPIRG-2 Experiment 1-1 in Problem C.2-b

\begin{tabular}{|c|c|c|c|c|c|c|c|c|}
\hline \multirow{3}{*}{$\begin{array}{c}\text { Material } \\
\text { Property } \\
\text { Specification }\end{array}$} & \multicolumn{6}{|c|}{ Participant } & & \\
\hline & \multicolumn{2}{|r|}{ F-3 1} & \multicolumn{2}{|c|}{$\mathbf{C}^{2}$} & \multicolumn{2}{|c|}{ A-3 } & \multicolumn{2}{|c|}{ IPIRG-2 1-1 } \\
\hline & $\begin{array}{c}\text { Moment, } \\
\text { kN-m }\end{array}$ & $\begin{array}{c}\text { Time, } \\
\text { sec }\end{array}$ & $\begin{array}{l}\text { Moment, } \\
\text { kN-m }\end{array}$ & $\begin{array}{c}\text { Time, } \\
\text { sec }\end{array}$ & $\begin{array}{c}\text { Moment, } \\
\text { kN-m }\end{array}$ & $\begin{array}{c}\text { Time, } \\
\text { sec }\end{array}$ & $\begin{array}{c}\text { Moment, } \\
\text { kN-m }\end{array}$ & $\begin{array}{c}\text { Time, } \\
\text { sec }\end{array}$ \\
\hline 1 & $\begin{array}{l}374 \\
580\end{array}$ & $\begin{array}{c}\text { not determined } \\
2.43\end{array}$ & $\begin{array}{l}428 \\
1100\end{array}$ & $\begin{array}{c}3.995 \\
13.4\end{array}$ & $\begin{array}{l}519^{2} \\
496^{3}\end{array}$ & $\begin{array}{c}2.38 \\
18.57\end{array}$ & & \\
\hline 2 & 816 & not determined & $\begin{array}{l}2662 \\
3673\end{array}$ & $\begin{array}{l}\text { no failure } \\
\text { no failure }\end{array}$ & $\begin{array}{l}841^{2} \\
605^{3}\end{array}$ & $\begin{array}{l}11.645 \\
18.565\end{array}$ & $\begin{array}{c}598 \\
\text { maximum }\end{array}$ & 5.03 \\
\hline 3 & $\begin{array}{l}625 \\
529 \\
556\end{array}$ & $\begin{array}{c}2.43 \\
\text { not determined } \\
2.43\end{array}$ & $\begin{array}{l}2773 \\
2960\end{array}$ & $\begin{array}{l}\text { no failure } \\
\text { no failure }\end{array}$ & $\begin{array}{l}500^{2} \\
607^{3}\end{array}$ & $\begin{array}{l}2.375 \\
18.56\end{array}$ & $\begin{array}{c}509 \\
\text { SC penetration }\end{array}$ & 14.035 \\
\hline 4 & $\begin{array}{l}612 \\
553 \\
582\end{array}$ & $\begin{array}{c}2.43 \\
\text { not determined } \\
2.43\end{array}$ & $\begin{array}{l}3161 \\
3376\end{array}$ & $\begin{array}{l}\text { no failure } \\
\text { no failure }\end{array}$ & $\begin{array}{l}669^{2} \\
618^{3}\end{array}$ & $\begin{array}{l}4.155 \\
18.56\end{array}$ & & \\
\hline
\end{tabular}

1 time estimate based on linear finite element analysis done by participant

2 time estimate based on original Problem C.2-a Battelle linear stress analysis

3 time estimate based on nonlinear finite element analysis done by participant 


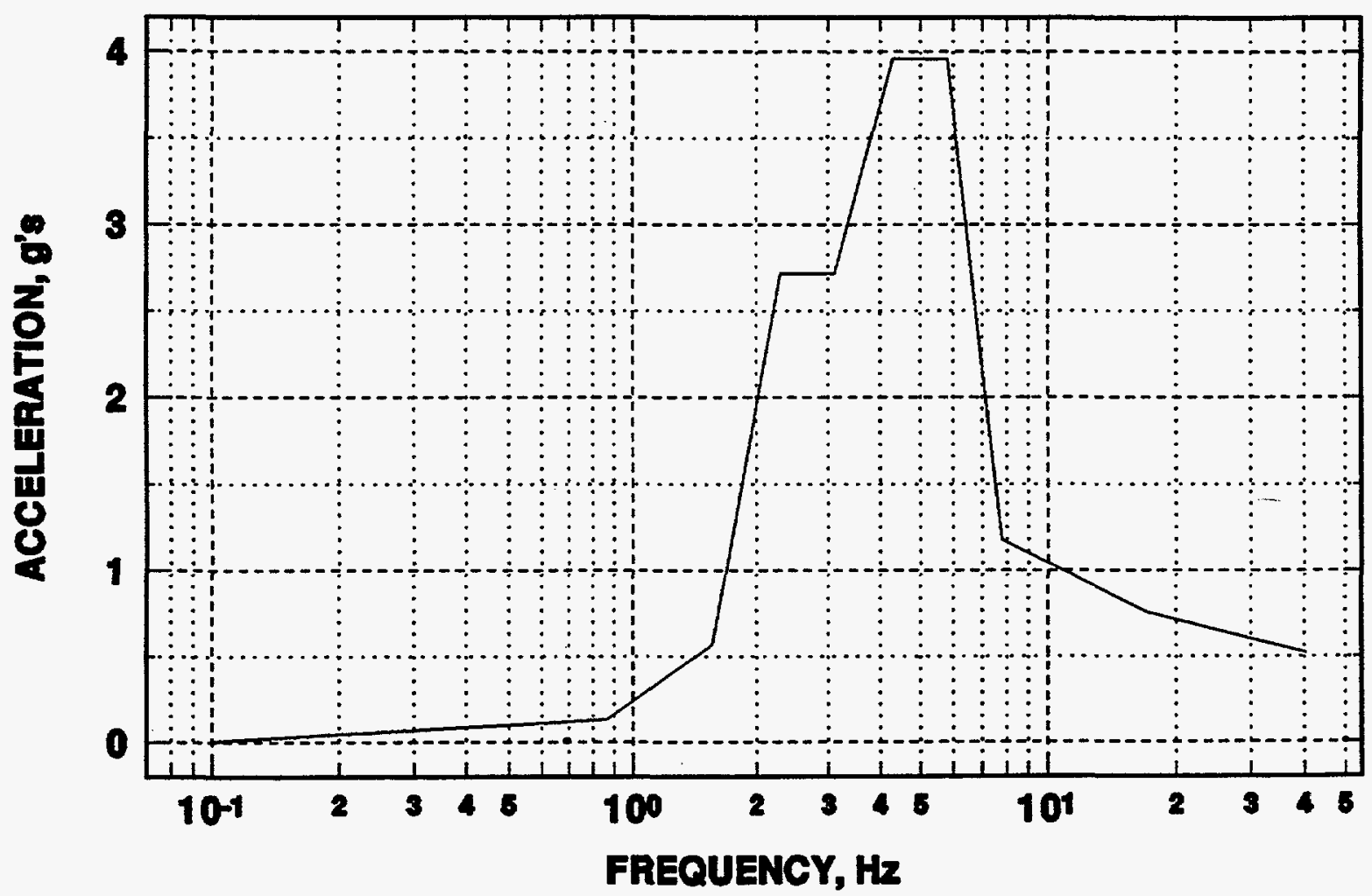

Figure 4.1 Peak-broadened actuator response spectrum for Problem C.1 


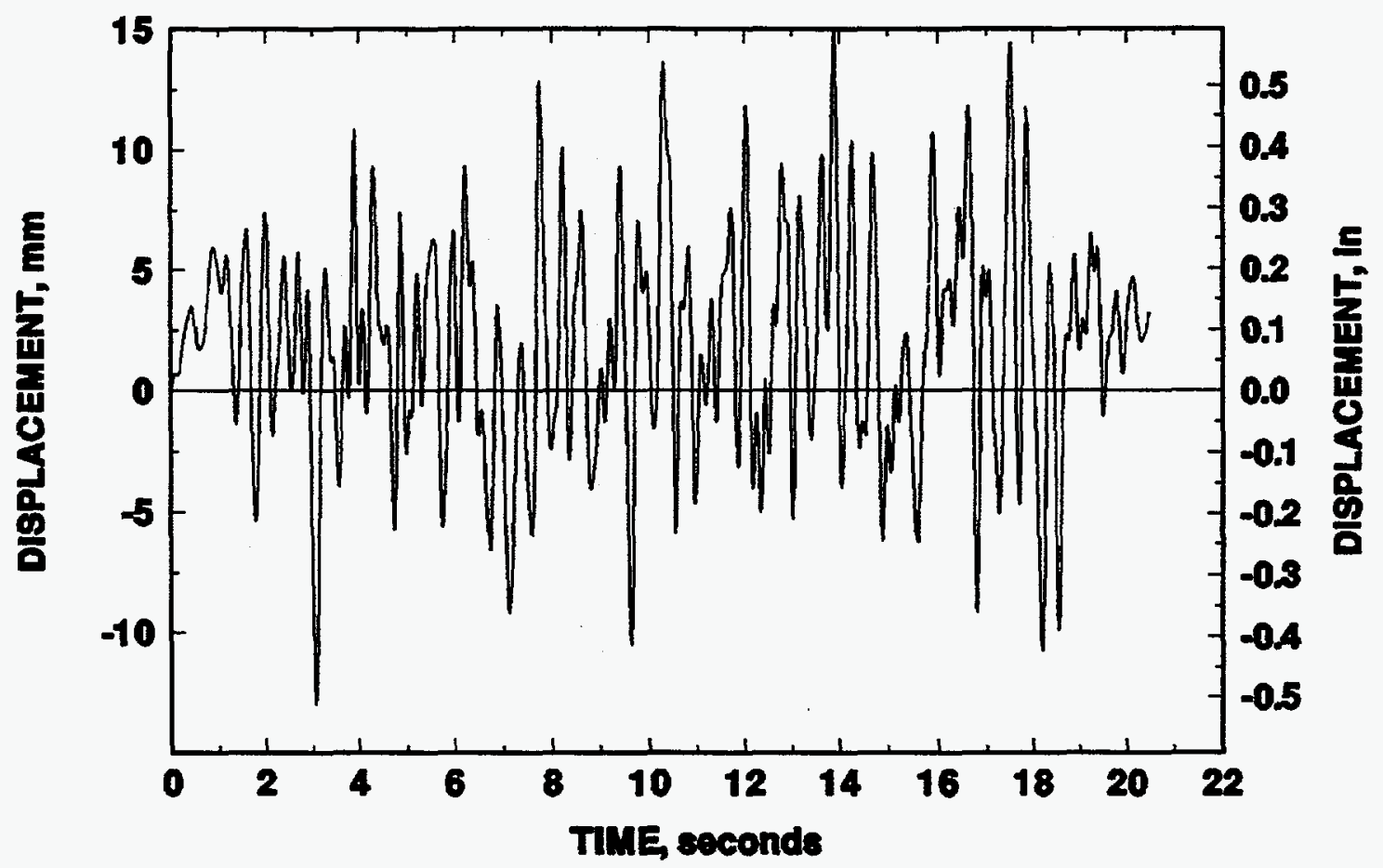

Figure 4.2 Spectrum-compatible displacement time history predicted by Participant C

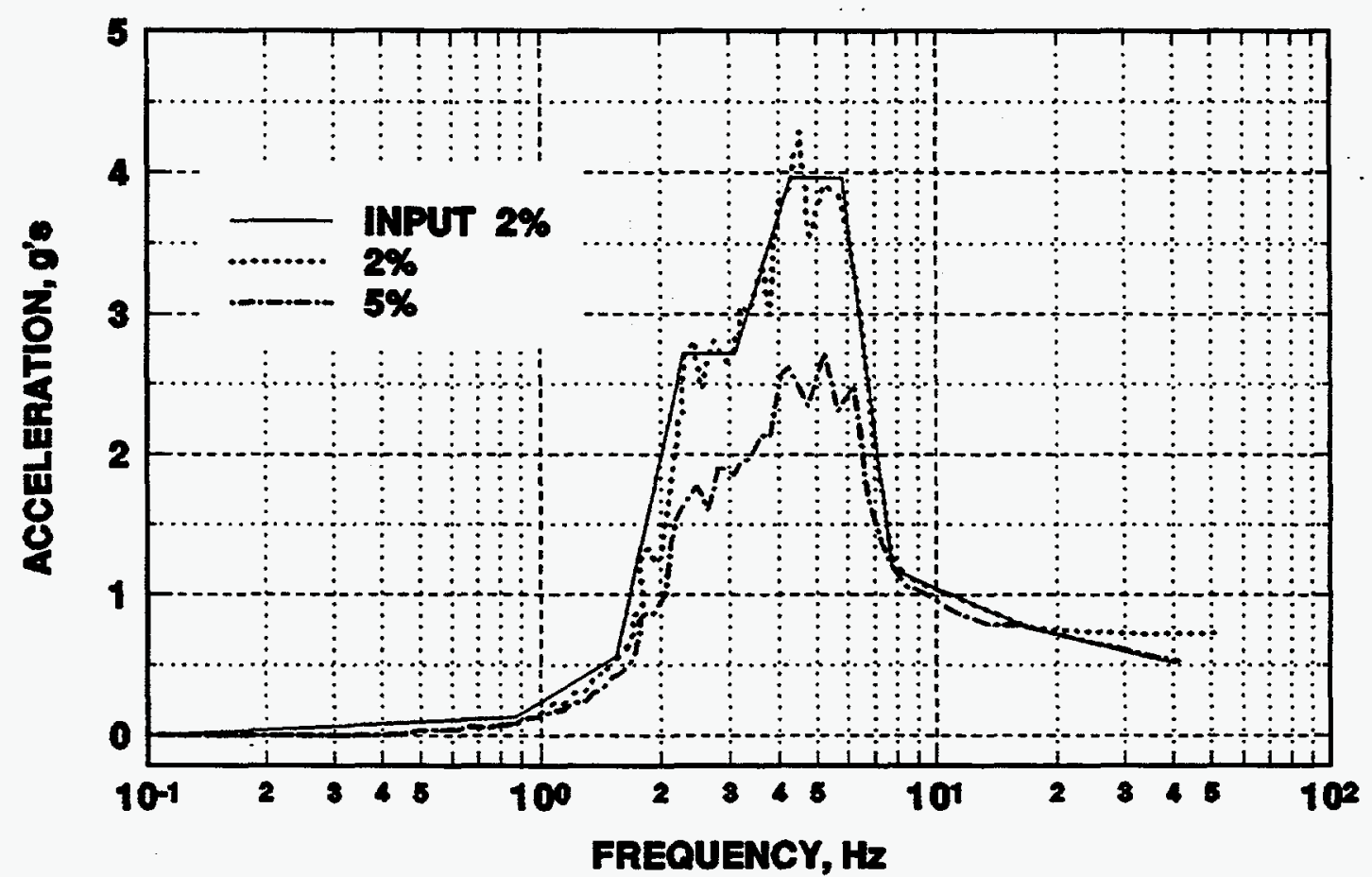

Figure 4.3 Participant C Spectra 


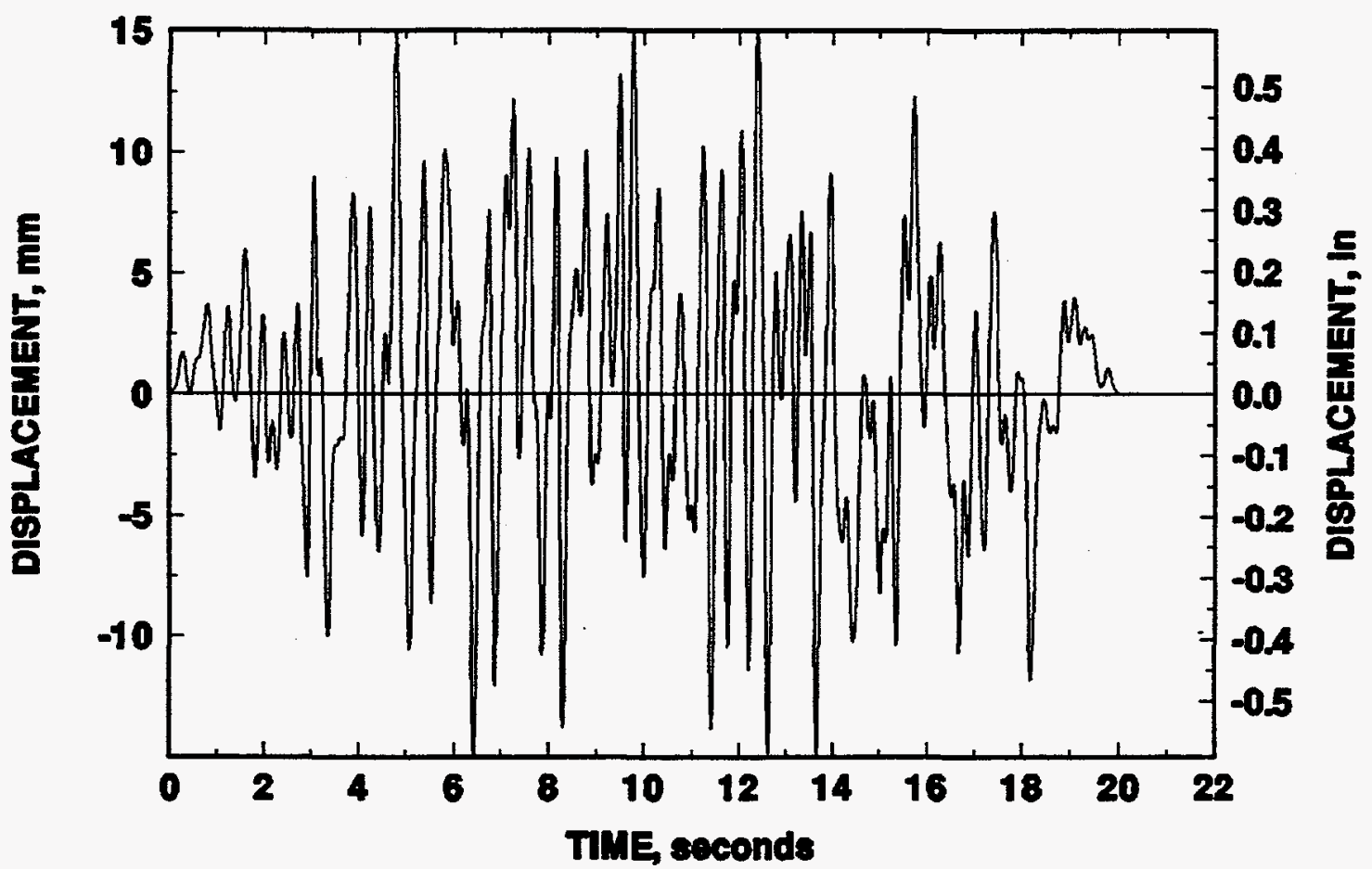

Figure 4.4 Spectrum-compatible displacement time history predicted by Participant D

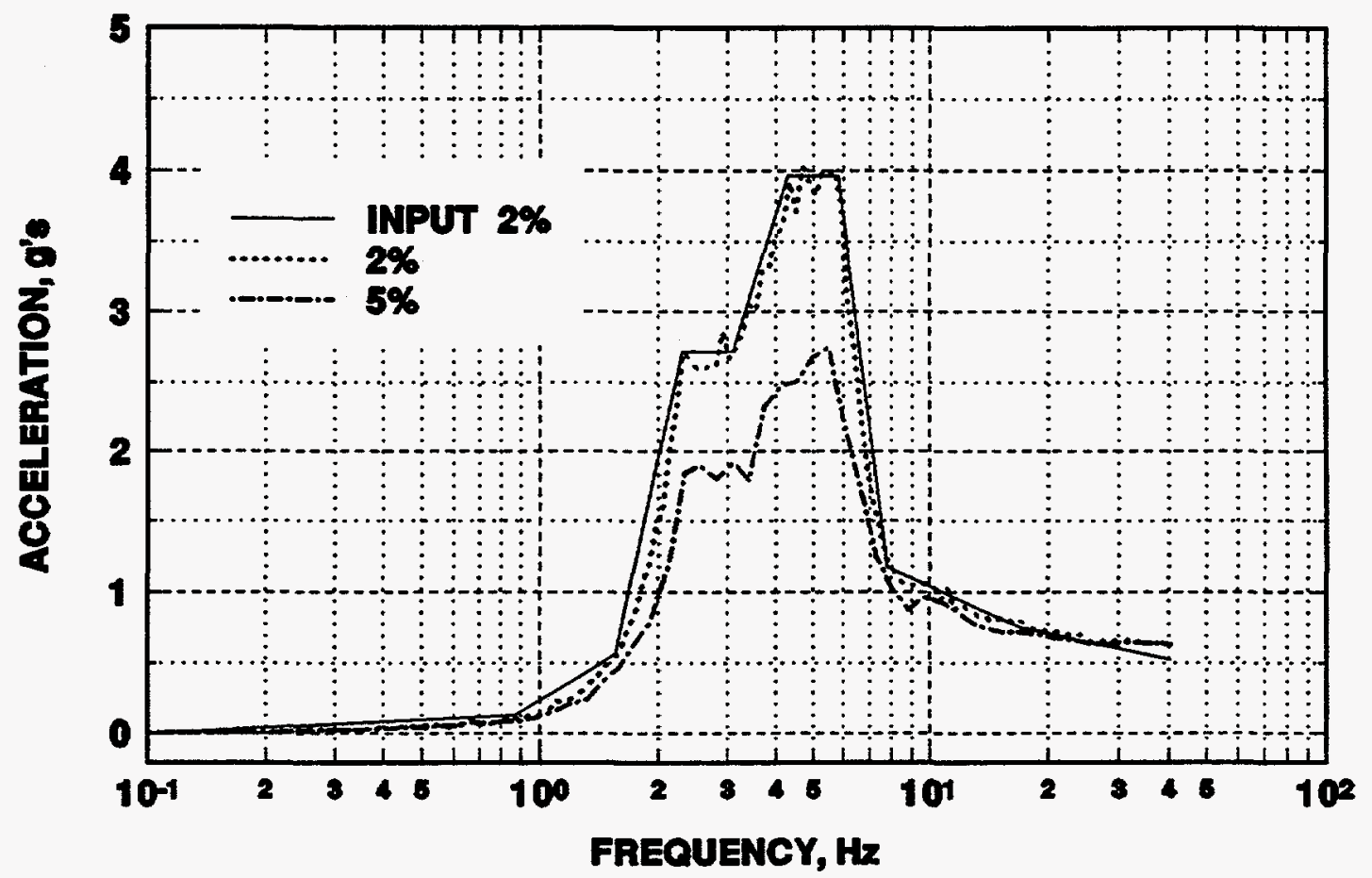

Figure 4.5 Participant D Spectra 


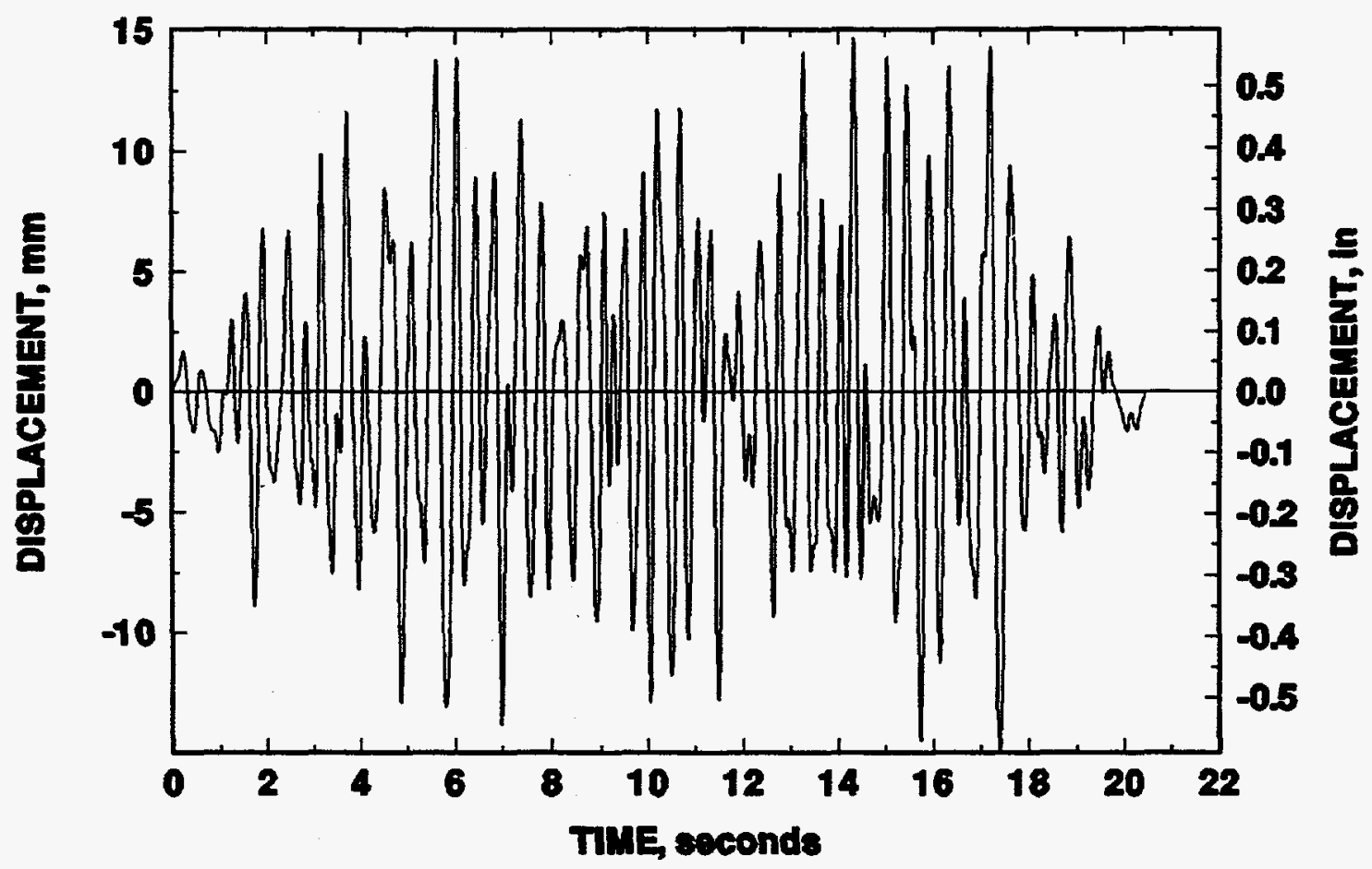

Figure 4.6 Spectrum-compatible displacement time history predicted by Participant F-3a

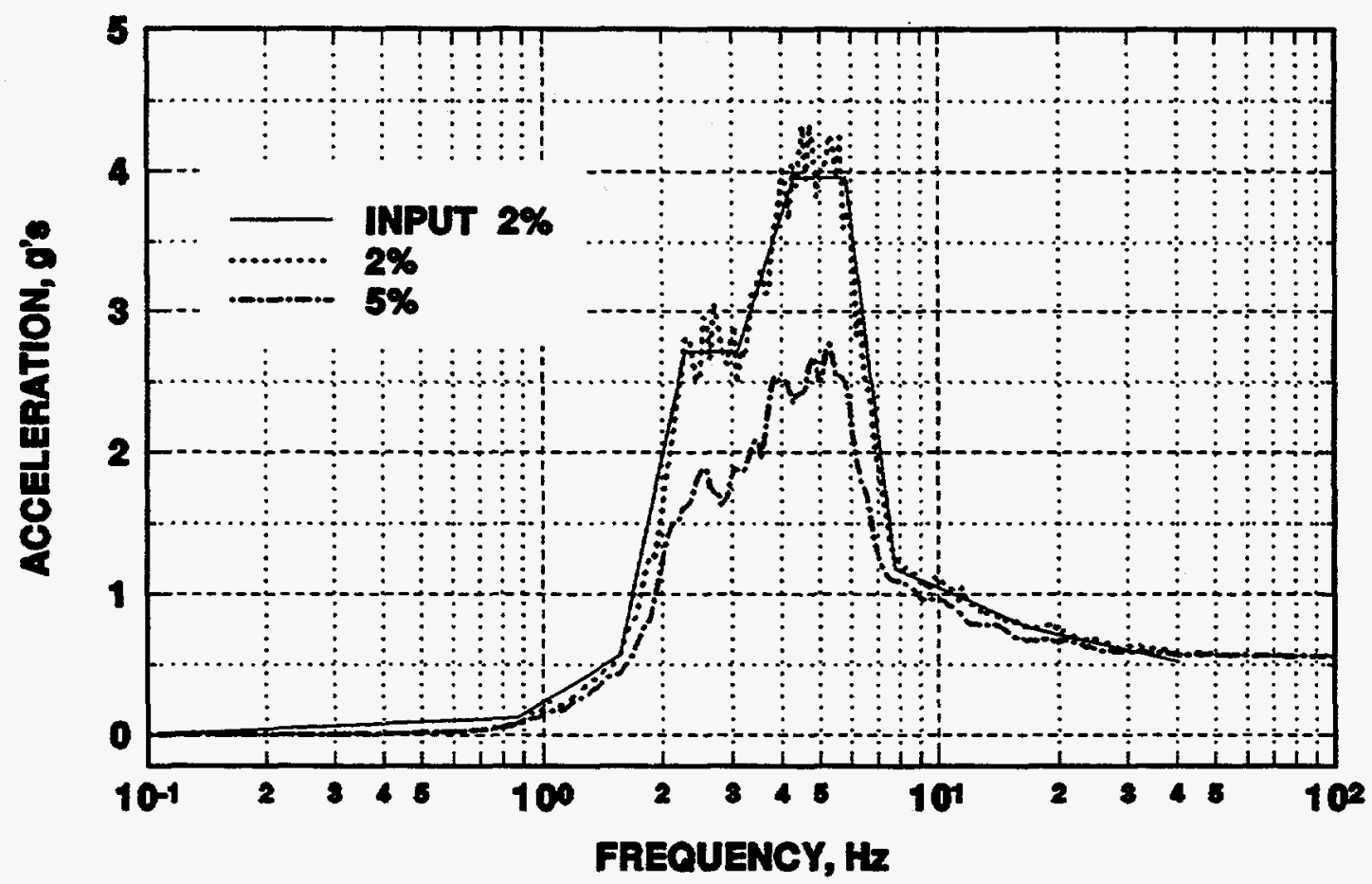

Figure 4.7 Participant F-3a Spectra 


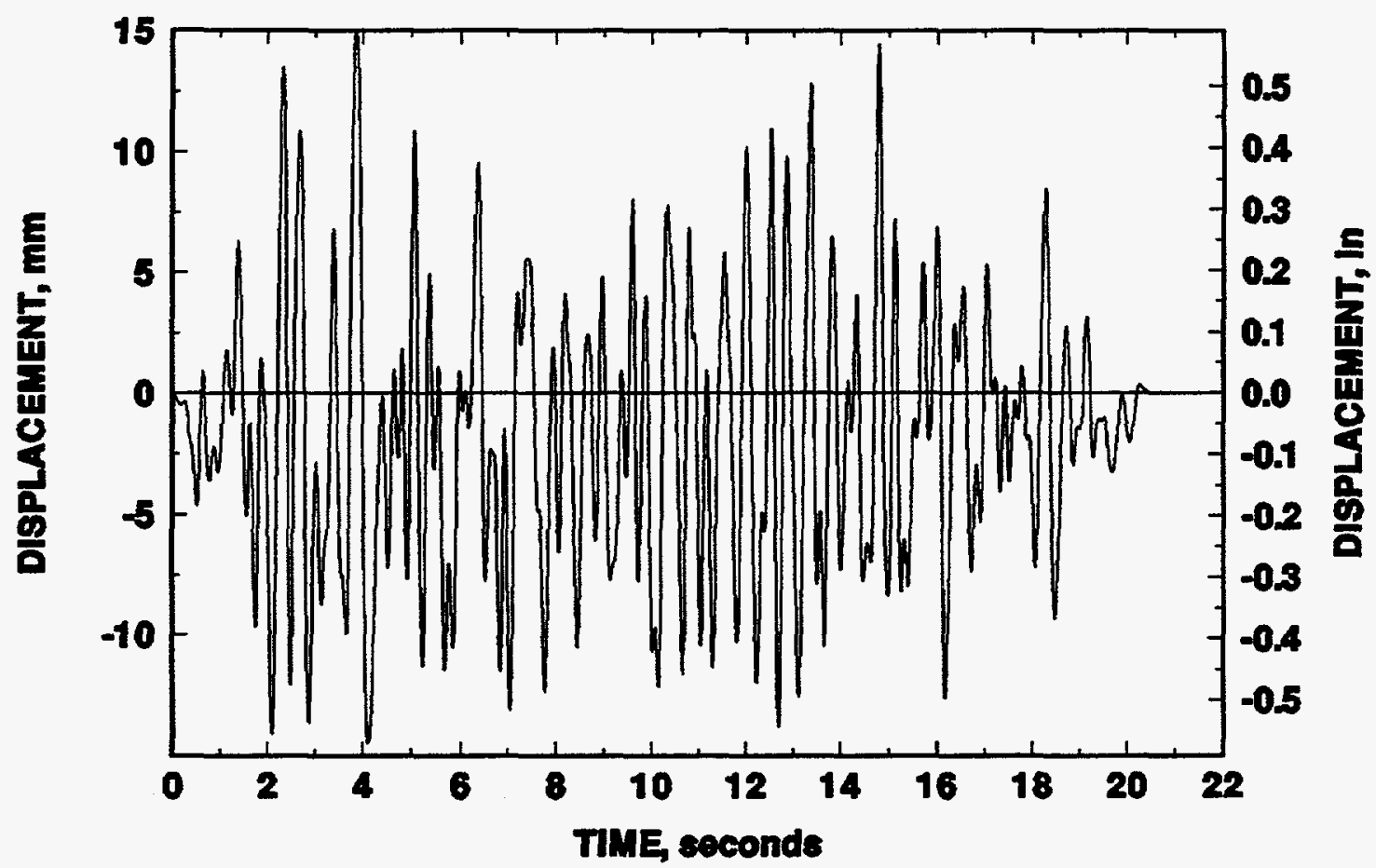

Figure 4.8 Spectrum-compatible displacement time history predicted by Participant F-3b

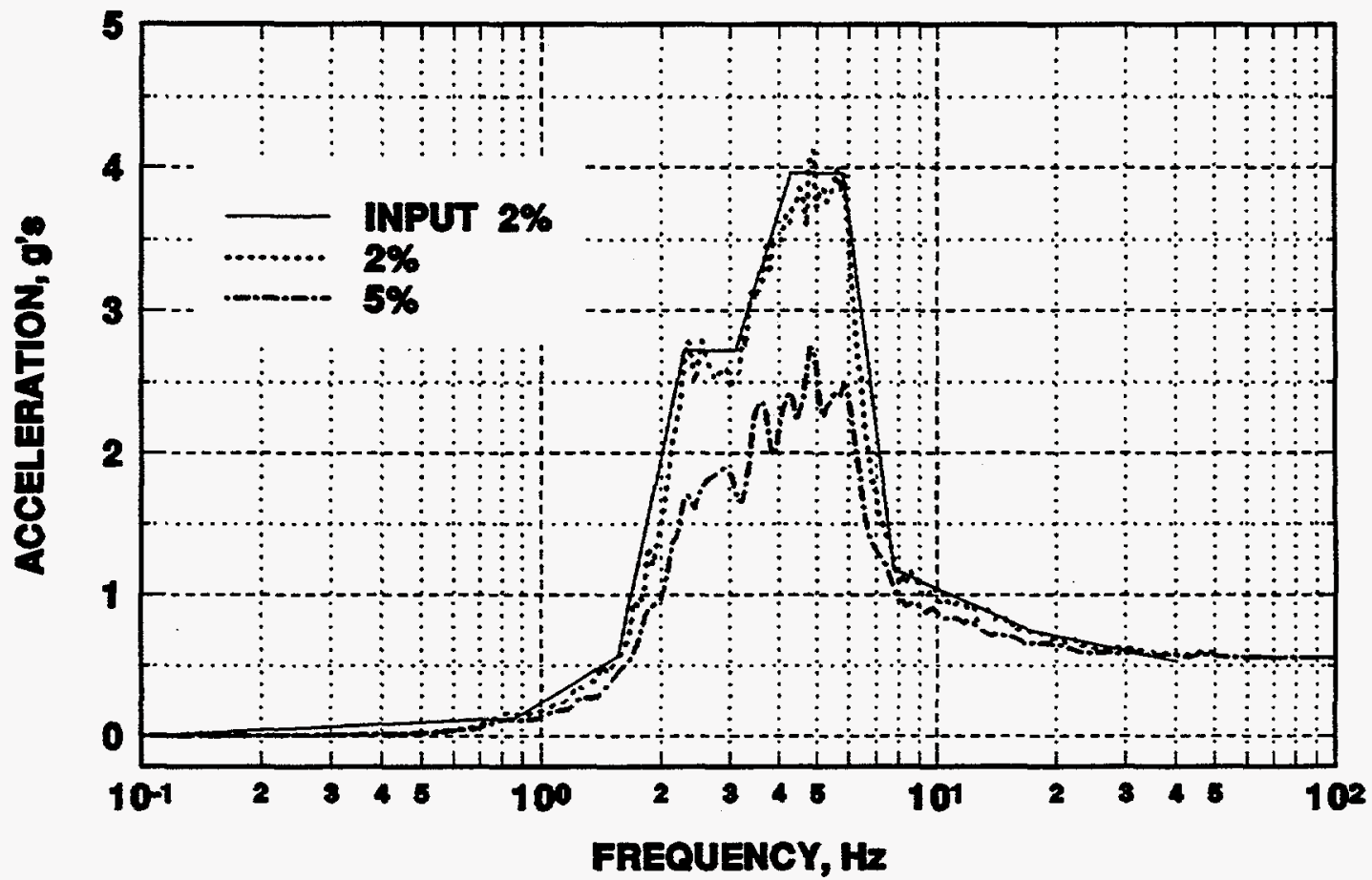

Figure 4.9 Participant F-3b Spectra 


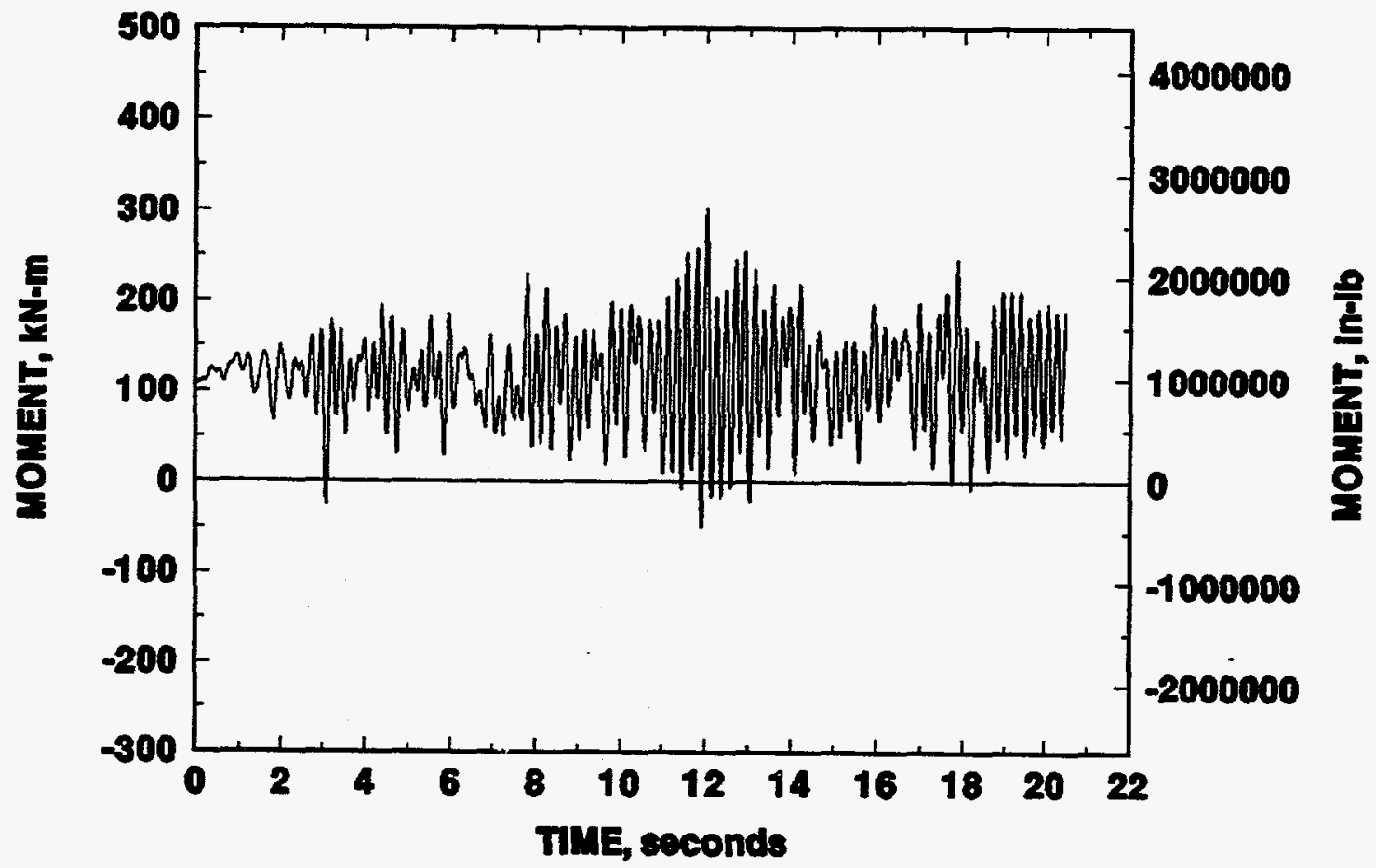

Figure 4.10 Predicted moment response at 0.5-percent damping using Participant C's spectrum-compatible displacement time history

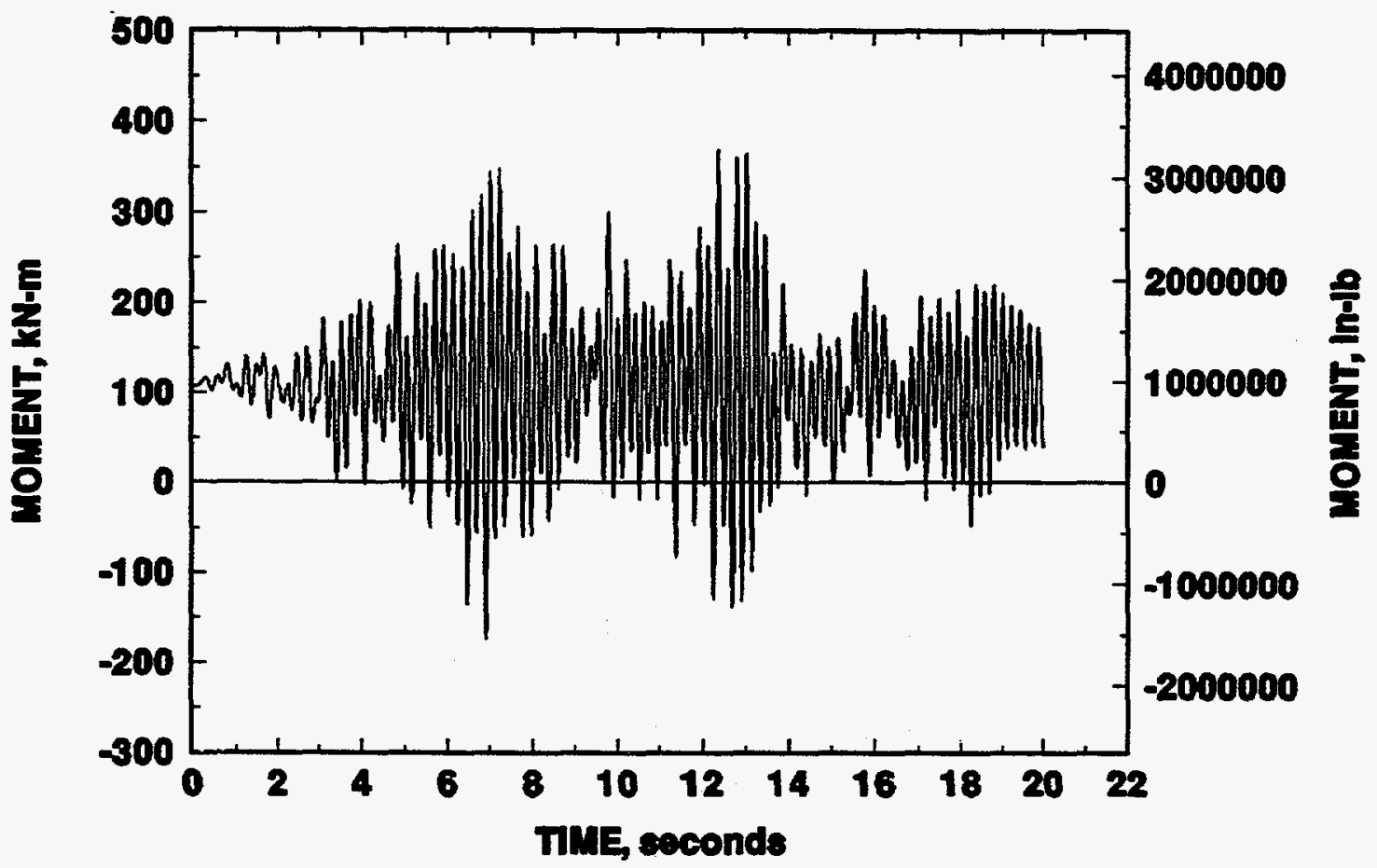

Figure 4.11 Predicted moment response at 0.5-percent damping using Participant D's spectrum-compatible displacement time history 


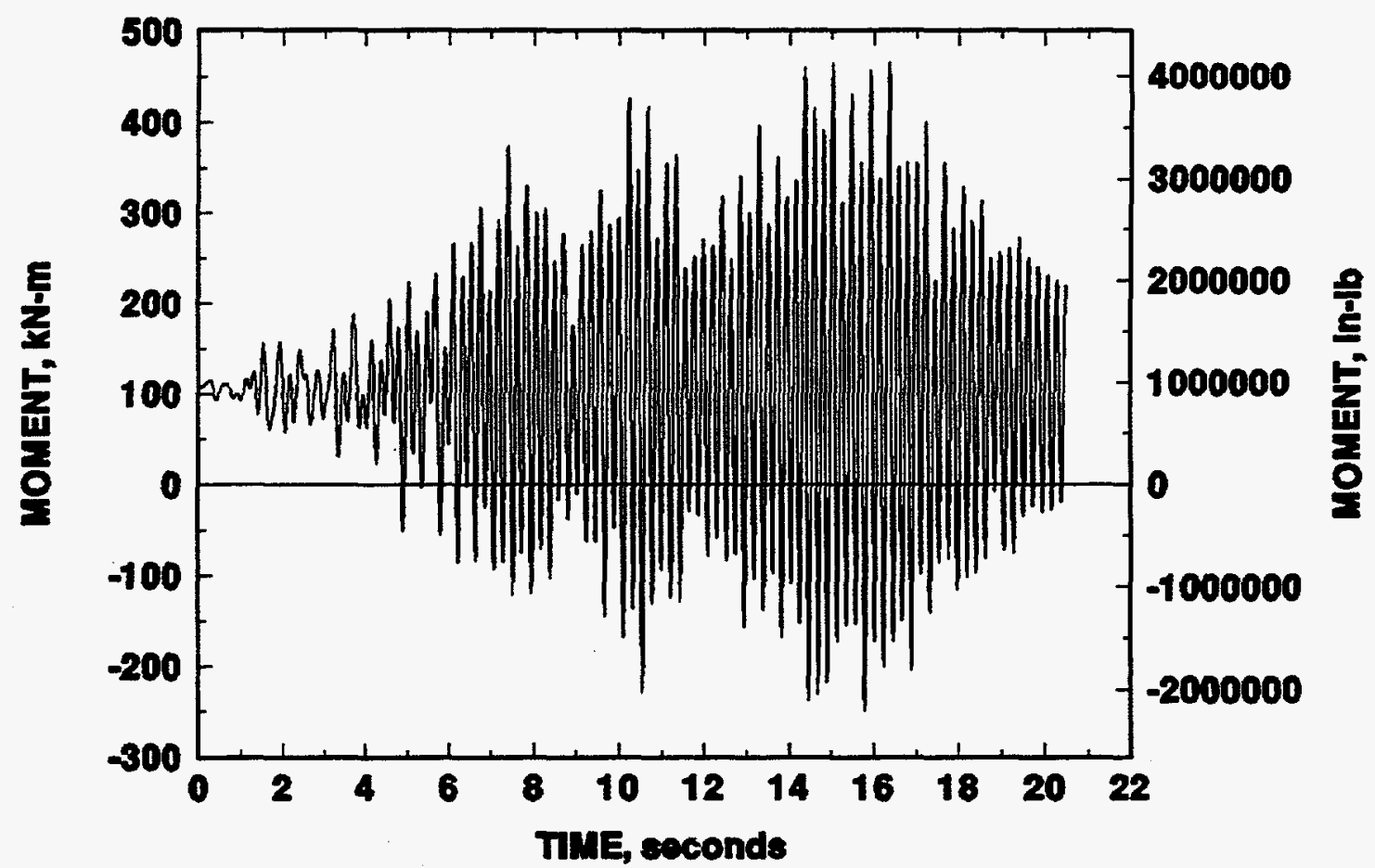

Figure 4.12 Predicted moment response at 0.5-percent damping using Participant F-3's spectrum-compatible displacement time history (Solution F-3a)

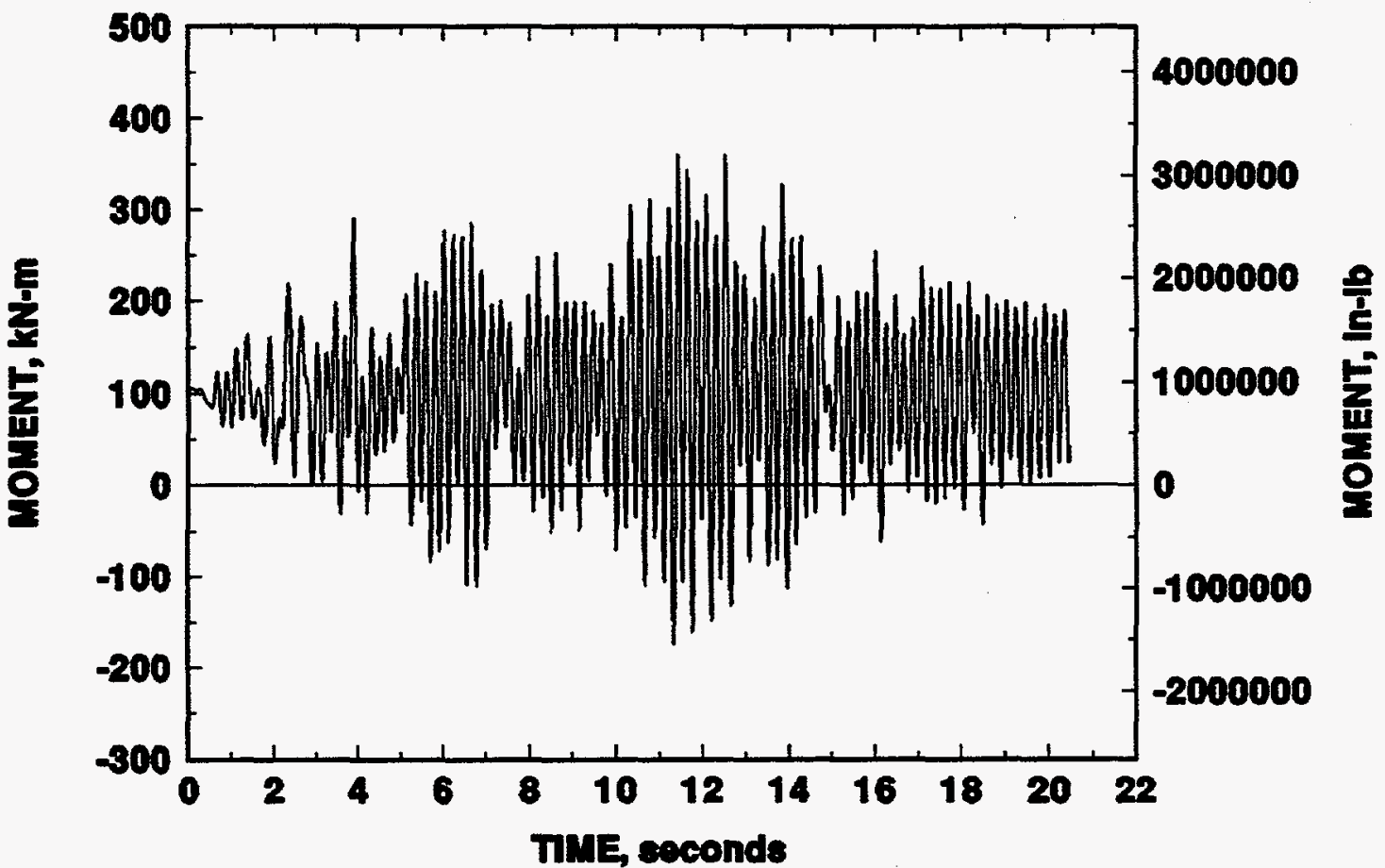

Figure 4.13 Predicted moment response at 0.5-percent damping using Participant F-3's spectrum-compatible displacement time history (Solution F-3b) 


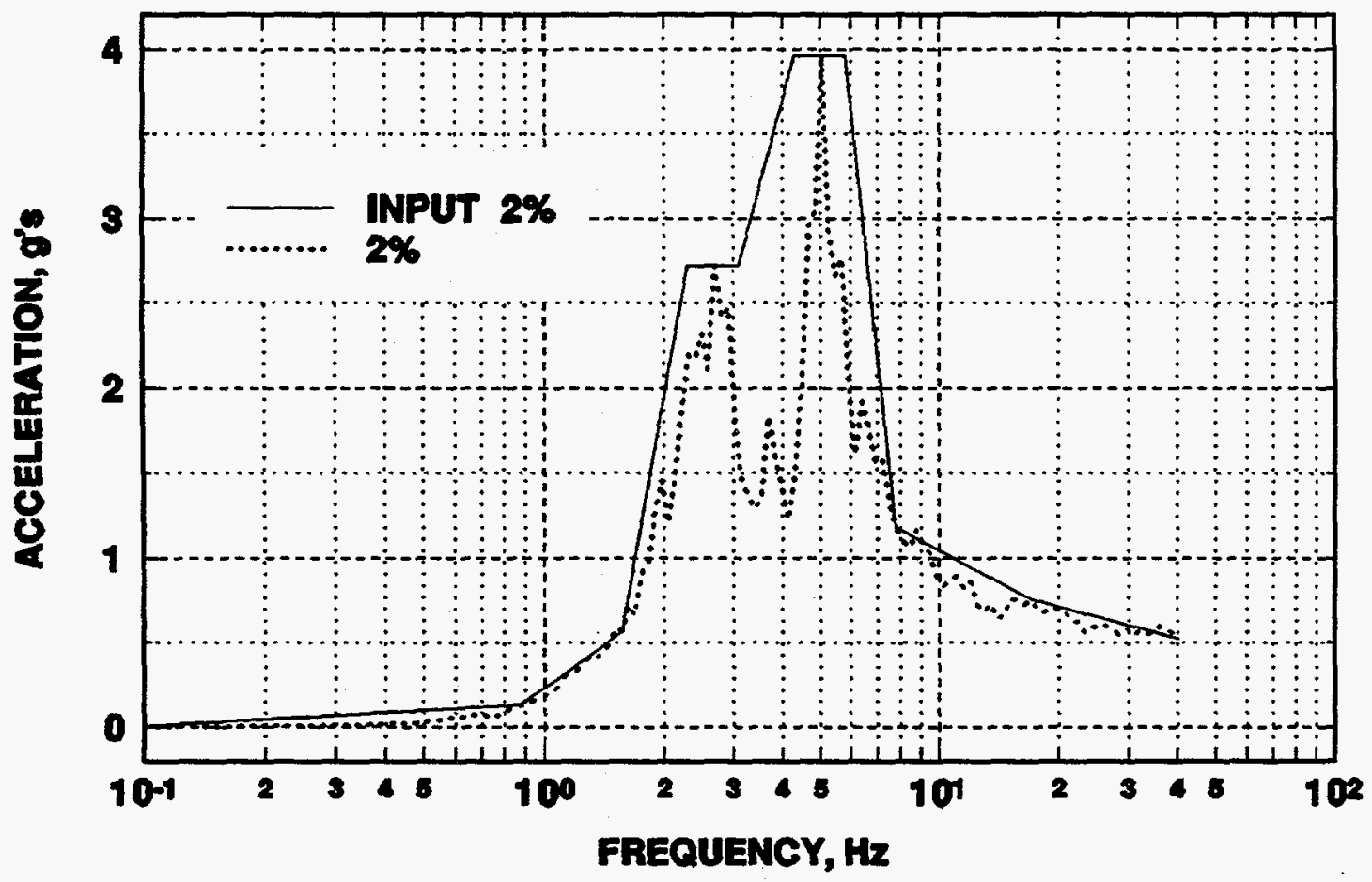

Figure 4.14 IPIRG-2 SSE spectra

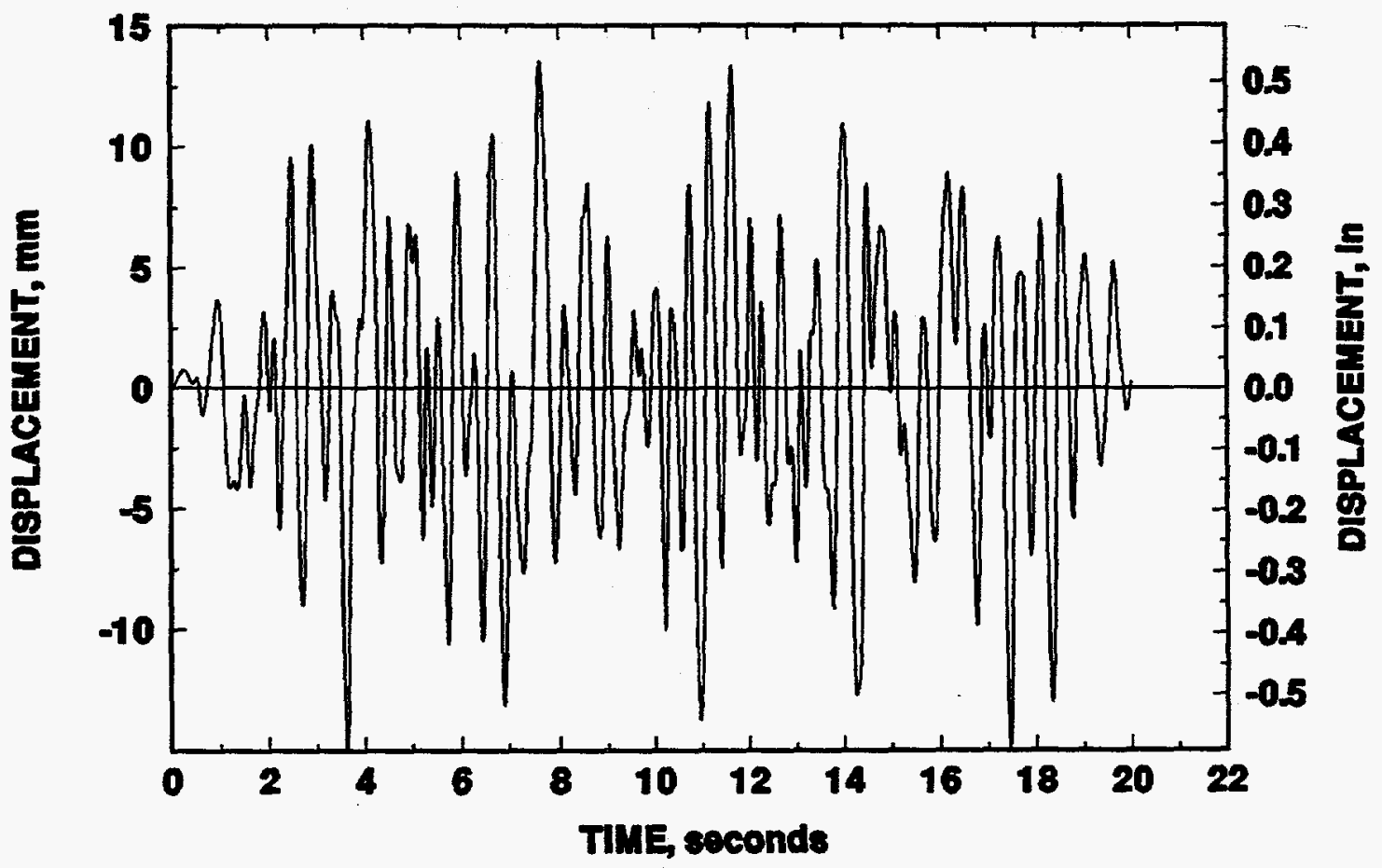

Figure 4.15 IPIRG-2 SSE displacement time history 


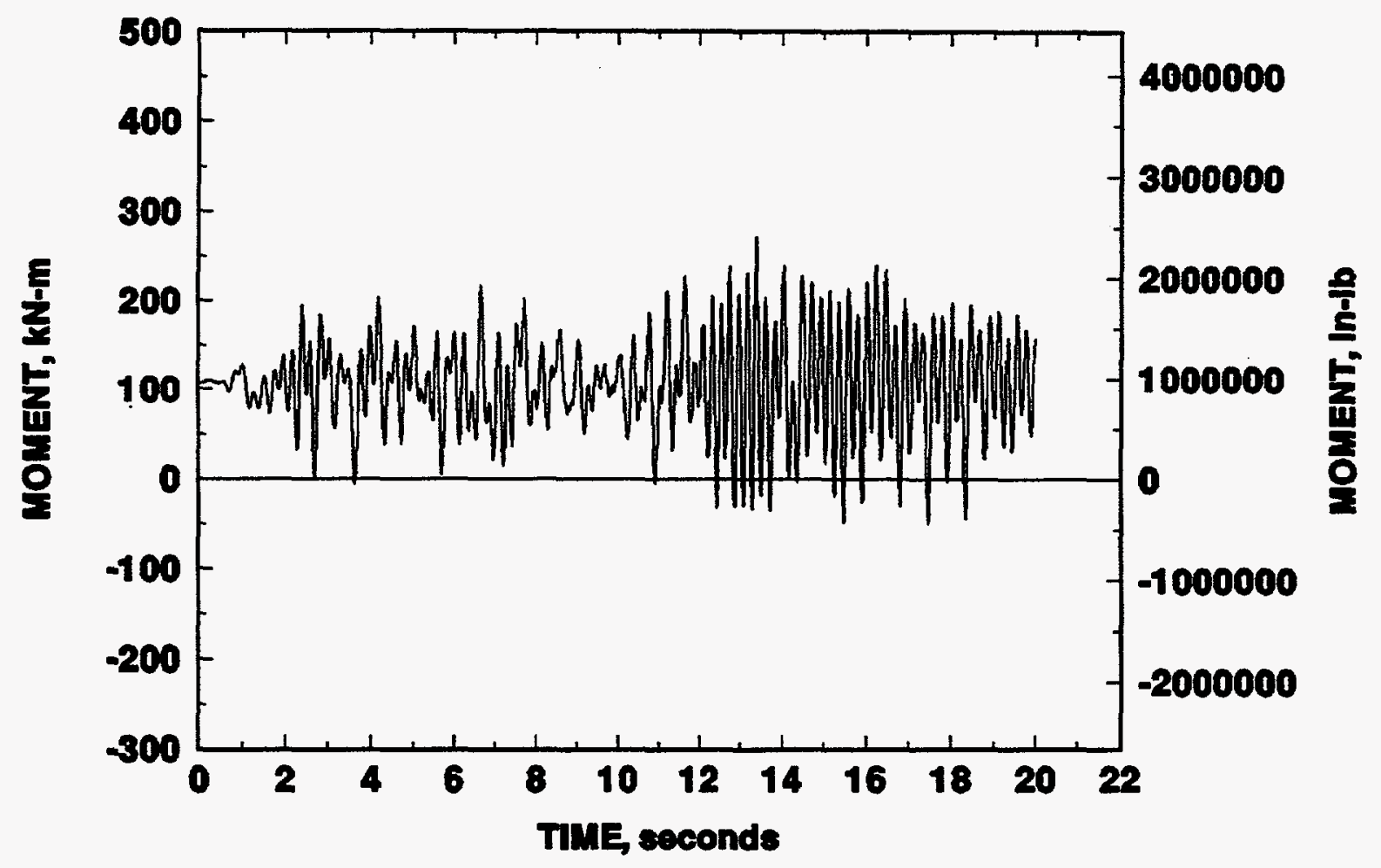

Figure 4.16 Moment response using IPIRG-2 SSE displacement time history 


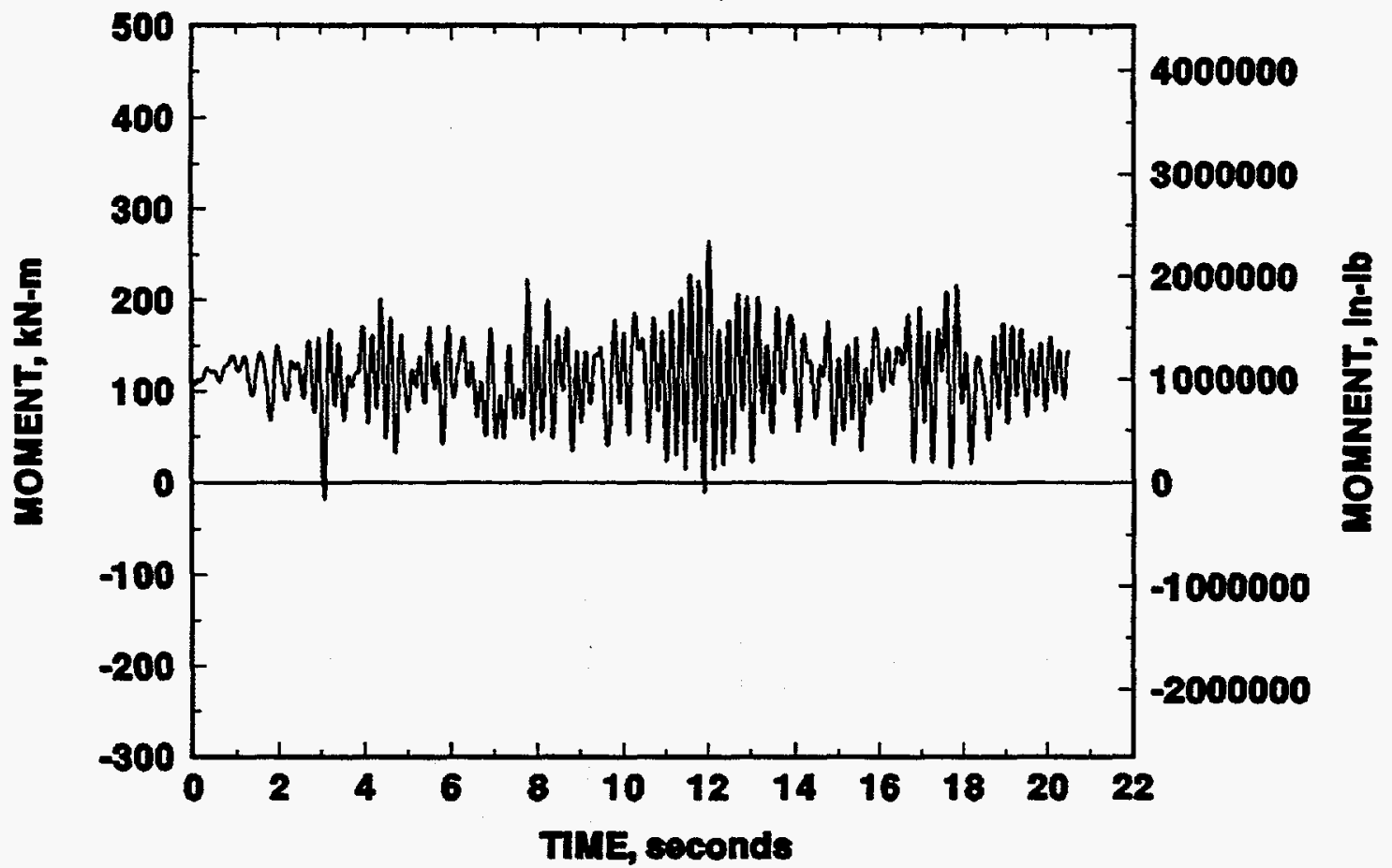

Figure 4.17 Predicted moment response at 2-percent damping using Participant C's spectrumcompatible displacement time history

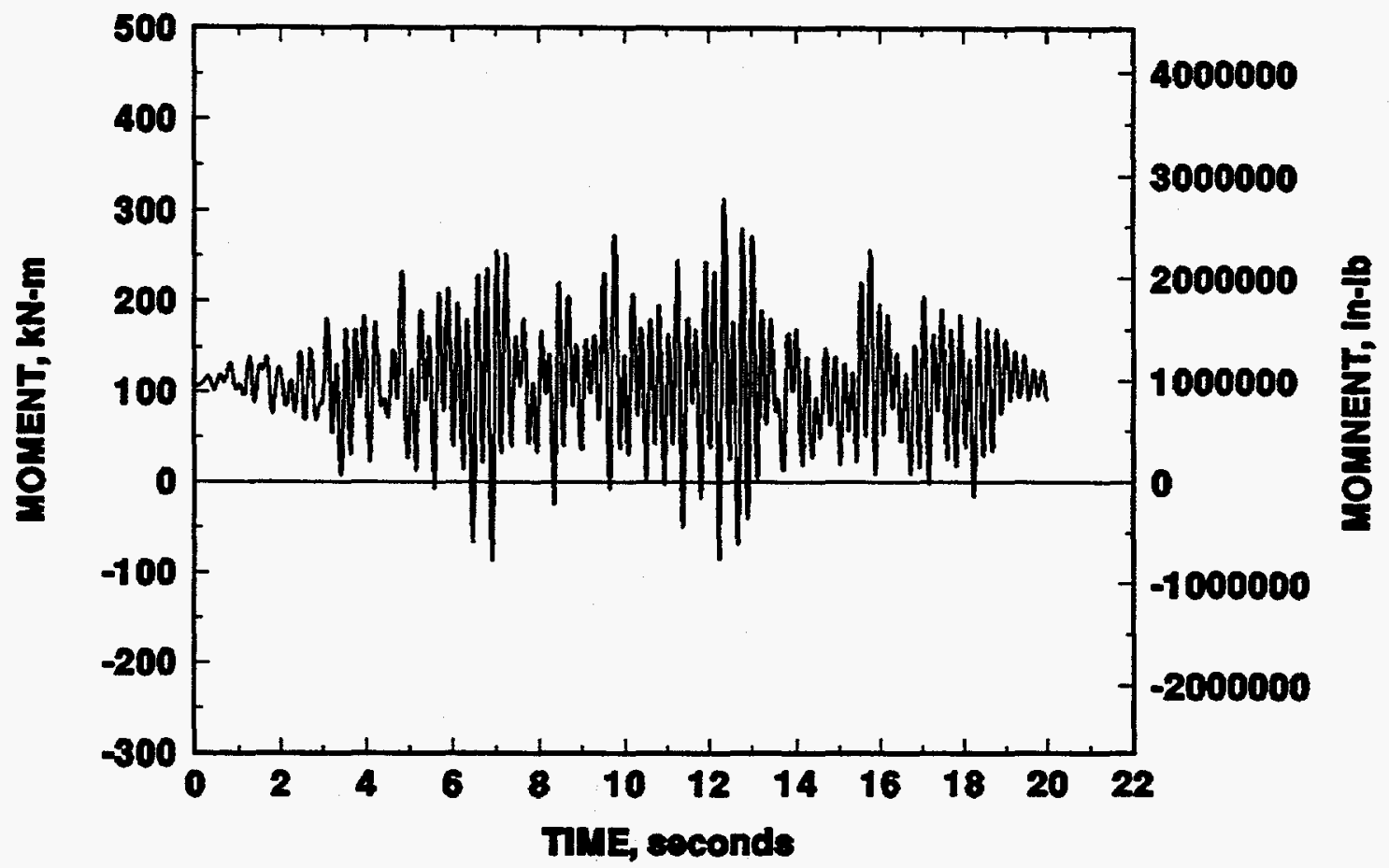

Figure 4.18 Predicted moment response at 2-percent damping using Participant D's spectrumcompatible displacement time history 


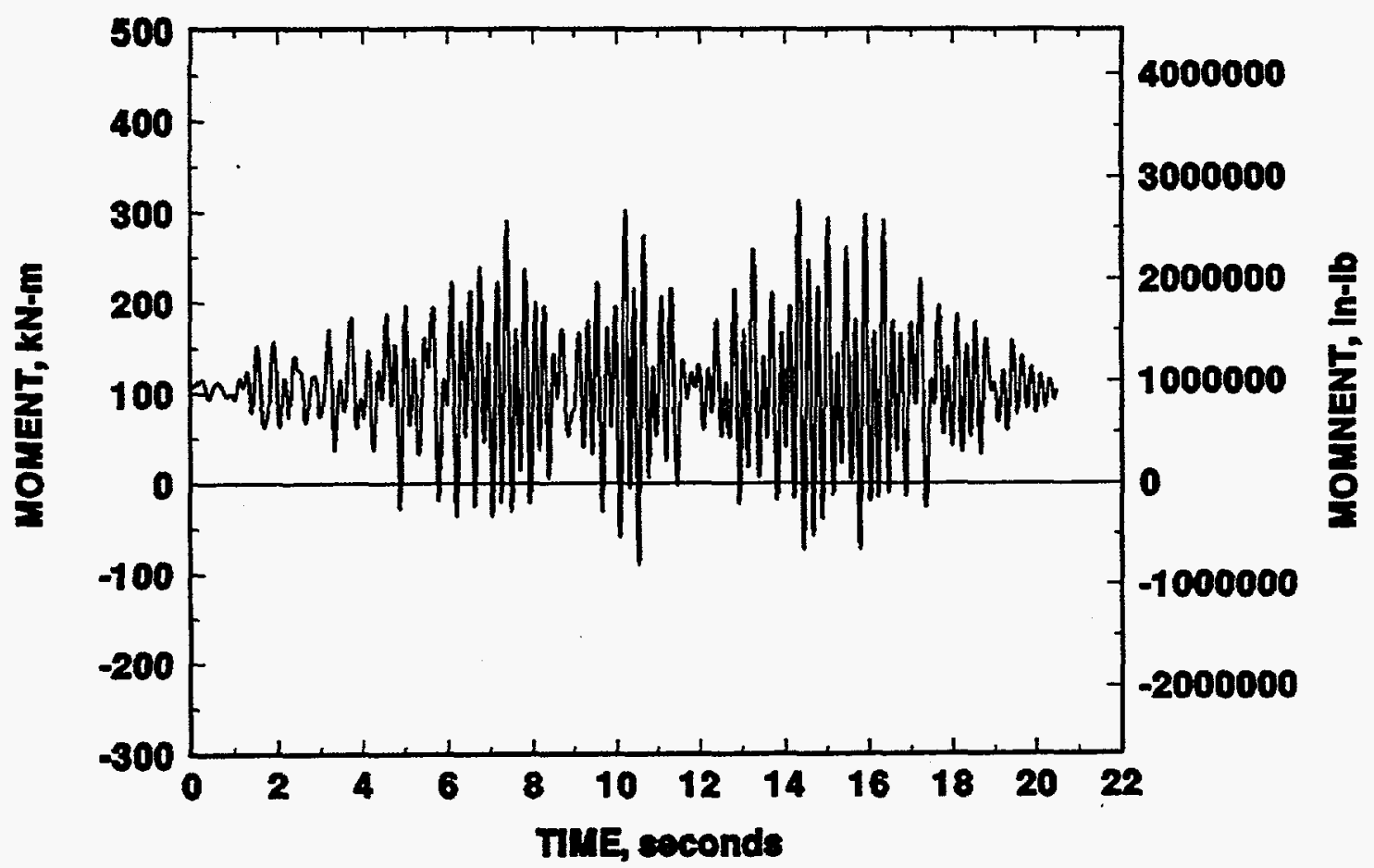

Figure 4.19 Predicted moment response at 2-percent damping using Participant F-3's spectrum-compatible displacement time history (Solution F-3a)

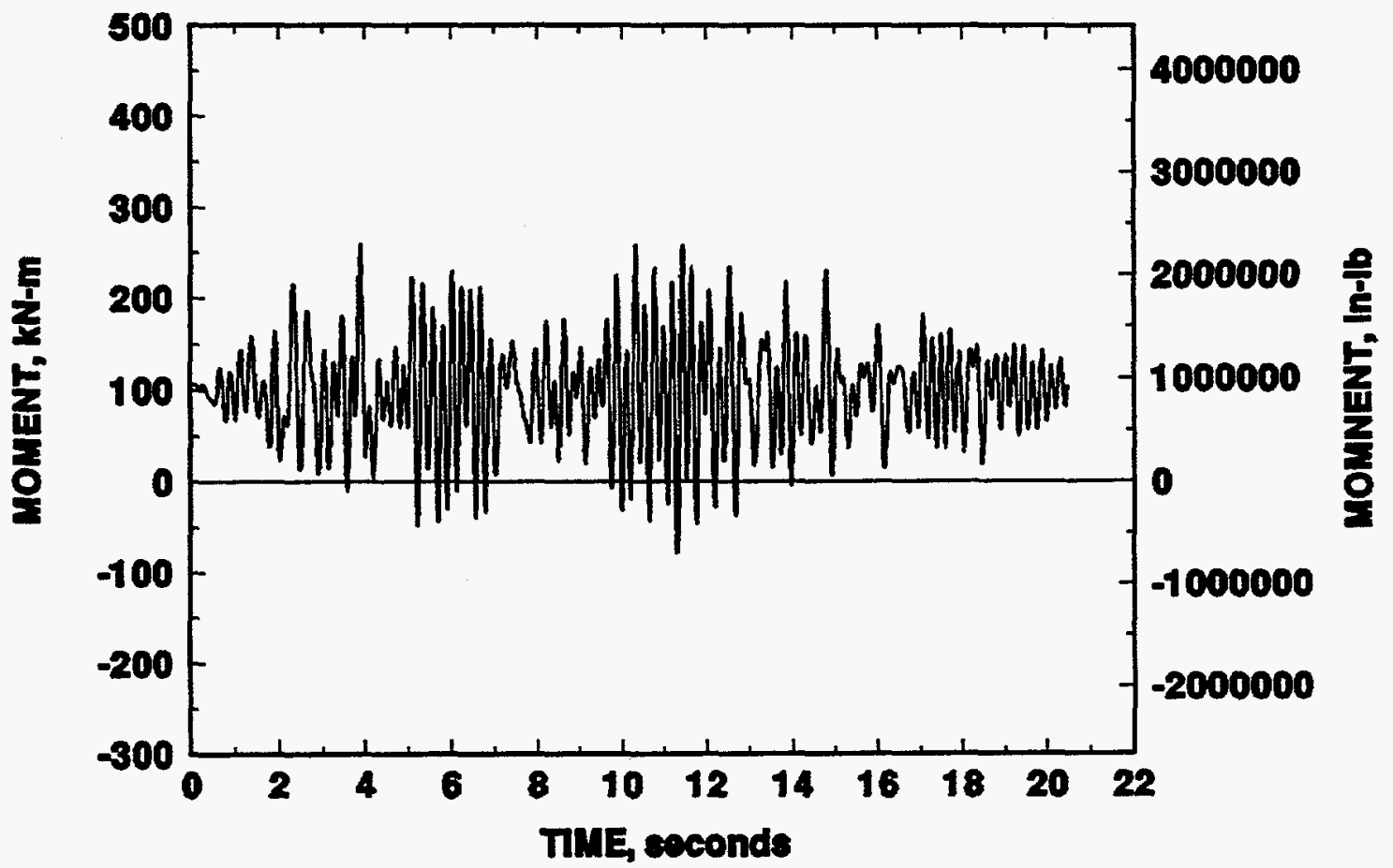

Figure 4.20 Predicted moment response at 2-percent damping using Participant F-3's spectrum-compatible displacement time history (Solution F-3b) 


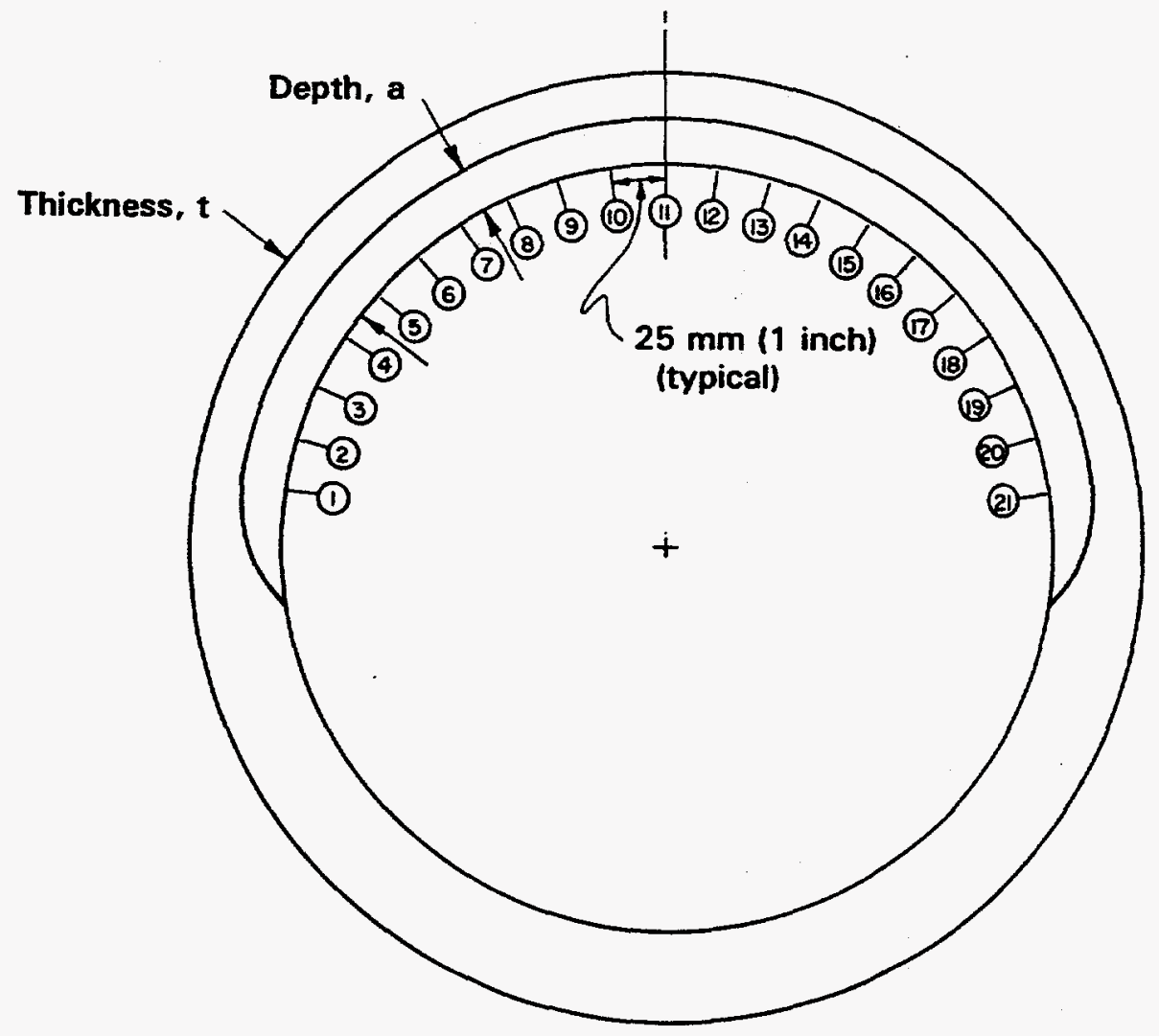

\begin{tabular}{cccc}
\multicolumn{5}{c}{$\begin{array}{c}\text { Flaw } \\
\text { Location }\end{array}$ Depth, Thickness, a/t } \\
mm & mm \\
1 & 11.49 & 25.55 & 0.450 \\
2 & 11.67 & 25.48 & 0.458 \\
3 & 12.04 & 25.55 & 0.471 \\
4 & 12.24 & 25.35 & 0.483 \\
5 & 12.73 & 25.60 & 0.497 \\
6 & 13.07 & 25.37 & 0.515 \\
7 & 13.12 & 25.55 & 0.513 \\
8 & 13.02 & 25.15 & 0.518 \\
9 & 13.84 & 25.65 & 0.540 \\
10 & 14.82 & 25.70 & 0.577 \\
11 & 16.04 & 25.68 & 0.625 \\
12 & 16.21 & 25.81 & 0.628 \\
13 & 15.34 & 25.73 & 0.596 \\
14 & 13.97 & 25.55 & 0.547 \\
15 & 13.02 & 25.63 & 0.508 \\
16 & 12.09 & 25.58 & 0.473 \\
17 & 11.19 & 25.68 & 0.436 \\
18 & 11.18 & 25.63 & 0.436 \\
19 & 11.30 & 25.60 & 0.441 \\
20 & 10.80 & 25.40 & $\mathbf{0 . 4 2 5}$ \\
21 & 11.35 & 25.65 & $\mathbf{0 . 4 4 3}$
\end{tabular}

Note: Crack length on inside pipe surface $=606 \mathrm{~mm}$ (23.85 inch)

Figure 4.21 IPIRG-2 Experiment 1-1 initial flaw geometry 


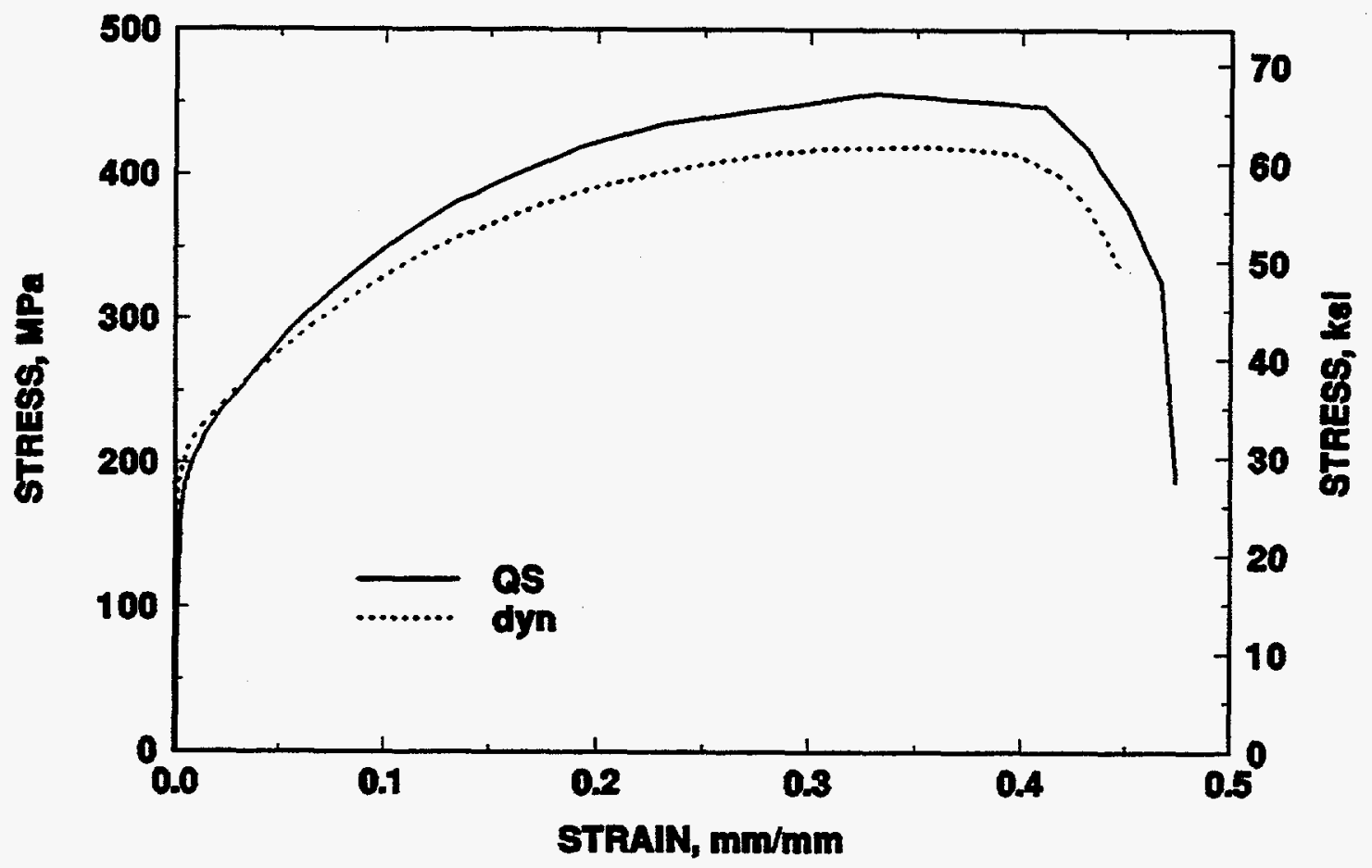

Figure 4.22 Quasi-static and dynamic stress-strain curves for Problems C.2-a and C.2-b

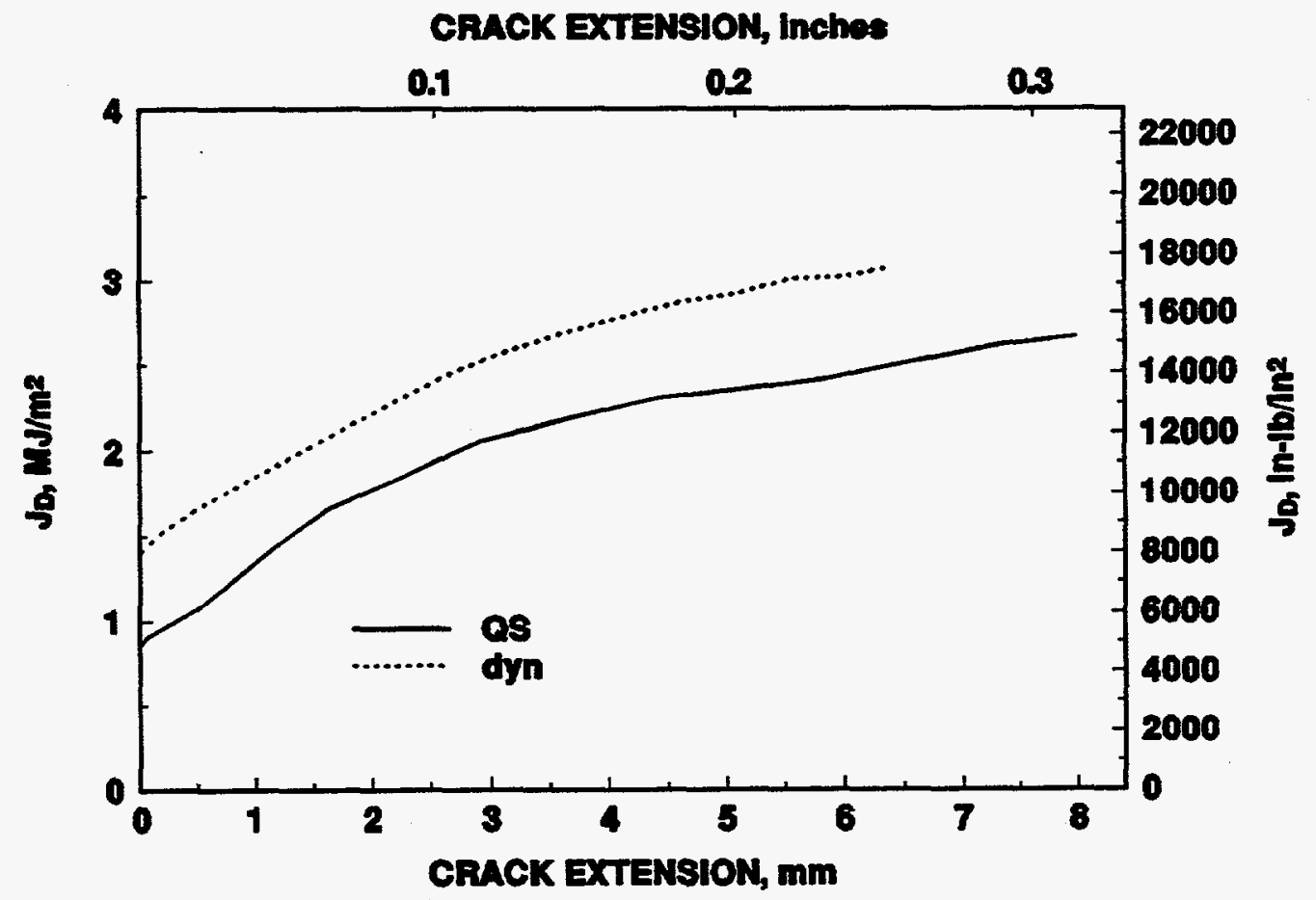

Figure 4.23 Quasi-static and dynamic J-R curves for Problems C.2-a and C.2-b 


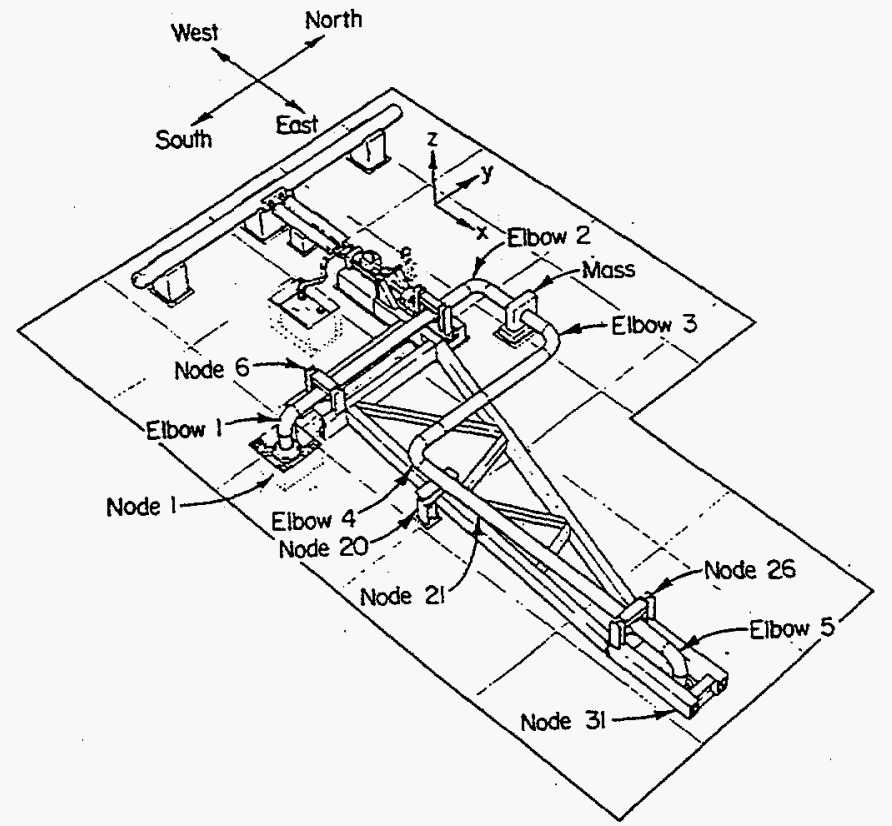

(a) Artist's conception

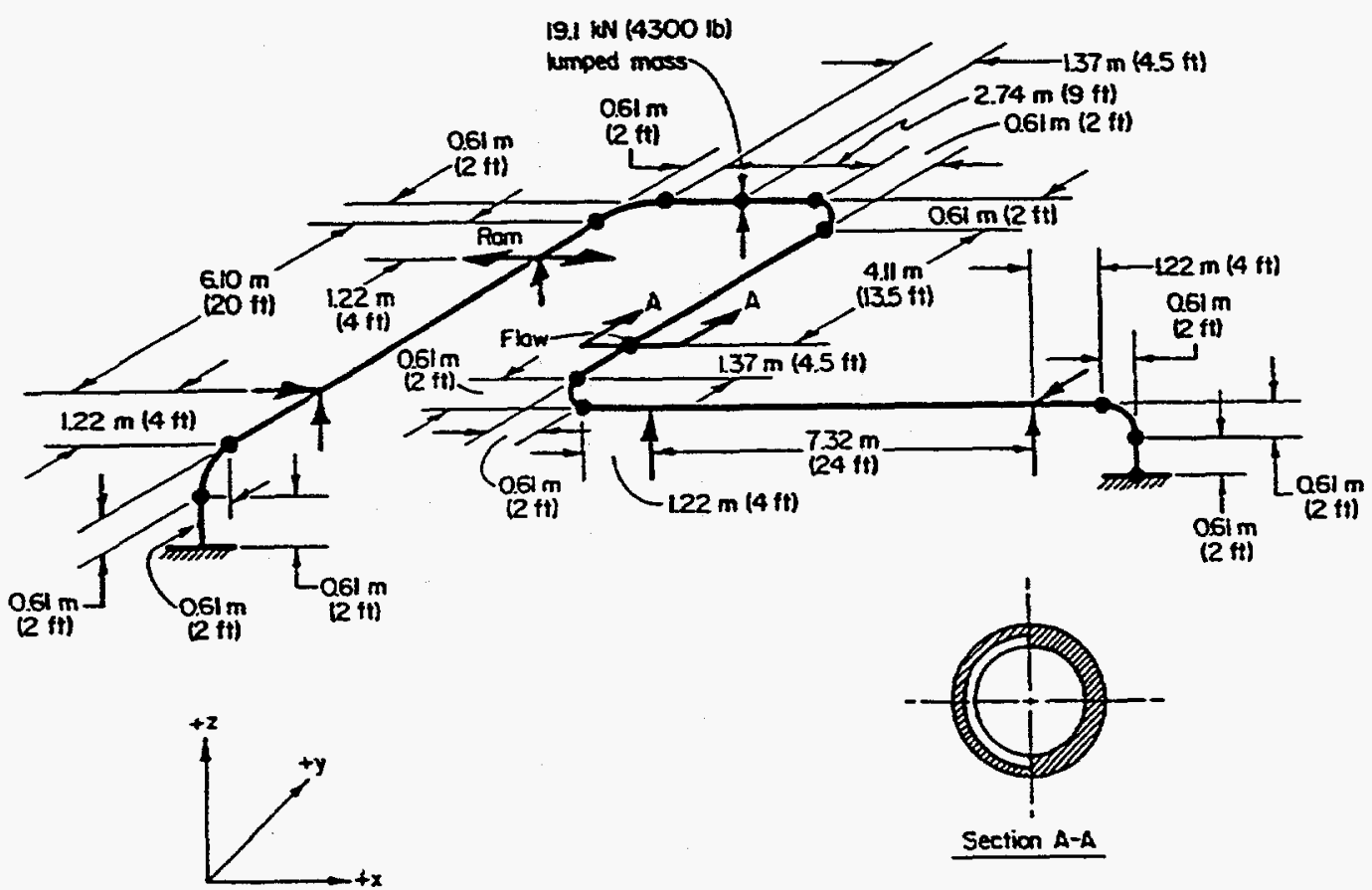

(b) Dimensions

Figure 4.24 IPIRG pipe system geometry 


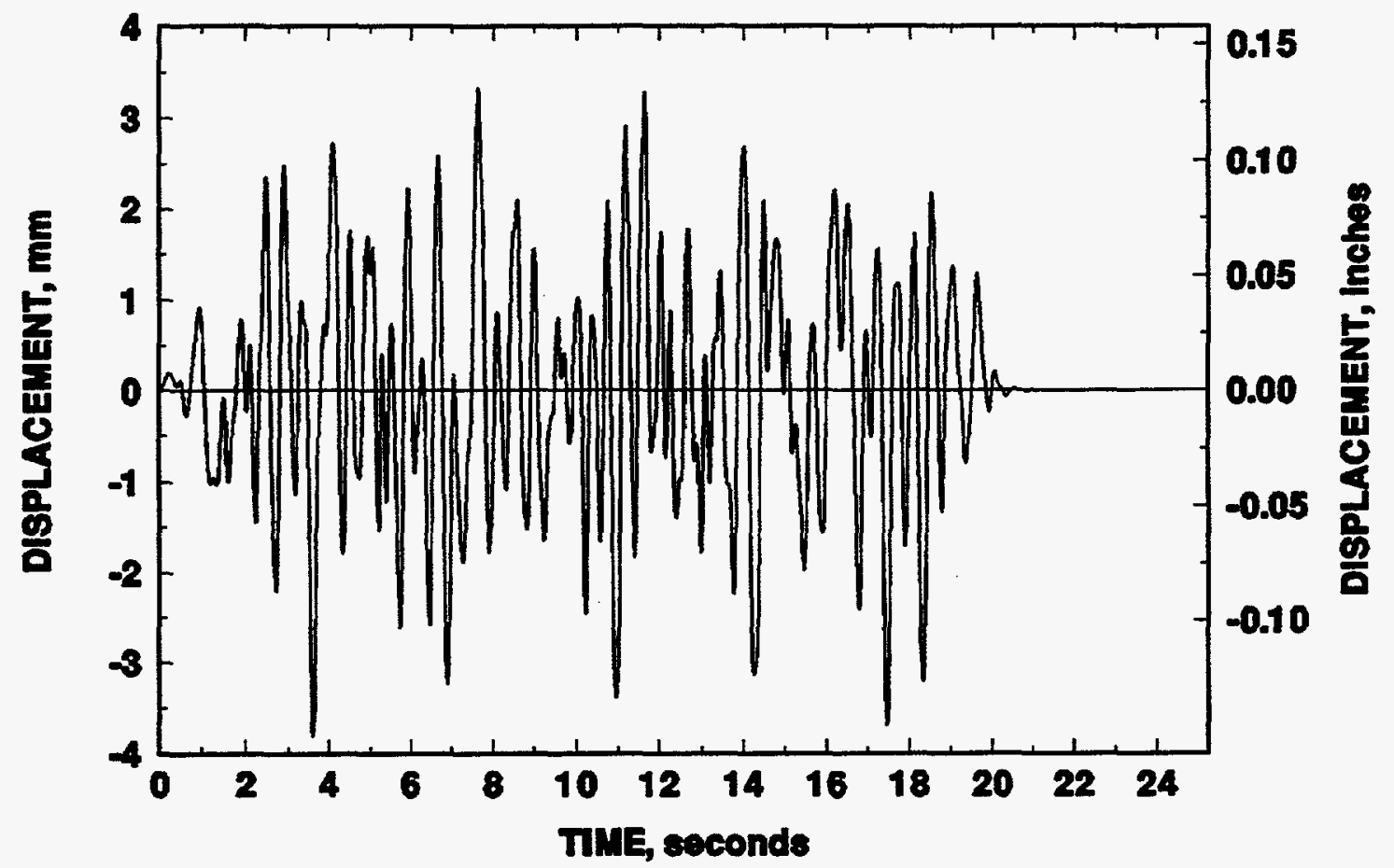

Figure 4.25 Forcing function in IPIRG-2 Experiment 1-1

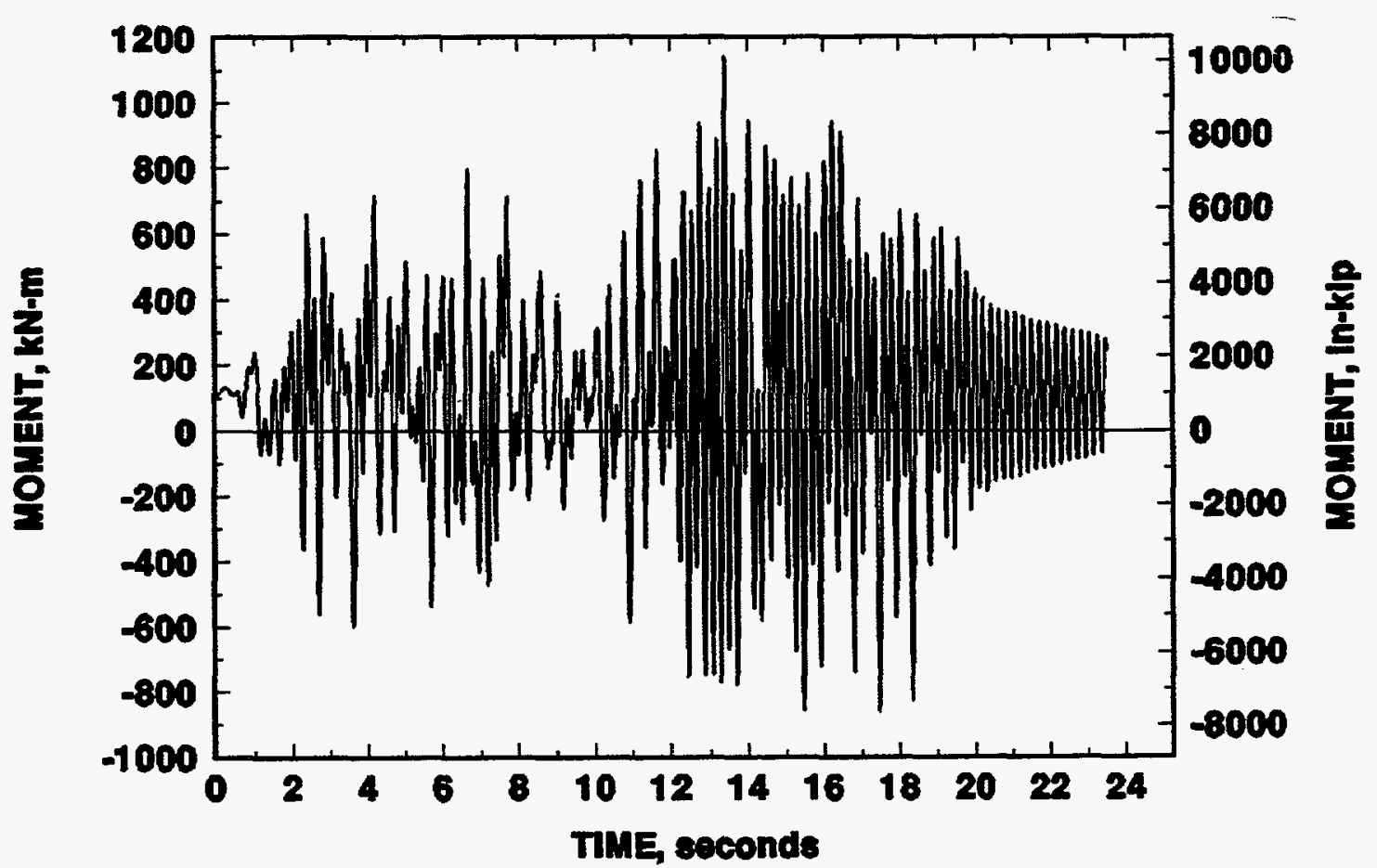

Figure 4.26 Typical linear-elastic stress analysis results for Problems C.2-a and C.2-b 



\subsection{ROUND-ROBIN PROBLEM SET D}

\subsection{Round-Robin Problem D.1 - Displacement Calculations for an Uncracked Elbow}

\subsubsection{Background}

In the IPIRG-1 Program (Ref 5.1), members of the Technical Advisory Group and Battelle conducted many finite element analyses of both uncracked and cracked IPIRG-1 pipe system tests. A common theme that was played out many times while the analyses were being conducted was that an analyst would make a subtle data input error or else a program feature would not function as the analyst expected. In either case, the results reported would not be correct, but the results, in many instances, would not be so incredible that they would raise suspicions.

To try to gain some understanding of the source of the discrepancies in finite element results for the IPIRG pipe system, an Analysts' Group Meeting was held at Battelle on September 25-26, 1989 to discuss the results that analysts were getting. In the end, it turned out that most of the discrepancies were caused by: (1) incomplete problem statements, (2) incorrect program inputs, (3) poorly documented program features, and (4) program errors. One issue that was not fully resolved at the meeting was discrepancies in solutions for the deflection of uncracked elbows loaded by pressure and forces. Solutions offered by various analysts differed substantially.

\subsubsection{Problem Definition}

The objective of Problem D.1 was to try to understand the origin of differences in elastic finite element solutions for uncracked elbows. The fact that elbow behavior may substantially influence the dynamics of a pipe system, and the fact that elbow specimens were to be tested in IPIRG-2 provided the motivation for pursuing this problem. With regard to the latter point, it was felt that if elastic analysis of elbows was uncertain, the complication of adding a crack would be overwhelming.

Problem D.1 consisted of a number of different load cases for an uncracked 90-degree elbow with tangent pipe on each end and the end of one of the tangent pipes held fixed per Figure 5.1. The required pipe information is as shown in Table 5.1, and the load cases considered are shown in Table 5.2. Predictions of the deflections of the free end of the unrestrained tangent pipe were requested in the problem statement.

\subsubsection{Summary and Conclusions}

Round-Robin Problem D.1 was first discussed in IPIRG-1 as Round-Robin Problem 4-2. Subsequently, it was re-introduced for consideration at the Third IPIRG-2 Technical Advisory Group (TAG) Meeting (August 2-6, 1993) and discussion was finally closed at the Fourth TAG Meeting (March 1-3, 1994). In the end, solutions to the problem were submitted by eight organizations, with many organizations offering multiple solutions using different programs, elements, or solution strategies. Convergence studies were performed in some cases, and several participants revised their 
solutions in light of discussions that took place prior to the 4th TAG Meeting. Tables 5.3 through 5.8 summarize the solutions offered for Round-Robin Problem D.1.

For purposes of discussion, the solutions can be conveniently divided into two categories: (1) the pressure only solutions, and (2) the applied load solutions. Except for the effect that pressure might have on stiffening an elbow, the pressure and applied load cases can be added to find the combined load solutions. Thus, if there is some defect in the pressure solution, it will manifest itself in the combined load cases.

Pressure in a capped-end elbow stiffens the elbow and should cause it to open. Much of the controversy associated with Round-Robin Problem D.1 was centered around this issue. In reviewing Table 5.3, there are a number of solutions that use pipe or beam-type elements that indicate that the $U_{x}$ and $U_{y}$ displacements are equal. These elements, which use curved beam elements with flexibility factors to model the elbow, are part of the foundation of most standard piping analysis programs. They are relatively simple elements that give a reasonable approximation to actual elbow behavior, but they do not include the pressure-induced moment loading which tends to open a pressurized elbow. Rather, these elements incorporate pressure loads as if the elbow segment was a complete torus. As a consequence, the elbow never opens up.

The shell and brick class of solutions, which nominally should be better than the curved-beam pipe solutions, exhibit an unexpected sensitivity to precisely how the pressure load is applied to the elbow. Through systematic investigation, it was discovered that the shell solutions could be changed rather dramatically by assuming that the internal pressure acted on the mean shell radius rather than the inner radius, or whether the end cap pressure was applied as element face pressures or as an equivalent elbow end load. The consensus opinion was that the $U_{x}=0.2 \mathrm{~mm}(0.008$ inch $), U_{y}=$ $1.8 \mathrm{~mm}(0.071 \mathrm{inch})$ solutions are correct for the pure pressure loading and that the others have one or more approximation errors.

In order to obtain shell solutions consistent with the closed-form and brick solutions, the following had to be done:

(1) The pressure had to be assumed to have a linear distribution from the specified internal pressure at the inner wall to zero at the outer wall. The pressure applied to the shell model is the pressure at the mid-surface of the pipe wall.

The end cap pressure is based on the mid-surface pressure and the mid-surface radius.

Without all of these conditions satisfied, an ABAQUS (Ref. 5.2) shell solution would not match the other solutions. The need for most of these requirements is not entirely obvious, and certainly, without the benefit of this Round-Robin problem, most analysts would not be sensitive to the need to specify the pressure and end cap loads this way.

Concerning the force-only solutions, Tables 5.4 and 5.5, all of the solutions are in fairiy close agreement. The ABAQUS nonlinear geometry solutions deviate the most from the rest of the 
solutions, but this may be explained by the fact that solution was found for a load of $1,978 \mathrm{kN}$ $(444,822 \mathrm{lb})$ and the displacements were simply scaled to a $100 \mathrm{kN}(22,481 \mathrm{lb})$ load. Technically, this is not appropriate for a nonlinear analysis.

A rather complete convergence study of elbow finite element mesh refinement, elbow element type, tangent (straight) pipe mesh refinement, and ABAQUS element integration order was undertaken by one of the Round-Robin Problem D.1 participants. From the results of these analyses, it was concluded that the linear ABAQUS elbow element (ELBOW31) with 24 elements in the elbow gave the most satisfactory results. Fewer, more sophisticated, elbow elements (ELBOW32) either degraded or did not improve the solution quality. The number and arrangement of straight pipe elements and integration order of the elbow elements had no significant impact on the solutions.

Because the solutions for the combined pressure and applied force cases are linear combinations of the pressure-only and force-only solutions, Tables 5.6 through 5.8 merely reflect superposition of solutions. If a particular pressure-only solution is poor, the combined load case solutions were affected. Due to the nature of the Round-Robin Problem D.1 geometry, small errors in the pressure solution, particularly as regards elbow opening behavior, are manifested as large changes in end displacements.

To summarize, all of the controversy that was associated with analyses of uncracked elbows was resolved. As in IPIRG-1, many of the differences in solutions can be traced to analysts not solving the same problem. The issue of pressure-only loading in the finite element programs remains somewhat problematic in that unless one has a very clear understanding of the theory for an element, one can get wrong answers that apparently look correct. Fortunately, the pressure contribution in most piping motion analyses is a small fraction of the total bending moment and axial force.

\subsection{References}

5.1 Schmidt, R. A., Wilkowski, G. M., and Mayfield, M. E., "The International Piping Integrity Research Group (IPIRG) Program: An Overview," Transactions of the 11th International Conference on Structural Mechanics in Reactor Technology, Vol. G2: Fracture Mechanics and Non-Destructive Evaluation - 2, Edited by H. Shibata, Tokyo, Japan, Paper No. G23/1, pp. 177-188, August 1991.

5.2 ABAQUS, User's Guide and Theoretical Manual, Versions 4.8 to 5.3, Hibbitt, Karlsson, \& Sorensen, Inc., Pawtucket, RI, 1993. 
Table 5.1 Pipe geometry and material property information for Round-Robin Problem D.1

\begin{tabular}{ll}
\hline \multicolumn{1}{c}{ Attribute } & Value \\
\hline Elbow Arc Length & 90 degrees \\
Elbow Radius of Curvature & $0.610 \mathrm{~m}$ (24.016 inches) \\
Outer Radius of Cross-Section & $0.203 \mathrm{~m}$ (7.992 inches) \\
Elbow Wall Thickness & $26.187 \mathrm{~mm}(1.031$ inches $)$ \\
Elastic Modulus & $210 \mathrm{GPa}(30.458 \mathrm{ksi})$ \\
Poisson's Ratio & 0.30 \\
\hline
\end{tabular}

Table 5.2 Load cases for Round-Robin Problem D.1

\begin{tabular}{cccc}
\hline Cases & $\begin{array}{c}\text { Internal Pressure, } \\
\mathbf{M P a}(\mathbf{p s i})\end{array}$ & $\begin{array}{c}\mathbf{F}_{\mathbf{x}}, \\
\mathbf{k N}(\mathbf{l b})\end{array}$ & $\begin{array}{c}\mathbf{F}_{\mathbf{y}}, \mathbf{k} \\
\mathbf{k N}(\mathbf{b})\end{array}$ \\
\hline Case A & $15(2,175)$ & 0 & 0 \\
Case B & 0 & $100(22,481)$ & 0 \\
Case C & 0 & 0 & $100(22,481)$ \\
Case D & $15(2,175)$ & $100(22,481)$ & 0 \\
Case E & $15(2,175)$ & 0 & $100(22,481)$ \\
Case F & $15(2,175)$ & $100(22,481)$ & $100(22,481)$ \\
\hline
\end{tabular}


Table 5.3 Results of load case A solution $\left[p=15 \mathrm{MPa}(2,175 \mathrm{psi}), \mathrm{F}_{\mathrm{x}}=0, \mathrm{~F}_{\mathrm{y}}=0\right]$

\begin{tabular}{|c|c|c|c|c|}
\hline Participant & Program & Comment & $\mathbf{U}_{\mathbf{x}}, \mathbf{m m}$ & $\mathrm{U}_{\mathrm{y}}, \mathbf{m m}$ \\
\hline A-2 & ANSYS & STIF16/STIF18 pipe w/ASME ff & 0.33 & 0.33 \\
\hline \multirow[t]{7}{*}{ B-3 } & ABAQUS & str:elbow32 @5, el:elbow31 @1 & 0.46 & 1.37 \\
\hline & & str:elbow32 @5, el:elbow31 @2 & 0.20 & 1.78 \\
\hline & & str:elbow32 @5, el:elbow31 @3 & 0.20 & 1.78 \\
\hline & & str:elbow32 @5, el:elbow31 @4 & 0.20 & 1.77 \\
\hline & & str:elbow32 @5, el:elbow31 @6 & 0.20 & 1.77 \\
\hline & & str:elbow32 @5, el:elbow31 @8 & 0.20 & 1.77 \\
\hline & & str:elbow32 @5, el:elbow31 @12 & 0.20 & 1.77 \\
\hline \multirow[t]{7}{*}{ v } & & str:elbow32 @5, el:elbow31 @24 & 0.20 & 1.77 \\
\hline & & str:elbow32 @5, el:elbow32 @1 & 56.64 & -85.71 \\
\hline & & str:elbow32@5, el:elbow32@2 & 15.73 & -22.46 \\
\hline & & str:elbow32@5, el:elbow32 @3 & 7.24 & -9.23 \\
\hline & & str:elbow32 @5, el:elbow32 @4 & 4.19 & -4.47 \\
\hline & & str:elbow32 @5, el:elbow32@6 & 1.98 & -1.02 \\
\hline & & str:elbow32 @5, el:elbow32@12 & 0.65 & 1.07 \\
\hline C & ANSYS & STIF16/STIF18 pipe & 0.33 & 0.33 \\
\hline \multirow[t]{5}{*}{ D } & ANSYS & STIF16/STIF18 pipe w/ASME ff & 0.33 & 0.33 \\
\hline & ABAQUS & shell & 0.10 & 4.55 \\
\hline & & brick & 0.06 & 4.80 \\
\hline & & elbow31 & 0.18 & 1.8 \\
\hline & BPAC20 & Novozihlov shell & 0.21 & 1.75 \\
\hline \multirow[t]{2}{*}{ E-2 } & ABAQUS & pipe31/elbow31B small-rot & 0.20 & 1.69 \\
\hline & & pipe31/elbow31 nl geom & 10.8 & 15.10 \\
\hline \multirow[t]{3}{*}{ F-2 } & ASTER & beam & 206.80 & -304.30 \\
\hline & & shell & -29.60 & 48.74 \\
\hline & & brick & 0.24 & 1.80 \\
\hline \multirow[t]{4}{*}{ F-3 } & CASTEM 2000 & beam & 0.82 & 0.82 \\
\hline & & shell & 0.29 & 2.10 \\
\hline & & brick & 0.25 & 1.82 \\
\hline & analytic & - & 0.82 & 0.82 \\
\hline
\end{tabular}


Table 5.4 Results of load case B solution $\left[p=0, F_{x}=100 \mathrm{kN}(22,481 \mathrm{lb}), F_{y}=0\right]$

\begin{tabular}{|c|c|c|c|c|}
\hline Organization & Program & Comment & $\mathbf{U}_{\mathbf{x}}, \mathbf{m m}$ & $\mathrm{U}_{\mathbf{y}}, \mathbf{m m}$ \\
\hline \multirow[t]{3}{*}{ A-2 } & ANSYS & STIF16/STIF18 pipe w/ASME ff & 14.20 & -22.35 \\
\hline & ABAQUS & pipe31/elbow31 & 14.42 & -22.47 \\
\hline & & pipe31/elbow32 & 13.60 & -20.51 \\
\hline \multirow[t]{14}{*}{ B-3 } & ABAQUS & str:elbow32 @5, el:elbow31 @1 & 15.08 & -23.94 \\
\hline & & str:elbow32 @5, el:elbow31 @2 & 14.41 & -22.62 \\
\hline & & str:elbow32 @5, el:elbow31 @3 & 14.30 & -22.37 \\
\hline & & str:elbow32 @5, el:elbow31 @4 & 14.26 & -22.28 \\
\hline & & str:elbow32 @5, el:elbow31 @6 & 14.24 & -22.22 \\
\hline & & str:elbow32 @5, el:elbow31 @8 & 14.23 & -22.20 \\
\hline & & str:elbow32 @5, el:elbow31 @12 & 14.22 & -22.18 \\
\hline & & str:elbow32 @5, el:elbow31 @24 & 14.22 & -22.17 \\
\hline & & str:elbow32 @5, el:elbow32 @1 & 14.23 & -22.21 \\
\hline & & str:elbow32 @5, el:elbow32 @2 & 14.22 & -22.17 \\
\hline & & str:elbow32 @5, el:elbow32 @3 & 14.22 & -22.17 \\
\hline & & str:elbow32 @5, el:elbow32 @4 & 14.22 & -22.17 \\
\hline & & str:elbow32 @5, el:elbow32 @6 & 14.22 & -22.17 \\
\hline & & str:elbow32 @5, el:elbow32 @12 & 14.22 & -22.17 \\
\hline C & ANSYS & STIF16/STIF18 pipe & 14.24 & -22.41 \\
\hline \multirow[t]{5}{*}{ D } & ANSYS & STIF16/STIF 18 pipe w/ASME ff & 14.20 & -22.35 \\
\hline & ABAQUS & shell & 14.12 & -22.25 \\
\hline & & brick & 13.98 & -22.08 \\
\hline & & elbow31 & 13.86 & --21.95 \\
\hline & BPAC20 & Novozihiov shell & 14.18 & -22.17 \\
\hline \multirow[t]{3}{*}{$\mathrm{E}-2$} & ABAQUS & pipe31/elbow31B small-rot & 14.05 & -22.34 \\
\hline & & pipe31/elbow31 nl geom & 11.37 & -16.27 \\
\hline & IMAGES3D & pipe $w / f f=1.41$ & 13.85 & -21.38 \\
\hline \multirow[t]{3}{*}{ F-2 } & ASTER & beam & 14.01 & -20.61 \\
\hline & & shell & 13.53 & -21.14 \\
\hline & & brick & 14.00 & -21.87 \\
\hline \multirow[t]{4}{*}{ F-3 } & CASTEM2000 & beam & 13.92 & -22.33 \\
\hline & & shell & 14.24 & -22.27 \\
\hline & & brick & 13.92 & -21.16 \\
\hline & analytic & - & 13.92 & -22.30 \\
\hline \multirow[t]{9}{*}{$F-4$} & CASTEM2000 & beam & 13.74 & -20.58 \\
\hline & & pipe & 13.91 & -22.18 \\
\hline & & thin shell, linear & 14.50 & -22.29 \\
\hline & & thin shell, nl geom & 14.25 & -21.86 \\
\hline & & thick shell, linear & 14.16 & -21.99 \\
\hline & & brick, 8 nodes & 13.62 & -20.89 \\
\hline & & brick, 20 nodes & 13.98 & -21.85 \\
\hline & closed-form & $\mathrm{RCCM}$ & 13.92 & -22.33 \\
\hline & & Roark & 13.95 & -22.64 \\
\hline
\end{tabular}


Table 5.5 Results of load case $C$ solution $\left[p=0, F_{x}=0, F_{y}=100 \mathrm{kN}(22,481 \mathrm{lb})\right]$

\begin{tabular}{|c|c|c|c|c|}
\hline Organization & Program & Comment & $\mathrm{U}_{\mathrm{x}}, \mathrm{mm}$ & $\mathbf{U}_{\mathbf{y}}, \mathbf{m m}$ \\
\hline \multirow[t]{3}{*}{ A-2 } & ANSYS & STIF16/STIF18 pipe w/ASME ff & -22.35 & 77.97 \\
\hline & ABAQUS & pipe31/elbow31 & -22.47 & 72.32 \\
\hline & & pipe31/elbow32 & -20.51 & 72.20 \\
\hline \multirow[t]{14}{*}{ B-3 } & ABAQUS & str:elbow32 @5, el:elbow31 @1 & -23.94 & 71.11 \\
\hline & & str:elbow32 @5, el:elbow31 @2 & -22.62 & 72.49 \\
\hline & & str:elbow32 @5, el:elbow31 @3 & -22.37 & 72.67 \\
\hline & & str:elbow32 @5, el:elbow31@4 & -22.28 & 72.71 \\
\hline & & str:elbow32 @5, el:elbow31 @6 & -22.22 & 72.72 \\
\hline & & str:elbow32 @5, el:elbow31 @8 & -22.20 & 72.72 \\
\hline & & str:elbow32@5, el:elbow31@12 & -22.18 & 72.72 \\
\hline & & str:elbow32 @5, el:elbow31@24 & -22.17 & 72.72 \\
\hline & & str:elbow32 @5, el:elbow32 @1 & -22.21 & 72.90 \\
\hline & & str:elbow32 @5, el:elbow32 @2 & -22.17 & 72.75 \\
\hline & & str:elbow32 @5, el:elbow32 @3 & -22.17 & 72.73 \\
\hline & & str:elbow32 @5, el:elbow32 @4 & -22.17 & 72.73 \\
\hline & & str:elbow32 @5, el:elbow32@6 & -22.17 & 72.72 \\
\hline & & str:elbow32@5, el:elbow32@12 & -22.17 & 72.72 \\
\hline C & ANSYS & STIF16/STIF18 pipe & -22.41 & 78.09 \\
\hline \multirow[t]{5}{*}{$\mathrm{D}$} & ANSYS & STIF16/STIF18 pipe w/ASME ff & -22.35 & 77.97 \\
\hline & ABAQUS & shell & -22.25 & 76.03 \\
\hline & & brick & -22.08 & 75.71 \\
\hline & & elbow31 & -21.95 & 72.06 \\
\hline & BPAC20 & Novozihlov shell & -22.13 & 72.71 \\
\hline \multirow[t]{3}{*}{$\mathrm{E}-2$} & ABAQUS & pipe31/elbow31B small-rot & -22.34 & 76.31 \\
\hline & & pipe31/elbow31 nl geom & -28.76 & 58.63 \\
\hline & IMAGES3D & pipe $w / f f=1.41$ & -21.38 & 63.17 \\
\hline \multirow[t]{3}{*}{ F-2 } & ASTER & beam & -20.61 & 51.95 \\
\hline & & shell & -21.15 & 69.95 \\
\hline & & brick & -21.87 & 71.52 \\
\hline \multirow[t]{4}{*}{$F-3$} & CASTEM 2000 & beam & -22.33 & 77.63 \\
\hline & & shell & -22.27 & 72.86 \\
\hline & & brick & -21.16 & 61.52 \\
\hline & analytic & - & -22.33 & 77.70 \\
\hline \multirow[t]{9}{*}{ F-4 } & CASTEM 2000 & beam & -20.58 & 51.67 \\
\hline & & pipe & -22.18 & 75.51 \\
\hline & & thin shell, linear & -22.30 & 69.44 \\
\hline & & thin shell, nl geom & -20.84 & 68.93 \\
\hline & & thick shell, linear & -21.01 & 69.14 \\
\hline & & brick, 8 nodes & -20.65 & 61.71 \\
\hline & & brick, 20 nodes & -21.16 & 71.81 \\
\hline & closed-form & $\mathrm{RCCM}$ & -22.33 & 77.68 \\
\hline & & Roark & -22.64 & 82.31 \\
\hline
\end{tabular}


Table 5.6 Results of load case $D$ solution $\left[p=15 \mathrm{MPa}(2,175 \mathrm{psi}), \mathrm{F}_{\mathrm{x}}=100 \mathrm{kN}(22,481 \mathrm{lb}), \mathrm{F}_{\mathrm{y}}=0\right]$

\begin{tabular}{|c|c|c|c|c|}
\hline Organization & Program & Comment & $\mathbf{U}_{\mathbf{x}}, \mathbf{m m}$ & $\mathbf{U}_{\mathbf{y}}, \mathbf{m m}$ \\
\hline \multirow[t]{2}{*}{$A-2$} & ANSYS & STIF16/STIF18 pipe w/ASME ff & 14.52 & -21.88 \\
\hline & ABAQUS & pipe31/elbow31 & 14.54 & -22.02 \\
\hline \multirow[t]{14}{*}{ B-3 } & ABAQUS & str:elbow32 @5, el:elbow31@1 & 15.55 & -22.57 \\
\hline & & str:elbow32 @5, el:elbow31 @2 & 14.61 & -20.83 \\
\hline & & str:elbow32 @5, el:elbow31 @3 & 14.50 & -20.59 \\
\hline & & str:elbow32 @5, el:elbow31 @4 & 14.46 & -20.51 \\
\hline & & str:elbow32 @5, el:elbow31 @6 & 14.44 & -20.45 \\
\hline & & str:elbow32 @5, el:elbow31 @8 & 14.43 & -20.43 \\
\hline & & str:elbow32 @5, el:elbow31 @12 & 14.42 & -20.41 \\
\hline & & str:elbow32 @5, el:elbow31 @24 & 14.42 & -20.40 \\
\hline & & str:elbow32 @5, el:elbow32 @1 & 70.87 & -107.9 \\
\hline & & str:elbow32 @5, el:elbow32 @2 & 29.94 & -44.63 \\
\hline & & str:elbow32 @5, el:elbow32@3 & 21.46 & -31.40 \\
\hline & & str:elbow32 @5, el:elbow32 @4 & 18.41 & -26.63 \\
\hline & & str:elbow32 @5, el:elbow32 @6 & 16.20 & -23.19 \\
\hline & & str:elbow32 @5, el:elbow32 @12 & 14.87 & -21.10 \\
\hline $\mathrm{C}$ & ANSYS & STIF16/STIF18 pipe & 14.56 & -21.92 \\
\hline \multirow[t]{5}{*}{ D } & ANSYS & STIF16/STIF18 pipe w/ASME ff & 14.52 & -21.88 \\
\hline & ABAQUS & shell & -17.75 & -33.03 \\
\hline & & brick & 14.04 & -17.28 \\
\hline & & elbow31 & 14.05 & -20.16 \\
\hline & sup-pos & Novozihlov shell & 14.39 & -20.41 \\
\hline \multirow[t]{2}{*}{ E-2 } & ABAQUS & pipe31/elbow31B small-rot & 14.24 & -22.10 \\
\hline & & pipe31/elbow31 nl geom & 22.08 & -31.12 \\
\hline F-3 & CASTEM & beam & 14.73 & -21.37 \\
\hline
\end{tabular}


Table 5.7 Results of load case $E$ solution $\left[p=15 \mathrm{MPa}(2,175 \mathrm{psi}), \mathrm{F}_{\mathrm{x}}=0, \mathrm{~F}_{\mathrm{y}}=100 \mathrm{kN}(22,481 \mathrm{lb})\right]$

\begin{tabular}{|c|c|c|c|c|}
\hline Organization & Program & Comment & $\mathbf{U}_{\mathbf{x}}, \mathbf{m m}$ & $\mathbf{U}_{\mathbf{y}}, \mathbf{m m}$ \\
\hline \multirow[t]{2}{*}{ A-2 } & ANSYS & STIF16/STIF18 pipe w/ASME ff & 21.88 & 76.15 \\
\hline & ABAQUS & pipe31/elbow31 & -22.02 & 78.30 \\
\hline \multirow[t]{14}{*}{ B-3 } & ABAQUS & str:elbow32@5, el:elbow31 @1 & -23.47 & 72.48 \\
\hline & & str:elbow32@5, el:elbow31 @2 & -22.41 & 74.28 \\
\hline & & str:elbow32@5, el:elbow31@3 & -22.17 & 74.46 \\
\hline & & str:elbow32@5, el:elbow31@4 & -22.08 & 74.48 \\
\hline & & str:elbow32@5, el:elbow31@6 & -22.02 & 74.49 \\
\hline & & str:elbow32@5, el:elbow31 @8 & -21.99 & 74.49 \\
\hline & & str:elbow32@5, el:elbow31 @12 & -21.98 & 74.49 \\
\hline & & str:elbow32 @5, el:elbow31 @24 & -21.97 & 74.49 \\
\hline & & str:elbow32@5, el:elbow32@1 & 34.43 & -12.81 \\
\hline & & str:elbow32 @5, el:elbow32 @2 & -6.45 & 50.28 \\
\hline & & str:elbow32 @5, el:elbow32@3 & -14.93 & 63.50 \\
\hline & & str:elbow32@5, el:elbow32@4 & -17.98 & 68.26 \\
\hline & & str:elbow32 @5, el:elbow32@6 & -20.18 & 71.70 \\
\hline & & str:elbow32@5, el:elbow32@12 & -21.52 & 73.79 \\
\hline $\mathrm{C}$ & ANSYS & STIF16/STIF18 pipe & -21.93 & 76.27 \\
\hline \multirow[t]{5}{*}{$\mathrm{D}$} & ANSYS & STIF16/STIF18 pipe w/ASME ff & -21.88 & 76.15 \\
\hline & ABAQUS & shell & -54.12 & 131.31 \\
\hline & & brick & -22.01 & 80.51 \\
\hline & & elbow31 & -21.77 & 73.86 \\
\hline & sup-pos & Novozihlov shell & -21.93 & 74.47 \\
\hline \multirow[t]{2}{*}{ E-2 } & ABAQUS & pipe31/elbow31B small-rot & -22.15 & 77.97 \\
\hline & & pipe31/elbow31 nl geom & -18.05 & 43.28 \\
\hline F-3 & CASTEM & beam & -21.37 & 76.31 \\
\hline
\end{tabular}


Table 5.8 Results of load case F solution $\left[p=15 \mathrm{MPa}(2,175 \mathrm{psi}), \mathrm{F}_{\mathrm{x}}=\mathrm{F}_{\mathrm{y}}=100 \mathrm{kN}(22,481 \mathrm{lb})\right]$

\begin{tabular}{|c|c|c|c|c|}
\hline Organization & Program & Comment & $\mathrm{U}_{\mathrm{x}}, \mathbf{m m}$ & $\mathbf{U}_{\mathbf{y}}, \mathbf{m m}$ \\
\hline A-2 & ANSYS & STIF16/STIF18 pipe w/ASME ff & -7.69 & 53.94 \\
\hline $\mathrm{C}$ & ANSYS & STIF16/STIF18 pipe & -7.71 & 54.01 \\
\hline \multirow[t]{14}{*}{ B-3 } & ABAQUS & str:elbow32@5, el:elbow31 @1 & -8.39 & 48.54 \\
\hline & & str:elbow32 @5, el:elbow31 @2 & -8.00 & 51.66 \\
\hline & & str:elbow32 @5, el:elbow31 @3 & -7.87 & 52.09 \\
\hline & & str:elbow32@5, el:elbow31 @4 & -7.82 & 52.20 \\
\hline & & str:elbow32 @5, el:elbow31 @6 & -7.78 & 52.27 \\
\hline & & str:elbow32@5, el:elbow31 @8 & -7.76 & 52.29 \\
\hline & & str:elbow32 @5, el:elbow31 @12 & -7.75 & 52.31 \\
\hline & & str:elbow32 @5, el:elbow31 @24 & -7.75 & 52.32 \\
\hline & & str:elbow32 @5, el:elbow32@1 & 48.65 & -35.02 \\
\hline & & str:elbow32 @5, el:elbow32 @2 & 7.77 & 28.11 \\
\hline & & str:elbow32@5, el:elbow32@3 & -0.71 & 41.33 \\
\hline & & str:elbow32@5, el:elbow32@4 & -3.76 & 46.09 \\
\hline & & str:elbow32@5, el:elbow32@6 & -5.97 & 49.54 \\
\hline & & str:elbow32 @5, el:elbow32 @12 & -7.30 & 51.63 \\
\hline \multirow[t]{5}{*}{$\mathrm{D}$} & ANSYS & STIF16/STIF18 pipe w/ASME ff & -7.69 & 53.94 \\
\hline & ABAQUS & shell & -40.00 & 109.06 \\
\hline & & brick & -8.04 & 58.43 \\
\hline & & elbow31 & -7.90 & 51.92 \\
\hline & sup-pos & Novozihlov shell & -7.74 & 52.30 \\
\hline \multirow[t]{2}{*}{$\mathrm{E}-2$} & ABAQUS & pipe31/elbow31B small-rot & -8.10 & 55.68 \\
\hline & & pipe31/elbow31 nl geom & 4.34 & 17.70 \\
\hline F-3 & CASTEM & beam & -7.46 & 56.12 \\
\hline
\end{tabular}




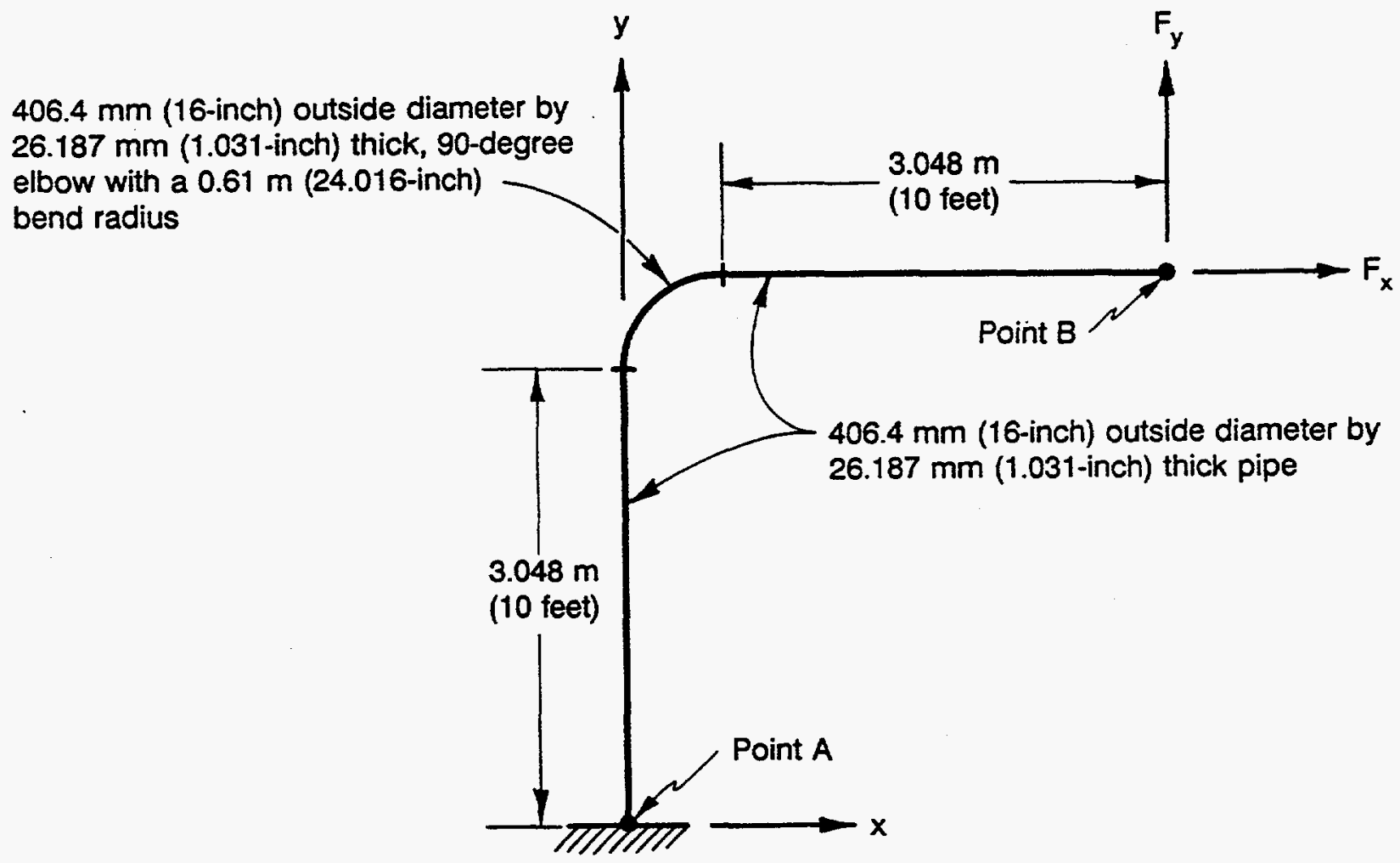

Figure 5.1 Elbow geometry for Problem D.1 


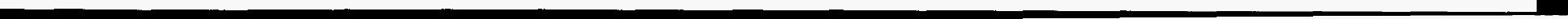




\section{APPENDIX A DEFINITION OF PROBLEM SET A}

\section{A.1 Problem A.1 - Predictions of J-R Curves and Tensile Properties Using Mill Data}

\section{Specific Objective:}

Frequently, the only information available on the properties of a pipe material are the mill data. This would include tensile properties at room temperature, and perhaps Charpy impact data at a few temperatures from room to 0 -degrees Fahrenheit. The specific objective is to calculate the properties at the service temperature using typical mill data.

\section{Given Information:}

Tables A.1, A.2, and A.3 define the mill data at low temperatures for Materials A, B; and C, respectively.

Table A.1 Low-temperature mill data for Material A

\begin{tabular}{lcccc}
\hline & \multicolumn{4}{c}{ Material A } \\
\hline Temperature, C & 20 & 25 & 13 & 0 \\
Yield Strength, MPa & 277 & & & \\
Ultimate Strength, MPa & 519 & & & \\
Reduction in Area, percent & 80.5 & & & \\
Charpy V-notch Energy, Joules & & 54.2 & 43.4 & 19.0 \\
Charpy V-notch Shear Area, percent & & 43 & 25 & 27 \\
\hline
\end{tabular}

Table A.2 Low-temperature mill data for Material B

\begin{tabular}{lcccc}
\hline & \multicolumn{5}{c}{ Material B } \\
\hline Temperature, C & 20 & 23.9 & 12.8 & 0 \\
Yield Strength, MPa & 269 & & & \\
Ultimate Strength, MPa & 439 & & & \\
Reduction in Area, percent & 51.6 & & & \\
Charpy V-notch Energy, Joules & & 135.6 & 122.0 & 69.2 \\
Charpy V-notch Shear Area, percent & & 60 & 55 & 30 \\
\hline
\end{tabular}


Table A.3 Low-temperature mill data for Material C

\begin{tabular}{lcccc}
\hline & \multicolumn{4}{c}{ Material C } \\
\hline Temperature, C & 20 & 23 & 0 & -18 \\
Yield Strength, MPa & & & & \\
Ultimate Strength, MPa & 46.4 & & & \\
Reduction in Area, percent & & 182 & 155.0 & 113.0 \\
Charpy V-notch Energy, Joules & & 67 & 52 & 38 \\
Charpy V-notch Shear Area, percent & & 67 &
\end{tabular}

Note: Material A is an A106 Grade B carbon steel pipe, Material B is an A517 Grade 70 ferritic steel, and Material $C$ is a ferritic steel weld.

\section{Problem Statement:}

For each of the three materials, determine the following. Show the relationships you used. Actual data at $288 \mathrm{C}$ will be given at the workshop. Calculate the following:

Problem A.1-a: Yield and ultimate strength at $288 \mathrm{C}$,

Problem A.1-b: Ramberg-Osgood coefficients at $288 \mathrm{C}$, (Use yield strength as $\sigma_{0}$, assume elastic modulus is $193.0 \mathrm{GPa}$ ),

Problem A.1-c: J value at crack initiation at $288 \mathrm{C}$,

Problem A.1-d: Initial $\mathrm{dJ} / \mathrm{da}$ at $288 \mathrm{C}$, and

Problem A.1-e: $\quad$ Entire J-R curve in power-law form at $288 \mathrm{C}$.

[Use power-law form of $\mathrm{J}=\mathrm{J}_{\mathrm{Ic}}+\mathrm{C}(\Delta \mathrm{a})^{\mathrm{m}}$.]

Please supply answers in SI units. Battelle will also translate the compiled results to U.S. Customary units in the summary of the results. 


\section{A.2 Problem A.2-a ${ }^{(a)}$ - Evaluation of J-R Curves Using Various International Standards}

\section{Specific Objective:}

To assess the differences in calculated J-R curves using different international standards.

\section{Given Information:}

The specimen size is a standard $1 \mathrm{~T} \mathrm{C(T),} \mathrm{by} \mathrm{U.S.} \mathrm{(ASTM)} \mathrm{designation,} \mathrm{or} \mathrm{a} 25 \mathrm{~T} \mathrm{C(T)}$ using SI unit designation. The precise measurements are:
Width of $50.8 \mathrm{~mm}$
Height of $60.96 \mathrm{~mm}$
Thickness of $20.85 \mathrm{~mm}$
Initial crack length of $26.97 \mathrm{~mm}$
Side-grooves of $1.98 \mathrm{~mm}$ on each side.

The test temperature is $288 \mathrm{C}$, and the yield and ultimate strength values are $231 \mathrm{MPa}$ and $504 \mathrm{MPa}$, respectively.

The load, load-line displacement, and crack growth data are supplied in the following table. For the crack growth, the average values are given, and photographs of three specimens are supplied to allow the participant to determine the crack length to any standard he chooses rather than using the average crack length values given in Table A.4.

Note: The data in Table A.4 were generated from four identical C(T) specimens where the data were also in very close agreement.

\section{Problem Statement:}

Using the data in Table A.4 and Figures A.1 through A.3, calculate the J-R curve by the various international standards that you are familiar with, i.e., ASTM, JSME, ISO, European, etc. Provide a table of data for each case, and send a digital ASCII file for PC use to Battelle.

Please supply answers in SI units. Battelle will also translate the compiled results to U.S. Customary units in their summary of the results.

(a) Problem A.2-a in this report was known as Problem A.2 in the First IPIRG-2 Round-Robin Workshop. This revision was needed due to the creation of Problem A.2-b discussed in the Second IPIRG-2 RoundRobin Workshop. 
Table A.4 Data for calculation of J-R curve in Problem A.2-a

\begin{tabular}{|c|c|c|}
\hline Load, N & $\begin{array}{c}\text { Load-Line } \\
\text { Displacement, } \mathbf{m m}\end{array}$ & $\begin{array}{c}\text { Average Crack } \\
\text { Growth, mm }\end{array}$ \\
\hline 4876 & 0.1245 & 0 \\
\hline 8780 & 0.1854 & 0 \\
\hline 13479 & 0.2362 & 0 \\
\hline 17869 & 0.2972 & 0 \\
\hline 21856 & 0.3962 & 0 \\
\hline 25846 & 0.5588 & 0 \\
\hline 29437 & 0.8814 & 0 \\
\hline 30990 & 1.0668 & 0 \\
\hline 32320 & 1.3157 & 0.081 \\
\hline 33428 & 1.5494 & 0.282 \\
\hline 34450 & 1.8847 & 0.640 \\
\hline 34849 & 2.2073 & 1.115 \\
\hline 34849 & 2.5552 & 1.649 \\
\hline 34663 & 2.8219 & $2.088^{(1)}$ \\
\hline 34450 & 2.9134 & 2.216 \\
\hline 33251 & 3.1369 & 2.880 \\
\hline 32366 & 3.4366 & 3.400 \\
\hline 31612 & 3.7465 & $3.912^{(2)}$ \\
\hline 31435 & 3.8456 & $4.358^{(3)}$ \\
\hline 30727 & 4.0691 & 5.022 \\
\hline
\end{tabular}

(1) Specimen 108, see Figure A.1 for more crack growth data.

(2) Specimen 107, see Figure A.2 for more crack growth data.

(3) Specimen 109, see Figure A.3 for more crack growth data. 


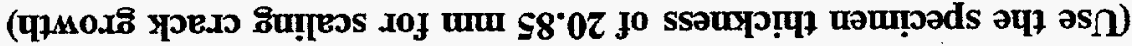

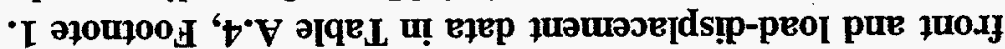

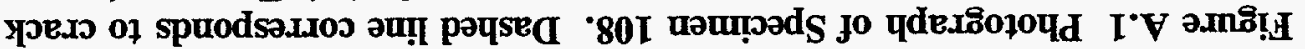

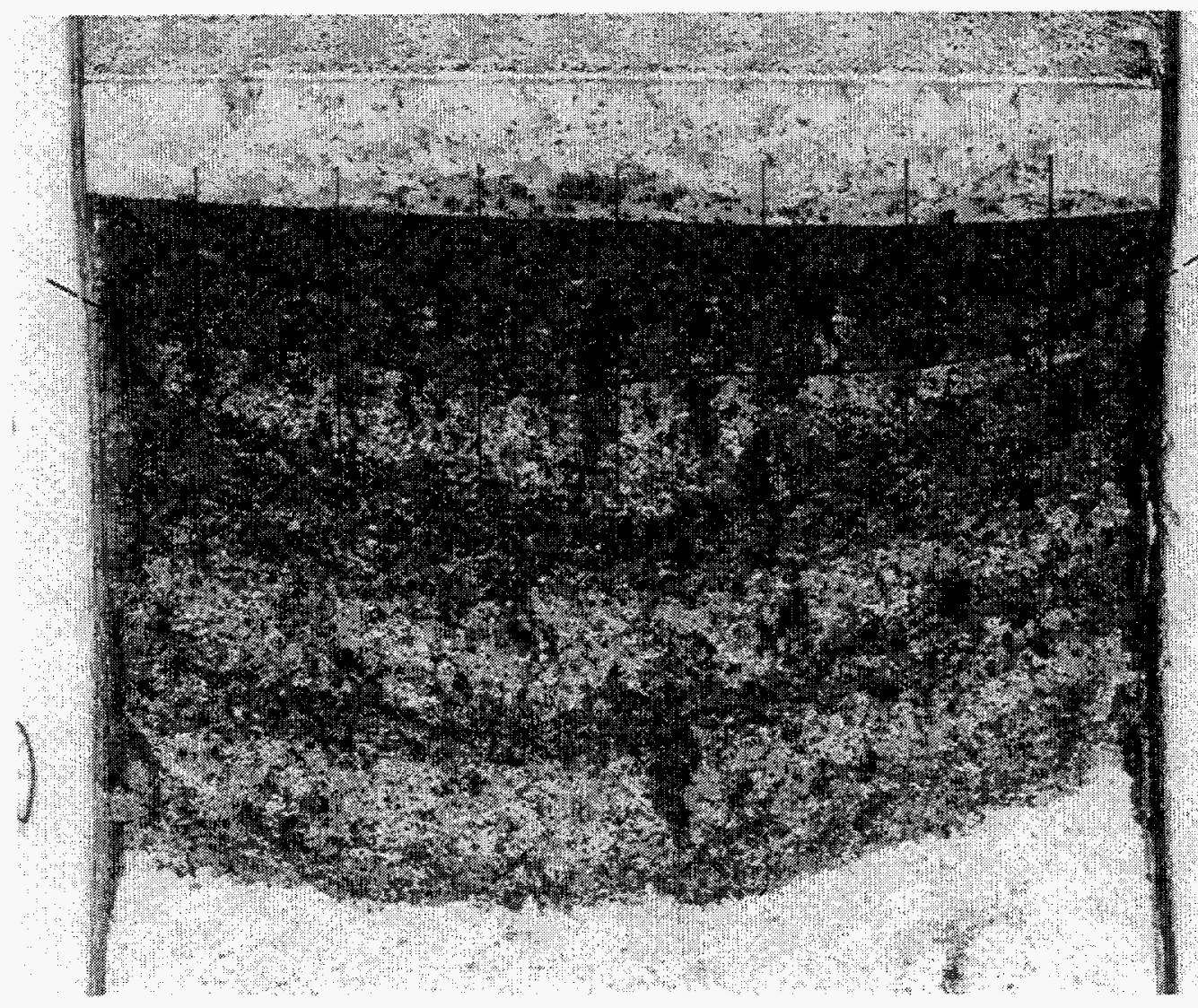




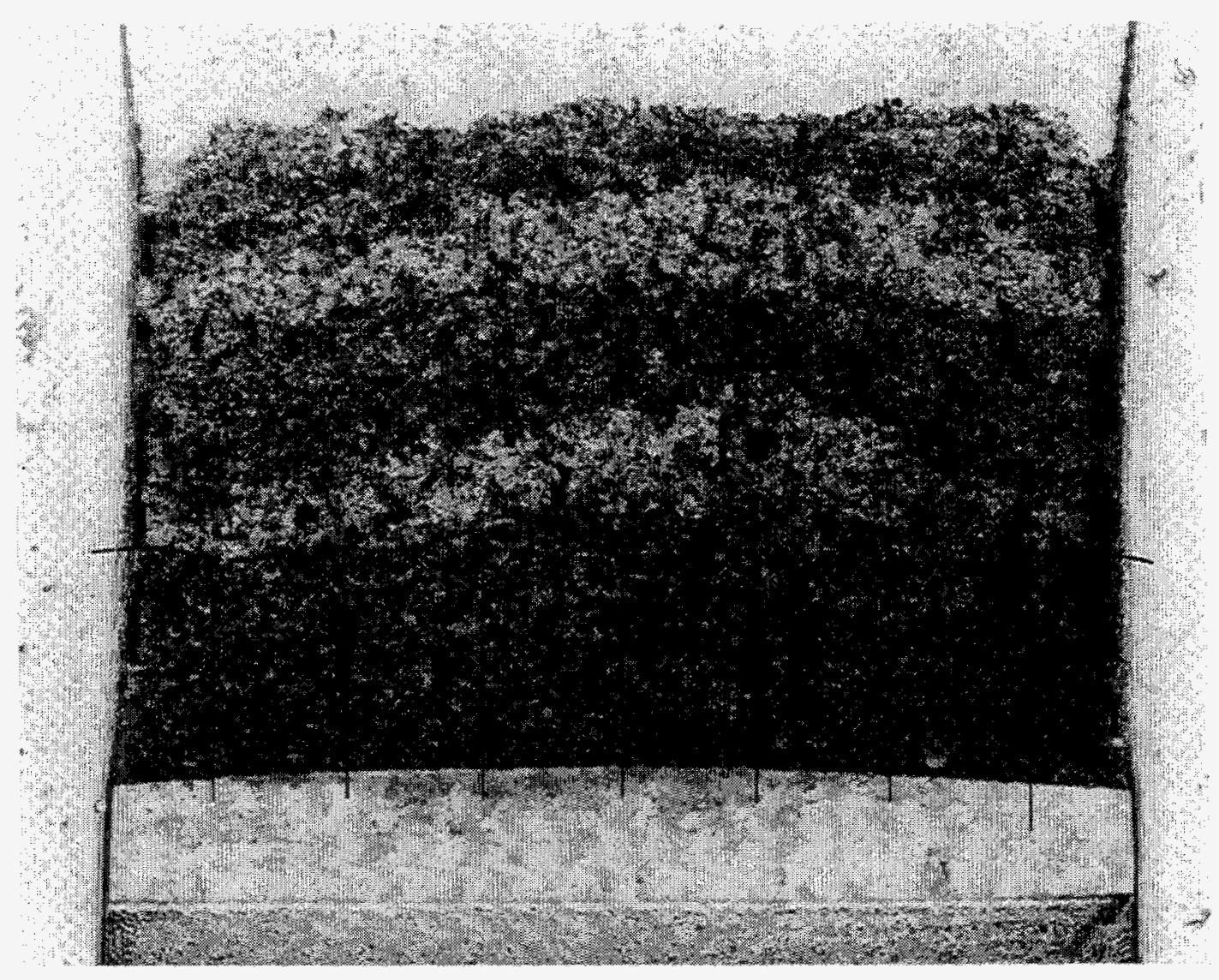

Figure A.2 Photograph of Specimen 107. Dashed line corresponds to crack front and load-displacement data in Table A.4, Footnote 2. (Use the specimen thickness of $\mathbf{2 0 . 8 5} \mathbf{~ m m}$ for scaling crack growth) 


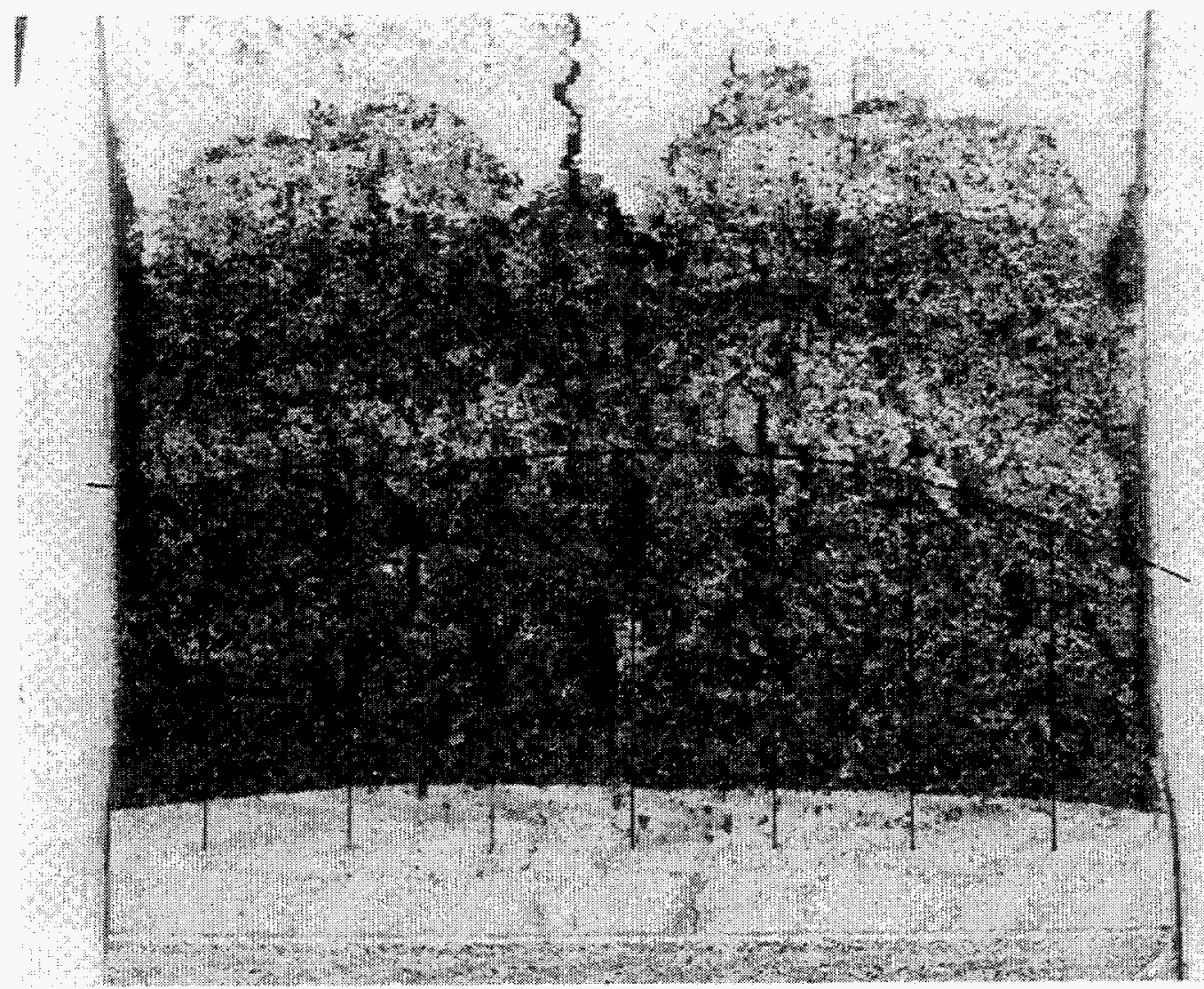

Figure A.3 Photograph of Specimen 109. Dashed line corresponds to crack front and load-displacement data in Table A.4, Footnote 3. (Use the specimen thickness of $\mathbf{2 0 . 8 5} \mathbf{~ m m}$ for scaling crack growth) 


\section{A.3 Problem A.2-b - Evaluation of J-R Curves Using Newly Proposed ASTM Standard}

\section{Specific Objective:}

To evaluate the proposed ASTM procedure entitled "Standard Test Method for Characterization of Fracture Toughness".

\section{Given Information:}

The specimen size is a standard 1T C(T), by U.S. (ASTM) designation, or a 25T C(T) using SI unit designation. The precise measurements are:

Width of $50.8 \mathrm{~mm}$

Height of $60.96 \mathrm{~mm}$

Thickness of $20.85 \mathrm{~mm}$

Initial crack length of $26.97 \mathrm{~mm}$

Side-grooves of $1.98 \mathrm{~mm}$ on each side.

The test temperature is $288 \mathrm{C}$, and the yield and ultimate strength values are $231 \mathrm{MPa}$ and $504 \mathrm{MPa}$, respectively.

The load, load-line displacement, and crack growth data are supplied in the following table. For the crack growth, the average values are given, and photographs of three specimens are supplied to allow the participant to determine the crack length to any standard he chooses rather than using the average crack length values given in Table A.4.

Note: The data in Table A.4 were generated from four identical $C(T)$ specimens using the electric potential method and the test geometry in Figure C1.2 of the proposed procedure. The four specimens were in close agreement. Crack lengths were calculated from Equation C1.1 of the proposed procedure. Assume that the physical crack length and electrical potential crack length were equal.

\section{Problem Statement:}

Using the data in Table A.4 (and Figures A.1 through A.3, if desired) calculate the J-R curve by the proposed ASTM procedure. Provide a table of data for each case, and preferably send a digital ASCII file for PC use or Fax a copy of the table to Battelle. Battelle will collect any comments that you would like us to forward to ASTM.

Please supply answers in SI units. Battelle will also translate the compiled results to U.S. Customary units in their summary of the results. 


\section{A.4 Problem A.3 - Fracture Load Evaluations Using J-R Curves from Various International Standards}

\section{Specific Objective:}

In Round-Robin Problem A.2, we examined the differences in calculating $\mathrm{J}$ using various international J-R curve standards. From that effort, we selected three J-R curves calculated in Problem A.2. These were the minimum, maximum and mean curves. The specific objective of this exercise is to see if there are any significant differences between the different $J-R$ curve predictions of initiation and maximum loads for cracked pipe.

\section{Given Information:}

Three different J-R curves for the same material from different J-R curve standards, as calculated in Problem A.2. The $J$ resistance curve is expressed as:

$$
\mathrm{J}=\mathrm{J}_{\mathrm{Ic}}+\mathrm{C}(\Delta \mathrm{a} / \mathrm{a})^{\mathrm{m}}
$$

where $J$ is expressed in $\mathrm{kN} / \mathrm{m}, J_{\mathrm{Ic}}$ is the value of $J$ at crack initiation, $\Delta \mathrm{a}$ is crack growth in mm, and $\mathrm{a}^{*}$ is a normalizing parameter equal to $1 \mathrm{~mm}$. Values of the parameters to be used in this problem are given in Table A.5. The Problem A.1 parameters were obtained from J-R estimates based on tensile and Charpy impact data. The Problem A.2 parameters were calculated from the load/load-line displacement record for the same steel. Note that the Problem A.1 estimates all exceed the Problem A.2 calculation for the first $\mathrm{mm}$ of crack growth.

Table A.5 J-R curve parameters for Problem A.3

\begin{tabular}{lccc}
\hline Cases & $\mathbf{J}_{\mathbf{I c}}, \mathbf{k N} / \mathbf{m}$ & $\mathbf{C}, \mathbf{k N} / \mathbf{m}$ & $\mathbf{m}$ \\
\hline $\begin{array}{l}\text { Problem A.1, } \\
\text { Upper Limit }\end{array}$ & 190 & 252 & 0.55 \\
$\begin{array}{l}\text { Problem A.1, } \\
\text { Lower Limit }\end{array}$ & 128 & 161 & 0.40 \\
$\begin{array}{l}\text { Problem A.2, } \\
\text { Median }\end{array}$ & 130 & 164 & 0.69 \\
\hline
\end{tabular}


The tensile properties of this material are:

Yield strength of $230.1 \mathrm{MPa}$, Ultimate strength of $544.0 \mathrm{MPa}$,

Flow stress is average of yield and ultimate,

Reference stress is equal to the yield strength,

Elastic modulus is $193.06 \mathrm{GPa}$,

$\alpha$ is 1.107 ,

Strain hardening exponent, $\mathrm{n}$, is 5.55 , and

Poisson's ratio is 0.30 .

\section{Problem Statement:}

Using each of the J-R curves provided, calculate the initiation and maximum moments for the following cases.

- Problems A.3-a to A.3-d: Pipe size is $711 \mathrm{~mm}$ outside diameter by $\mathbf{2 3 . 6} \mathbf{~ m m}$ thick

Problem A.3-a: Circumferential through-wall crack 6.3 percent of the circumference, unpressurized,

Problem A.3-b: Circumferential through-wall crack 37 percent of the circumference, unpressurized,

Problem A.3-c: Circumferential surface crack 50 percent of the circumference and 66 percent deep, pressurized to $9.56 \mathrm{MPa}$ (axial loading occurs due to pressure on an endcap),

Problem A.3-d: Circumferential surface crack 25 percent of the circumference and 50 percent deep, pressurized to $9.56 \mathrm{MPa}$ (axial loading occurs due to pressure on an endcap).

- Problems A.3-e to A.3-h: Pipe size is $219 \mathrm{~mm}$ outside diameter by $12.7 \mathrm{~mm}$ thick

Problem A.3-e: Circumferential through-wall crack 6.3 percent of the circumference, unpressurized,

Problem A.3-f: Circumferential through-wall crack 37 percent of the circumference, unpressurized,

Problem A.3-g: Circumferential surface crack 50 percent of the circumference and 66 percent deep, pressurized to $9.56 \mathrm{MPa}$ (axial loading occurs due to pressure on an endcap),

Problem A.3-h: Circumferential surface crack 25 percent of the circumference and 50 percent deep, pressurized to $9.56 \mathrm{MPa}$ (axial loading occurs due to pressure on an endcap).

It should not matter if you do the calculations in either load- or displacement-control since only the crack initiation and maximum loads are required to be calculated. Use any elastic-plastic fracture mechanics analysis procedure. Document all your calculations. Please supply answers in SI units. Battelle will also translate the compiled results to U.S. Customary units in the summary of the results. 


\section{A.5 Problem A.4 - Fracture Load Evaluations Using J-R Curves from Different Load Histories}

\section{Specific Objective:}

In Round-Robin Problem A.3, we examined the effects of differences in quasi-static J-R curves in predicting initiation and maximum loads of circumferential through-wall-cracked and surface-cracked pipes. Problem A.4 is designed to conduct similar calculations, but the material toughness properties will now involve the J-R curves from (1) quasi-static and monotonic, (2) dynamic and monotonic, and (3) dynamic and cyclic tests. Three such J-R curves, obtained from the IPIRG-1 A106B pipe experiments, are identified. The specific objective of this problem is to determine if there are any significant differences in the initiation and maximum load predictions when the J-R curves are developed using different load-histories.

\section{Given Information:}

The J-R curve of the pipe material is expressed as:

$$
J=J_{I c}+C\left(\frac{\Delta a}{a^{*}}\right]^{m}
$$

where $\mathrm{J}$ is expressed in $\mathrm{kJ} / \mathrm{m}^{2}, \mathrm{~J}_{\mathrm{Ic}}$ is the fracture toughness at crack initiation in $\mathrm{kJ} / \mathrm{m}^{2}, \Delta \mathrm{a}$ is the crack length extension in $\mathrm{mm}$, and $\mathrm{C}$ and $\mathrm{m}$ are power-law parameters. In Equation $\mathrm{A}-2, \mathrm{a}^{*}$ is a normalizing parameter with the value equal to $1 \mathrm{~mm}$. The values of J-R curve parameters, which were available from quasi-static and monotonic, dynamic and monotonic, and dynamic and cyclic tests conducted in IPIRG-1, are shown in Table A.6.

Table A.6 J-R curve parameters for Problem A.4

\begin{tabular}{cccc}
\hline Cases & $\mathbf{J}_{\mathbf{I c}}, \mathbf{k J} / \mathbf{m}^{2}$ & $\mathbf{C}, \mathbf{k J} / \mathbf{m}^{2}$ & $\mathbf{~ m}$ \\
\hline Quasi-static and Monotonic & 222.0 & 93.0 & 0.77 \\
Dynamic and Monotonic & 97.2 & 75.9 & 0.78 \\
Dynamic and Cyclic (R=-1) & 71.3 & 86.9 & 0.50 \\
\hline
\end{tabular}


For all cases, the uniaxial stress-strain $(\sigma-\epsilon)$ curve is idealized as:

$$
\frac{\epsilon}{\epsilon_{\mathrm{o}}}=\frac{\sigma}{\sigma_{\mathrm{o}}}+\alpha\left[\frac{\sigma}{\sigma_{\mathrm{o}}}\right]^{\mathrm{n}}
$$

where $\sigma_{\mathrm{o}}$ is the reference stress, $\epsilon_{\mathrm{o}}=\sigma_{\mathrm{o}} / \mathrm{E}$ is the reference strain with $\mathrm{E}$ as the modulus of elasticity, and $\alpha$ and $\mathbf{n}$ are the Ramberg-Osgood parameters. The tensile properties including those for the Ramberg-Osgood model are given below:

Yield strength is $294 \mathrm{MPa}$, Ultimate strength is $599 \mathrm{MPa}$,

Flow stress is average of yield and ultimate strengths,

Reference stress $\left(\sigma_{0}\right)$ is equal to yield strength,

Elastic modulus $(\mathrm{E})$ is $193.4 \mathrm{GPa}$,

Ramberg-Osgood coefficient, $\alpha$ is 1.97 ,

Ramberg-Osgood exponent, $\mathrm{n}$ is 5.366, and

Poisson's ratio is 0.3 .

\section{Problem Statement:}

Using each of the J-R curves defined by Equation A-2 and the Table A.6 values, calculate the initiation and maximum moments for the following problems:

- Problems A.4-a to A.4-d: Pipe size is $711 \mathrm{~mm}$ outside diameter by $\mathbf{2 3 . 6} \mathrm{mm}$ thick

Problem A.4-a: Circumferential through-wall crack 6.3 percent of the circumference, unpressurized

Problem A.4-b: Circumferential through-wall crack 37 percent of the circumference, unpressurized

Problem A.4-c: Circumferential internal surface crack 50 percent of the circumference and 66 percent deep (constant depth), pressurized to $9.56 \mathrm{MPa}$ (axial loading occurs due to pressure on an endcap)

Problem A.4-d: Circumferential internal surface crack 25 percent of the circumference and 50 percent deep (constant depth), pressurized to $9.56 \mathrm{MPa}$ (axial loading occurs due to pressure on an endcap) 
- Problems A.4-e to A.4-h: Pipe size is $168 \mathrm{~mm}$ outside diameter by $14.0 \mathrm{~mm}$ thick

Problem A.4-e: Circumferential through-wall crack 6.3 percent of the circumference, unpressurized

Problem A.4-f: Circumferential through-wall crack 36 percent of the circumference, unpressurized

Problem A.4-g: Circumferential internal surface crack 50 percent of the circumference and 66 percent deep (constant depth), pressurized to $9.56 \mathrm{MPa}$ (axial loading occurs due to pressure on an endcap)

Problem A.4-h: Circumferential internal surface crack 25 percent of the circumference and 50 percent deep (constant depth), pressurized to $9.56 \mathrm{MPa}$ (axial loading occurs due to pressure on an endcap)

Note: It should not matter if you do the calculations in either load- or displacement-control since only the crack initiation and maximum loads are required to be calculated.

Use any elastic-plastic fracture mechanics analysis procedure. Document all your calculations.

Please supply answers in SI units. Battelle will also translate the compiled results to U.S. Customary units in the summary of results. 


\section{A.6 Problem A.6 - Fracture Load Evaluations Using Stress-Strain Curves from Various Methods}

\section{Specific Objective:}

In Round-Robin Problems A.3 and A.4, we examined the effects of differences in J-R curves in predicting initiation and maximum loads of circumferential through-wall-cracked and surface-cracked pipes. From the discussions at the Second IPIRG-2 Round-Robin, a new problem (Problem A.6) was created to conduct similar calculations by varying the stress-strain curve instead of the J-R curve. In Problem A.2, we also examined the differences in calculating stress-strain curves by various methods and participants. From that effort, we selected three different stress-strain curves (Case 1, Case 2, and Case 3) and the median J-R curve for Material B (DP2-F26). The specific objective of this problem is to determine if there are any significant differences in the initiation and maximum load predictions using different stress-strain curves.

\section{Given Information:}

The J-R curve of the pipe material is expressed as:

$$
J=130+164(\Delta a)^{0.69}
$$

where $\mathrm{J}$ is expressed in $\mathrm{kJ} / \mathrm{m}^{2}$ and $\Delta \mathrm{a}$ is the crack length extension in $\mathrm{mm}$. The $\mathrm{J}-\mathrm{R}$ curve parameters in Equation A-4 are obtained from Problems A.2 and A.3 (median J-R curve).

The uniaxial stress-strain $(\sigma-\epsilon)$ curve is idealized as:

$$
\frac{\epsilon}{\epsilon_{\mathrm{o}}}=\frac{\sigma}{\sigma_{\mathrm{o}}}+\alpha\left(\frac{\sigma}{\sigma_{\mathrm{o}}}\right)^{\mathrm{n}}
$$

where $\sigma_{\mathrm{o}}$ is the reference stress, $\epsilon_{\mathrm{o}}=\sigma_{\mathrm{o}} / \mathrm{E}$ is the reference strain with $\mathrm{E}$ as the elastic modulus, and $\alpha$ and $n$ are the Ramberg-Osgood parameters. From Problem A.2, three cases of stress-strain curves are identified. The corresponding Ramberg-Osgood parameters for each of these cases are defined in Table A.7. 
Table A.7 Ramberg-Osgood parameters $\alpha$ and $n$ for Problem A.6

\begin{tabular}{ccc}
\hline Cases & $\boldsymbol{\alpha}$ & $\mathbf{n}$ \\
\hline Upper Limit & 2.1 & 3.3 \\
Lower Limit & 0.67 & 6.1 \\
Actual Curve & 1.2 & 4.6 \\
\hline
\end{tabular}

Also, for all three cases: Yield strength is $230.1 \mathrm{MPa}$, Ultimate strength is $544.0 \mathrm{MPa}$, Flow stress is the average of yield and ultimate strengths, Reference stress $\left(\sigma_{0}\right)$ is equal to yield strength, Elastic modulus (E) is $193.06 \mathrm{GPa}$, and Poisson's ratio is 0.30 .

\section{Problem Statement:}

Using the J-R curve defined by Equation A-4 and each of the stress-strain curves defined by Equation A-5 and Table A.7 values, calculate the initiation and maximum moment for the following problems:

- Problems A.6-a to A.6-d: Pipe size is $711 \mathrm{~mm}$ outside diameter by $\mathbf{2 3 . 6} \mathbf{~ m m}$ thick

Problem A.6-a: Circumferential through-wall crack 6.3 percent of the circumference, unpressurized

Problem A.6-b: Circumferential through-wall crack 37 percent of the circumference, unpressurized

Problem A.6-c: Circumferential internal surface crack 50 percent of the circumference and 66 percent deep (constant depth), pressurized to $9.56 \mathrm{MPa}$ (axial loading occurs due to pressure on an endcap)

Problem A.6-d: Circumferential internal surface crack 25 percent of the circumference and 50 percent deep (constant depth), pressurized to $9.56 \mathrm{MPa}$ (axial loading occurs due to pressure on an endcap) 
- Problems A.6-e to A.6-h: Pipe size is $219 \mathrm{~mm}$ outside diameter by $12.7 \mathrm{~mm}$ thick

Problem A.6-e: Circumferential through-wall crack 6.3 percent of the circumference, unpressurized

Problem A.6-f: Circumferential through-wall crack 37 percent of the circumference, unpressurized

Problem A.6-g: Circumferential internal surface crack 50 percent of the circumference and 66 percent deep (constant depth), pressurized to $9.56 \mathrm{MPa}$ (axial loading occurs due to pressure on an endcap)

Problem A.6-h: Circumferential internal surface crack 25 percent of the circumference and 50 percent deep (constant depth), pressurized to $9.56 \mathrm{MPa}$ (axial loading occurs due to pressure on an endcap)

Note: It should not matter if you do the calculations in either load- or displacement-control since only the crack initiation and maximum loads are required to be calculated.

Use any elastic-plastic fracture mechanics analysis procedure. Document all your calculations.

Please supply answers in SI units. Battelle will also translate the compiled results to U.S. Customary units in the summary of results. 


\section{APPENDIX B DEFINITION OF PROBLEM SET B}

\section{B.1 Problems B.1-a and B.1-b - Calculation of Crack-Opening Displacements for Pipes Under Various Loads Using F29 Material}

\section{Specific Objective:}

The specific objective of this problem is to assess the accuracy of crack-opening-area analyses typically used in LBB analyses.

\section{Given Information:}

A pipe with a circumferential through-wall crack is loaded in four-point bending. The inner span is 3.352 meters, and the outer span is 11.582 meters. The crack size is 12 percent of the circumference. Assume the crack length on the inside diameter is the same as on the outside diameter in terms of percent of circumference. The pipe size is $402.6 \mathrm{~mm}$ outside diameter by $26.41 \mathrm{~mm}$ thick. The properties of the base metal are:

Yield strength of $237.2 \mathrm{MPa}$, Ultimate strength of $610.2 \mathrm{MPa}$, Elastic modulus is $193.06 \mathrm{GPa}$, $\alpha$ is 2.157 , Strain hardening exponent, $\mathrm{n}$, is 4.042 , and Poisson's ratio is 0.30 .

The flow stress is the average of the yield and ultimate strengths. The reference stress is equal to the yield strength. The reference strain is the yield stress divided by the elastic modulus. No crack growth occurs in the loading. (Note: the Ramberg-Osgood parameters are supplied only if you wish to conduct elastic-plastic analyses.)

\section{Problem Statement:}

Using any crack-opening analysis you are familiar with, calculate the following.

Problem B.1-a: Calculate the center-crack-opening displacement assuming there is no internal pressure and the total applied bending loads ${ }^{(a)}$ are: $45,75,140,185,210,300$, and $350 \mathrm{kN}$.

Problem B.1-b: Calculate the center-crack-opening displacement assuming there is $15.5 \mathrm{MPa}$ internal pressure (pressure induces an axial stress) and the total applied bending loads $^{(a)}$ are: $0,20,35,60,75,86,120$, and $150 \mathrm{kN}$.

(a) Total applied bending load is the total vertical load from both of the inner support locations. 
Please supply answers in SI units. Battelle will also translate the compiled results to U.S. Customary units in the summary of the results. 


\section{B.2 Problem B.1-c - Calculation of Crack-Opening Displacements for Pipes Under Various Loads Using F23 Material}

\section{Specific Objective:}

The specific objective of this problem is to assess the accuracy of crack-opening-area analyses typically used in LBB analyses. This is a new problem created from the discussions of the First IPIRG-2 Round-Robin, and is specifically designed to have all the features of IPIRG-2 Experiment $1-8$ that will be conducted in the future.

This is a repeat of Problem B.1-b, but uses the exact material properties for the material to be used in this experiment.

\section{Given Information:}

A pipe with a circumferential through-wall-crack is loaded in four-point bending. The inner span is 3.352 meters, and the outer span is 11.582 meters. The crack size is 12 percent of the mean pipe circumference. Assume that the crack length on the inside diameter is the same as on the outside diameter in terms of percent of circumference. The pipe size is $406.4 \mathrm{~mm}$ outside diameter by 26.19 $\mathrm{mm}$ thick. The base metal (F23) properties of the pipe in Experiment 1.8 are:

$\begin{array}{lll}\text { Yield strength, } \sigma_{\mathrm{y}} & = & 216 \mathrm{MPa}, \\ \text { Ultimate strength, } \sigma_{\mathrm{u}} & = & 506.5 \mathrm{MPa}, \\ \text { Elastic Modulus, } \mathrm{E} & = & 193.06 \mathrm{GPa}, \\ \text { Ramberg-Osgood fit, } \alpha & = & 2.038, \\ \text { Strain-hardening exponent, } \mathrm{n} & = & 4.266, \text { and } \\ \text { Poisson's ratio, } \nu & = & 0.30 .\end{array}$

The Ramberg-Osgood parameters were determined from the least-square fit of raw test data in the low-strain range between 0.5 and 5.0 percent. The flow stress is the average of the yield and ultimate strengths. The reference stress in the Ramberg-Osgood model is equal to the yield strength. The reference strain is the yield stress divided by the elastic modulus. No crack growth occurs in the loading. (Note: the Ramberg-Osgood parameters are supplied only in case you wish to conduct elastic-plastic analyses.)

\section{Problem Statement:}

Using any crack-opening analysis you are familiar with, please calculate the following:

Problem B.1-c: Calculate the center-crack-opening displacements assuming there is $15.5 \mathrm{MPa}$ internal pressure (pressure induces an axial stress) and the total applied bending loads $^{(\mathrm{a})}$ are: $0,20,35,60,75,86,120$, and $150 \mathrm{kN}$.

(a) Total applied bending load is the sum of the vertical loads from both of the inner support locations. 


\section{B.3 Problems B.2-a and B.2-b - Leak-Rate Analysis of Cracked Pipes with Various Cracking Mechanisms}

\section{Specific Objective:}

In LBB analyses, structural mechanics engineers are often involved in determining the leak rate, or the crack size for a given leak rate. Significant safety factors are applied in leak-rate calculations due to uncertainties. The specific objective of this problem is to assess the effect of variation in input parameters on leak-rate calculations.

\section{Given Information:}

The crack-opening geometry on the outside surface is defined by a crack length of $133.21 \mathrm{~mm}$ and an opening shape that is ellipsoidal. The thickness of the pipe is $26.19 \mathrm{~mm}$. The pipe is filled with water at $288 \mathrm{C}$ and pressurized to $15.5 \mathrm{MPa}$ (PWR subcooled conditions). Assume the crack-opening displacement is identical on the inside and outside surfaces of the pipe.

\section{Problem Statement:}

Calculate the leak rate for the following cases.

Problem B.2-a: Assume a corrosion-fatigue crack occurs (use appropriate crack morphology variables) and calculate the leak rate for the following total center-crack-opening displacements: $0.056,0.094,0.193,0.3045,0.404,0.935,1.153 \mathrm{~mm}$.

Problem B.2-b: Assume an IGSCC crack occurs (use appropriate crack morphology variables) and calculate the leak rate for the following total center-crack-opening displacements: $0.094,0.175,0.368,0.576,0.764,1.139$, and $1.207 \mathrm{~mm}$.

Please supply answers in SI units. Battelle will also translate the compiled results to U.S. Customary units in the summary of the results. 


\section{B.4 Problems B.2-c and B.2-d - Leak-Rate Analysis of Cracked Pipes with Various Cracking Mechanisms}

\section{Specific Objective:}

In LBB analyses, structural mechanics engineers are often involved in determining the leak rate, or the crack size for a given leak rate. Significant safety factors are applied in leak-rate calculations due to uncertainties. In Problem B.2, we made leak-rate predictions for corrosion-fatigue and IGSCC cracks in which various participants exercised their own judgement in characterizing the crackmorphology variables. Significant differences in the leak-rate results were exhibited. From the discussions at the 2nd IPIRG-2 Round-Robin, two additional problems were suggested (Problems B.2-c and B.2-d) in which the crack-morphology variables are to be defined explicitly. The specific objective of these problems is to assess the leak-rate predictions by various participants using identical input for crack-morphology variables.

\section{Given Information:}

The crack-opening geometry on the outside surface is defined by a crack length of $133.21 \mathrm{~mm}$ and an opening shape that is ellipsoidal. The thickness of the pipe is $26.19 \mathrm{~mm}$. The pipe is filled with water at $288 \mathrm{C}$ and pressurized to $15.5 \mathrm{MPa}$ (PWR subcooled conditions). Assume the crack-opening displacement is identical on the inside and the outside surfaces of the pipe. Two types of cracking mechanisms, such as corrosion-fatigue and IGSCC, are considered. The crack morphology variables for each of these mechanisms are defined in Table B.1.

Table B.1 Crack-morphology variables for Problems B.2-c and B.2-d ${ }^{(a)}$

\begin{tabular}{l|c|c}
\hline $\begin{array}{l}\text { Crack-Morphology } \\
\text { Variable }\end{array}$ & $\begin{array}{c}\text { Corrosion- } \\
\text { Fatigue }\end{array}$ & IGSCC \\
\hline Surface Roughness, mm & 0.04 & 0.08 \\
$\begin{array}{l}\text { Number of } 90^{\circ} \text { Turns per mm of } \\
\text { Crack Depth }^{(\mathrm{b})}, \mathrm{mm}^{-1}\end{array}$ & 0.7 & 2.8 \\
Discharge Coefficient $^{(\mathrm{c})}$ & 0.95 & 0.95 \\
\hline
\end{tabular}

(a) Service values from NUREG/CR-6004 report.

(b) Assume pathway loss coefficient due to $90^{\circ}$ turns only (no $45^{\circ}$ turns).

(c) Assume round or smooth-edged crack entrances for both types of cracks. 


\section{Problem Statement:}

Calculate the leak-rate for the following cases:

Problem B.2-c: Assuming that a corrosion-fatigue crack occurs, calculate the leak rate for the following total center-crack-opening displacements: $0.056,0.094,0.193,0.3045$, $0.404,0.935$, and $1.153 \mathrm{~mm}$.

Problem B.2-d: Assuming that an IGSCC crack occurs, calculate the leak rate for the following total center-crack-opening displacements: $0.094,0.175,0.368,0.576,0.764$, 1.139 , and $1.207 \mathrm{~mm}$.

Please provide both mass and volume flow rates and supply results in SI units. Battelle will also translate the compiled results to U.S. Customary units in the summary of the results. 


\section{B.5 Problem B.3 - Crack-Opening-Area Analysis of Pipes with Off- Centered Cracks}

\section{Specific Objective:}

A question raised at the first IPIRG-2 meeting was how to analyze the leak rate for a crack that is not centered on the plane of bending. No engineering deterministic models exist that we are aware of, other than conducting FEM analyses. The specific objective of this problem is to assess the crack opening that might occur for an off-centered crack. This can be solved in an approximate engineering manner, or by finite element analyses. Ideally, both types of solutions will be presented to assess engineering methods.

\section{Given Information:}

A pipe with a circumferential through-wall crack is loaded in four-point bending. The inner span is 3.352 meters, and the outer span is 11.582 meters. The crack size is 12 percent of the outside circumference. Assume the crack length on the inside diameter is the same as on the outside diameter in terms of percent of circumference. The pipe size is $406.4 \mathrm{~mm}$ outside diameter by $26.19 \mathrm{~mm}$ thick. Assume all loading is elastic, so there is no plasticity or crack growth. The elastic modulus is $193.06 \mathrm{GPa}$.

The pipe is unpressurized. The total applied bending load ${ }^{(a)}$ is $254 \mathrm{kN}$.

\section{Problem Statement:}

Calculate, or estimate, the center-crack-opening on the outside surface (inside surface values are optional) and the crack-opening area on the outside surface for the following cases.

Problem B.3-a: The crack is symmetrically located on the bending plane, Problem B.3-b: The center of the crack is 15 degrees from the bending plane, Problem B.3-c: The center of the crack is 30 degrees from the bending plane, Problem B.3-d: The center of the crack is 45 degrees from the bending plane, Problem B.3-e: The center of the crack is 60 degrees from the bending plane, Problem B.3-f: The center of the crack is 90 degrees from the bending plane.

Please supply answers in SI units. Battelle will also translate the compiled results to U.S. Customary units in the summary of the results.

(a) Total applied bending load is the sum of the vertical loads from both of the inner support locations. 


\section{B.6 Problem B.4 - Effects of Weld Residual Stresses on Crack-Opening Analysis of Pipes}

\section{Specific Objective:}

A question raised at the first IPIRG-2 meeting was how to account for the effect of residual stresses in leak-rate analyses. The effect of residual stresses would be most pronounced on the crack-opening variations through the thickness. We are not aware of any simple engineering deterministic models for calculating the effect of residual stresses on the differences in the center-crack-opening displacement on the outside diameter versus the inside diameter. (The thermal-hydraulic models can account for effects on leak rates due to differences in COD on the ID versus OD.) The specific objective of this problem is to assess the effects of a typical residual stress distribution on the centercrack-opening displacement through the thickness. This can be solved in an approximate engineering manner, or by finite element analyses. Ideally, both solutions will be presented to assess engineering methods and the significance of the results.

\section{Given Information:}

Assume the crack length on the inside diameter is the same as on the outside diameter in terms of percent of circumference. Assume all loading is elastic, so there is no plasticity or crack growth. The elastic modulus is $193.06 \mathrm{GPa}$ and Poisson's ratio is 0.3 .

The pipe is unpressurized. The crack is symmetrically located on the bending plane. The residual stress fields through the thickness are given in Figure B.1.

\section{Problem Statement:}

Calculate the center-crack-opening displacement for the following cases.

Problem B.4-a: The pipe size is $402.6 \mathrm{~mm}$ outside diameter by $26.41 \mathrm{~mm}$ thick. The pipe has a circumferential through-wall crack length of 12 percent of the circumference. The bending moment is $522.07 \mathrm{kN}-\mathrm{m}$. Use the residual stress field in Figure B.1. Also, calculate the center-crack opening without the residual stress field.

Problem B.4-b: The pipe size is $102 \mathrm{~mm}$ outside diameter by $8.9 \mathrm{~mm}$ thick. The pipe has a circumferential through-wall crack length of 20 percent of the circumference. The bending moment is $8.83 \mathrm{kN}$-m. Use the residual stress field in Figure B.1. Also, calculate the center-crack opening without the residual stress field.

Please supply answers in SI units. Battelle will also translate the compiled results to U.S. Customary units in the summary of the results. 


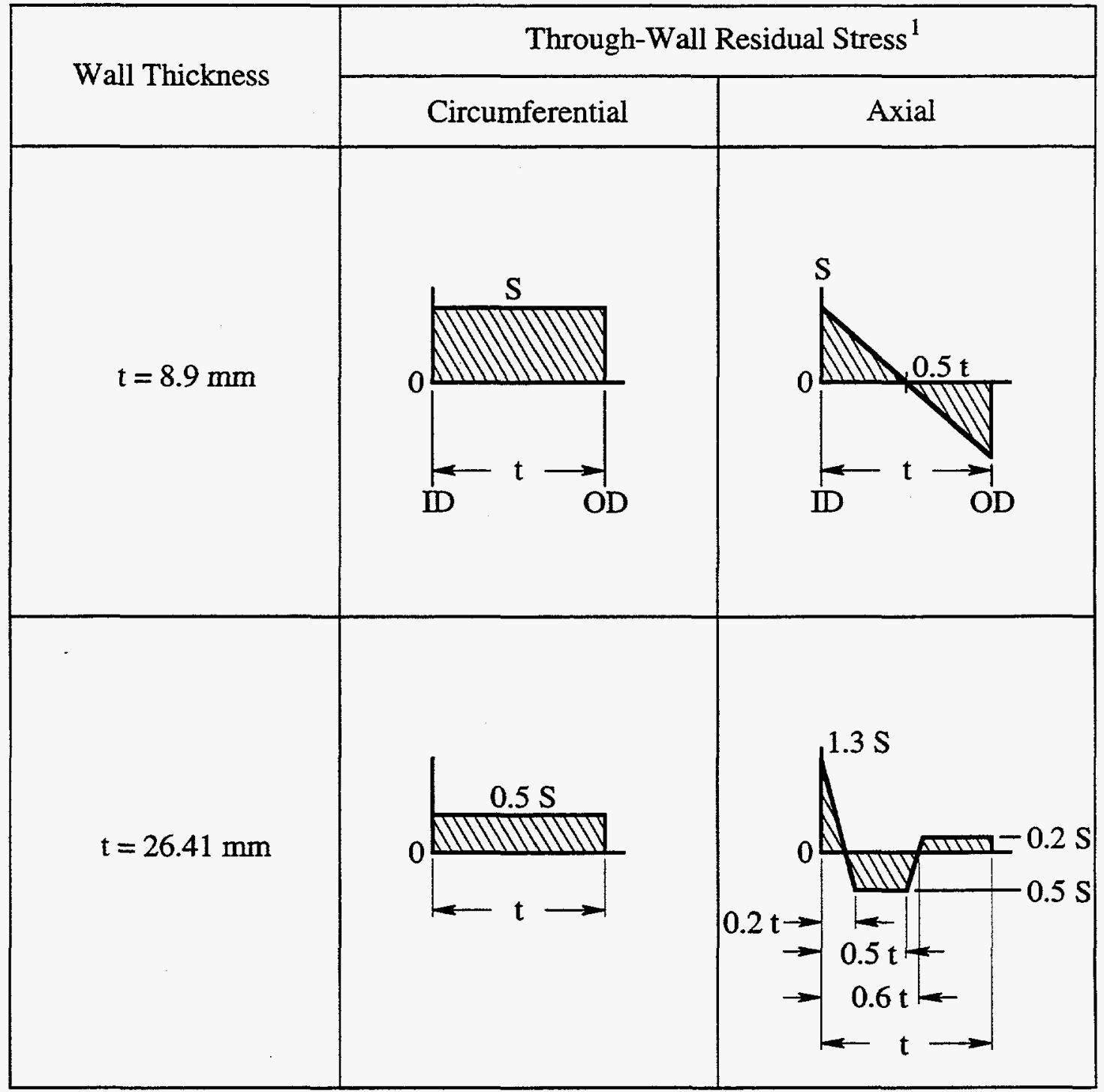

$$
{ }^{1} \mathrm{~S}=207 \mathrm{MPa}(30 \mathrm{ksi})
$$

Figure B.1 Weld residual stress field from ASME IWB-3640 draft technical basis document 


\section{B.7 Problems B.5 - Crack-Opening Analysis of a Girth Weld Nozzle Crack at a Thickness Transition}

\section{Specific Objective:}

A question raised at the second IPIRG-2 round-robin meeting was how to evaluate the effects of a thickness transition on the crack-opening area analysis of a circumferential crack. The thickness transition can occur when a crack develops in a girth weld at a nozzle with a thickness taper on one side. We are not aware of any simple engineering models for calculating crack-opening displacement for such a girth weld nozzle crack. The specific objective of this problem is to assess the effects of a typical thickness transition and geometric constraint associated with heavy integrally reinforced nozzles on the crack-opening displacement for a circumferential through-wall-crack in a carbon steel nozzle.

\section{Given Information:}

Figure B.2 shows a typical carbon steel nozzle between a cold leg and a safety injection line with their geometric properties obtained from the optional Experiment 2-5 of the IPIRG-2 program. For this round-robin problem, it is suggested to idealize this problem by Figure B.3 which represents a nozzle having the same geometric parameters of Figure B.2 with one end completely fixed. Due to the slanted configuration of the nozzle, three distinct locations of this fixed boundary condition will be tried to determine their effects on crack-opening area analyses as opposed to full 3D analysis of the nozzle and the cold-leg pipe. They are shown in Figure B.2 as Sections A-A, B-B, and C-C.

A circumferential through-wall-crack is placed in Section D-D of the nozzle shown in Figures B.2 and B.3. The crack size is 12.5 percent of the mean pipe circumference measured at Section D-D.

Assume that the crack length on the inside diameter is the same as on the outside diameter in terms of percent of pipe circumference. The pipe is pressurized with $15.514 \mathrm{MPa}(2,250 \mathrm{psi})$ representing PWR operating condition at $288 \mathrm{C}(550 \mathrm{~F})$. The material properties of the carbon steel nozzle at 288 $\mathrm{C}(550 \mathrm{~F})$ are as follows:

Yield strength $=237.2 \mathrm{MPa}$, Ultimate strength $=610.2 \mathrm{MPa}$, Flow stress is average of yield and ultimate stresses, Reference stress is equal to yield stress, Elastic modulus $=193.06 \mathrm{GPa}$, Ramberg-Osgood coefficient, $\alpha=2.157$, Ramberg-Osgood exponent, $n=4.042$, and Poisson's ratio $=0.3$.

Assume no crack growth in your analysis. 


\section{Problem Statement:}

Calculate the center-crack-opening displacement and detailed crack-opening profile at the inner and outer surfaces of the nozzle shown in Figure B.3 for each location of the fixed plane (i.e., Sections $\mathrm{A}-\mathrm{A}, \mathrm{B}-\mathrm{B}$, and $\mathrm{C}-\mathrm{C}$ ) when the pipe is subjected to internal pressure of $15.514 \mathrm{MPa}$ and the applied bending moments are:
(1) $0.0 \mathrm{MN}-\mathrm{m}$ (pure pressure)
(2) $0.2 \mathrm{MN}-\mathrm{m}$ (elastic)
(3) $0.6 \mathrm{MN}-\mathrm{m}$ (significantly elastic and slightly plastic)
(4) 1.0 MN-m (significantly plastic)

Figure B.4 shows an example of expected output from the participants of this problem. In Figure B.4, $\mathrm{x}$ is a spatial coordinate representing points along the direction of crack length and $\delta=\mathrm{y}+\mathrm{z}$ is the total crack-opening displacement as a function of $\mathrm{x}$, where $\mathrm{y}$ and $\mathrm{z}$ are components of crackopening displacement in the direction of thinner and thicker pipe wall, respectively. Please, provide results in the tabular form also depicted schematically in Figure B.4.

Please supply all results in SI units. Battelle will translate the compiled results to U.S. Customary units in the summary of the results. 


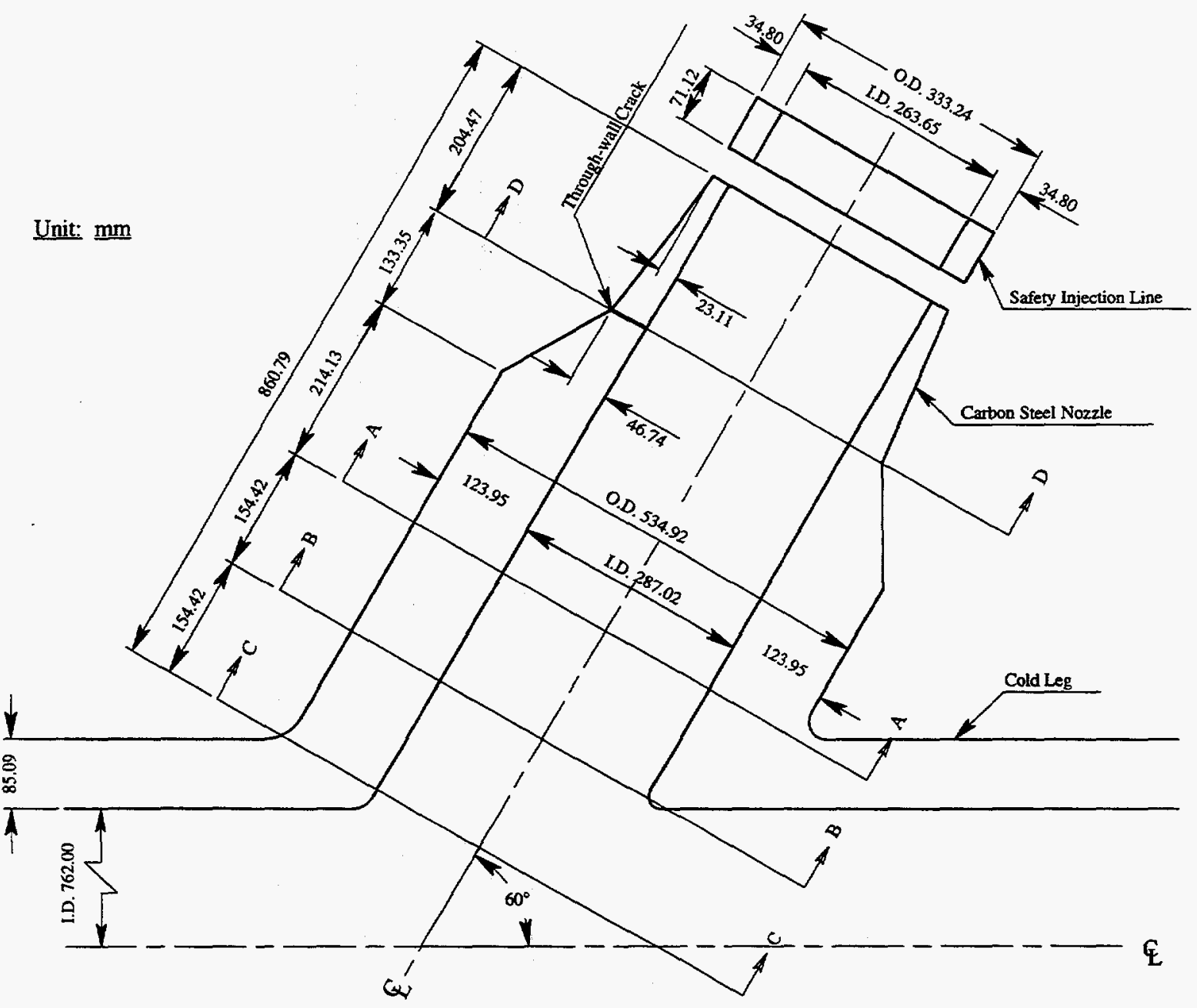

Figure B.2 Geometric details of a cracked carbon steel nozxle with thickness gradients 


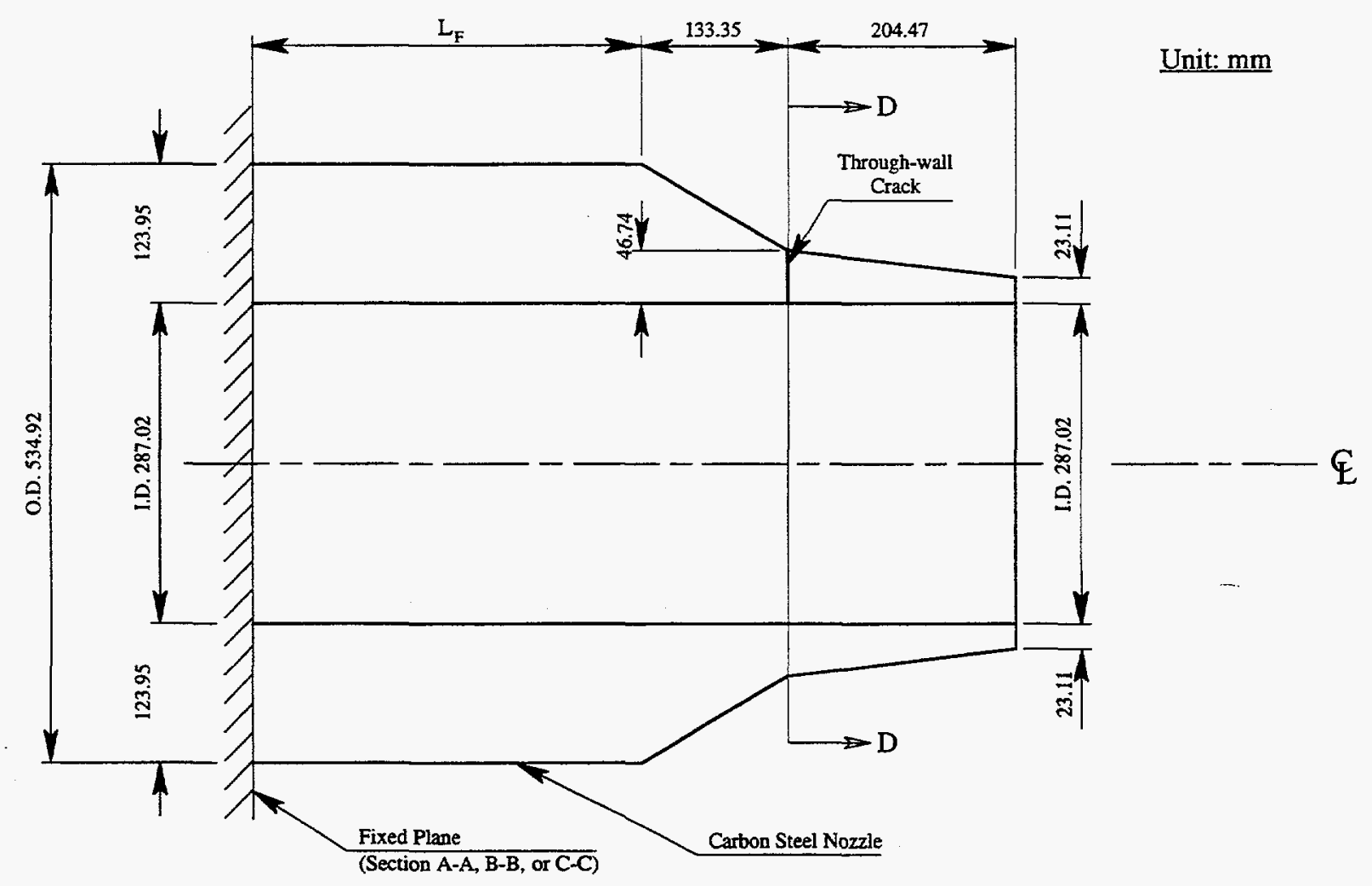

\begin{tabular}{l|l} 
Case 1 & $\mathrm{L}_{F}=214.13 \mathrm{~mm}$ \\
\hline Case 2 & $\mathrm{L}_{\mathrm{F}}=368.55 \mathrm{~mm}$ \\
\hline Case 3 & $\mathrm{L}_{\mathrm{F}}=522.97 \mathrm{~mm}$
\end{tabular}

Figure B.3 Idealized nozzle geometry with fixed boundary condition 


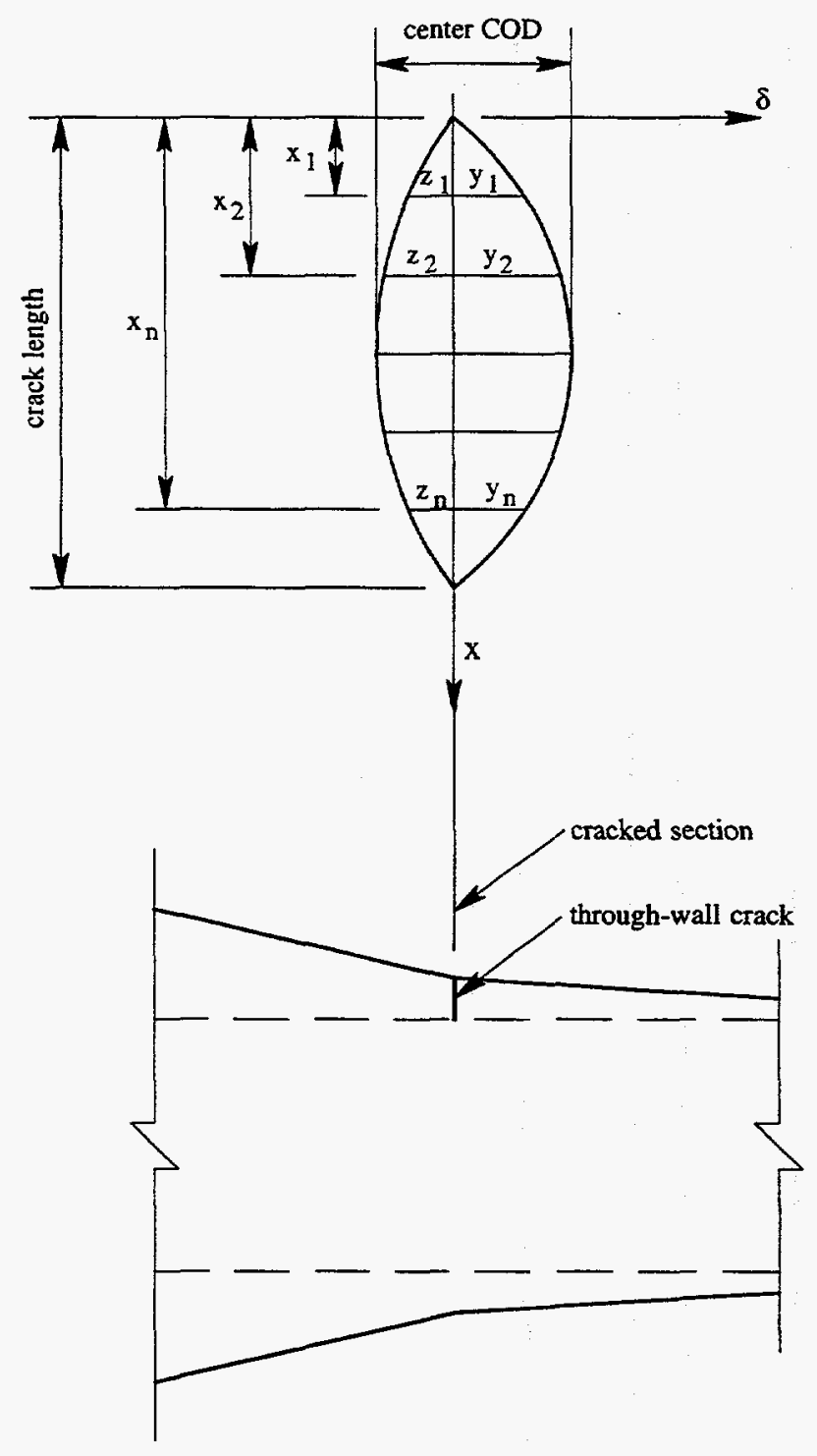

\begin{tabular}{c|c|c|c}
\hline$x$ & $y$ & $z$ & $\delta=y+z$ \\
\hline$x_{1}$ & $y_{1}$ & $z_{1}$ & $\delta_{1}$ \\
\hline$x_{2}$ & $y_{2}$ & $z_{2}$ & $\delta_{2}$ \\
$:$ & $\vdots$ & $\vdots$ & $\vdots$ \\
$:$ & $\vdots$ & $:$ & $\vdots$ \\
$x_{n}$ & $y_{n}$ & $z_{n}$ & $\delta_{n}$ \\
\hline
\end{tabular}

Figure B.4 Schematic of expected results from Problem B.5 


\section{APPENDIX C DEFINITION OF PROBLEM SET C}

\section{C.1 Problem C.1 - Spectrum-Compatible Time-Histories}

\section{Specific Objective:}

In this problem, the participants will generate a spectrum-compatible displacement time history from a given actuator acceleration response spectrum. To evaluate the impact of different time histories on the stresses generated in a piping system, finite element analyses with the displacement function provided by each participant will be performed.

\section{Given Information:}

The known factor will be the actuator acceleration response spectrum at 2-percent damping and a maximum displacement of $\pm 15 \mathrm{~mm}$. Figure $C .1$ is a plot of the response spectrum, while Table C. 1 is a listing of the control points in the spectrum.

\section{Problem Statement:}

Participants are asked to generate a consistent displacement time history from the supplied acceleration response spectrum. For consistency, and to provide data that are finite element piping system analysis ready, participants are required to use a 0.005 second time step. The duration of the stationary phase should be 10 seconds, and to bound the time-history response, displacements should be limited to a maximum of $\pm 15 \mathrm{~mm}$. Beyond this, participants can make any other assumptions needed to complete the problem. In addition to the time history of displacement, participants should also supply spectral acceleration versus frequency at 2-percent and 5-percent damping for their time history so that agreement with the prescribed input floor response can be judged.

Participants should document the approach used to generate the time history from the response spectrum and they should document any assumptions needed to complete the problem.

The time history data should be provided as a two-column computer file with time in the first column and displacement in millimeters in the second column. The spectral acceleration data should be provided as a three-column computer file with frequency in the first column (Hertz) and spectral acceleration (g's) in the second and third columns at 2- and 5-percent damping, respectively. Data should be written as an ASCII text file on an IBM-compatible $3 \frac{1}{2}$-inch disk. Battelle will translate the compiled results to U.S. customary units for the analyses and presentations, as needed.

\section{Evaluation:}

Battelle will compile the results and compare the displacements from the submitted time histories. In addition, Battelle will also use each time history as an input to a linear elastic finite element analysis of the IPIRG pipe loop test system. The maximum and minimum moments at the test section, actuator maximum force, and selected maximum and minimum displacements will be tabulated for 
comparison. To assess the quality of the time history synthesis, each participant's spectral acceleration versus frequency will be compared to the input data.

Table C.1 Floor response spectrum control points

\begin{tabular}{cc}
\hline Frequency, Hz & Acceleration, g's \\
\hline 0.100 & 0.000824 \\
0.865 & 0.126567 \\
1.557 & 0.565768 \\
2.292 & 2.718219 \\
3.101 & 2.718219 \\
4.293 & 3.962111 \\
5.808 & 3.962111 \\
7.775 & 1.178113 \\
17.036 & 0.756765 \\
40.374 & 0.521829 \\
\hline
\end{tabular}




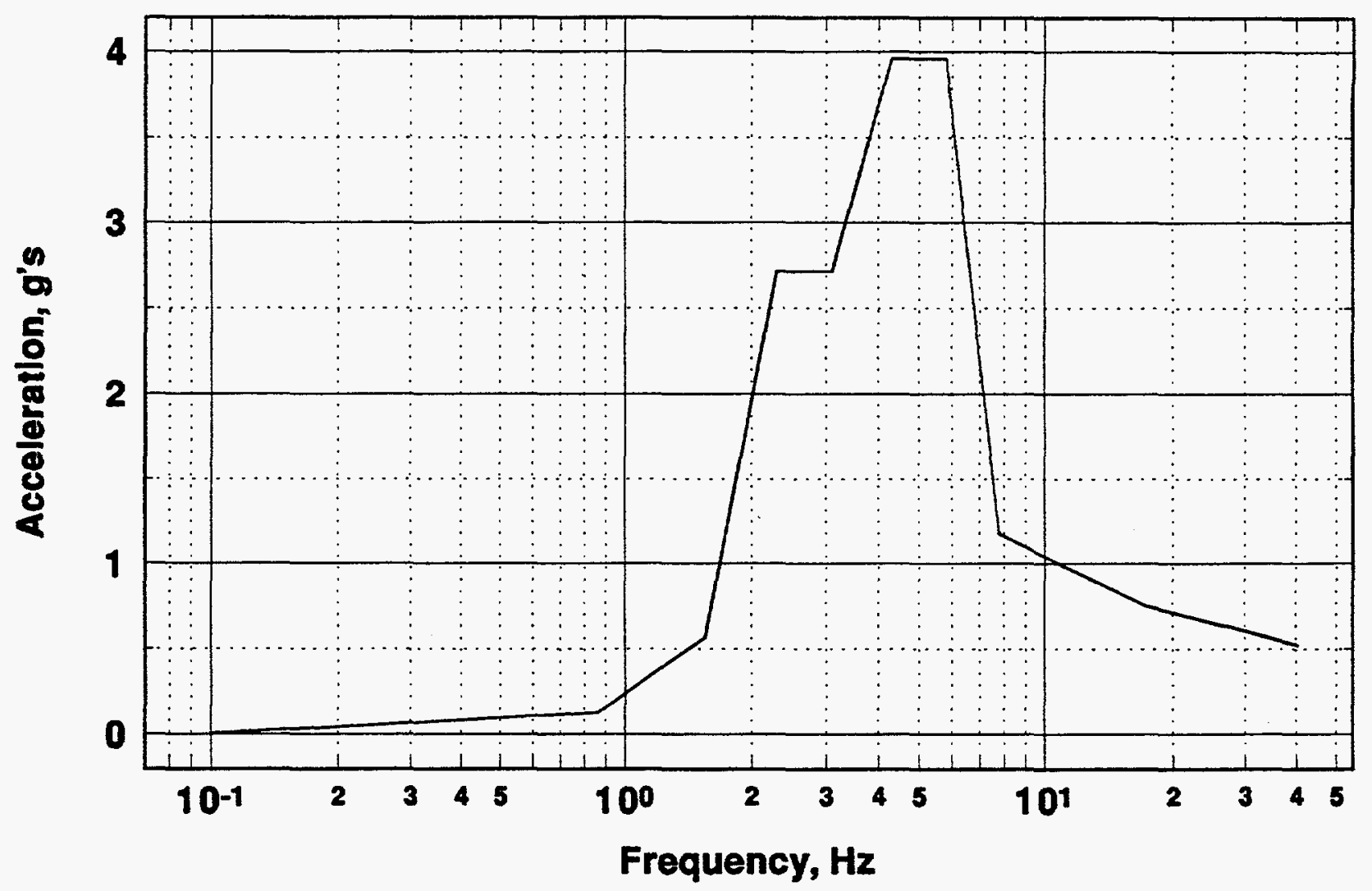

Figure C.1 Actuator response spectrum at 2-percent damping 


\section{C.2 Problem C.2 - Analysis of IPIRG-2 Seismic Surface-Cracked Pipe System Experiment}

\section{Specific Objective:}

In this problem, the participants will predict the maximum moment at the crack location for a surfacecracked pipe subjected to simulated seismic loading with various material property assumptions. Given a prediction of the maximum moment at the crack section, the participants will then make an estimate of when, or if, the maximum moment will be achieved in a given seismic time history. Participants may use code approaches or more detailed fracture mechanics approaches to make the maximum moment prediction. The time estimate can be performed using a Battelle-supplied pipe stress analysis or an analysis done by the participant. This problem will be a blind prediction of IPIRG-2 Experiment 1-1. Results of the predictions will be compared with the observed experimental behavior.

\section{Given Information:}

The primary known factors will be the test section dimensions and initial flaw geometry, material properties, test conditions, and results of an elastic finite element stress analysis.

Test Section Dimensions and Initial Flaw Geometry. The pipe geometry at the test section and initial flaw geometry for Experiment 1-1 are shown in Figure C.2.

We suggest using the following flaw dimensions for your primary calculations, $a / t=0.628$ and $\theta / \pi$ $=0.383$. This is the maximum depth and the equivalent crack length based on the crack area divided by the maximum depth. As an alternative, the ASME flaw dimensions (maximum depth and length) of $a / t=0.628$ and $\theta / \pi=0.527$ can be used for secondary calculations. Finally any other flaw geometry based on the data in Figure C.2-1 could be used in additional calculations. Please define the basis for this last option.

Material Properties. Material properties at four different levels of detail are provided.

Level 1 Assume material properties for ASTM A358 TP304 stainless steel.

Level 2 The information from Level 1 plus typical mill test property data at room temperature, per Table C.2.

Level 3 The information from Levels 1 and 2 plus quasi-static tensile and J-R data at 288 C (550 F), per Tables C. 3 through C.5.

Level 4 The information from Levels 1 through 4 plus dynamic tensile and J-R data at $288 \mathrm{C}$ (550 F), per Tables C.6 through C.8.

The coefficient of thermal expansion of the stainless steel is $1.78 \times 10^{-5} \mathrm{~mm} / \mathrm{mm} / \mathrm{C}\left(9.9 \times 10^{-6} \mathrm{in} / \mathrm{in} / \mathrm{F}\right)$. 
The stress strain and J-R material property data for Levels 3 and 4 are supplied as IBM-compatible ASCII text files on the enclosed disk.

Test Conditions. Experiment 1-1 was conducted at a temperature of $288 \mathrm{C}(550 \mathrm{~F})$, with the specimen pressurized to $15.5 \mathrm{MPa}(2,250 \mathrm{psi})$.

Stress Analysis Results. An elastic uncracked pipe stress analysis using the Experiment 1-1 loading was performed and is provided on the enclosed disk as ASCII text files ELASTIC.SI and ELASTIC.USC. File ELASTIC.SI contains the data in SI units, while file ELASTIC.USC contains the data in U.S. customary units. There are 4701 lines in the files, from $\mathrm{T}=0$ seconds to $\mathrm{T}=23.5$ seconds at 0.005 second increments. Selected data from these files are shown in Table C.9. The loads at the crack location have been separated into various components to facilitate use of analysis approaches where different stress components have different "safety factors". Static analysis data for thermal only and pressure only loading are given in Table C.10.

For those wanting to perform their own finite element pipe stress analysis, detailed dimensions, material property data, and loading for Experiment 1-1 are supplied in Section C.3.

\section{Problem Statement:}

Step 1: The participants will use the given information to determine the maximum moment by one or all of the following methods: ASME Section XI approach, R6 approach, or more detailed fracture analyses. The possible effect of load cycling and stress-ratio may be included by considering the load history provided in Step 2.

A maximum moment prediction is expected from the participants at each of the four levels of material property specification.

Step 2: The participants are to make their best estimate as to whether the maximum moments determined in Step 1 will be attained in Experiment 1-1 and if so, when. There are three options for making these estimates:

Option 1: A Battelle-supplied ANSYS uncracked pipe finite element analysis will be the basis for the estimates in Option 1. The uncracked analysis will provide the different force and moment components at the crack section, i.e., thermal expansion, pressure, inertial, and SAM membrane and bending as a function of time.

Option 2: The participants can choose to conduct their own uncracked pipe elastic stress analysis and use these results as the basis for predicting whether or not the surface crack will penetrate the pipe wall and if it does, when.

Option 3: The participants can conduct their own more sophisticated (nonlinear) pipe stress analysis and use these results as the basis for predicting whether or not the surface crack will penetrate the pipe wall and if it does, when. In the Option 3 analyses, nonlinear crack models, plasticity remote from the crack, nonlinear damping, etc. can all be considered. 
All participants are asked to supply solutions using Option 1. Options 2 and 3 can be used as desired.

Please supply answers in SI units on the form supplied as Table C.11. For participants electing to use Option 2 and/or Option 3 in Step 2, a computer file containing moment as a function of time should be provided as a two-column computer file with time in the first column and total applied moment in $\mathrm{kN}-\mathrm{m}$ in the second column. Data should be written as an ASCII text file on an IBMcompatible $3^{1 / 2} / 2$-inch disk. In addition to the numerical results, the participant should provide precise, written details on how the moments in Step 1 were calculated. Battelle will translate the compiled results to U.S. customary units, as needed.

\section{Evaluation:}

Battelle will compile the results and compare the predicted maximum moments to the maximum moment attained in IPIRG-2 Experiment 1-1. The predicted time and measured time at failure will also be tabulated.

Table C.2 Material properties at Level 2, room temperature longitudinal tensile-test data (Data for Specimen A8-35 from NUREG/CR-2175)

\begin{tabular}{cc}
\hline Yield Strength, MPa (ksi) & $295(42.8)$ \\
Ultimate Strength, MPa (ksi) & $743(107.8)$ \\
Elongation, percent & 75.9 \\
\hline
\end{tabular}

Table C.3 Material properties at Level 3, quasi-static longitudinal tensile-test data at 288 C (550 F) (Data from Specimen A8-40)

Yield Strength, MPa (ksi)

Ultimate Strength, MPa (ksi)

Elongation, percent
$171(24.8)$

$456(66.2)$

47.0 
Table C.4 Material properties at Level 3, quasi-static longitudinal stress-strain data at 288 C (550 F) (Data from Specimen A8-40)

\begin{tabular}{|c|c|c|c|c|c|}
\hline \multicolumn{3}{|c|}{ Engineering } & \multicolumn{3}{|c|}{ True } \\
\hline \multicolumn{2}{|c|}{ Stress } & \multirow[b]{2}{*}{ Strain } & \multicolumn{2}{|c|}{ Stress } & \multirow[b]{2}{*}{ Strain } \\
\hline $\mathbf{M P a}$ & psi & & $\mathbf{M P a}$ & psi & \\
\hline 0.0 & 0 & 0.00000 & 0.0 & 0 & 0.00000 \\
\hline 42.1 & 6,112 & 0.00028 & 42.2 & 6,113 & 0.00028 \\
\hline 63.2 & 9,167 & 0.00040 & 63.2 & 9,171 & 0.00040 \\
\hline 84.3 & 12,220 & 0.00056 & 84.3 & 12,230 & 0.00056 \\
\hline 105.4 & 15,280 & 0.00080 & 105.4 & 15,290 & 0.00080 \\
\hline 126.4 & 18,330 & 0.00116 & 126.6 & 18,360 & 0.00116 \\
\hline 145.3 & 21,080 & 0.00160 & 145.6 & 21,120 & 0.00160 \\
\hline 156.3 & 22,670 & 0.00200 & 156.7 & 22,720 & 0.00200 \\
\hline 164.4 & 23,840 & 0.00240 & 164.7 & 23,890 & 0.00240 \\
\hline 169.4 & 24,570 & 0.00280 & 169.9 & 24,640 & 0.00280 \\
\hline 173.6 & 25,180 & 0.00320 & 174.2 & 25,260 & 0.00320 \\
\hline 178.2 & 25,850 & 0.00360 & 178.9 & 25,940 & 0.00359 \\
\hline 181.2 & 26,280 & 0.00400 & 181.9 & 26,380 & 0.00399 \\
\hline 184.2 & 26,710 & 0.00440 & 184.9 & 26,820 & 0.00439 \\
\hline 186.6 & 27,070 & 0.00480 & 187.5 & 27,200 & 0.00479 \\
\hline 190.9 & 27,690 & 0.00560 & 192.0 & 27,840 & 0.00558 \\
\hline 194.7 & 28,240 & 0.00640 & 196.0 & 28,420 & 0.00638 \\
\hline 198.0 & 28,720 & 0.00720 & 199.5 & 28,930 & 0.00717 \\
\hline 201.0 & 29,150 & 0.00800 & 202.6 & 29,390 & 0.00797 \\
\hline 205.2 & 29,760 & 0.00920 & 207.1 & 30,040 & 0.00916 \\
\hline 209.4 & 30,370 & 0.01080 & 211.7 & 30,700 & 0.01074 \\
\hline 212.0 & 30,740 & 0.01204 & 214.5 & 31,110 & 0.01197 \\
\hline 219.1 & 31,780 & 0.01404 & 222.2 & 32,230 & 0.01394 \\
\hline 227.5 & 33,000 & 0.01804 & 231.7 & 33,600 & 0.01788 \\
\hline 235.9 & 34,220 & 0.02204 & 241.2 & 34,980 & 0.02180 \\
\hline 244.4 & 35,450 & 0.02704 & 251.0 & 36,410 & 0.02668 \\
\hline
\end{tabular}


Table C.4 (Continued)

\begin{tabular}{|c|c|c|c|c|c|}
\hline \multicolumn{3}{|c|}{ Engineering } & \multicolumn{3}{|c|}{ True } \\
\hline \multicolumn{2}{|c|}{ Stress } & \multirow[b]{2}{*}{ Strain } & \multicolumn{2}{|c|}{ Stress } & \multirow[b]{2}{*}{ Strain } \\
\hline $\mathbf{M P a}$ & psi & & $\mathbf{M P a}$ & psi & \\
\hline 252.8 & 36,670 & 0.03204 & 260.9 & 37,840 & 0.03154 \\
\hline 265.5 & 38,500 & 0.03904 & 275.9 & 40,010 & 0.03830 \\
\hline 278.1 & 40,340 & 0.04704 & 291.2 & 42,230 & 0.04597 \\
\hline 290.8 & 42,170 & 0.05404 & 306.5 & 44,450 & 0.05263 \\
\hline 303.4 & 44,000 & 0.06304 & 322.5 & 46,780 & 0.06113 \\
\hline 316.1 & 45,840 & 0.07304 & 339.1 & 49,180 & 0.07050 \\
\hline 328.7 & 47,670 & 0.08304 & 356.0 & 51,630 & 0.07977 \\
\hline 341.3 & 49,500 & 0.09404 & 373.4 & 54,160 & 0.08988 \\
\hline 354.0 & 51,340 & 0.10500 & 391.2 & 56,730 & 0.09985 \\
\hline 366.6 & 53,170 & 0.11800 & 409.8 & 59,440 & 0.11150 \\
\hline 381.4 & 55,310 & 0.13500 & 432.9 & 62,780 & 0.12660 \\
\hline 384.9 & 55,820 & 0.14100 & 439.1 & 63,690 & 0.13190 \\
\hline 393.3 & 57,040 & 0.15100 & 452.7 & 65,650 & 0.14060 \\
\hline 399.6 & 57,960 & 0.16100 & 464.0 & 67,290 & 0.14930 \\
\hline 405.9 & 58,870 & 0.17100 & 475.3 & 68,940 & 0.15790 \\
\hline 418.6 & 60,710 & 0.19100 & 498.5 & 72,300 & 0.17480 \\
\hline 427.0 & 61,930 & 0.21100 & 517.1 & 75,000 & 0.19140 \\
\hline 435.4 & 63,150 & 0.23100 & 536.0 & 77,740 & 0.20780 \\
\hline 439.6 & 63,760 & 0.25100 & 550.0 & 79,770 & 0.22390 \\
\hline 443.8 & 64,370 & 0.27100 & 564.1 & 81,820 & 0.23980 \\
\hline 448.1 & 64,990 & 0.29100 & 578.5 & 83,900 & 0.25540 \\
\hline 452.3 & 65,600 & 0.31100 & 593.0 & 86,000 & 0.27080 \\
\hline 456.5 & 66,210 & 0.33100 & 607.6 & 88,120 & 0.28590 \\
\hline 448.1 & 64,990 & 0.41100 & & & \\
\hline 418.6 & 60,710 & 0.43100 & & & \\
\hline 376.5 & 54,600 & 0.45100 & & & \\
\hline 325.9 & 47,260 & 0.46700 & & & \\
\hline 186.9 & 27,110 & 0.47400 & 824.5 & 119580 & 1.485 \\
\hline
\end{tabular}


Table C.5 Material properties at Level 3, quasi-static L-C oriented C(T) specimen J-R curve at $288 \mathrm{C}$ (550 F) (Specimen A8-12A, 20-percent side-grooved 1T C(T) specimen)

\begin{tabular}{cccc}
\hline \multicolumn{2}{c}{ Crack growth } & \multicolumn{2}{c}{$\mathbf{J}_{\mathbf{D}}($ Using ASTM E1152) } \\
\hline $\mathbf{m m}$ & inch & $\mathbf{M J} / \mathbf{m}^{2}$ & in-lb/in ${ }^{2}$ \\
\hline 0.00 & 0.000 & 0.854 & 4,875 \\
0.06 & 0.002 & 0.903 & 5,161 \\
0.51 & 0.020 & 1.087 & 6,138 \\
0.84 & 0.033 & 1.251 & 7,141 \\
1.20 & 0.047 & 1.447 & 8,261 \\
1.62 & 0.064 & 1.657 & 9,459 \\
2.27 & 0.089 & 1.847 & 10,545 \\
2.92 & 0.115 & 2.055 & 11,733 \\
3.66 & 0.144 & 2.186 & 12,485 \\
4.43 & 0.174 & 2.307 & 13,176 \\
5.04 & 0.198 & 2.353 & 13,435 \\
5.85 & 0.230 & 2.417 & 13,799 \\
6.60 & 0.260 & 2.516 & 14,365 \\
7.32 & 0.288 & 2.610 & 14,906 \\
7.98 & 0.314 & 2.660 & 15,190 \\
\hline & & &
\end{tabular}

Table C.6 Material properties at Level 4, dynamic longitudinal tensile-test data at $288 \mathrm{C}$ ( $550 \mathrm{~F}$ ) (Specimen A8-101, strain rate of $1 \mathrm{sec}^{-1}$ )

\begin{tabular}{cc}
\hline Yield Strength, MPa (ksi) & $171(24.8)$ \\
Ultimate Strength, MPa (ksi) & $456(66.2)$ \\
Elongation, percent & 47.0 \\
\hline
\end{tabular}


Table C.7 Material properties at Level 4, dynamic longitudinal stress-strain data at $288 \mathrm{C}(550 \mathrm{~F})$ (Specimen A8-101, strain rate of $1 \mathrm{sec}^{-1}$ )

\begin{tabular}{|c|c|c|c|c|c|}
\hline \multicolumn{3}{|c|}{ Engineering } & \multicolumn{3}{|c|}{ True } \\
\hline \multicolumn{2}{|c|}{ Stress } & \multirow[b]{2}{*}{ Strain } & \multicolumn{2}{|c|}{ Stress } & \multirow[b]{2}{*}{ Strain } \\
\hline $\mathbf{M P a}$ & psi & & $\mathbf{M P a}$ & psi & \\
\hline 0.0 & 0 & 0.00000 & 0.0 & 0 & 0.00000 \\
\hline 184.9 & 26,810 & 0.00104 & 185.0 & 26,830 & 0.00104 \\
\hline 190.2 & 27,590 & 0.00182 & 190.6 & 27,640 & 0.00182 \\
\hline 195.2 & 28,310 & 0.00263 & 195.7 & 28,390 & 0.00263 \\
\hline 199.8 & 28,980 & 0.00347 & 200.5 & 29,080 & 0.00346 \\
\hline 204.0 & 29,580 & 0.00435 & 204.9 & 29,710 & 0.00434 \\
\hline 207.7 & 30,120 & 0.00527 & 208.8 & 30,280 . & 0.00526 \\
\hline 211.0 & 30,600 & 0.00621 & 212.3 & 30,790 & 0.00619 \\
\hline 214.0 & 31,040 & 0.00718 & 215.5 & 31,260 & 0.00715 \\
\hline 221.3 & 32,100 & 0.01018 & 223.6 & 32,430 & 0.01013 \\
\hline 241.5 & 35,030 & 0.02316 & 247.1 & 35,840 & 0.02290 \\
\hline 260.0 & 37,710 & 0.03635 & 269.5 & 39,080 & 0.03570 \\
\hline 278.0 & 40,320 & 0.05129 & 292.3 & 42,390 & 0.05002 \\
\hline 294.7 & 42,740 & 0.06563 & 314.0 & 45,540 & 0.06357 \\
\hline 311.6 & 45,190 & 0.08108 & 336.8 & 48,850 & 0.07796 \\
\hline 327.3 & 47,470 & 0.09806 & 359.4 & 52,130 & 0.09354 \\
\hline 342.2 & 49,630 & 0.11510 & 381.6 & 55,340 & 0.10890 \\
\hline 356.1 & 51,650 & 0.13390 & 403.8 & 58,570 & 0.12570 \\
\hline 367.8 & 53,350 & 0.15340 & 424.2 & 61,530 & 0.14270 \\
\hline 378.9 & 54,950 & 0.17350 & 444.6 & 64,480 & 0.16000 \\
\hline 389.2 & 56,450 & 0.19460 & 465.0 & 67,440 & 0.17780 \\
\hline 397.1 & 57,590 & 0.21580 & 482.8 & 70,020 & 0.19540 \\
\hline 403.8 & 58,570 & 0.23780 & 499.9 & 72,500 & 0.21330 \\
\hline 410.0 & 59,460 & 0.26010 & 516.6 & 74,920 & 0.23120 \\
\hline 414.9 & 60,170 & 0.28260 & 532.2 & 77,180 & 0.24890 \\
\hline 417.8 & 60,600 & 0.30550 & 545.5 & 79,110 & 0.26660 \\
\hline 418.7 & 60,730 & 0.32920 & 556.6 & 80,720 & 0.28460 \\
\hline 419.6 & 60,860 & 0.35210 & 567.4 & 82,290 & 0.30170 \\
\hline 418.0 & 60,630 & 0.37600 & & & \\
\hline 414.3 & 60,080 & 0.39870 & & & \\
\hline 400.7 & 58,120 & 0.41710 & & & \\
\hline 378.4 & 54,880 & 0.43080 & & & \\
\hline 356.6 & 51,720 & 0.44010 & & & \\
\hline 337.2 & 48,910 & 0.44640 & & & \\
\hline 333.6 & 48,390 & 0.44740 & & & \\
\hline
\end{tabular}


Table C.8 Material properties at Level 4, dynamic L-C oriented C(T) specimen J-R curve at $288 \mathrm{C}$ (550 F) (Data from Specimen A8-11A, 20-percent side-grooved $1 \mathrm{~T} C(\mathrm{~T})$ specimen)

\begin{tabular}{cccc}
\hline Crack growth & & \multicolumn{2}{c}{$\mathrm{J}_{\mathbf{D}}$ (Using ASTM E1152) } \\
\hline $\mathbf{m m}$ & inch & $\mathbf{M J} / \mathbf{m}^{2}$ & in-lb/in \\
\hline 0.000 & 0.000 & 1.399 & 7,985 \\
0.178 & 0.007 & 1.510 & 8,624 \\
0.493 & 0.019 & 1.659 & 9,471 \\
0.945 & 0.037 & 1.824 & 10,414 \\
1.405 & 0.055 & 1.993 & 11,378 \\
1.798 & 0.071 & 2.145 & 12,248 \\
2.197 & 0.087 & 2.284 & 13,041 \\
2.690 & 0.106 & 2.455 & 14,016 \\
3.134 & 0.123 & 2.574 & 14,700 \\
3.622 & 0.143 & 2.684 & 15,326 \\
4.150 & 0.163 & 2.787 & 15,915 \\
4.676 & 0.184 & 2.876 & 16,420 \\
5.098 & 0.201 & 2.918 & 16,663 \\
5.555 & 0.219 & 3.007 & 17,168 \\
6.005 & 0.236 & 3.018 & 17,233 \\
6.360 & 0.250 & 3.069 & 17,525 \\
\hline & & &
\end{tabular}


Table C.9 Selected data records from elastic uncracked finite element stress analysis results in SI units

\begin{tabular}{|c|c|c|c|c|c|c|}
\hline $\begin{array}{l}\text { Time, } \\
\text { seconds }\end{array}$ & $\begin{array}{c}\text { Total } \\
\text { Moment, } \\
\text { kN-m }\end{array}$ & $\begin{array}{c}\text { Inertial } \\
\text { Moment, } \\
\text { kN-m }\end{array}$ & $\begin{array}{c}\text { SAM } \\
\text { Moment, } \\
\text { kN-m }\end{array}$ & $\begin{array}{c}\text { Total } \\
\text { Force, } \\
\text { N }\end{array}$ & $\begin{array}{c}\text { Inertial } \\
\text { Force, } \\
\mathbf{N}\end{array}$ & $\begin{array}{c}\text { SAM } \\
\text { Force, } \\
\mathbf{N}\end{array}$ \\
\hline 0.000 & 106.37 & 0.00 & 0.00 & 1491.86 & 0.00 & 0.00 \\
\hline 0.005 & 106.37 & 0.00 & 0.00 & 1491.86 & 0.00 & 0.00 \\
\hline 0.010 & 106.37 & 0.00 & 0.00 & 1491.86 & 0.00 & 0.00 \\
\hline 0.015 & 106.38 & -0.11 & 0.12 & 1491.82 & 0.00 & -0.04 \\
\hline 0.020 & 106.46 & -0.16 & 0.25 & 1491.89 & 0.11 & -0.08 \\
\hline 0.025 & 106.65 & -0.09 & 0.37 & 1492.13 & 0.39 & -0.11 \\
\hline 0.030 & 106.89 & -0.1 & 0.62 & 1491.92 & 0.25 & -0.19 \\
\hline 0.990 & 240.04 & 32.46 & 101.21 & 1465.12 & 4.10 & -30.84 \\
\hline 0.995 & 240.21 & 36.45 & 97.39 & 1466.08 & 3.89 & -29.68 \\
\hline 1.000 & 239.65 & 40.32 & 92.96 & 1469.28 & 5.75 & -28.33 \\
\hline 1.005 & 237.51 & 43.1 & 88.03 & 1471.43 & 6.40 & -26.82 \\
\hline 1.010 & 234.9 & 46.16 & 82.37 & 1473.43 & 6.67 & -25.10 \\
\hline 9.995 & 209.08 & -9.34 & 112.04 & 1452.47 & -5.25 & -34.14 \\
\hline 10.000 & 230.23 & 8.98 & 114.87 & 1457.16 & 0.31 & -35.00 \\
\hline 10.005 & 249.07 & 25.61 & 117.09 & 1461.33 & 5.15 & -35.68 \\
\hline 10.010 & 265.03 & 39.72 & 118.93 & 1463.33 & 7.71 & -36.24 \\
\hline 10.015 & 277.44 & 50.65 & 120.41 & 1466.31 & 11.15 & -36.69 \\
\hline 20.005 & 423.13 & 305.43 & 11.33 & 1544.64 & 56.23 & -3.45 \\
\hline 20.010 & 408.45 & 288.16 & 13.91 & 1540.63 & 53.01 & -4.24 \\
\hline
\end{tabular}


Table C.10 Static results from elastic uncracked finite element stress analysis

\begin{tabular}{ccc}
\hline Loading & $\begin{array}{c}\text { Moment, } \mathbf{k N}-\mathbf{m} \\
\text { (in-lb) }\end{array}$ & $\begin{array}{c}\text { Force, } \mathbf{N} \\
\text { (lb) }\end{array}$ \\
\hline Thermal Only Loading & 102.79 & -33.93 \\
& $(909,834)$ & $(-7,627)$ \\
Pressure Only Loading & 3.58 & $1,525,79$ \\
& $(31,691)$ & $(343,010)$ \\
\hline
\end{tabular}

Table C.11 Expected analysis results for Round-Robin Problem C.2

(a) Step 1 Results

\begin{tabular}{ccc}
\hline Material Property Information & $\begin{array}{c}\text { Predicted Maximum Moment } \\
(\mathbf{k N}-\mathbf{m})\end{array}$ & Prediction Method \\
\hline Level 1 & \\
Level 2 & \\
Level 3 & \\
Level 4 \\
\hline
\end{tabular}

(b) Step 2 Results

Material Property Information $\quad$ Predicted Time to Reach Maximum Moment
(seconds)

Level 1

Level 2

Level 3

Level 4 


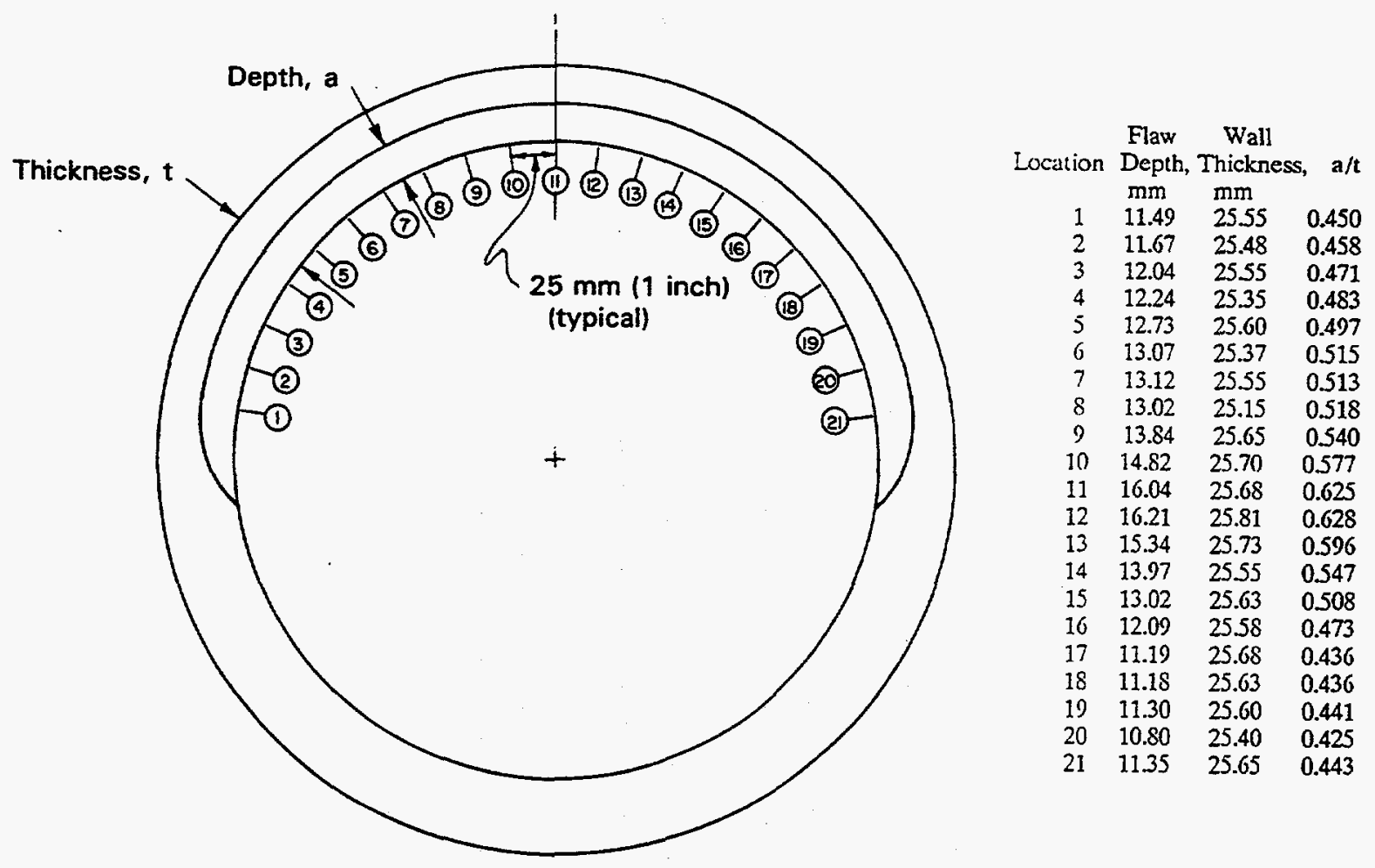

Note: Crack length on inside pipe surface $=606 \mathrm{~mm}$ (23.85 inch)

Figure C.2 Flaw geometry for IPIRG-2 Experiment 1-1 


\section{C.3 IPIRG-2 Pipe Loop Finite Element Analysis Data for Problem C.2}

The data needed to perform linear elastic or nonlinear finite element modeling of the IPIRG pipe system consist of pipe dimensions, boundary condition information, pipe system material properties, system damping, and loading.

\section{Pipe Dimensions:}

Most of the straight pipe in the loop is constructed with 406-mm (16-inch) outside diameter Schedule 100 pipe. The nominal thickness is $26.2 \mathrm{~mm}$ (1.031 inch). An artist's sketch of the pipe loop is shown in Figure C.3, while detailed dimensions are given in Figure C.4. In addition, Table C.12 gives the basic element data used in the Battelle ANSYS calculations.

The data in Table C.12 reflect all of the changes to the pipe loop adopted in the IPIRG-2 program; thicker pipe where the strain gages are located, the additional mass of the restraint system, inclusion of the restraint system baffle plates, elimination of the thicker section at the hanger in the longest pipe run, and measured elbow thicknesses.

\section{Boundary Conditions:}

The following boundary conditions are to be imposed. Note: Figure C. 3 gives the coordinate system.

(1) At the two anchor points, all displacements and rotations are restrained.

(2) At the actuator, the displacements in the z-direction are restrained, all pipe rotations and axial motion are permitted.

(3) At the lumped mass, motion is restrained only in the z-direction.

(4) There are pipe supports $1.219 \mathrm{~m}$ (4 feet) from each elbow near the anchor locations. The support near Elbow 1 restrains displacements in the $z$ - and $x$-directions. The support near Elbow 5 restrains displacements in the $z$ - and y-directions. The pipe supports permit all pipe rotations and unrestrained axial motion.

(5) There is a vertical support which restrains displacements only in the z-direction at $1.219 \mathrm{~m}$ (4 feet) from Elbow Number 4.

\section{System Material Properties:}

The pipe loop and elbows are constructed from high strength steel. The straight pipe is ASTM A710, Grade A, Class 3 material while the elbow material has a designation of WPHY-65. The summary material properties for the loop materials at $288 \mathrm{C}(550 \mathrm{~F})$ are given in Table C.13. The pipe loop remains elastic during the loading. 


\section{System Damping}

The predicted behavior of the IPIRG piping loop is a strong function of amount of damping that is assumed in the system. Based on system damping measurements, the damping is approximately 0.5 percent at the first natural frequency, even at large motion amplitudes. This low amount of damping can be directly attributed to the use of hydrostatic bearings at the vertical supports, linear bearings at the actuator, and spherical bearings at the hangers.

\section{Loading:}

The pipe loop has a stress free temperature of $21 \mathrm{C}(70 \mathrm{~F})$, when unpressurized. The pipe is always filled with water. At the PWR condition, the whole loop is at a temperature of $288 \mathrm{C} \mathrm{(550} \mathrm{F)} \mathrm{and} \mathrm{a}$ pressure of $15.51 \mathrm{MPa}(2,250 \mathrm{psi})$. At this temperature and pressure, the water has a specific weight of $7260.8 \mathrm{~N} / \mathrm{m}^{3}\left(0.026748\right.$ pounds $\left./ \mathrm{in}^{3}\right)$. The temperature and pressure are applied to the loop with the actuator held at zero displacement prior to application of the time-history forcing function.

The forcing function for Experiment 1-1 is plotted in Figure C.5. A portion of these data are listed in Table C.14. The complete 4701-line forcing function data are supplied on the enclosed IBM PC format disk. 
Table C.12 Elements used in Battelle ANSYS IPIRG-2 pipe system model

\begin{tabular}{cccccc}
\hline $\begin{array}{c}\text { Element } \\
\text { Number }\end{array}$ & Direction & $\begin{array}{c}\text { Element } \\
\text { Type }\end{array}$ & $\begin{array}{c}\text { Diameter, } \\
\text { mm (in) }\end{array}$ & $\begin{array}{c}\text { Thickness, } \\
\text { mm (in) }\end{array}$ & $\begin{array}{c}\text { Length, } \\
\text { m (in) }\end{array}$ \\
\hline & \multicolumn{7}{c}{ (a) Fixed End: Restraint in all degrees of freedom } \\
1 & $z$ & Straight Pipe & $406(16)$ & $26.2(1.031)$ & $0.305(12.0)$ \\
2 & $z$ & Straight Pipe & $406(16)$ & $26.2(1.031)$ & $0.305(12.0)$ \\
3 & $z-y$ & Elbow \#1 & $406(16)$ & $26.2(1.031)$ & 45 -degrees \\
4 & $z-y$ & Elbow \#1 & $406(16)$ & $26.2(1.031)$ & 45 -degrees \\
5 & $y$ & Straight Pipe & $406(16)$ & $26.2(1.031)$ & $0.914(36.0)$ \\
6 & $y$ & Straight Pipe & $406(16)$ & $26.2(1.031)^{(a)}$ & $0.305(12.0)$
\end{tabular}

(b) Node 6 Hanger: Restraint in $x$ - and z-directions

$\begin{array}{llllll}7 & \text { y } & \text { Straight Pipe } & 406(16) & 40.5(1.593) & 0.305(12.0) \\ 8 & & & 26.2(1.031)^{(a)} & \\ 9 & \text { y } & \text { Straight Pipe } & 406(16) & 26.2(1.031) & 0.914(36.0) \\ 10 & \text { y } & \text { Straight Pipe } & 406(16) & 26.2(1.031) & 1.219(48.0) \\ 11 & \text { y } & \text { Straight Pipe } & 406(16) & 26.2(1.031) & 1.219(48.0) \\ 12 & \text { y } & \text { Straight Pipe } & 406(16) & 26.2(1.031) & 0.914(36.0) \\ & \text { y } & \text { Straight Pipe } & 406(16) & 26.2(1.031)^{(a)} & 0.305(12.0)\end{array}$

(c) Actuator Location: Restraint in z-direction, forcing function applied displacements in x-direction

$\begin{array}{lccccc}13 & y & \text { Straight Pipe } & 406(16) & 40.5(1.593) & 0.305(12.0) \\ 14 & & & 26.2(1.031)^{(a)} & \\ 15 & y & \text { Straight Pipe } & 406(16) & 26.2(1.031) & 0.914(36.0) \\ 16 & x-y & \text { Elbow \#2 } & 406(16) & 37.9(1.493) & 45 \text {-degrees } \\ 17 & x-y & \text { Elbow \#2 } & 406(16) & 37.9(1.493) & 45 \text {-degrees } \\ & x & \text { Straight Pipe } & 406(16) & 26.2(1.031) & 1.372(54.0)\end{array}$

(d) Lumped Weight: 19,127 N (4,300 pound) to simulate a swing check valve, restraint in z-direction

\begin{tabular}{cccccc}
18 & $\mathrm{x}$ & Straight pipe & $406(16)$ & $26.2(1.031)$ & $1.372(54.0)$ \\
19 & $\mathrm{x}-\mathrm{y}$ & Elbow \#3 & $406(16)$ & $37.2(1.466)$ & 45 -degree \\
20 & $\mathrm{x}-\mathrm{y}$ & Elbow \#3 & $406(16)$ & $37.2(1.466)$ & 45 -degree \\
\hline
\end{tabular}


Table C.12 (Continued)

\begin{tabular}{|c|c|c|c|c|c|}
\hline $\begin{array}{l}\text { Element } \\
\text { Number }\end{array}$ & Direction & $\begin{array}{c}\text { Element } \\
\text { Type } \\
\end{array}$ & $\begin{array}{c}\text { Diameter, } \\
\text { mm (in) }\end{array}$ & $\begin{array}{l}\text { Thickness, } \\
\text { mm (in) }\end{array}$ & $\begin{array}{l}\text { Length, } \\
\text { m (in) }\end{array}$ \\
\hline 21 & $\mathrm{y}$ & Straight Pipe & $406(16)$ & $26.2(1.031)$ & $0.762(30.0)$ \\
\hline 22 & $\mathrm{y}$ & Straight Pipe & $406(16)$ & $26.2(1.031)$ & $0.762(30.0)$ \\
\hline 23 & y & Straight Pipe & $406(16)$ & $26.2(1.031)$ & $1.473(57.5)$ \\
\hline 24 & $\mathrm{y}$ & Straight Pipe & $406(16)$ & $\begin{array}{c}26.2(1.031)^{(a)} \\
38.1(1.500)\end{array}$ & $0.216(8.5)$ \\
\hline \multicolumn{6}{|c|}{ (e) North Strain Gage Location } \\
\hline 25 & y & Straight Pipe & $406(16)$ & $38.1(1.500)$ & $0.140(5.5)$ \\
\hline 26 & $\mathrm{y}$ & Straight Pipe & $406(16)$ & $38.1(1.500)$ & $0.546(21.5)$ \\
\hline \multicolumn{6}{|c|}{ (f) Restraint System Lumped Weight: 1,579 N (355 pounds) } \\
\hline $\begin{array}{c}27 \\
\text { (Baffle Plate) }\end{array}$ & y & Straight Pipe & $406(16)$ & $152.4(6.000)$ & $0.076(3.0)$ \\
\hline $\begin{array}{c}28 \\
\text { (Specimen) }\end{array}$ & y & Straight Pipe & $406(16)$ & $26.2(1.031)$ & $0.152(6.0)$ \\
\hline \multicolumn{6}{|c|}{ (g) Crack Location } \\
\hline $\begin{array}{c}29 \\
\text { (Specimen) }\end{array}$ & y & Straight Pipe & $406(16)$ & $26.2(1.031)$ & $0.152(6.0)$ \\
\hline $\begin{array}{c}30 \\
\text { (Baffle Plate) }\end{array}$ & y & Straight Pipe & $406(16)$ & $152.4(6.000)$ & $0.076(3.0)$ \\
\hline 31 & y & Straight Pipe & $406(16)$ & $38.1(1.500)$ & $0.546(21.5)$ \\
\hline 32 & $\mathrm{y}$ & Straight Pipe & $406(16)$ & $38.1(1.500)$ & $0.140(5.5)$ \\
\hline \multicolumn{6}{|c|}{ (h) South Strain Gage Location } \\
\hline 33 & y & Straight Pipe & $406(16)$ & $38.1(1.500)$ & $0.457(18.0)$ \\
\hline 34 & $x-y$ & Elbow \#4 & $406(16)$ & $51.4(2.022)$ & 45-degrees \\
\hline 35 & $x-y$ & Elbow \#4 & $406(16)$ & $51.4(2.022)$ & 45-degrees \\
\hline 36 & $\mathrm{x}$ & Straight Pipe & $406(16)$ & $\begin{array}{c}40.5(1.500) \\
26.2(1.031)^{(a)}\end{array}$ & $0.216(8.5)$ \\
\hline 37 & $x$ & Straight Pipe & $406(16)$ & $26.2(1.031)$ & $1.003(39.5)$ \\
\hline \multicolumn{6}{|c|}{ (i) Pipe Support: Restraint in z-direction } \\
\hline 38 & $\mathrm{x}$ & Straight Pipe & $406(16)$ & $26.2(1.031)$ & $0.864(34.0)$ \\
\hline
\end{tabular}


Table C.12 (Continued)

\begin{tabular}{cccccc}
\hline $\begin{array}{c}\text { Element } \\
\text { Number }\end{array}$ & Direction & $\begin{array}{c}\text { Element } \\
\text { Type }\end{array}$ & $\begin{array}{c}\text { Diameter, } \\
\text { mm (in) }\end{array}$ & $\begin{array}{c}\text { Thickness, } \\
\text { mm (in) }\end{array}$ & $\begin{array}{c}\text { Length, } \\
\text { m (in) }\end{array}$ \\
\hline 39 & $\mathrm{x}$ & Straight Pipe & $406(16)$ & $26.2(1.031)$ & $1.575(62.0)$ \\
40 & $\mathrm{x}$ & Straight Pipe & $406(16)$ & $26.2(1.031)$ & $1.219(48.0)$ \\
41 & $\mathrm{x}$ & Straight Pipe & $406(16)$ & $26.2(1.031)$ & $1.219(48.0)$ \\
42 & $\mathrm{x}$ & Straight Pipe & $406(16)$ & $26.2(1.031)$ & $1.219(48.0)$ \\
43 & $\mathrm{x}$ & Straight Pipe & $406(16)$ & $26.2(1.031)$ & $0.914(36.0)$ \\
44 & $\mathrm{x}$ & Straight Pipe & $406(16)$ & $26.2(1.031)$ & $0.305(12.0)$ \\
& & (j) Pipe Hanger: Restraint in y- and z-direction & \\
45 & $\mathrm{x}$ & Straight Pipe & $406(16)$ & $26.2(1.031)$ & $0.305(12.0)$ \\
46 & $\mathrm{x}$ & Straight Pipe & $406(16)$ & $26.2(1.031)$ & $0.914(36.0)$ \\
47 & $\mathrm{x}-\mathrm{z}$ & Elbow \#5 & $406(16)$ & $26.2(1.031)$ & $45-$ degree \\
48 & $\mathrm{x}-\mathrm{z}$ & Elbow \#5 & $406(16)$ & $26.2(1.031)$ & $45-$ degree \\
49 & $\mathrm{z}$ & Straight Pipe & $406(16)$ & $26.2(1.031)$ & $0.305(12.0)$ \\
50 & $\mathrm{z}$ & Straight Pipe & $406(16)$ & $26.2(1.031)$ & $0.305(12.0)$ \\
& (k) Fixed End: Restraint in all degrees of freedom & \\
\hline
\end{tabular}

(a) Pipe wall thickness tapers: $49 \mathrm{~mm}$ (2.00 inches) of $26.2 \mathrm{~mm}$ (1.031 inches) at pipe segment end, $76.2 \mathrm{~mm}$ (3.00 inches) of taper from $26.2 \mathrm{~mm}$ (1.031 inches) to larger thickness.

Note: All elbows have long radius, $R=609.6 \mathrm{~mm}$ ( 24.00 inches)

Table C.13 IPIRG-2 pipe loop material properties at 288 C (550 F)

\begin{tabular}{ccc}
\hline Component & Straight Pipe & Elbows \\
\hline Designation & A710 Gr A Cl 3 & WPHY-65 \\
$\begin{array}{c}\text { Elastic Modulus, } \\
\text { GPa (psi) } \\
\text { Poisson's Ratio }\end{array}$ & $195.39\left(28.34 \times 10^{6}\right)$ & $193.05\left(28.00 \times 10^{6}\right)$ \\
$\begin{array}{c}\text { Coefficient of Thermal Expansion, } \\
\mathrm{mm} / \mathrm{mm} / \mathrm{C}(\mathrm{in} / \mathrm{in} / \mathrm{F})\end{array}$ & 0.285 & 0.285 \\
\hline
\end{tabular}


Table C.14 Selected IPIRG-2 Experiment 1-1 simulated seismic loading forcing function data

\begin{tabular}{|c|c|c|}
\hline $\begin{array}{l}\text { Time, } \\
\text { seconds }\end{array}$ & $\begin{array}{c}\text { Displacement, } \\
\mathbf{m m}\end{array}$ & $\begin{array}{c}\text { Displacement, } \\
\text { inches }\end{array}$ \\
\hline 0.000 & 0.00 & 0.000 \\
\hline 0.005 & 0.00 & 0.000 \\
\hline 0.010 & 0.00 & 0.000 \\
\hline 0.015 & 0.03 & 0.001 \\
\hline 0.020 & 0.05 & 0.002 \\
\hline 0.025 & 0.08 & 0.003 \\
\hline 0.030 & 0.13 & 0.005 \\
\hline 0.990 & 20.88 & 0.822 \\
\hline 0.995 & 20.09 & 0.791 \\
\hline 1.000 & 19.18 & 0.755 \\
\hline 1.005 & 18.16 & 0.715 \\
\hline 1.010 & 16.99 & 0.669 \\
\hline 9.995 & 23.11 & 0.91 \\
\hline 10.000 & 23.7 & 0.933 \\
\hline 10.005 & 24.16 & 0.951 \\
\hline 10.010 & 24.54 & 0.966 \\
\hline 10.015 & 24.84 & 0.978 \\
\hline 20.005 & 2.34 & 0.092 \\
\hline 20.010 & 2.87 & 0.113 \\
\hline
\end{tabular}




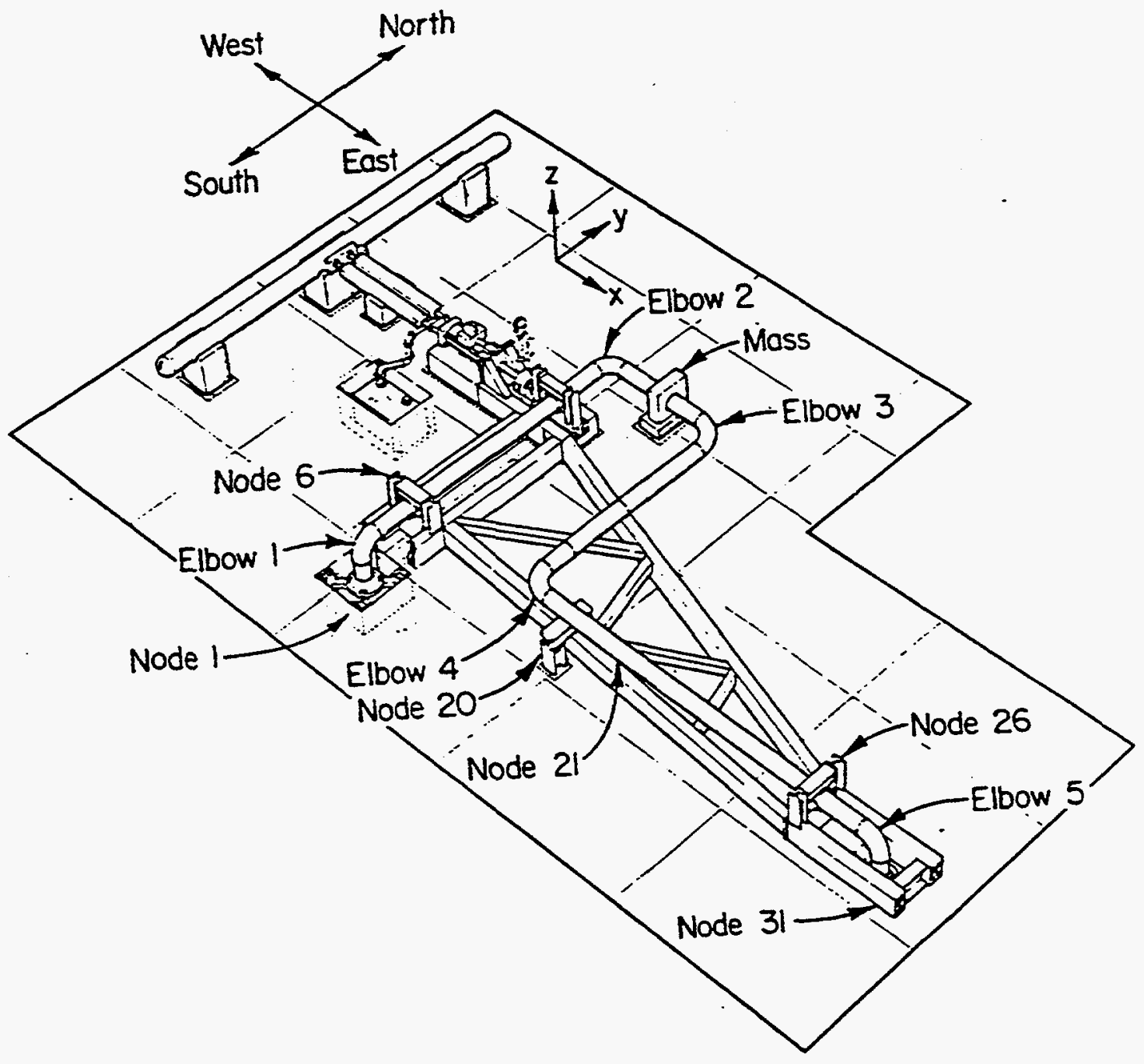

Figure C.3 Artist's conception of the IPIRG Pipe Loop 


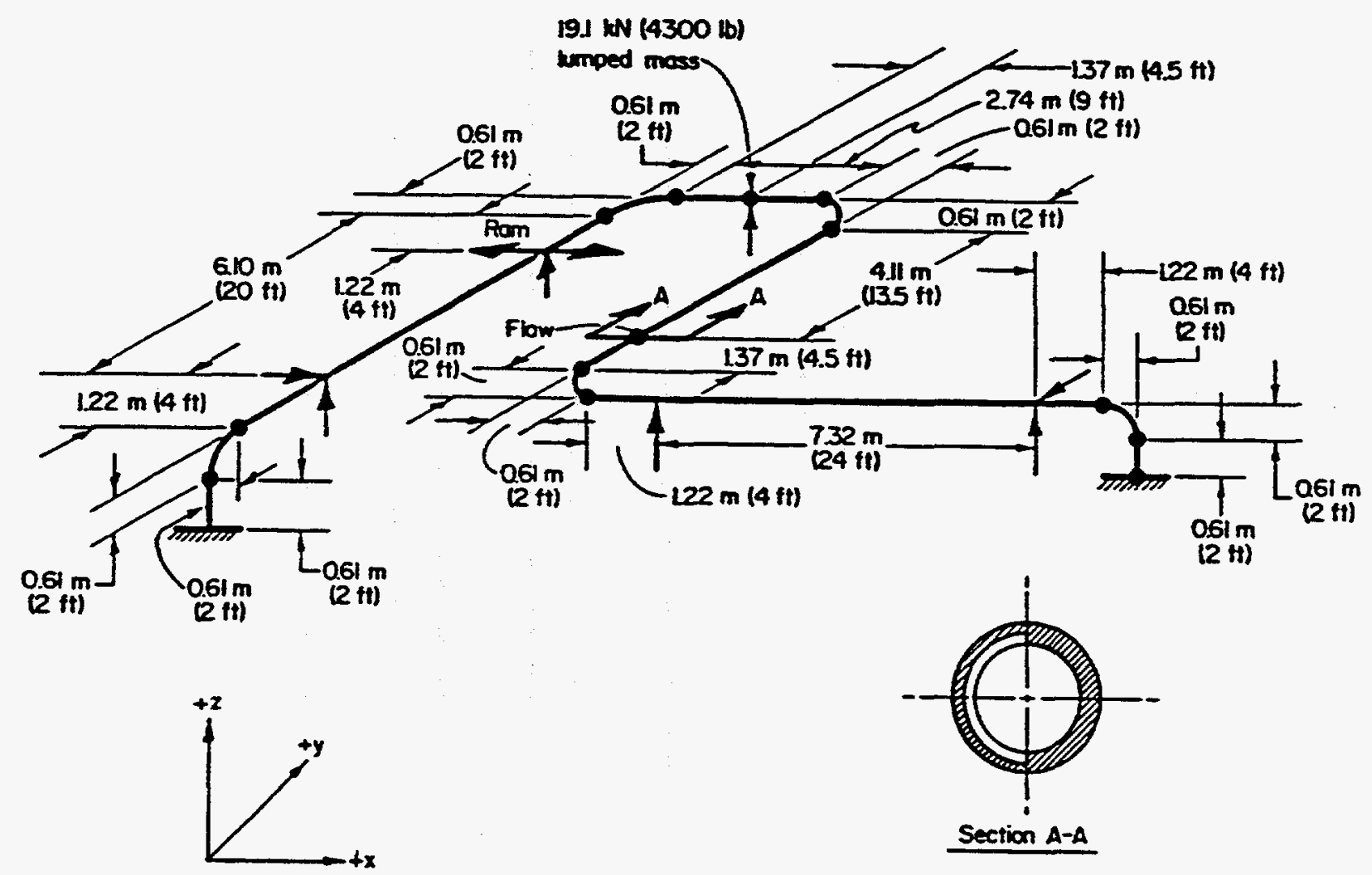

Figure C.4 IPIRG pipe loop dimensions 


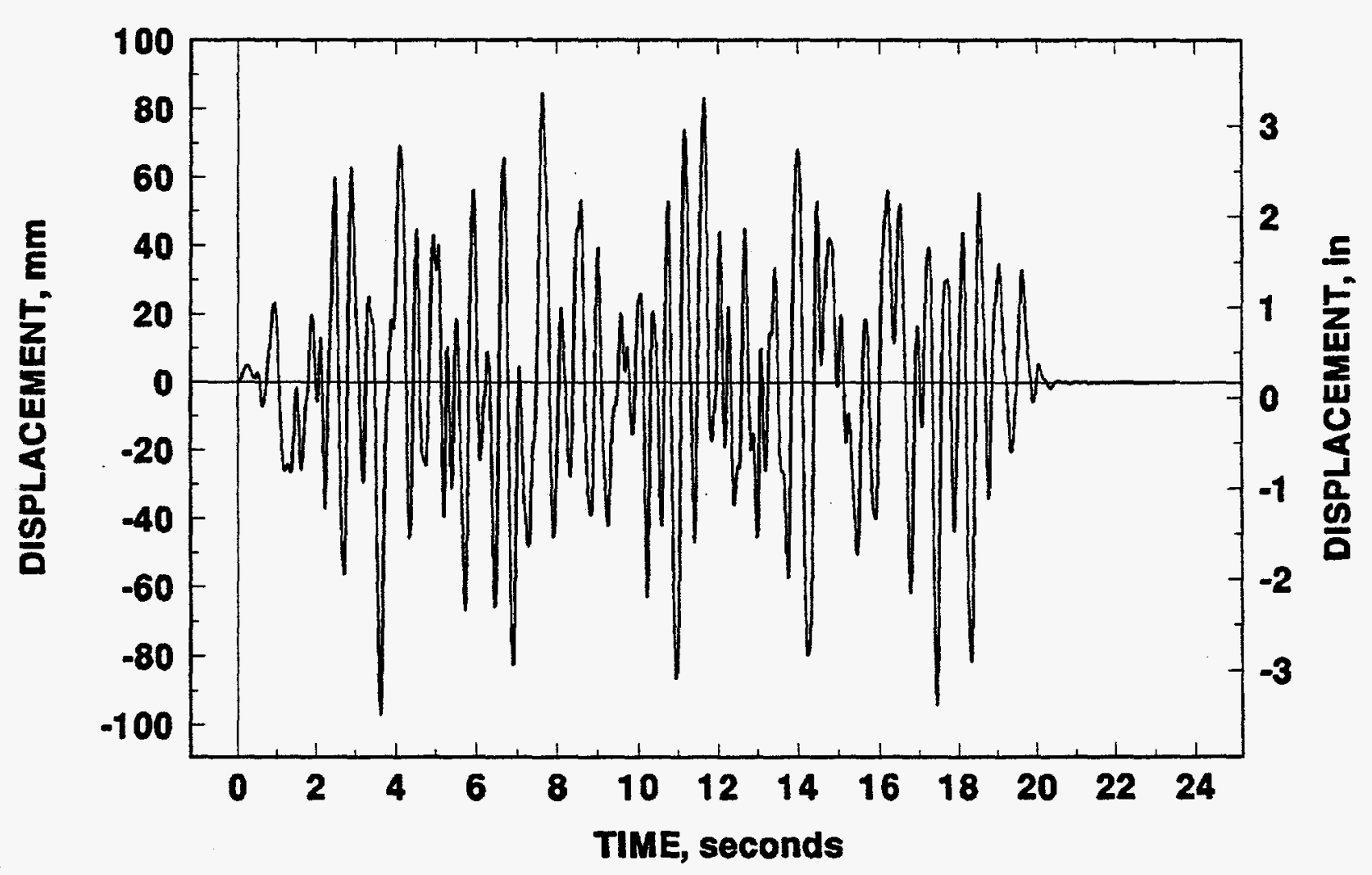

Figure C.5 IPIRG-2 Experiment 1-1 forcing function 


\section{APPENDIX D DEFINITION OF PROBLEM SET D}

\section{D.1 Problem D.1 - Displacement Calculations for an Uncracked Elbow}

\section{Specific Objective:}

The specific objective of this problem is to repeat analyses conducted in the IPIRG-1 program on finite element predictions for elastic loads on an uncracked elbow. There was not good agreement in the past results, hence this simple problem warrants further attention.

\section{Problem Statement:}

For a simple 90 -degree elbow with $3.048 \mathrm{~m}$ (10 ft) of straight 406.4-mm (16-inch) diameter by 26.187-mm (1.031-inch) thick pipe on each end, determine the $x$ and $y$ displacements at the free end (Point B in Figure D.1) for the following five loading conditions:

(a) Internal pressure of $15 \mathrm{MPa}(2,175 \mathrm{psi})$ and $\mathrm{F}_{\mathrm{x}}=\mathrm{F}_{\mathrm{y}}=0$.

(b) Internal pressure of $0, F_{x}=100 \mathrm{kN}(444,822 \mathrm{lb})$, and $F_{y}=0$.

(c) Internal pressure of $0, F_{x}=0$, and $F_{y}=100 \mathrm{kN}(444,822 \mathrm{lb})$.

(d) Internal pressure of $15 \mathrm{MPa}(2,175 \mathrm{psi}), \mathrm{F}_{\mathrm{x}}=100 \mathrm{kN}(444,822 \mathrm{lb})$, and $\mathrm{F}_{\mathrm{y}}=0$.

(e) Internal pressure of $15 \mathrm{MPa}(2,175 \mathrm{psi}), \mathrm{F}_{\mathrm{x}}=0$, and $\mathrm{F}_{\mathrm{y}}=100 \mathrm{kN}(444,822 \mathrm{lb})$.

(f) Internal pressure of $15 \mathrm{MPa}(2,175 \mathrm{psi}), F_{x}=F_{y}=100 \mathrm{kN}(444,822 \mathrm{lb})$.

\section{Given Information:}

Arc length:

90 degrees

Radius of curvature of elbow:

$0.610 \mathrm{~m}$ ( 24.016 inches)

Outer radius of cross-section:

$0.203 \mathrm{~m}$ (7.992 inches)

Thickness:

$26.187 \mathrm{~mm}$ (1.031 inches)

Elastic modulus:

$210 \mathrm{GPa}(30,458,000 \mathrm{psi})$

Poisson's ratio:

0.3

\section{Assumptions:}

(1) Material properties are assumed to be elastic and independent of temperature.

(2) Forces are applied to Node B. Node B is free to move in both the $x$ - and $y$-directions.

Also see sketch in Figure D.1.

Please supply answers in SI units. Battelle will also translate the compiled results to U.S. Customary units in the summary of the results. 


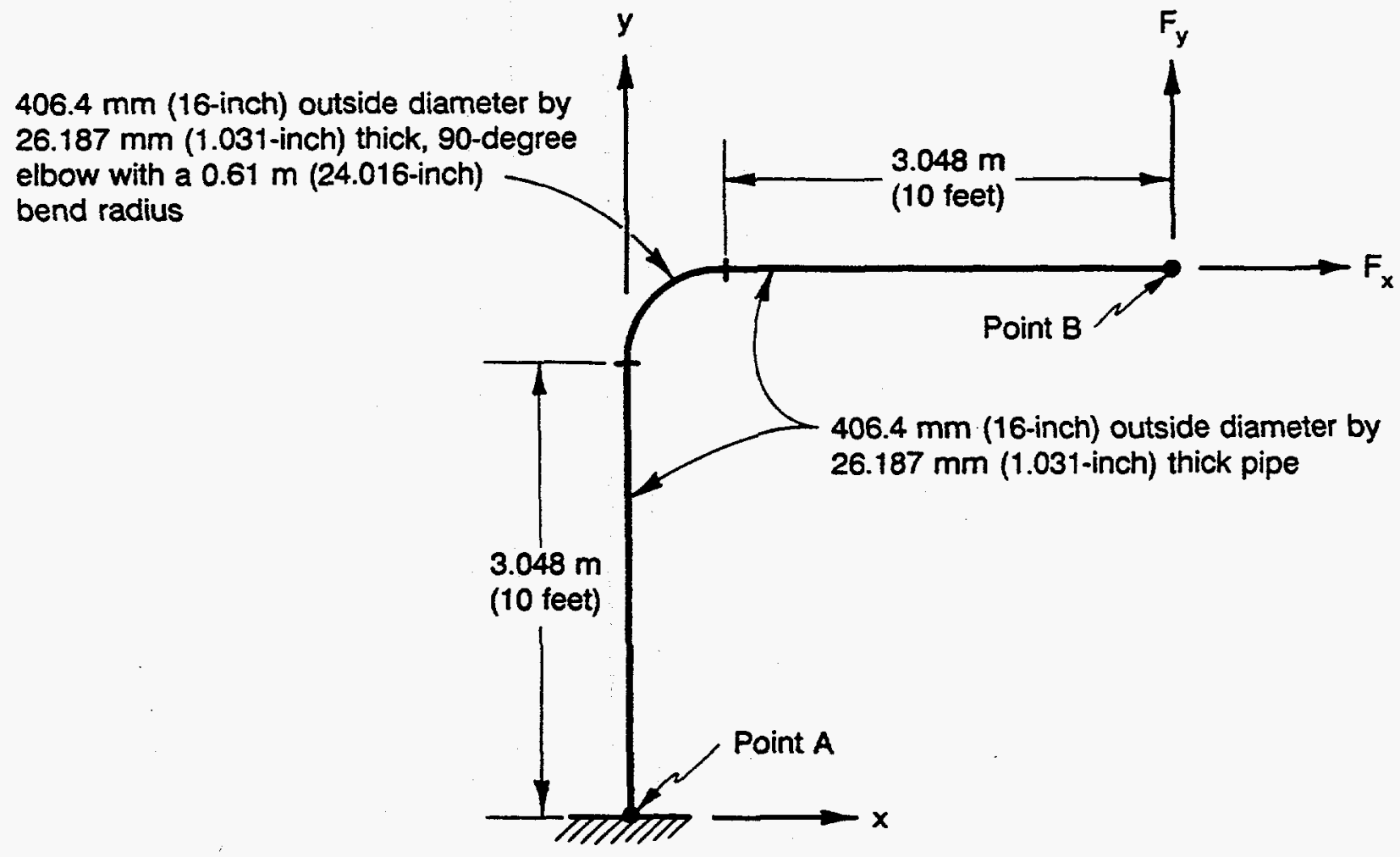

Figure D.1 Elbow geometry for IPIRG-2 Round-Robin Problem D.1. 


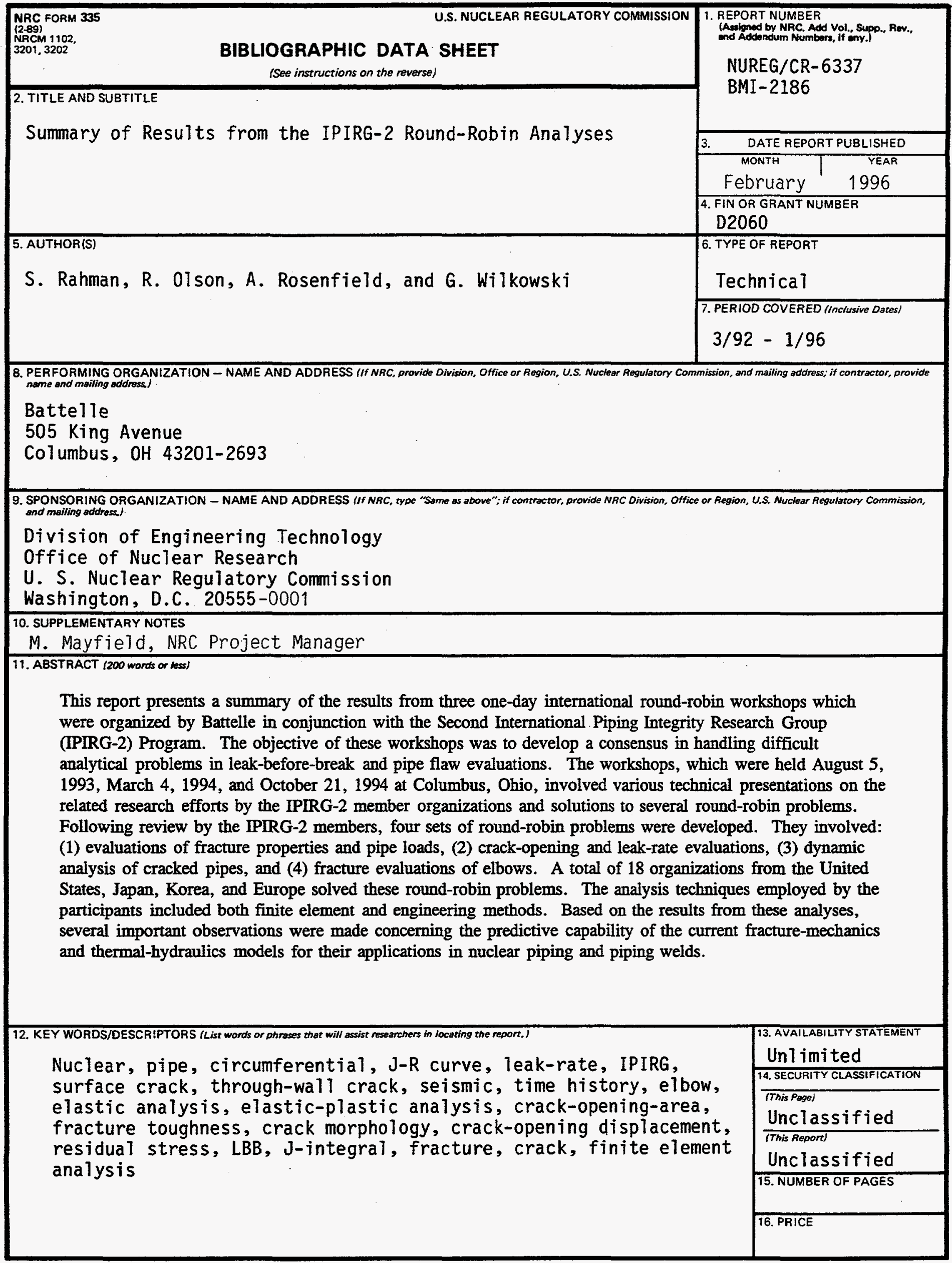

